\title{
AVANÇOS E ATUALIDADES NA BOTÂNICA BRASILEIRA
}

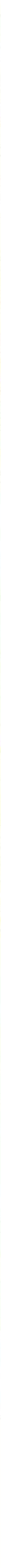


Renato Abreu Lima

(Organizador)

\section{Avanços e Atualidades na Botânica Brasileira}

Rio Branco, Acre 


\section{Stricto Sensu Editora}

CNPJ: 32.249.055/001-26

Prefixo Editorial: 80261

Editora Geral: Profa. Dra. Naila Fernanda Sbsczk Pereira Meneguetti

Editor Científico: Prof. Dr. Dionatas Ulises de Oliveira Meneguetti

Bibliotecária: Tábata Nunes Tavares Bonin - CRB 11/935

Avaliação: Foi realizado avaliação por pares, por pareceristas ad hoc.

Revisão: Os autores

\section{Conselho Editorial}

Profa. Dra. Ageane Mota da Silva (Instituto Federal de Educação Ciência e Tecnologia do Acre)

Prof. Dr. Amilton José Freire de Queiroz (Universidade Federal do Acre)

Prof. Dr. Edson da Silva (Universidade Federal dos Vales do Jequitinhonha e Mucuri)

Profa $^{a}$. Dra . Denise Jovê Cesar (Instituto Federal de Educação Ciência e Tecnologia de Santa Catarina)

Prof. Dr. Francisco Carlos da Silva (Centro Universitário São Lucas)

Prof. Dr. Humberto Hissashi Takeda (Universidade Federal de Rondônia)

Prof. Dr. Jader de Oliveira (Universidade Estadual Paulista Júlio de Mesquita Filho)

Prof. Dr. Leandro José Ramos (Universidade Federal do Acre - UFAC)

Prof. Dr. Luís Eduardo Maggi (Universidade Federal do Acre - UFAC)

Prof. Msc. Marco Aurélio de Jesus (Instituto Federal de Educação Ciência e Tecnologia de Rondônia)

Prof.a Dra. Mariluce Paes de Souza (Universidade Federal de Rondônia)

Prof. Dr. Paulo Sérgio Bernarde (Universidade Federal do Acre)

Prof. Dr. Romeu Paulo Martins Silva (Universidade Federal de Goiás)

Prof. Dr. Renato Abreu Lima (Universidade Federal do Amazonas)

Prof. Msc. Renato André Zan (Instituto Federal de Educação Ciência e Tecnologia de Rondônia)

Prof. Dr. Rodrigo de Jesus Silva (Universidade Federal Rural da Amazônia) 


\section{Ficha Catalográfica}

Dados Internacionais de Catalogação na Publicação (CIP)

A946 Avanços e atualidade na botânica brasileira / Renato Abreu Lima
(org.). - Rio Branco : Stricto Sensu, 2020.
226 p. : il.
ISBN: 978-65-86283-00-6
DOI: 10.35170/ss.ed.9786586283006
1. Botânica. 2. Vegetais. 3. Brasil. I. Lima, Renato Abreu. II.
Título.

CDD 22. ed. 580.79811

Bibliotecária Responsável: Tábata Nunes Tavares Bonin / CRB 11-935

O conteúdo dos capítulos do presente livro, correções e confiabilidade são de responsabilidade exclusiva dos autores.

É permitido o download deste livro e o compartilhamento do mesmo, desde que sejam atribuídos créditos aos autores e a editora, não sendo permitido a alteração em nenhuma forma ou utilizá-la para fins comerciais.

www.sseditora.com.br 


\section{APRESENTAÇÃO}

A Botânica constitui-se em uma área da Biologia que se ocupa de estudar os vegetais inferiores e superiores. A importância das plantas no cotidiano é inerente, pois ela está presente com relevante papel na história da humanidade e na economia. Estuda-la, é de fundamental notabilidade porque diminui as barreiras e os desafios da famosa "cegueira botânica", esta considerada como uma falta de habilidade das pessoas para perceber as plantas no seu próprio ambiente.

A Botânica abrange uma abundância de disciplinas científicas que estudam o crescimento, reprodução, metabolismo, desenvolvimento, doenças e evolução da vida das plantas. E seu ensino teórico e prático nos permite uma melhor compreensão da Ciência para a conscientização da preservação e conservação dos ambientes e ecossistemas naturais, que são essenciais para a manutenção da vida no planeta Terra.

A questão da preservação e conservação dos vegetais está longe de ser um tema esgotável, estando aliada sempre a outra área do conhecimento biológico. Estes são e devem ser debates em foco permanente, nas instituições públicas e privadas de ensino e de pesquisas, numa convergência multidisciplinar a fim de colocar à luz do conhecimento científico a conduta do ser humano em relação ao meio ambiente onde se vive para se ter um entendimento da biodiversidade brasileira e seus problemas.

A obra "Avanços e Atualidades na Botânica Brasileira" traz ao leitor diversos temas da área, reunindo 15 trabalhos científicos, na qual o leitor poderá conferir pontos da Biologia Vegetal Aplicada abrangentes no tocante a Conservação da Natureza, Ensino de Botânica, Etnobotânica, Florística, Fisiologia Vegetal, dentre outras. A abrangência desses temas nos diversos setores da sociedade é um ponto crucial nesta obra, uma vez que proporciona ao leitor um enriquecimento sobre o tema e as experiências relatadas por diversos pesquisadores brasileiros.

Neste sentido, ressalto a importância desta leitura de forma a incrementar e valorizar o conhecimento da aplicabilidade da Botânica em nosso dia a dia. Espera-se que este livro forneça um suporte para as atividades do ensino de graduação e pós-graduação nas áreas relacionadas da Botânica, com foco nas disciplinas de produção vegetal, morfologia vegetal, fitoterapia, biotecnologia, fitoquímica, dentre outras. 
Gostaria de agradecer a colaboração de todos os autores, e esperamos continuar contando com o apoio da comunidade científica para o aprimoramento constante desta obra, fortalecendo assim a pesquisa para todos.

Desejo a todos uma ótima leitura

Renato Abreu Lima 


\section{SUMÁRIO}

CAPÍTULO. 1

\section{A ARBORIZAÇÃO EM PRAÇAS PÚBLICAS NO MUNICÍPIO DE HUMAITÁ-AM}

Daniela de Moraes Batista (Universidade Federal do Amazônas)

Doraci Brito de Souza (Universidade Federal do Amazônas)

Rafael Bel Prestes da Silva (Secretaria de Estado de Educação e Desporto do Amazonas)

Guilherme Abadia da Silva (Universidade Federal do Amazônas)

Maria de Nazaré da Silva Braga (Universidade Federal do Amazônas)

Kayllan Virgilio Aleixo Diogo (Universidade Federal do Amazônas)

Fábio Geraldo de Souza (Universidade Federal do Amazônas)

Renato Abreu Lima (Universidade Federal do Amazônas)

DOI: $10.35170 /$ ss.ed. 9786586283006.01

CAPÍTULO. 2

AVALIAÇÃO DA ESTRUTURA DE POPULAÇÕES VEGETAIS EM SÍTIOS DE MATA ATLÂNTICA NO PARQUE NACIONAL SERRA DE ITABAIANA, SERGIPE, BRASIL

Daniel Oliveira Reis (Universidade Federal de Sergipe)

Diego de Andrade Mendonça (Universidade Federal de Sergipe)

Josias Gomes Junior (Universidade Federal de Sergipe)

Anny Bianca Santos Cruz (Universidade Federal de Sergipe)

Rony dos Santos Nascimento (Universidade Federal de Sergipe)

Thieres Santos Almeida (Universidade Federal de Sergipe)

José Leandro Santos Souza (Universidade Federal de Sergipe)

lara Ferreira da Silva (Universidade Federal de Sergipe)

Tayná Menezes Lima (Universidade Federal de Sergipe)

Bruno Fonseca Fernandes (Universidade Federal de Sergipe)

Jane Barbosa dos Santos (Universidade Federal de Sergipe)

Juliano Ricardo Fabricante (Universidade Federal de Sergipe)

DOI: $10.35170 /$ ss.ed.9786586283006.02 
GERMINAÇÃO DE SEMENTES DE MANGABA (HANCORNIA SPECIOSA GOMES) SUBMETIDAS A ARMAZENAMENTO E TRATAMENTO COM CÁLCIO

Cristina Filomena Justo (Universidade Federal de Mato Grosso)

Nathallya da Cruz Mota (Universidade Federal de Mato Grosso)

DOI: $10.35170 /$ ss.ed.9786586283006.03

CAPÍTULO. 4

ARBORIZAÇÃO URBANA EM PRAÇAS DE MARICÁ, RIO DE JANEIRO, BRASIL

Luciana Cavalcante de Moura (Universidade Estadual do Norte Fluminense Darcy Ribeiro)

George Azevedo de Queiroz (Universidade Federal do Rio de Janeiro)

Fernanda Stefany Nunes Costa (Universidade Federal do Rio de Janeiro)

DOI: $10.35170 /$ ss.ed.9786586283006.04

CAPÍTULO. 5

BIOTECNOLOGIA UTILIZANDO O ÓLEO ESSENCIAL DE DUAS ESPÉCIES DE Capsicum ADAPTADAS NA REGIÃO AMAZÔNICA PARA O DESENVOLVIMENTO DE DEFENSIVO AGRÍCOLA NATURAL BIODEGRADAVEL COM APLICAÇÃO EM ALIMENTOS

André Luiz dos Santos Oliveira (Instituto Federal de Alagoas)

Nélio Ranieli Ferreira de Paula (Instituto Federal de Rondônia)

Maicon Gildisnei Alves (Instituto Federal de Rondônia)

Gleison Serafim Justino (Instituto Federal de Rondônia)

Luiza Carvalho Sagrado (Instituto Federal de Rondônia)

Amanda Eloise Machado de Souza (Instituto Federal de Rondônia)

Gabriela Saiki (Instituto Federal de Rondônia)

DOI: $10.35170 /$ ss.ed.9786586283006.05

CAPÍTULO. 6

CARACTERIZAÇÃO MORFOANATÔMICA DO FOLÍOLO, MESOFILO E CAULE DA ESPÉCIE Lantana camara Linn (VERBENACEAE)

Thalyta Julyanne Silva de Oliveira (Universidade Regional do Cariri)

Jailson Renato de Lima Silva (Universidade Regional do Cariri)

Elayne Eally Silva de Oliveira Morais (Universidade Regional do Cariri) 
Natália Correia Aguiar (Universidade Regional do Cariri)

Adrielle Rodrigues Costa (Universidade Regional do Cariri)

Antonia Eliene Duarte (Universidade Regional do Cariri)

Luiz Marivando Barros (Universidade Regional do Cariri)

DOI: $10.35170 /$ ss.ed.9786586283006.06

CAPÍTULO. 7

COMPOSIÇÃO FLORÍSTICA DE PLANTAS RUDERAIS EM UMA ÁREA DO SEMIÁRIDO NORDESTINO

Antônio Reis de Sousa (Universidade Federal do Piauí)

Maria do Socorro Meireles de Deus (Universidade Federal do Piauí)

Thiago Pereira Chaves (Universidade Federal do Piauí)

Maria Carolina de Abreu (Universidade Federal do Piauí)

Kairo Michel Lima Borges (Universidade Federal do Piauí)

Andreia de Moura Araújo (Universidade Federal do Piauí)

Fernanda Beatriz do Nascimento (Universidade Federal do Piauí)

DOI: $10.35170 /$ ss.ed.9786586283006.07

CAPÍTULO. 8

EFEITOS DAS MUDANÇAS CLIMÁTICAS EM PLANTAS CULTIVADAS E NATIVAS:

ATUAL ESTADO DAS PESQUISAS BRASILEIRAS

Eduardo Habermann (Universidade de São Paulo)

Daniele Ribeiro Contin (Universidade de São Paulo)

Dilier Olivera Viciedo (Universidade Estadual Paulista)

Rafael Ferreira Barreto (Universidade Estadual Paulista)

Marcela Aparecida de Moraes (Universidade de São Paulo)

Eduardo Augusto Dias de Oliveira (Universidade de Illinois em Chicago)

Carlos Alberto Martinez (Universidade de São Paulo)

DOI: $10.35170 /$ ss.ed.9786586283006.08 
ESTRUTURA POPULACIONAL DE ESPÉCIES EXÓTICAS INVASORAS EM SÍTIOS DE MATA ATLÂNTICA, ITABAIANA, SERGIPE, BRASIL

Thieres Santos Almeida (Universidade Federal de Sergipe)

Rony dos Santos Nascimento (Universidade Federal de Sergipe)

Kelianne Carolina Targino de Araújo (Universidade Federal de Sergipe)

Laina Caroline de Santana Pereira (Universidade Federal de Sergipe)

Janisson da Costa Silva (Universidade Federal de Sergipe)

Diego de Andrade Mendonça (Universidade Federal de Sergipe)

Fabiana Jesus Tavares (Universidade Federal de Sergipe)

Jackeline Santos da Silva (Universidade Federal de Sergipe)

Mércia Passos da Cruz (Universidade Federal de Sergipe)

Daniel Oliveira Reis (Universidade Federal de Sergipe)

Juliano Ricardo Fabricante (Universidade Federal de Sergipe)

DOI: $10.35170 /$ ss.ed.9786586283006.09

CAPÍTULO. 10

AGRODIVERSIDADE FLORÍSTICA EM QUINTAIS URBANOS DE ITACOATIARA, ESTADO DO AMAZONAS

Luís Enrique Gainette Prates (Universidade do Estado do Amazonas)

DOI: $10.35170 /$ ss.ed.9786586283006.10

CAPÍTULO. 11

HERBÁRIO DIDÁTICO COMO FERRAMENTA PARA O ENSINO DE BOTÂNICA NA EDUCAÇÃO SUPERIOR A DISTÂNCIA

Renata Maria Almeida da Silva Biango (Universidade Estadual do Norte Fluminense Darcy Ribeiro)

George Azevedo de Queiroz (Universidade Federal do Rio de Janeiro)

Fernanda Stefany Nunes Costa (Universidade Federal do Rio de Janeiro)

DOI: 10.35170/ss.ed.9786586283006.11 
HERBÁRIOS VIRTUAIS E DIVULGAÇÃO CIENTÍFICA: DESAFIOS E AVANÇOS RECENTES DO HERBÁRIO SMDB

Liliana Essi (Universidade Federal de Santa Maria)

Maria Eduarda do Nascimento Kowalski (Universidade Federal de Santa Maria)

Rute Vitória Malinski Pessoa (Universidade Federal de Santa Maria)

Deborah Sosmayer Saydelles (Universidade Federal de Santa Maria)

Benardete de Fátima Panno (Universidade Federal de Santa Maria)

Tania Maria Boucinha Viana (Universidade Federal de Santa Maria)

Tanea Maria Bisognin Garlet (Universidade Federal de Santa Maria)

DOI: $10.35170 /$ ss.ed.9786586283006.12

CAPÍTULO. 13

LEVANTAMENTO DE PLANTAS CONDIMENTARES NA FEIRA MUNICIPAL DE HUMAITÁ - AM

Luciana Diniz Ferreira (Universidade Federal do Amazonas)

Carolina Wagner (Universidade Federal do Amazonas)

Adriana Pires de Lima (Universidade Federal do Amazonas)

Elizabeth da Silva Lima (Universidade Federal do Amazonas)

Jakeline Coelho dos Santos (Universidade Federal do Amazonas)

Izabela Augusta Veiga de Souza (Universidade Federal do Amazonas)

Renato Abreu Lima (Universidade Federal do Amazonas)

DOI: $10.35170 /$ ss.ed.9786586283006.13

CAPÍTULO. 14

RESPOSTA DE GENÓTIPOS DE MILHO A INTERAÇÃO COM BACTÉRIAS ENDOFÍTICAS DE NÓDULOS DE LEGUMINOSAS

\author{
Alaide Maria Silva Santos (Universidade Federal de Alagoas) \\ Joseliane Fernandes Miguel dos Santos (Universidade Federal de Alagoas) \\ José Wilisson Ferreira dos Santos (Universidade Federal de Alagoas) \\ Roberta Samara Nunes de Lima (Universidade Federal de Alagoas) \\ Flávia de Barros Prado Moura (Universidade Federal de Alagoas) \\ Jakson Leite (Universidade Federal de Alagoas)
}


DOI: $10.35170 /$ ss.ed.9786586283006.14

CAPÍTULO. 15 202

VISITANTES FLORAIS DE TRÊS ESPÉCIES DE PLANTAS RUDERAIS: Alternanthera tenella, Mimosa debilis E Tridax procumbens

Cristina Filomena Justo (Universidade Federal de Mato Grosso)

Camila Abreu Rocha (Universidade Federal de Mato Grosso)

DOI: $10.35170 /$ ss.ed.9786586283006.15

ORGANIZADORES 


\title{
CAPÍTULO 1
}

\section{A ARBORIZAÇÃO EM PRAÇAS PÚBLICAS NO MUNICÍPIO DE}

\author{
HUMAITÁ-AM
}

\author{
Daniela de Moraes Batista1, Doraci Brito de Souza1', Rafael Bel Prestes da Silva², \\ Guilherme Abadia da Silva1, Maria de Nazaré da Silva Braga1, Kayllan Virgilio Aleixo \\ Diogo', Fábio Geraldo de Souza1, Renato Abreu Lima1
}

1. Licenciatura em Ciências: Biologia e Química, Instituto de Educação, Agricultura e Ambiente (IEAA), Universidade Federal do Amazonas (UFAM), Humaitá, Amazonas, Brasil;

2. Secretaria de Estado de Educação e Desporto do Amazonas (SEDUC/AM), Humaitá, Amazonas, Brasil.

\section{RESUMO}

As praças públicas servem como escape para as pessoas que desejam um pouco de natureza no seu dia a dia, pois é um ambiente que propicia elementos naturais aos cidadãos, trazendo harmonia e bem-estar, sendo uma área de lazer, tendo importância em aspectos ecológicos, sociais e políticos contribuindo na preservação da flora. Teve como objetivo realizar o levantamento de espécies vegetais nas praças públicas de Humaitá-AM. Foram visitados cinco bairros com cinco praças, sendo uma praça em cada bairro que são; Praça da Matriz, Praça da Saúde, Praça da Rodoviária, Praça Santo Antônio e Praça da Olaria. A identificação das espécies foi realizada por meio de levantamento de campo e confirmada com auxílio de identificadores botânicos e da literatura científica. As espécies mais encontradas foram da família Arecaceae; areca bambu com dezessete espécimes (Dypsis lutescens (H. Wendl.) Beentje \& J.) e palmeira azul com dezessete espécimes (Bismarckia nobilis Hildebr. \& H. Wendl.); da família Moraceae, figueira-benjamim com quarenta e oito espécimes (Ficus benjamina L.); da família Myrtaceae, jambo vermelho com quarenta espécimes (Syzygium malaccense (L.) Merr. \& L.M. Perry); da família Chrysobalanaceae; oiti com quinze espécimes (Licania tomentosa (Benth.) Fritsch.); da família Rubiaceae, ixora compacta com onze espécimes (Ixora coccinea L.) e família Anacardiaceae, manguá com 13 espécimes (Mangifera indica L.). Portanto as praças são importantes para o lazer e bem-estar, pois serve para as pessoas perceberem que a natureza faz parte da vida humana e é essencial viver em equilíbrio com a mesma.

Palavras-chaves: Espécies Vegetais, Equilíbrio e Myrtaceae.

\section{ABSTRACT}

Public squares serve as an escape for people who want a little bit of nature in their daily lives, as it is an environment that provides natural elements to citizens, bringing harmony and well-being, being a leisure area, having importance in ecological aspects, social, political and contributing to the preservation of flora. It aimed to carry out a survey of plant species in public squares in Humaitá-AM. Five neighborhoods with five squares were visited, with a square in each neighborhood that they are; Praça da Matriz, Praça da Saúde, Praça da Rodoviária, Praça Santo Antônio and Praça da Olaria. The identification of the species 
was carried out by means of a field survey and confirmed with the aid of botanical identifiers and scientific literature. The most found species were from the Arecaceae family; areca bamboo with seventeen specimens (Dypsis lutescens ( $\mathrm{H}$. Wendl.) Beentje \& J.) and blue palm tree with seventeen specimens (Bismarckia nobilis Hildebr. \& H.Wendl.); from the Moraceae family, fig-benjamim with forty-eight specimens (Ficus benjamina L.); from the family Myrtaceae, red jambo with forty specimens (Syzygium malaccense (L.) Merr. \& L.M. Perry); of the Chrysobalanaceae family; oiti with fifteen specimens (Licania tomentosa (Benth.) Fritsch.); from the Rubiaceae family, ixora compact with eleven specimens (Ixora coccinea L.) and Anacardiaceae family, mango with 13 specimens (Mangifera indica L.). So the squares are important for leisure and well-being, as it serves for people to realize that nature is part of human life and it is essential to live in balance with it.

Keywords: Plant Species, Equilibrium, Myrtaceae.

\section{INTRODUÇÃO}

A presença de praças públicas nas cidades é de extrema importância, pois estas oferecem, em meio às vastas construções dos centros urbanos, um ambiente que possua elementos naturais, trazendo harmonia ao local, sendo os principais territórios ao ar livre voltado para o bem-estar das pessoas (SILVA; BORGES, 2018).

As praças urbanas são locais representativos para distintas manifestações, estão diretamente associadas à história das cidades, tornando-se um dos ambientes públicos mais comuns em muitas regiões. É um importante espaço devido a fatores relacionados ao lazer como os aspectos ecológicos, sociais, políticos, históricos ou educativos (SILVA, 2012).

De acordo com Brito et al. (2012), as praças são áreas públicas, geralmente localizadas em zonas urbanas, e se destinam a lazer recreação, ponto de encontros, etc., proporcionando o convívio mútuo do público que as frequentam. Normalmente esses ambientes apresentam grandes áreas verdes e livres de impermeabilização, o que os torna uma área de exceção na maioria das grandes cidades.

A praça como espaço público sempre teve um referencial urbano marcado pela convivência humana, servindo como um importante equipamento histórico cultural urbano que, especialmente no Brasil, expressa o surgimento e desenvolvimento de inúmeras cidades (ROMANI et al., 2012).

No contexto atual, as praças são definidas como espaços livres públicos, com forte função social, inseridas na malha urbana como elementos organizadores da circulação e de amenização pública, geralmente contendo expressiva cobertura vegetal, mobiliário 
lúdico, canteiros e bancos (HARDER, 2002; MENDONÇA, 2007; LINDENMAIER; SANTOS, 2008; FREITAS et al., 2015).

Nos espaços urbanos, têm-se as áreas verdes, que são lugares onde predominam a vegetação arbórea, praças, jardins e parques cuja distribuição deve servir a toda a população, sem distinguir diferentes classes sociais, atingindo as necessidades reais e os anseios para o lazer. As áreas verdes exercem influência direta sobre o bem-estar do homem, agindo sobre o lado físico e mental, amenizando o sentimento de opressão frente às grandes edificações, em virtude dos múltiplos benefícios que essas áreas proporcionam ao meio, contribuindo com a estabilização climática, fornecendo abrigo e alimento à fauna, bem como embelezando as cidades (RABELO et al., 2008).

Segundo Gomes e Amorim (2003), a vegetação é responsável pela redução térmica da urbanização local. Uma vez que a radiação solar é utilizada nos processos biológicos da vegetação, como fotossíntese e respiração. Para Santos e Teixeira (2001), as árvores, através de sua diversidade de formas, aromas e cores, identificam os locais, qualificam os espaços e são consideradas como patrimônio, cujo zelo compete a todos.

As praças prestam inúmeros serviços ambientais aos centros urbanos, dentre eles pode-se citar a melhoria da qualidade do ar, através da fixação do dióxido de carbono $\left(\mathrm{CO}_{2}\right)$, emitido principalmente pelos veículos automotivos, e liberação de oxigênio $\left(\mathrm{O}_{2}\right)$ através do processo de fotossíntese (ALBERTIN et al., 2011).

Segundo Nucci (1996), as praças ainda servem como barreira ou obstáculo para a propagação do som e de resíduos sólidos no ar; atuam na estabilidade climática, com a redução de temperatura e aumento da umidade do ar; favorecem a melhoria das condições do solo urbano, do ciclo hidrológico, facilitando o escoamento e absorção das águas pluviais pelo solo.

Para Santos e Teixeira (2001), as árvores, através de sua diversidade de formas, aromas e cores, identificam os locais, qualificam os espaços e são consideradas como patrimônio, cujo zelo compete a todos. A vegetação é um dos componentes principais da paisagem e serve para indicar outros atributos do ambiente e sua variação no espaço. Colabora ainda com muitos produtos e serviços ecossistêmicos como produção de alimento, conservação do solo, dos recursos hídricos e da vida silvestre (BOHRER et al., 2009).

Para Carcereri (2013) afirma que as praças são locais livres urbanas utilizadas como espaço público que servem também como pontos de encontro, cuja principal função é de incentivar a socialização e o lazer. 
Tendo fundamental importância em uma cidade, as praças são utilizadas por pessoas de todas as idades e classes sociais, com a função de buscar uma qualidade de vida melhor para a comunidade, fornecendo aos seus usuários recreação, lazer e uma vida mais saudável (SILVA et al., 2008). São locais essenciais para a vida urbana, e o seu modo de tratamento e uso indicam o nível de civilidade de seus usuários e o exercício dos direitos e deveres de cidadania nela vivenciados (GIMENES et al., 2011).

Dessa forma, o presente trabalho teve como objetivo realizar o levantamento de espécies vegetais nas praças públicas de Humaitá-AM, fazendo uma analogia das espécies nativas e as de outros países, como também realizando essa analogia entre as praças.

\section{MATERIAIS E MÉTODOS}

Este trabalho foi realizado com a finalidade de quantificar e qualificar no seu total os espécimes vegetais das cinco praças que foram visitadas para o levantamento dos dados. Foram selecionadas cinco praças públicas no município de Humaitá-AM, com visitas feitas as mesmas foram contabilizadas os espécimes vegetais ali alocados, sendo elas a Praça da Matriz localizada no bairro Centro, Praça da Saúde localizada no bairro São José, Praça da Rodoviária localizada no bairro São Pedro, Praça do bairro Santo Antônio e praça do bairro da Olaria. O levantamento dos espécimes vegetais ocorreu entre outubro de 2018 a maio de 2019.

A identificação das espécies foi realizada por meio de levantamento de campo e confirmada com auxílio de identificadores botânicos e da literatura científica, com isso foram registrados através de fotos para ajudar na confirmação das espécies foi utilizado o sistema APG III e artigos que compõem a referência, após isso foram contabilizados os espécimes e identificados com seus nomes científicos e populares e também a que famílias pertenciam como constar na tabela 1.

\section{RESULTADOS E DISCUSSÃO}

Os espécimes vegetais foram identificados com nome popular, nome científico e família botânica, com isso foram registradas 24 espécies, pertencentes a 15 famílias 
botânicas. Dentre as famílias observadas as de maior representatividade foram Arecaceace (sete espécies), Rubiaceae e Anacardiaceae (duas espécies cada), Moraceae, Myrtaceae e Chrysobalanaceae (uma espécie cada).

Segundo Silva (2016), foi possível notar que as famílias com maior abundância foram Arecaceae e Fabaceae, apresentando sete espécies diferentes cada uma. Seguidas destas, estão às famílias das Bignoniaceae, e Myrtaceae, com seis e quatro espécies respectivamente.

A família Arecaceae, já denominada Palmae, é formada por um grupo de espécies popularmente conhecidas como palmeiras, que atingem grandes alturas. Destaca-se em função de suas antigas e atuais utilizações, apresenta grande importância devido à vasta diversidade de frutos e sementes que possui. Muitas espécies estão sendo exploradas de maneira indiscriminada, priorizando seu aspecto econômico e ignorando sua relevância cultural e ecológica (SODRÉ, 2016).

Enquanto que a família Arecaceae representa uma grande importância para o homem, por sua ampla distribuição, abundância, produtividade e diversidade de usos, como alimentação, fitoterapia e economia para populações locais. As palmeiras, tanto os indivíduos autóctones quanto os alóctones, se dispersam facilmente por se adaptarem a diversos climas e solos, mas é na região equatorial quente e úmida que elas se propagam em maior número, podendo dispersar-se até mesmo sob climas temperados (SOARES et al., 2014).

Além disso, a família Arecaceae é muito importante para manter o ecossistema em equilíbrio, sendo considerada a terceira família mais importante para o ser humano. A maioria dessas espécies é nativa da Amazônia, tendo importância econômica, medicinal e artesanal (SOUZA; LIMA, 2019).

As espécies mais frequentes foram areca bambu (Dypsis lutescens $(\mathrm{H}$. Wendl.) Beentje \& J.) e palmeira azul (Bismarckia nobilis Hildebr. \& H.Wendl.); figueira-benjamim (Ficus benjamina L.); jambo vermelho (Syzygium malaccense (L.) Merr. \& L.M. Perry); oiti (Licania tomentosa (Benth.) Fritsch.); ixora (Ixora coccinea L.); e manguá (Mangifera indica L.). Com isso, é importante ressaltar que os espaços de lazer como as praças são importantes, pois fazem uma interação homem/natureza e também servem como preservadores dos espécimes vegetais. 
Tabela 1. Relação das espécies encontradas em cinco praças públicas de Humaitá-

AM.

\begin{tabular}{|c|c|c|c|}
\hline FAMÍLIA & NOME CIENTÍFICO & NOME POPULAR & QUANTIDADE \\
\hline \multirow{7}{*}{ Arecaceae } & Phoenix dactylifera L. & Tamareira & 01 \\
\hline & Roystonea oleracea (Jacq.) O. F. Cook & Palmeira Imperial & 04 \\
\hline & Bismarckia nobilis (Hildebr. \& H.Wendl.) & Palmeira-Azul & 17 \\
\hline & Cocos nucifera L. & Coco verde & 02 \\
\hline & Euterpe oleracea Mart & Açaí & 05 \\
\hline & Bactris gasipaes H.B. K. & Pupunha & 01 \\
\hline & $\begin{array}{c}\text { Dypsis lutescens (H. Wendl.) Beentje \& } \\
\text { J.) }\end{array}$ & Areca Bambu & 17 \\
\hline \multirow[t]{2}{*}{ Myrtaceae } & $\begin{array}{c}\text { Syzygium malaccense (Syzygium } \\
\text { malaccense (L.) }\end{array}$ & Jambo & 40 \\
\hline & Psidium guajava L. & Goiaba & 01 \\
\hline \multirow{2}{*}{ Rubiaceae } & Ixora coccinea L. & Ixora Compacta & 11 \\
\hline & Genipa americana L. & Jenipapo & 02 \\
\hline Moraceae & Ficus benjamina L. & Fiqueira Benjamim & 48 \\
\hline Anacardiaceae & Mangifera indica L. & $\begin{array}{l}\text { Maga Massa ou } \\
\text { Manga Comum }\end{array}$ & 13 \\
\hline Asparagaceae & Dracaena fragrans L. Ker Grawl & Pau d'água & 01 \\
\hline Malvaceae & Hibiscus rosa-sinensis L. & Hibisco & 02 \\
\hline Euphorbiaceae & Jatropha curcas L. & Pião Roxo & 01 \\
\hline Annonaceae & Annona muricata L. & Graviola & 01 \\
\hline Fabaceae & Inga laurina (Sw.) Willd. & Inga do brejo & 03 \\
\hline Laxmanniaceae & Cordyline terminalis L. & Dracema Vermelha & 01 \\
\hline Rutaceae & Citrus $X$ sinensis (L.) Osbeck. & Laranja & 01 \\
\hline Chrysobalanaceae & Licania tomentosa (Benth.) Fritsch.) & Oiti & 15 \\
\hline Oleaceae & Licania tomentosa (Benth.) Fritsch & Azeitona & 01 \\
\hline Araceae & Dieffenbachia seguinte (Jacq.) Schott & $\begin{array}{l}\text { Comigo ninguém } \\
\text { pode }\end{array}$ & 01 \\
\hline $\begin{array}{l}15 \text { famílias } \\
\text { botânicas }\end{array}$ & 24 espécies vegetais & & 189 espécimes \\
\hline
\end{tabular}

Segundo Silva e Borges (2018), dentre os indivíduos levantados e totalizados, a espécie em maior quantidade é a Licania tomentosa (oiti), com 61 indivíduos. A Licania tomentosa é uma árvore perenifólia, frutífera, muito utilizada na arborização urbana por 
apresentar copa globosa com folhagem densa, produzindo excelente sombra e grande efeito ornamental. As folhas são simples, alternas, elípticas, com face abaxial aveludada e suas flores são pequenas e brancas (MACHADO, 2006).

Das espécies encontradas observou-se que tem uma grande quantidade de jambos, pois estes servem como alimentos para os cidadãos e também são de grande porte, logo fazem sombras bastante amplas.

As praças fazem pessoas terem interação social com seus familiares e terceiros, faz parte da vida das pessoas, pois desde muito pequenos tem-se encontros familiares aonde chegar a ser uma tradição familiar, esses espaços verdes abrigam fauna e flora, pois ali será possível encontrar vida animal, além de ter importância social inquestionável, pois fortalece os laços familiares das pessoas que ali frequentam estas por sua vez, procuram um lugar com um ar mais saudável que é o caso das praças, por causa dos seus espécimes vegetais que ali estão alocados.

Segundo Brito et al. (2012), com esses espaços verdes é possível promover a conservação ambiental e o paisagismo urbanístico das cidades. A vegetação urbana desempenha um importante papel, com principais vantagens, podem ser citadas: melhor efeito estético; sombra para os pedestres e veículos; protegem e direcionam o vento; amortecem o som, amenizando a poluição sonora; reduzem o impacto da água de chuva e seu escorrimento superficial; auxiliam na diminuição da temperatura; melhoram a qualidade do ar; preservam a fauna silvestre.

Contudo vai haver uma interação entre homem e natureza, está se faz necessária, pois assim o ser humano em um dado momento pode perceber que é possível haver um equilíbrio entre ambos sem a destruição de um ou outro.

A melhoria da qualidade ambiental e climática nos centros urbanos está intrinsecamente ligada à inclusão de espaços livres vegetados no contexto deste ecossistema. O aumento da consciência sobre questões ambientais tem mobilizado diversas áreas do conhecimento em busca de soluções para mitigar os impactos na natureza (OLIVEIRA et al., 2013).

As árvores são elementos fundamentais para a paisagem urbana, atuando como fator de atributo ambiental, pois melhora a qualidade do ar, da água, dos solos e do clima, evitando o reflexo do calor provocado pelo aquecimento do asfalto e elevando a umidade do ar devido à evapotranspiração. A arborização urbana pode ser considerada como um dos mais importantes elementos naturais que compõem o ecossistema das cidades e que, 
pelos benefícios que produz, deveria compor de maneira sistematizada qualquer planejamento urbano (OLIVEIRA et al., 2013).

A construção e existência de espaços públicos como diferentes lugares que compõem nossos espaços referenciais cotidianos exigem apropriação de inter-relações cada vez mais complexas dependentes das múltiplas formas de organização e utilização desses lugares. A ausência de modelos de ocupação e uso dos espaços públicos, induzindo a um modelo de percepção individualista, em detrimento do coletivo, agrava e aprofunda a fragmentação dos lugares, eliminando o cotidiano compartilhado (LEITE, 1998).

Floresta urbana enfoca o elemento vegetal como coletivo estando relacionado com cobertura vegetal dos diversos espaços do perímetro urbano. A Silvicultura Urbana é sinônimo para floresta urbana e tem-se estabelecido como a ciência que objetiva o estudo de técnicas de cultivo e manejo de árvores no meio urbano que possam contribuir para alcançar o bem-estar fisiológico, social e econômico (COUTO, 1994).

Muitos municípios brasileiros, sabendo da importância da realização da arborização de forma planejada, elaboram um guia de arborização, que tem como função nortear a implantação e manutenção da vegetação arbórea, de acordo com características como solo, clima e vegetação da cidade e com base em critérios técnicos- científicos. Os guias oferecem informações referentes à arborização para as diferentes categorias que compõem a cidade: passeios de vias públicas, áreas livres públicas e áreas internas públicas ou privadas (CEMIG, 2011).

A qualidade ambiental nas cidades está ligada à forma como os espaços de construções e arborizados se relacionam. O crescimento desordenado das cidades evidencia a falta de um planejamento que concilie a convivência harmônica entre estes dois espaços. A consequência disso são áreas verdes incompatíveis com os critérios adequados de plantio e manutenção, resultando em prejuízos à população (ABREU; OLIVEIRA; CARTAXO, 2017).

\section{CONSIDERAÇÕES FINAIS}

Portanto, as praças são localidades de suma importância para o lazer e bem estar das pessoas, pois são nestes locais que a comunidade no geral pode desfrutar de um pequeno contato com a natureza, sendo esse contato importante, pois o mesmo serve para que as 
pessoas percebam que a natureza faz parte da vida humana e é essencial viver em equilíbrio com a mesma, além de tudo isso as praças também são locais onde há conservação de germoplasma e ainda oferecem sombra, consumo e melhoram a qualidade do ar para os cidadãos.

\section{REFERÊNCIAS}

ABREU, D.I.; OLIVEIRA, A.D.S.; CARTAXO, S.L. Diagnóstico da arborização nas praças públicas de Cajazeiras-PB: interferência no mobiliário urbano. Revista Principia, n.36, p.116-124, 2017.

ARAÚJO, T.A.S., MELO, J.G.; ALBUQUERQUE, U.P. Plantas medicinais. In: ALBUQUERQUE, U.P. (org.) Introdução à etnobiologia. Recife: NUPEEA. p.91-98, 2014.

BADKE, M.R. et al. Saberes e Práticas Populares de Cuidado em Saúde com o Uso de Plantas Medicinais. Texto \& Contexto - Enferm, v. 21, n.2, p.363-370, 2012.

BRITO, D.R.S. et al. Diagnóstico da arborização das praças pública no município de Bom Jesus. Scientia Plena, v. 8, n. 4, p.047312, 2012.

BOHRER, C.B.A. et al. Mapeamento da vegetação e do uso do solo no Centro de Diversidade Vegetal de Cabo Frio, Rio de Janeiro, Brasil. Rodriguésia, v.1, p.1-23, 2009.

CARNEIRO, K.A.; BITAR, N.A.B. Composição florística e análise fitossociológica das principais praças da cidade de Lagoa Formosa - MG. 2013. 50 f. Monografia (Especialização) - Curso de Ciências Biológicas, Centro Universitário de Patos de Minas Unipam, Patos de Minas, 2013.

COMPANHIA ENERGÉTICA DE MINAS GERAIS - CEMIG. Manual de arborização. Belo Horizonte: Cemig / Fundação Biodiversitas, 2011.

DAVID, M.; MAMEDE, J.S.S.; DIAS, G.S.; PASA, M.C. 2014. Uso de plantas medicinais em comunidade escolar de Várzea Grande, Mato Grosso, Brasil. Biodiversidade, v.13, n.1, p.38-50, 2014.

DOSSA, N.L.B. et al. Levantamento e identificação das espécies vegetais na praça universitária, Goiânia - GO. VI Congresso Brasileiro de Gestão Ambiental Porto Alegre/RS - 23 a 26/11/2015.

FREITAS, W.K. et al. Análise da Arborização de Quatro Praças no Bairro da Tijuca, RJ, Brasil. Floresta e Ambiente, v.22, n.1, p.23-31, 2015.

GIMENES, R. et al. Interpretação do uso, do mobiliário e da arborização da praça Sete de Setembro, Ribeirão Preto, SP. Revista da Sociedade Brasileira de Arborização Urbana, v.6, n.3, p.22- 42, 2011. 
GOMES, M.A.S.; AMORIN, M.C.C.T. Arborização e conforto térmico no espaço urbano: estudo de casos nas praças públicas de Presidente Prudente (SP). Caminhos de Geografia - revista on line, Instituto de Geografia da UFU, 2003.

HARDER, I.C.F. Inventário quali-quantitativo da arborização e infraestrutura das Praças da cidade de Vinhedo/SP [dissertação]. Piracicaba: Escola Superior de Agricultura Luiz de Queiroz, Universidade de São Paulo; 2002.

LINDENMAIER, D.S.; SANTOS, N.O. Arborização urbana das praças de Cachoeira do Sul RS-Brasil: fitogeografia, diversidade e Índice de áreas verdes. São Leopoldo: Instituto Anchietano de Pesquisas; 2008. Pesquisas, Série Botânica n. 59.

MACHADO, R.R.B. et al. Árvores nativas para a arborização de Teresina, Piauí. Revista da Sociedade Brasileira de Arborização Urbana, v.1, n.6, p.10-18, 2006.

MENDOÇA, E.M.S. Apropriações do espaço público: alguns conceitos. Revista Estudos e Pesquisas em Psicologia, 2007.

RABELO, F.R.C. et al. Levantamento dendrológico preliminar nas áreas verdes do Instituto Ricardo Bernnand, Recife-PE. 2008. Disponível em: Acesso em: 12 fev. de 2016.

ROMANI, G.N. et al. Análise quali-quantitativa da arborização na praça XV de novembro em Ribeirão Preto - SP, Revista Árvore, 2012.

SANTOS, N.R.Z.; TEIXEIRA, I.F. Arborização de vias públicas: ambiente $\mathbf{x}$ vegetação. Santa Cruz do Sul: Instituto Souza Cruz, 2001.

SOARES, K.P. et al. Palmeiras (Arecaceae) no Rio Grande do Sul, Brasil. Rodriguésia, 65(1):113-139, 2014.

SILVA, A.P.; BORGES, N.M. Levantamento quantitativo da composição vegetal das praças da cidade de Serra do Salitre-MG. Revista Perquirere, v.15, n.1, p.311-327, 2018.

SILVA, R.N. Caracterização e análise quali-quantitativa da arborização em praças da área central da cidade de Arapiraca, AL. Revista da Sociedade Brasileira de Arborização Urbana, v.7, n.2, p.102-115, 2012.

SODRÉ, J.B. (Inhaúma MG). Centro de Estudos Ambientais e Paisagísticos. Fabaceae. Disponível em: <http://www.ceapdesign.com.br/familias botânicas/fabaceae.html>. Acesso em: 19 jan. 2020.

SOUZA, F.G.; LIMA, R.A. A Importância da família Arecaceae para a Região Norte. Revista Educamazônia, v.23, n.2, p.100-110, 2019.

VASCONCELOS, J.; VIEIRA, J.G.P.; VIEIRA, E.P.P. Plantas Tóxicas: Conhecer para Prevenir. Revista Científica da UFPA, v.7, n.1, p.1-10, 2009. 


\title{
CAPÍTULO 2
}

\section{AVALIAÇÃO DA ESTRUTURA DE POPULAÇÕES VEGETAIS EM SÍTIOS DE MATA ATLÂNTICA NO PARQUE NACIONAL} SERRA DE ITABAIANA, SERGIPE, BRASIL

\author{
Daniel Oliveira Reis' ${ }^{1}$, Diego de Andrade Mendonça1, Josias Gomes Junior ${ }^{1}$, Anny
}

Bianca Santos Cruz', Rony dos Santos Nascimento', Thieres Santos Almeida ${ }^{1}$, José

Leandro Santos Souza², lara Ferreira da Silva³, Tayná Menezes Lima4, Bruno

Fonseca Fernandes ${ }^{5}$, Jane Barbosa dos Santos ${ }^{6}$, Juliano Ricardo Fabricante ${ }^{1}$

1. Universidade Federal de Sergipe, Laboratório de Ecologia e Conservação da Biodiversidade, Itabaiana, Sergipe, Brasil;

2. Universidade Federal de Sergipe, Laboratório de Neurobiologia Comportamental e Evolutiva, Itabaiana, Sergipe, Brasil;

3. Universidade Federal de Sergipe, Laboratório de Neurobiologia das Doenças Degenerativas do Sistema Nervoso, Itabaiana, Sergipe, Brasil;

4. Universidade Federal de Sergipe, Laboratório de Bioquímica e Microbiologia, Itabaiana, Sergipe, Brasil;

5. Universidade Federal de Sergipe, Laboratório de Biologia e Ecologia de Vertebrados, Itabaiana, Sergipe, Brasil;

6. Universidade Federal de Sergipe, Itabaiana, Sergipe, Brasil.

\section{RESUMO}

A avaliação da estrutura populacional gera dados importantes para a compreensão da ecologia da espécie estudada. Assim, objetivou-se neste estudo, analisar esse atributo para as espécies Heliconia psittacorum L.f., Vellozia dasypus Seub., Pteridium arachnoideum (Kaulf.) e Melocactus violaceus Pfeiff Maxon, na região do Parna Serra de Itabaiana, no município de Itabaiana, SE. A coleta de dados foi efetuada por meio de parcelas de $1 \mathrm{~m}^{2}$, onde os indivíduos tiveram sua altura e diâmetro a altura do solo (DAS) aferidos. Os indivíduos foram categorizados quanto ao estágio ontogenético. De acordo com os dados obtidos, foram calculadas as densidades, o índice de distribuição espacial de Morisita (Id), e para verificar a correlação de um estádio ontogenético sobre o outro, foi aplicado o coeficiente de correlação de Pearson ( $r$ ). Todos os táxons apresentaram valores de densidade inferiores quando comparados a grande maioria das espécies herbáceas encontradas em outros trabalhos no Nordeste. $O$ índice de distribuição espacial demonstrou que a maioria das espécies possuem um padrão agregado, exceto a espécie $M$. violaceus. Além disso, quanto a distribuição em classe diamétrica apenas as espécies $V$. dacypus e $H$. psittacorum apresentaram o padrão em "J" invertido, indicando uma estabilidade populacional. Já as espécies $M$. violaceus e $P$. arachnoideum possuem populações instáveis.

Palavras-Chave: Espécies autóctones, ervas e Parque Nacional Serra de Itabaiana. 


\section{ABSTRACT}

The evaluation of the population structure generates important data for the understanding of the ecology of the studied species. Thus, the objective of this study was to analyze this attribute for the species Heliconia psittacorum Lf, Vellozia dasypus Seub., Pteridium arachnoideum (Kaulf.) and Melocactus violaceus Pfeiff Maxon, in the region of PARNA Serra de Itabaiana, in the municipality of Itabaiana, SE. The data collection was performed using plots of $1 \mathrm{~m}^{2}$, where individuals had their height and diameter measured from the ground (DAS). The individuals were categorized according to the ontogenetic stage. According to the data obtained, the densities, the Morisita spatial distribution index (Id) were calculated, and to check the correlation of one ontogenetic stage over the other, Pearson's correlation coefficient $(r)$ was applied. All taxa showed lower density values when compared to the vast majority of herbaceous species found in other studies in the Northeast. The spatial distribution index showed that most species have an aggregate pattern, except for the species $M$. violaceus. In addition, regarding the distribution in diametric class, only the species $V$. dacypus and $H$. psittacorum presented the inverted "J" pattern, indicating population stability. The species $M$. violaceus and $P$. arachnoideum have unstable populations.

Key-word: Autochthonous species, herbs and Parque Nacional Serra de Itabaiana.

\section{INTRODUÇÃO}

A estrutura populacional de uma vegetação pode ser compreendida como a variabilidade genética e morfológica dos indivíduos, associada à distribuição da espécie no tempo e no espaço (HUTCHINGS, 1998). Essa conformação estrutural resulta das ações e interações de vários mecanismos evolutivos e ecológicos (ROUGHGARDEN, 1979), sejam eles de origem biótica ou abiótica (HUTCHINGS, 1998). O conhecimento sobre o funcionamento da estrutura populacional de uma espécie pode fornecer dados importantes sobre a estabilidade dessa no ambiente (BEGON; HARPER; TOWHSEND, 2006). Os parâmetros morfológicos adquiridos com o estudo da estrutura populacional de um táxon ainda podem contribuir para o entendimento da sucessão ecológica e competição (VANCLAY, 1994).

A família Heliconiaceae é categorizada por plantas rizomatosas, herbáceas e perenes, que em sua maioria se encontram nas regiões tropicais (BERRY; KRESS, 1991). Heliconia psittacorum L. f, ou, Helicônia-papagaio é nativa do Brasil, mas não é considerada endêmica. Possui ocorrência em praticamente todas as regiões brasileiras, encontrandose principalmente em locais úmidos, em florestas e bordas de matas, bem como em restingas e a pleno sol (ANDERSSON, 1981). Compreende-se que tal espécie possui um grande potencial ornamental, por conta da sua ampla variação de caracteres florais, bem 
como uma alta adaptação ao cultivo, florescendo praticamente o ano inteiro com picos em setembro e janeiro (ANDERSSON, 1981). Vale ressaltar que suas populações naturais vêm sofrendo com a exploração irracional. Em estudos recentes efetuados por Cerqueira et al. (2008) e Monaco et al. (2017), demonstram que tal espécie possui uma grande eficiência em tratamentos sustentáveis da água de utilização doméstica.

Velloziaceae é uma família de plantas herbáceas com caule coberto pelas bainhas foliares ou folhas marcescentes, onde estas são reconhecidas por serem mais frequentes nas vegetações de regiões neotropicais (IBISCH et al., 1995). Vellozia dasypus Seub., ou, popularmente conhecida como canela-de-ema, é endêmica do Brasil, tendo ocorrência registrada aos Estados de Sergipe e Bahia (Reflora, 2020). Encontrada principalmente no Cerrado, Campos Rupestres e em diversos ambientes xéricos (JOLY, 1966; EITEN, 1982). Compreende-se que tal espécies é encontrada em regiões de domínio da caatinga, principalmente em locais que sofrem com intensa antropização, como afloramentos rochosos (MICHAEL et al., 2010; SIMMONS, 1986). Observa-se que devido a esses fatores, a espécie pode estar correndo risco de extinção. Outro ponto importante é que espécies como $V$. dacypus possuim grande importância ecológica nesse tipo de ambiente (IBISCH et al., 1995).

A família Dennstaedtiaceae é reconhecida por samambaias de caule ereto, raramente arborescente, coberto por tricomas ou escamas e folhas geralmente pinadas, onde estas são amplamente distribuídas pelo mundo, predominantemente em regiões tropicais (Tryon \& Tryon 1982). Pertencente a esta família, Pteridium arachnoideum (Kaulf.) Maxon, ou, samambaia do campo, é nativa do Brasil. Distribuída de forma natural, principalmente em regiões montanhosas ou sub montanhosas nas regiões Nordeste, Sudeste e Centro-Oeste, em locais com solos ácidos, drenados e com boa pluviosidade (THOMSON, 2000; TOKARNIA et al., 2012). Compreende-se que tal espécie possui fácil adaptação, possuindo defesa contra herbívoria e competidores (GUERIN, 2010). Essa espécie é comumente descrita como pioneira, agressiva e de difícil manejo, invadindo áreas abandonadas e pósdistúrbios (JABOTA, 2016). Devido a características como, grande produção de biomassa, extensos rizomas e grande quantidade de serapilheira, essa espécie é considerada uma problemática para ambientes de Mata Atlântica e Cerrado no Brasil (MATOS; BELINATO, 2010). Apesar de ser uma espécie nativa, essa possui um comportamento invasor, onde é capaz de se estabelecer e fazer alterações no ambiente, prejudicando as demais espécies no local em que está inserida (JABOTA, 2016). 
Cactaceae é uma das principais famílias da ordem Caryophyllales, cuja a monofilia é suportada por caracteres específicos, evidenciando-se os curtos segmentos caulinares modificados em aréolas e ovário protegido em receptáculo, além de caracteres moleculares, onde estão distribuídas nos mais variados ambientes, com ampla diversidade de hábitos e formas espalhadas pelo mundo (Gilbson \& Nobel, 1986; JUDD et al. 2009; ANDERSON 2001). Pertencente a essa família, Melocactus violaceus Pfeiff., ou, simplesmente coroa-de-frade é uma espécie endêmica do Brasil, que ocorre em praticamente todos estados das regiões Nordeste e Sudeste. Encontrada em ambientes dos domínios fitogeográficos da Caatinga e Mata Atlântica, predominantemente em vegetações como os Campos Rupestres, Cerrado e Restinga (REFLORA, 2020). Essa espécie foi categorizada como "Vulnerável" (VU) (IUCN, 2010). Tal categorização deve-se principalmente a perda de seu habitat e ao seu extrativismo constante (CRUZ; RICHERS; ZAMITH, 2013; CRUZ, 2011) que causa a redução das suas populações e produtividade de frutos (TEIXEIRA, 2014; CRUZ; RICHERS; ZAMITH, 2013; CRUZ, 2011).

Uma vez que trabalhos envolvendo a ecologia de espécies vegetais são de extrema importância para o entendimento da dinâmica populacional de determinadas espécies no ambiente em que estão inseridas. E que no estado de Sergipe, principalmente na região do Parque Nacional de Itabaiana são escassos os estudos evidenciando tais aspectos (LIMA et al., 2019; DANTAS; RIBEIRO, 2010a). O presente trabalho tem como objetivo avaliar a estrutura populacional das seguintes espécies nativas presentes no Parque Nacional Serra de Itabaiana: Melocactus violaceus, Vellozia dasypus, Pteridium arachnoideum e Heliconia psittacorum.

\section{MATERIAIS E METÓDOS}

\section{1 ÁREA DE ESTUDO}

O presente trabalho foi realizado no Parque Nacional Serra de Itabaiana $\left(10^{\circ} 42^{\prime} 36^{\prime \prime}\right.$ e $10^{\circ} 50^{\prime} 16^{\prime \prime}$ sul, e $37^{\circ} 16^{\prime} 42^{\prime \prime}$ e $37^{\circ} 25^{\prime} 14^{\prime \prime}$ oeste), localizado entre os municípios de Itabaiana, Laranjeiras, Areia Branca, Campo do Brito e Itaporanga D'ajuda, no estado de Sergipe Brasil. O citado parque possui uma área de 7990 ha, e está inserido em uma região 
de clima tropical, o qual apresenta verões secos e amenos com excedente hídrico no inverno (VICENTE, 1999; ICMBio 2016).

O relevo do parque é classificado como levemente ondulado a ondulado. O mesmo se encontra em uma região de transição entre a Mata Atlântica e a Caatinga (DANTAS; RIBEIRO, 2010b). Os principais solos são os neossolos litólicos distróficos. O Parque em questão é uma Unidade de Conservação (UC) de proteção integral devido a sua grande biodiversidade (SNUC, 2000). Com isso todas as espécies nativas do presente trabalho foram estudadas dentro do Parque Nacional Serra de Itabaiana (Figura 1).

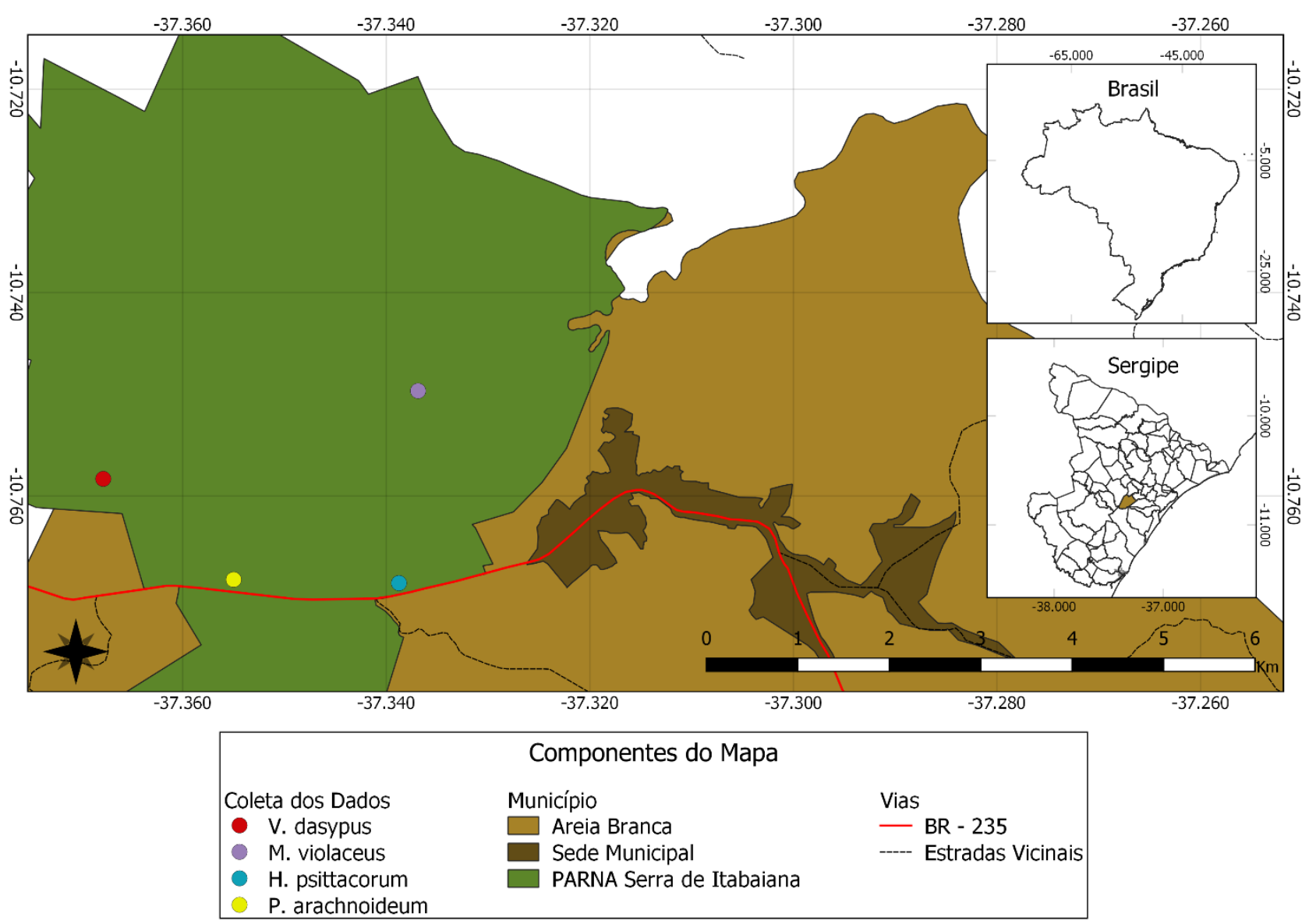

Figura1: Pontos de localização das populações estudadas de quatro espécies nativas no munícipio de Areia Branca, Sergipe, Brasil. 


\subsection{METODOLOGIA EM CAMPO}

Para cada espécie foram plotadas 20 parcelas de $1 \mathrm{~m}^{2}$, por conseguinte todos os indivíduos presentes no interior das unidades amostrais foram contabilizados e tiveram seus diâmetros a altura do solo (DAS) aferidos com auxílio de um paquímetro. Além disso, os indivíduos foram classificados de acordo com seu estádio ontogenético, sendo considerado adulto caso houvesse a presença ou resquício de material reprodutivo ou regenerante quando os órgãos reprodutores estavam ausentes (FABRICANTE; OLIVEIRA; SIQUEIRA-FILHO, 2013; FABRICANTE et al., 2015).

Com as informações obtidas calculou-se os valores de densidade total, densidade dos regenerantes e densidade dos indivíduos adultos (RECHENMACHER; SCHMITT; BUDKE, 2007) e o Índice de Dispersão Espacial de Morisita (Id) para as três situações (Id total, Id regenerantes e Id adultos), no qual valores superiores, iguais ou inferiores a 1 indicam respectivamente dispersão agregada, uniforme e aleatória (MORISITA, 1959, 1962; DANTAS; RIBEIRO, 2010a). A correlação entre os estádios ontogenéticos foi avaliada pelo Índice de Correlação Linear de Pearson (RODGERS; NICEWANDER, 1988; LIRA; NETO, 2006; FABRICANTE et al., 2009; JYOTHI et al., 2015). A distribuição dos indivíduos foi realizada em classe de frequência diamétrica e hipsométricas. As analises foram realizadas utilizando os softwares BioEstat 5.0 e Microsoft Excel (AYRES et al., 2007; MATIELO et al., 2016).

\section{RESULTADOS E DISCUSSÃO}

H. psittacorum apresentou 209 indivíduos, perfazendo uma densidade total (DT) de 10,45 ind. $\mathrm{m}^{2}$, sendo de 1,15 ind. $\mathrm{m}^{2}$ para os adultos e de 9,3 ind. $\mathrm{m}^{2}$ para os regenerantes.

$V$. dasypus com 140 indivíduos, obteve os seguintes valores: $\mathrm{DT}=7$ ind. $\mathrm{m}^{2} ; \mathrm{DA}=$ 4,8 ind. $\mathrm{m}^{2}$ e $\mathrm{DA}=2,2$ ind. $\mathrm{m}^{2}$. Para $M$. violaceus foram contabilizados 123 indivíduos para população e densidades de: $\mathrm{DT}=5,04$ ind. $\mathrm{m}^{2} ; \mathrm{DA}=1,16$ ind. $\mathrm{m}^{2} ; \mathrm{DA}=3,46$ ind. $\mathrm{m}^{2}$. Por fim, $P$. arachnoideum com 85 indivíduos ( $D T=4,25$ ind.m2) amostrados, desses, 20 pertencem a Classe 1 ( $D A=1$ ind.m2), 40 pertencem a Classe $2(D A=2$ ind.m2) e 25 pertencem a Classe $3\left(\mathrm{DA}=1,25\right.$ ind. $\left.\mathrm{m}^{2}\right)$. 
Todos os táxons apresentaram valores de densidade inferiores quando comparados a grande maioria das espécies herbáceas encontradas em outros trabalhos no Nordeste (ARAÚJO et al., 2005; MARACAJÁ; BENEVIDES, 2006). As áreas aqui estudadas são menores em comparação aos trabalhos citados e as condições de conservação concorrem para explicar essas diferenças (SOBRAL et al., 2007; OLIVEIRA, 2008; SOBRALOLIVEIRA et al., 2009; DANTAS; RIBEIRO, 2010b; COSTA, 2014).

A densidade total da espécie $V$. dasypus neste estudo foi superior a outras espécies do gênero. Jacobi, Carmo e Vincent (2008) obtiveram valores de $D A=1,58$ ind. $\mathrm{m}^{2}$ para Vellozia graminea Pohl e DA $=1,02$ ind. $\mathrm{m}^{2}$ para Vellozia compacta Mart. Souza (2015) obteve 0,21 ind. $\mathrm{m}^{2}$ como valor de maior densidade para Vellozia aff. sincorana. O estudo realizado por Batista (2016) indica que as vellozias tendem a formar grandes populações em ambientes rupestres, essa colonização de ambientes rupestres, como o estudado neste trabalho, ocorre devido a sua capacidade de suportarem flutuações de luminosidade, temperatura e limitações hídricas (BJORKMAN, 1981).

Embora $P$. arachnoideum tenha obtido baixos valores de densidade em comparação com as herbáceas dos trabalhos já citados, a espécie é reconhecidamente agressiva e possui a capacidade de interferir negativamente no processo de sucessão ecológica (GUERIN, 2017). O M. violaceus, além de apresentar valores baixos quando comparado aos trabalhos anteriormente citados, também demonstrou valores inferiores em relação a outras espécies de Melocactus estudadas no Brasil, 17,8 ind. $\mathrm{m}^{2}$ para Melocactus zehntneri (Britton \& Rose) (FABRICANTE et al., 2010) e 13,15 ind. $\mathrm{m}^{2}$ para Melocactus ernestii Vaupel subsp. Ernestii (FABRICANTE; OLIVEIRA, 2013). Esse é um fator preocupante, uma vez que essa espécie está categorizada como ameaçada (MARTINELLI; MORAES, 2013) e se encontra em locais no parque sob intensa pressão antrópica.

No que diz respeito ao Índice de Dispersão (Id) H. psittacorum apresentou valor de 1,14 para população total, 1,81 para adultos e 1,22 para regenerantes. $V$. dacypus teve um Id de 1,05 para toda população, 0,91 para adultos e 1,7 para regenerantes. $M$. violaceus apresentou valores de 0,93 para população total, 1,14 para adultos e 1,20 para regenerantes. Por fim, $P$. arachnoideum apresentou Id de 1,14 para população total, 2 para Classe 1, 1,1 para Classe 2 e 1,9 para Classe 3. Devido a apresentarem valores acima de um, $V$. dacypus, H. psittacorum e $P$. arachnoideum apresentaram distribuição agregada para população total, enquanto que $M$. violaceus apresentou distribuição aleatória. 
De acordo com Leite (2001), a dispersão de uma espécie é determinada por ações bióticas e abióticas. Begon, Harper e Townsend (1990) relatam que, na distribuição agregada, uma dessas ações abióticas é a convergência atrativa dos indivíduos a certas partes do ambiente. $H$. psittacorum e $P$. arachnoideum são descritas como espécies que ocorrem predominantemente em locais antropizados, como clareiras (BELINATO, 2010; COSTA; ESPINELLI; FIGUEIREDO, 2011; MELO, 2011; SOUZA, 2012; MATOS; JATOBA, 2016). Observações in situ, assim como a própria literatura constatam a existência de áreas antropizadas no PARNASI (DANTAS; RIBEIRO, 2010b) portanto justificam os resultados obtidos. Esse padrão de distribuição para os táxons corrobora com Nasi (1993) uma vez que, segundo ela, espécies encontradas em ambientes de fase inicial de sucessão tendem a se agregar.

A síndrome de dispersão é um fator que também pode estar relacionada com a distribuição agregada de $H$. psittacorum e $V$. dasypus, já que essas espécies apresentam dispersão por zoocoria (RAMIREZ; BRITO, 1988) e reprodução vegetativa (VILAR; ZYNGIER; CARVALHO, 2000), respectivamente. Essas são características que já foram descritas como importantes na formação de agrupamentos desses e de outros táxons (JANZEN, 1976; LEIRANA-ALCOCER; PARRA-TABLA, 1999; VILAR; ZYNGIER; CARVALHO, 2000; BUDKE, et al., 2005; SANTOS, et al., 2012).

A dispersão espacial observada para $M$. violaceus pode estar relacionado com a pouca influência de fatores abióticos, como disponibilidade de espaço e luz, fazendo com que os organismos possam ocupar qualquer área (IKEMOTO et al., 2003). As características do local onde a população dessa espécie foi estudada, Areias Brancas (vegetação arenícola), corroboram com essa afirmação, uma vez que apresentam solos homogêneos, compostos inteiramente por areias brancas (DANTAS; RIBEIRO, 2010b).

Em relação as correlações entre os estágios ontogenéticos, $H$. psittacorum $(r=-$ $0,30 ;=0,19 ; t=-135)$ e $V$. dasypus $(r=-0,0645 ; t=-0,02740 ; p=7,92 ;)$ apresentaram correlação não significativa. Da mesma forma, a correlação entre as Classes 1 e $2(r=$ $0,3349 ; t=1,5077 ; p=14,89)$, Classes 1 e $3(r=0,1549 ; t=0,6652 ; p=51,44)$ e Classes 2 e $3(0,0804 ; t=0,3424 ; p=73,60)$ de $P$. arachnoideum também não foram significativas. Entretanto, a correlação entre os estágios ontogenéticos de $M$. violaceus foi negativo e apresentou significância $(r=-0.7215 ; t=4.4204 ; p=0.03)$. 
Essa correlação negativa demonstra que à medida que há um aumento no número de indivíduos de um determinado estádio ontogenético, ocorre a diminuição do outro na área. Isso pode ser resultado de fuga da planta-mãe, algo também relatado para outros cactos estudados no Nordeste brasileiro (FABRICANTE; ANDRADE; MARQUES, 2010; FABRICANTE; OLIVEIRA, 2013; HUGHES, 2014; MATA, 2014).

Quanto a distribuição dos indíviduos em classes de frequência diamétricas, as espécies H. psittacorum (Figura 2) e $V$. dasypus (Figura 3) apresentaram padrão em "Jinvertido". Nesse padrão a maioria dos indivíduos se agruparam nas classes iniciais e diminuem conforme ocorre o aumento do diâmetro.

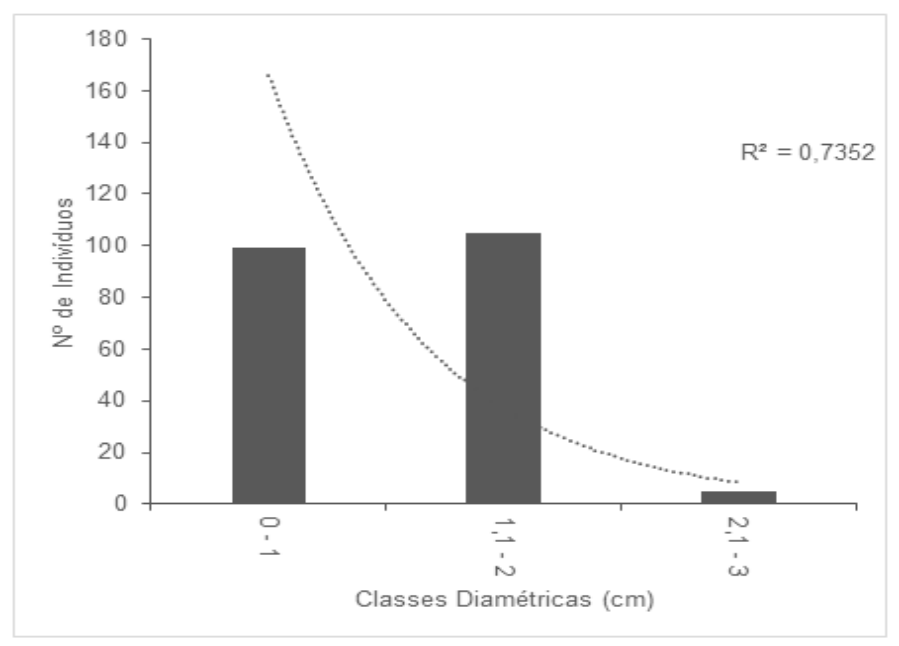

Figura 2. Gráfico de classes de frequência diamétricas de Heliconia psittacorum no Parque Nacional Serra de Itabaiana, SE.

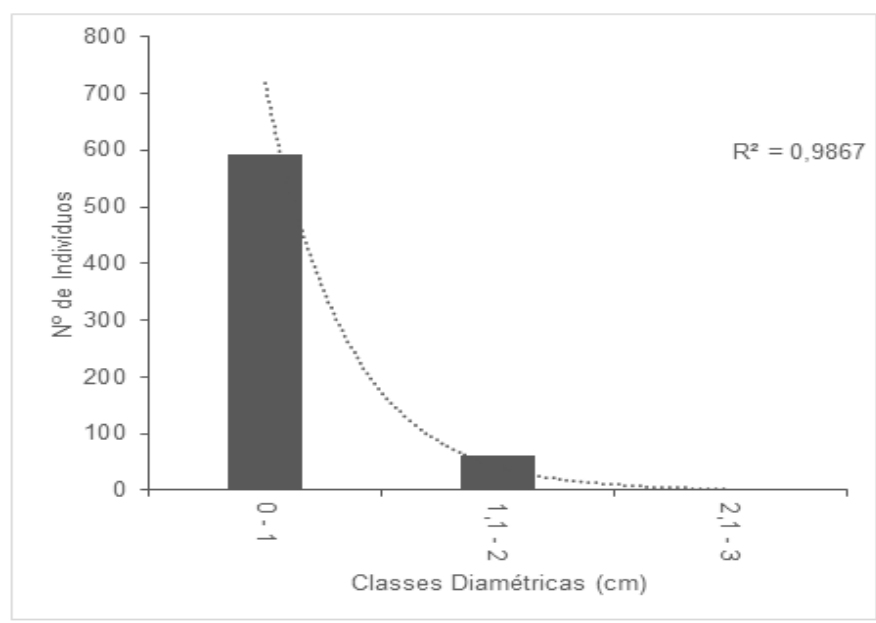

Figura 3. Gráfico de classes de frequência diamétrica de Vellozia dasypus no Parque Nacional Serra de Itabaiana, SE. 
O padrão de distribuição em J-invertido é um indicativo de que a população está estável, com regeneração constante (AGREN; ZARACKINSON, 1990; SILVERTOWN, 1987). Essa capacidade de autorregeneração é evidenciada pela presença de um maior número de indivíduos nas classes de frequências com menor diâmetro (HESS et al., 2010). Segundo Webb et al. (1972), tal distribuição pode ser simplesmente consequência da permanência das plântulas neste estágio por longos períodos, o qual há grandes chances de um desenvolvimento rápido posteriormente.

Ademais, as espécies de P. arachnoideum (Figura 4) e M. violaceus (Figura 5) apresentaram um padrão que difere do padrão de J-invertido, onde a maior concentração de indivíduos foi nas classes centrais.

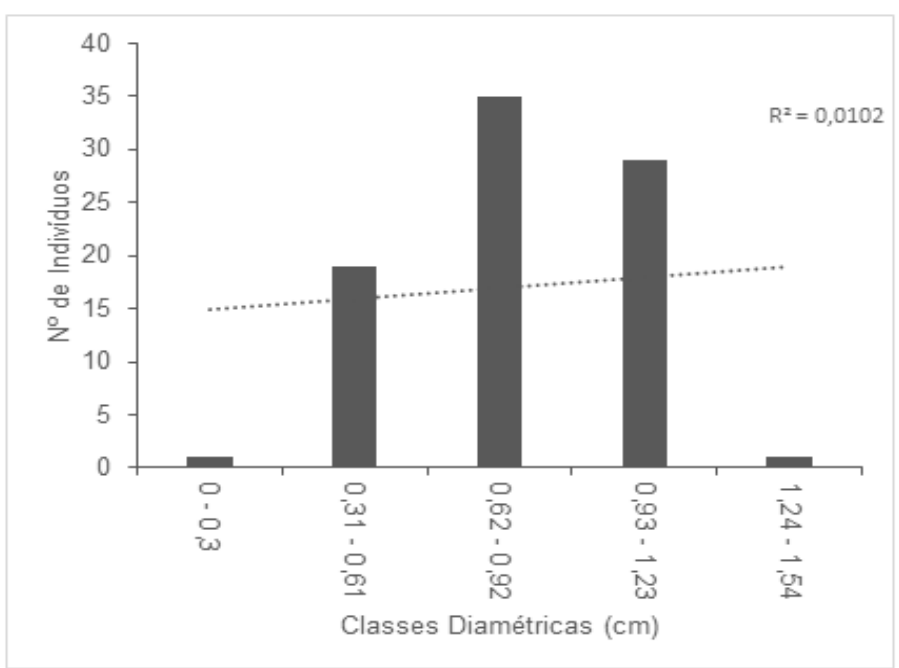

Figura 4. Gráfico de classes de frequência diamétrica de Pteridium arachnoideum no Parque Nacional Serra de Itabaiana, SE.

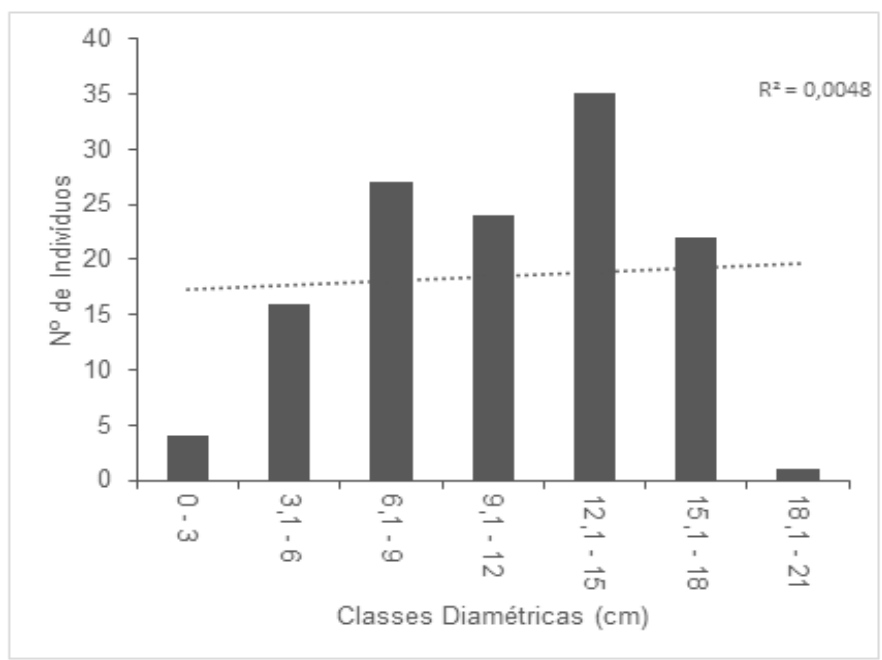

Figura 5. Gráfico de classes de frequência diamétricas de Melocactus violaceus no Parque Nacional Serra de Itabaiana, SE. 
Essa distribuição nas espécies que difere do padrão de "J-invertido" indica problemas na regeneração das mesmas (CYSNEIROS ET AL., 2017). No caso da $P$. arachnoideum essa distribuição unimodal dos indivíduos pode ser explicada devido aos impactos recentes decorrentes de ação antrópica no local onde esse estudo foi realizado.

De maneira semelhante, a situação do M. violaceus, também pode estar relacionado a pressão antrópica dentro e nos entornos do parque, já que o parque possui uma baixa fiscalização, alta número de visitantes e suas trilhas e entornos apresentam altos níveis de degradação (COSTA, 2014; SOBRAL, et al., 2007; OLIVEIRA, 2008; SOBRAL-OLIVEIRA, et al ., 2009; DANTAS; RIBEIRO, 2010b), outro ponto é que a espécie é utilizada de diversas formas, como planta alimentícia não convencional, ração animal, terapêutica e ornamental (SANTANA, 2018). Essa utilização pode resultar no distúrbio observado nas classes de frequências diamétricas.

\section{CONCLUSÃO}

Conclui-se que as espécies $H$. psittacorum e $V$. dasypus, apresentam uma estabilidade em suas populações, tal fator foi indicado pelo padrão em "J" invertido nas classes diamétricas menores, o que aponta um potencial constante de regeneração, além de um elevado número de indivíduos. A estabilidade dessas duas populações é um ponto positivo uma vez que, esses são táxons nativos e de importância nos locais onde ocorrem.

Já as espécies $P$. arachnoideum apresentou um padrão em classe diamétrica que difere do "J" invertido, indicando instabilidade populacional, a qual pode ser resultado das ações antrópicas presentes na região. Entretanto, mesmo com esse impacto na área, foi possível observar in situ a presença quase única da espécie no local avaliado. Essa é uma característica preocupante e que precisa de mais atenção devido a possibilidade da espécie estar inviabilizando o processo de sucessão no local.

Da mesma forma, a população de $M$. violaceus também se apresentou instável. Esse é um resultado preocupante visto que se trata de uma espécie nativa ameaçada de extinção. Ademais, observa-se que são necessárias outras pesquisas para uma melhor compreensão da ecologia dessas espécies evidenciadas no presente estudo. 


\section{REFERÊNCIAS}

AGREN, J.; ZACKRISSON, O. Age and size structure of Pinus sylvestris populations on mires in central and northern Sweden. The Journal of Ecology., v. 78, n. 4, p. 1049-1062, 1990.

ANDERSON, E. F. The cactus family. Timber Press (OR), 2001.

ANDERSSON, L. Revision of Heliconia sect. Heliconia (Musaceae). Nordic Journal of Botany, v. 1, n. 6, p. 759-786, 1981.

ARAÚJO, E.D.L.; SILVA, K.A.D.; FERRAZ, E.M.N.; SAMPAIO, E.V.D.S.B.; SILVA, S.I.D. Diversidade de herbáceas em microhabitats rochoso, plano e ciliar em uma área de caatinga, Caruaru, PE, Brasil. Acta Botanica Brasilica., v. 19, n. 2, p. 285-294, 2005.

AYRES, M.; AYRES, M.J.; AYRES, D.L. \& SANTOS, S.A. Bioestat 5.0: aplicações estatísticas nas áreas das Ciências Biomédicas. Belém, Mamirauá/CNPq., 2007.

BATISTA, D.D.S. Vellozia ramosissima: estrutura populacional, anatomia foliar e avaliação nutricional em áreas de Complexos Rupestres, sob diferentes substratos, na Serra do Espinhaço, MG. (Dissertação) Mestrado em Ciências Florestais Universidade Federal dos Vales do Jequitinhonha e Mucuri, Diamantina, 2016.

BEGON, M.; HARPER J.L.; TOWHSEND, C.R. Ecology: Individuals, Populations and Communities. 3aㅗ ed, Blackwell Scientific Publications, 1990.

BEGON, M.; HARPER J.L.; TOWHSEND, C.R. Fundamentos em Ecologia. 4a ed, Artmed, 2006.

BERRY, F.; KRESS, W.J. Heliconia: an identification guide. $1^{\text {a }}$ ed, Smithsonian Books, 1991.

BJORKMAN, O. Responses to different quantum flux densities. In: LANGE, O.L. et al., (eds). $1^{\mathrm{a}}$ ed, Encyclopedia of plant Physiology, 1981.

BUDKE, J.C.; ATHAYDE, E.A.; GIEHL, E.L.H.; ZÁCHIA, R.A.; EISINGER, S.M. Composição florística e estratégias de dispersão de espécies lenhosas em uma floresta ribeirinha, arroio Passo das Tropas, Santa Maria, RS, Brasil. Iheringia - Série Botânica., v.60, n.1, p.17-24, 2005.

CERQUEIRA, L.L.; FADIGAS, F.D.S.; PEREIRA, F.A.; GLOAGUEN, T.V.; COSTA, J.A. Desenvolvimento de Heliconia psittacorum e Gladiolus hortulanus irrigados com águas residuárias tratadas. Revista Brasileira de Engenharia Agrícola e Ambiental., v. 12, n. 6, p. 606-613, 2008.

COSTA, C.C. Parque Nacional Serra de Itabaiana-SE: Realidade e gestão. Revista Monografias Ambientais., v. 13, n. 5, p. 3933-3951, 2014.

COSTA, F.R.; ESPINELLI, F.P.; FIGUEIREDO, F.O. Guia de zingiberales dos sítios PPBio na Amazônia Ocidental brasileira. 19a ed, Áttema Design Editorial, 2011. 
CRILEY, R.A.; SAKAI, W.S. Heliconia wagneriana Petersen is a Short-day Plant. HortScience., v. 32, n. 6, p. 1044-1045, 1997.

CRUZ, B.M. Estudos de longevidade e germinação em sementes de espécies do gênero Melocactus (cactaceae) de Morro do Chapéu, Chapada Diamantina, Bahia. (Dissertação) Mestrado em Recursos Genéticos Vegetais - Universidade Federal de Feira de Santana, Feira de Santana, Bahia, 2011.

CRUZ, D.D.; RICHERS, B.T.T; ZAMITH, L.R. The effect of temperature on the germination of Melocactus violaceus Pfeiff. (Cactaceae), a threatened species in restinga sandy coastal plain of Brazil. Anais da Academia Brasileira de Ciências., v. 85, n. 2, p. 615-622, 2013.

CYSNEIROS, V.C.; AMORIM, T.A.; JÚNIOR, J.D.O.M.; GAUI, T.D.; MORAES, J.C.R., BRAZ, D.M.; Machado, S.A. Distribuição diamétrica de espécies da Floresta Ombrófila Densa no Sul do Estado do Rio de Janeiro. Pesquisa Florestal Brasileira., v. 37, n. 89, p. 1-10, 2017.

DANTAS, T.V.P.; RIBEIRO, A.D.S. Caracterização da vegetação do Parque Nacional Serra de Itabaiana, Sergipe-Brasil. Biotemas., v. 23, n. 4, p. 9-18, $2010 \mathrm{~b}$.

DANTAS, T.V.P.; RIBEIRO, A.S. Estrutura populacional de Kielmeyera rugosa Choisy (Clusiaceae) no Parque Nacional Serra de Itabaiana, Estado do Sergipe. Acta Scientiarum. Biological Sciences., n. 32, v. 2, p. 141-146, 2010 a.

DUNCAN, R.D. Competition and the coexistence of species in a mixed podocarp stand. Journal of Ecology., v. 79, n. 1, p. 1073-1084, 1991.

Eiten, G. 1982. Brazilian "savannas", p. 25-47 In: Ecology of tropical savannas (Huntley, B.J. \& B.H. Walker, Eds.). Springer, New York.

FABRICANTE, J.R.; ANDRADE, L.A.; MARQUES, F.J. Caracterização populacional de Melocactus zehntneri (Britton \& Rose) Luetzelburg (Cactaceae) ocorrente em um inselbergue da Caatinga paraibana. Biotemas., v. 23, n. 1, p. 61-67, 2010.

FABRICANTE, J.R.; CASTRO, R.A.; ARAÚJO, K.C.T.; SIQUEIRA-FILHO, J.A. Atributos ecológicos da bioinvasora Nicotiana glauca Graham (Solanaceae) e avaliação da susceptibilidade de sua ocorrência no Brasil. Ciência Florestal., v. 25, n. 4, p. 959-967, 2015.

FABRICANTE, J.R.; FEITOSA, S.S.; BEZERRA, F.T.C.; FEITOSA, R.C.; XAVIER, R.F. Análise populacional de Caesalpinia pyramidalis Tul. (Fabaceae Lindl.) na caatinga da região do Seridó nordestino. Revista Brasileira de Biociências., v. 7, n. 3, p. 285-290, 2009.

FABRICANTE, J.R.; OLIVEIRA, C.R.S. Estrutura populacional de Melocactus ernestii Vaupel (Cactaceae). Scientia Plena., v. 9, n. 6, p. 1-8, 2013.

FABRICANTE, J.R.; OLIVEIRA, M.N.A.; SIQUEIRA-FILHO, J.A. Aspectos da ecologia de Calotropis procera (Apocynaceae) em uma área de Caatinga alterada pelas obras do Projeto de Integração do Rio São Francisco em Mauriti, CE. Rodriguésia., v. 64, n. 3, p. 647-654, 2013. 
FURLAN, F.H.; COSTA, F.L.D.; TORRES JÚNIOR, S.C.; KERBER, F.L.; DAMASCENO, E.D.S.; SALINO, A.; RIET-CORREA, F. Perfil de propriedades rurais com pastos invadidos por Pteridium arachnoideum na região norte de Mato Grosso e prevalência de hematúria enzoótica bovina. Pesquisa Veterinária Brasileira., v. 34, n. 8, p. 753-759, 2014.

GIBSON, A. C.; NOBEL, P. S. The cactus primer. Harvard University Press, 1986.

GUERIN, N. Impactos da invasão e mecanismos de regeneração natural do cerradão em áreas ocupadas por Pteridium arachnoideum (Kaulf.) Maxon (Dennstaedtiaceae) no sudoeste do Estado de São Paulo. (Dissertação) Mestrado em Ciências da Engenharia Ambiental - Universidade de São Paulo, São Carlos, 2010.

Harley, R.M. \& N.A. Simmons. 1986. Florula of mucugê-Chapada Diamantina, Bahia, BrazilA descriptive check-list of a campo rupestre area. Royal Botanic Gardens, Kew. 227p.

HESS, A.F.; CALGAROTTO, A.R.; PINHEIRO, R.; WANGINIAK, T.C.R. Proposta de manejo de Araucaria angustifolia utilizando o quociente de Liocourt e análise de incremento, em propriedade rural no Município de Lages, SC. Pesquisa Florestal Brasileira., v. 30, n. 64, p. 337-345, 2010.

HUGHES, F.M. Biossistemática, filogeografia, estrutura microespacial e dinâmica populacional do complexo Melocactus oreas (Cactaceae) no Brasil. (Tese) Doutorado em Ciências Biológicas - Universidade Federal de Minas Gerais, Belo Horizonte, Brasil, 2014.

IBISCH, P.L.; RAUER, G.; RUDOLPH, D.; BARTHLOTT, W. Floristic, biogeographical and vegetation aspect of Pre-Cambrian rock outcrops (inselberg) in eastern Bolivia. Flora., v. 190, n. 4, p. 299-314, 1995.

ICMBio. Plano de Manejo Parque Nacional Serra de Itabaiana. 2016.

ICMBio. Plano de Manejo Parque Nacional Serra de Itabaiana. Disponível em: $<$ http://www.icmbio.gov.br/portal/images/stories/plano-de-

manejo/dcom_plano_de_manejo_Parna_Serra_de_Itabaiana.pdf> acesso em: 17/01/20020

IKEMOTO, E.; HORNINK, G.G.; RICARTE, J.D.; MISAE, T. Análise da Estrutura Espacial de Xylopia aromatica em um Trecho de um Fragmento de Cerrado no Município de ItirapinaSP. Universidade Estadual de Campinas, p. 1-9, 2003.

IUCN. Red List of threatened species. Disponível em: <https://www.iucnredlist.org/species/40925/121501259> acesso em 20/01/2020.

JABTOBA, L.J. Alelopatia em Pteridium arachnoideum (Kaulf.) Maxon. (Dennstaedtiaceae). (Tese) Doutorado em Ciências - Universidade Federal de São Carlos (UFSCar), São Paulo, 2016.

JACOBI, C.M.; CARMO, F.F.; VINCENT, R.C. Estudo fitossociológico de uma comunidade vegetal sobre canga como subsídio para a reabilitação de áreas mineradas no Quadrilátero Ferrífero, MG. Revista Árvore., v. 32, n. 2, p. 345-353, 2008.

JANZEN, D.H. Why bamboos take so long to flower. Annual Review of Ecology and Systematics., v. 7, n. 1, p. 347-391, 1976. 
Joly, A.B. Botânica - Introdução à taxonomia vegetal. Comp. Ed. Nacional/Editora da Univ. São Paulo. 1966.

JUDD, W. S.; CAMPBELL, C. S.; KELLOGG, E. A., STEVENS, P. F.; DONOGHUE, M. J. Sistemática Vegetal: Um Enfoque Filogenético. Artmed Editora, 2009.

JYOTHI, H.J.; VIDYADHAR, D.J.; MAHADEVA, A.; PHILIP, M.; PARMAR, S.K.; MANOHARI, S.G.; SHANKAR, S. K.; RAJU, T. R. E ALLADI, P. A. Aging causes morphological alterations in astrocytes and micróglia in human substantia nigra pars compacta. Elsevier., v. 36, n. 1, p. 3321-3333, 2015.

LEIRANA-ALCOCER, J.; PARRA-TABLA, V. Factors affecting the distribution, abundance, and seedling survival of Mammillaria gaumeri, an endemic cactus of coastal Yucatán, México. Journal of Arid Environments., v. 41, n. 1, p. 421-428, 1999.

LEITE, E.J. Spatial distribution patterns of riverine Forest taxa in Brasília, Brazil. Forest Ecology and Management., v. 140, p. 257-264, 2001.

LIMA, T.N.M.; MOURA, D.M.D.O.; GOMES, L.J.; MELLO, A.A.D.; FERREIRA, R.A. Etnobotânica e estrutura populacional da mangabeira (Hancornia speciosa Gomes) em assentamento agroextrativista, Pirambu, Sergipe, Brasil. Ethnoscientia., v. 4, n. 1, p. 1-15, 2019.

LIRA, S.A.; NETO, A.C. Coeficientes de correlação para variáveis ordinais e dicotômicas derivados do coeficiente linear de Pearson. Revista Recie., v. 15, n 1/2, p. 45-53, 2006.

MARACAJÁ, P.B.; BENEVIDES, D.S. Estudo da flora herbácea da Caatinga no município de Caraúbas no Estado do Rio Grande do Norte. Revista de Biologia e Ciências da Terra., v. 6 , n. 1, p. 165-175, 2006.

MARACAJÁ, P.B; BENEVIDES, D.S. Estudo da flora herbácea da Caatinga no município de Caraúbas no Estado do Rio Grande do Norte. Revista de Biologia e Ciências da Terra, v. 6, n. 1, p. 165-175, 2006.

MARTINELLI, G.; MORAES, M.A. Livro vermelho da flora do Brasil. $1^{\text {a }}$ ed, Andrea Jakobsson: Instituto de Pesquisas Jardim Botânico do Rio de Janeiro 2013.

MATA, P.A.D. Diversidade e estrutura de Cactaceae Juss. Em uma área do semiárido paraibano. (Tese) Licenciatura em Ciências Biológicas - Universidade Estadual da Paraíba (UEPB), Campina Grande, 2014.

MATIELO, M.D.; SAUZA, T.B.; MENDONÇA P.P.; SELVATICI, P.D.C.; JUNIOR, L.P.G. A população do mexilhão Perna perna no costão rochoso de Piúma-ES, e sua utilidade para agricultura. Arquivo de Ciências do Mar., v. 49, n.1, p.38-42, 2016.

MATOS, D.M.D.S.; BELINATO, T.A. Interference of Pteridium arachnoideum (Kaulf.) Maxon. (Dennstaedtiaceae) on the establishment of rainforest trees. Brazilian Journal of Biology., v. 70, n. 2, p. 311-316, 2010.

MELO, A.A.D. Efeito da aplicação de doses de regulador de crescimento e de períodos de incubação no enraizamento e brotação inicial de rizomas de Heliconia psittacorum Lf $x$ Heliconia spathocircinata aristeguieta cv. alan carle. (Monografia) Graduação em Engenharia Agronômica - Universidade de Brasília (UnB), Distrito Federal, 2011. 
MICHAEL, D. R.; LINDENMAYER, D. B.; CUNNINGHAM, Ross B. Managing rock outcrops to improve biodiversity conservation in Australian agricultural landscapes. Ecological Management \& Restoration, v. 11, n. 1, p. 43-50, 2010.

MONACO, P.A.V.L.; SOELA, D.M.; HADDADE, I.R.; OZA, E.F.; SANTOS, M.M. Nota técnica: tratamento de água residuária de suinocultura em sistemas alagados construídos cultivados com Heliconia psittacorum e Hedychium coronarium. Revista Engenharia na Agricultura., v. 25, n. 6, p. 561-568, 2017.

MORISITA, M. la-index, a measure of dispersion of individuals. Researches on population ecology. v. 4, n. 1, p. 1-7, 1962

MORISITA, M. Measuring of the dispersion of individuals and analysis of the distributional patterns. Mem. Fac. Sci. Kyushu Univ. Ser. E., v. 2, n. 21, p. 5-23, 1959.

NASI, R. Analysis of the spatial structure of a rattan population in a mixed dipterocarp forest of Sabah (Malaysia). Acta Oecologica., v. 34, n. 1, p. 73-85, 1993.

NETO, M.; ALVES, J.A.; MARTINS, F.R. Estrutura do sub-bosque herbáceo arbustivo da mata da silvicultura, uma floresta estacional semidecidual no município de Viçosa-MG. Revista Árvore., v. 27, n. 4, p. 459-471, 2003.

OLIVEIRA, D.G.; PRATA, A.P.N.; FERREIRA, R.A. Herbáceas da Caatinga: composição florística, fitossociologia e estratégias de sobrevivência em uma comunidade vegetal. Revista Brasileira de Ciências Agrárias., v. 8, n. 4, p. 623-633, 2013.

OLIVEIRA, I.S.S. Estudo dos impactos ambientais como subsídio para o planejamento das trilhas do parque nacional na serra de Itabaiana, SE. Boletim Goiano de Geografia., v. 28, n. 1, 115-126, 2008.

RAMIREZ, N.; BRITO, Y. Síndromes de dispersión de una comunidad de pantanos de palmeras (morichal) en los Altos Llanos centrales. Revista Chilena de Historia Natural., v. 61 , n. 1, p. 53-60, 1988.

RECHENMACHER, C.; SCHMITT, J.L.; BUDKE, J.C. Estrutura e distribuição espacial de uma população de Blechnum tabulare (thunb.) kuhn (Pteridophyta, blechnaceae) em um mosaico floresta-campo no Sul do Brasil. Pesquisas, Botânica., n. 58, p.177-186, 2007.

Reflora. Melocactus violaceus Pfeiff. Disponível em: <http://floradobrasil.jbrj.gov.br/reflora/floradobrasil/FB1591> acesso em 29/01/2020.

Reflora. Vellozia dasypus Seub. Disponível em: <http://servicos.jbrj.gov.br/flora/search/Vellozia_dasypus> acesso em 23/01/2020.

RODGERS, J.L.; NICEWANDER, W.A. Thirteen ways to look at the correlation coefficient. The American Statistician., v. 42, n. 1, p. 59-66, 1988.

ROUGHGARDEN, J. Theory of population genetics and evolutionary ecology: and introduction. 1를 $\mathrm{ed}$, MacMillan, 1979.

RUNDEL, P.W.; SHARIFI, M.R.; GIBSON, A.C.; ESLER, K.J. Structural and physiological adaptation to light environments in neotropical Heliconia (Heliconiaceae). Journal of Tropical Ecology., v. 14, n. 6, p. 789-801, 1998. 
SANTANA, M.C.D.; SANTOS, P.A.A.; RIBEIRO, A.D.S. Levantamento etnobotânico da família Cactaceae no estado de Sergipe. Fitos., v. 12, n. 1, p. 41-53, 2018.

SANTOS, C.S. Tipificação do Lixo Visando Estratégias de Educação Ambiental no Parque Nacional Serra de Itabaiana. (Dissertação) Monografia para conclusão de curso de graduação em Engenharia Florestal - Universidade Federal de Sergipe, São Cristóvão, 2006.

SANTOS, N.É.F.; DIAS, U.N.S.; KARLA, J.B.; SILVA, C.D.A.; RIBEIRO, L.B. Frugivoria e dispersão de sementes por lagartos em ecossistemas brasileiros: uma revisão. Revista Nordestina de Zoologia., v. 6, n. 2, p. 74-102, 2012.

SILVA, A.C.C.; SILVA, E.V.O.; ALVES, M.; FARIAS, M.C.V.; MOTA, A.C.; SOUZA, C.A.S.; PRATA, A.P.N. Lista atualizada da flora vascular do Parque Nacional (PARNA) Serra de Itabaiana, Sergipe, Brasil. Pesquisa e Ensino em Ciências Exatas e da Natureza., v. 3, n. 1, p. 40-67, 2019.

SILVERTOWN, J.W. Introdution to plant population ecology. $2^{\mathrm{a}}$ ed, Longman, 1987.

SNUC - Sistema Nacional de Unidades de Conservação. Ministério do meio ambiente. Brasília-DF, 2000.

SOBRAL, I.S.; OLIVEIRA, S.R.K.; GOMES, L.J.; RIBEIRO, G.T.; SANTOS, J.R.; COSTA, M. Avaliação dos impactos ambientais no Parque Nacional Serra de Itabaiana-SE. Caminhos de Geografia., v. 8, n. 24, p. 102-110, 2007.

SOBRAL-OLIVEIRA, I.S.; COSTA, C.C.; GOMES, L.J.; SANTOS, J. Planejamento de trilhas para o uso público no Parque Nacional Serra de Itabaiana, SE. Turismo-Visão e Ação., v. 11, n. 2, p. 242-262, 2009.

Souza, F.S. Pteridófitas da Serra do Caparaó, Brasil: inventário e relações florísticas. (Dissertação) Mestrado em Ecologia Aplicada ao Manejo e Conservação dos Recursos Naturais - Universidade Federal de Juiz de Fora, Juiz de Fora, 2012.

SOUZA, Jumara Marques et al. Efeitos do fogo nas populações de Vellozia aff. sincorana, espécie útil e endêmica da Serra do Sincorá, Bahia, Brasil. (Tese) Doutorado em Botânica - Universidade Federal de Feira de Santana, Bahia, 2015.

TEIXEIRA, V.D. Distribuição espacial e biologia floral e reprodutiva de Uebelmannia buiningii Donald (Cactoideae, cactaceae): Espécie endêmica dos campos rupestres, Minas Gerais - Brasil. (Dissertação) Mestrado em Recursos genéticos vegetais Universidade Federal do Recôncavo da Bahia, Cruz das Almas, Bahia, 2014.

THOMSON, J. A. Morphological and genomic diversity in the genus Pteridium (Dennstaedtiaceae). Annals of Botany, v. 85, n.1, p. 77-99, 2000.

TOKARNIA, C. H. Plantas tóxicas do Brasil para animais de produção. Ed. Helianthus, 2012.

TRYON, R. M.; TRYON, A. F. Ferns and allied plants: with special reference to tropical America. Springer Science \& Business Media, 2012. 
VANCLAY, J.K. Modelling forest growth and yield: applications to mixed tropical forests. $1^{\text {a }}$ ed, School of Environmental Science and Management Papers, 1994.

VICENTE, A. Levantamento florístico de um fragmento florestal na Serra de Itabaiana - Sergipe. (Dissertação) Mestrado em Biologia Vegetal - Universidade Federal Rural de Pernambuco, Recife, Brasil,1999.

VILAR, J.C.; ZYNGIER, N.A.C.; CARVALHO, C.M. Distribuição espacial de Vellozia dasypus Seubert (Veloziaceae) e Melocactus zehntneri (Britt. et Rose) Lutzelb. (Cactaceae) na Serra de Itabaiana, Sergipe. Biologia Geral e Experimental., v. 1, n. 1, p. 5-15, 2000.

WEBB, L.J.; TRACEY, J.G.; WILLIAMS, W.T. Regeneration and pattem in the subtropical rain forest. Journal of Ecology, v. 60, n. 3, p. 675-695, 1972. 


\title{
CAPÍTULO 3
}

\section{GERMINAÇÃO DE SEMENTES DE MANGABA (HANCORNIA SPECIOSA GOMES) SUBMETIDAS A ARMAZENAMENTO E TRATAMENTO COM CÁLCIO}

\author{
Cristina Filomena Justo', Nathallya da Cruz Mota²
}

1. Curso de Ciências Biológicas, Instituto de Ciências Biológicas e da Saúde/ Campus Universitário do Araguaia/Universidade Federal de Mato Grosso, Pontal do Araguaia, MT, Brasil;

2. Curso de Agronomia, Instituto de Ciências Exatas e da Terra/Campus Universitário do Araguaia/Universidade Federal de Mato Grosso, Barra do Garças, MT, Brasil;

\section{RESUMO}

A mangabeira (Hancornia speciosa Gomes, Apocynaceae), é originária do Brasil. A propagação é realizada por sementes, sendo estas consideradas recalcitrantes. O objetivo do trabalho foi avaliar a persistência da capacidade de germinação após armazenamento das sementes e uso de solução de $\mathrm{CaCl}_{2}$ em testes de germinação. As sementes foram armazenadas a $12^{\circ} \mathrm{C}$ e realizou-se testes de germinação até 75 dias de armazenamento, os quais foram conduzidos em dois tratamentos: (1) papel de germinação umedecido com solução de $\mathrm{CaCl}_{2} 100$ mMolar ("CC") e (2) papel de germinação umedecido com água destilada ("SC"), com quatro repetições em rolos de papel com 30 sementes em cada. Avaliou-se o teor de água em base úmida (b.u.), que reduziu-se de 63,9\% para 50,0\% durante o armazenamento, enquanto a germinação (G\%) diminuiu de $66,1 \%$ para $22,8 \%$. Não houve diferença significativa entre tratamentos CC e SC para G\% e tempo médio de emergência. No entanto, nas outras variáveis como tempo médio de germinação, índice de velocidade de germinação, emergência, índice de velocidade de emergência, comprimento total das plântulas, relação raiz/parte aérea e massa fresca das plântulas, o desenvolvimento foi prejudicado no tratamento CC. Houve perda de vigor durante o armazenamento e o uso de $\mathrm{CaCl}_{2}$ não prejudicou a germinação, mas retardou o desenvolvimento das plântulas, portanto o uso desse soluto não é recomendado para sementes de mangaba na concentração utilizada.

Palavras-chave: Cloreto de Cálcio, semente recalcitrante e vigor de sementes.

\section{ABSTRACT}

The mangabeira (Hancornia speciosa Gomes, Apocynaceae) originates from Brazil. Its propagation is carried out by seeds, which are considered recalcitrant. The aim of this work was to evaluate the persistence of the germinability after storage of these seeds in a refrigerator and the usage of a solution of $\mathrm{CaCl}_{2}$ in germination tests. The seeds were stored at $12^{\circ} \mathrm{C}$ and submitted to germination tests at different storage times up to 75 days. They were divided in two treatments: (1) seeds treated with calcium chloride solution $\left(\mathrm{CaCl}_{2}, 100\right.$ mMolar) (labelled "CC") and (2) seeds wetted with distillated water (labelled "SC"), and in 
each one, four rolls were used with 30 seeds in each of them. The water content was measured on a wet basis (w. b.) and it reduced from $63,9 \%$ to $50,0 \%$ during the storage, while the germination (G\%) shrinked from $66,1 \%$ to $22,8 \%$. There was no significant difference between the treatments for $\mathrm{G} \%$ and average emergence time. However, in the other variables such as mean germination time, germination velocity index, aerial part emission, aerial part emission velocity index, total length, root/aerial part ratio and fresh mass of the seedlings, there was an impairment detected within the CC treatment. There was a loss of vigour during the storage and the usage of $\mathrm{CaCl}_{2}$ did not damage $\mathrm{G} \%$, but it delayed the development of the seedlings, so the use of this solution is not recommended for these seeds in the used concentration.

Keywords: Calcium chloride, recalcitrante seed and seed vigour.

\section{INTRODUÇÃO}

A mangabeira (Hancornia speciosa Gomes) é originária do Brasil, ocorrendo no Cerrado e regiões litorâneas da região Nordeste, também é encontrada em países vizinhos como o Paraguai, Bolívia, Peru e Venezuela. Pertence à família Apocynaceae, embora a espécie tenha sido explorada para a produção de látex no século XIX, essa atividade foi abandonada e o principal interesse atual são seus frutos carnosos, que são bastante apreciados in natura, na forma de sucos, sorvetes, compotas entre outros. Existem recomendações de plantio, mas manejo tem sido essencialmente extrativista, sendo uma cultura em fase de domesticação (BARROS et al., 2006; LEDO et al., 2015; PEREIRA et al., 2016; SILVA-JÚNIOR et al., 2017).

A espécie foi denominada também como mangabiba e mangaiba em relato do período colonial, durante a ocupação holandesa no litoral de Pernambuco (MARCGRAVI, 1648). O significado do termo é "coisa boa de comer" em tupi-guarani (LEDO et al., 2015), além disso algumas partes da planta têm aplicação na medicina popular (SILVA-JÚNIOR, 2004) e pesquisas de atividade farmacológica são promissoras (ALMEIDA et al., 2016).

Devido à rápida perda de viabilidade das sementes, a conservação ocorre por meio de coleções a campo (NUNES, 2018). Tais coleções, no entanto, são vulneráveis aos mesmos problemas que pequenas populações na natureza (HAVENS et al., 2006). Estudos pioneiros da germinação da espécie constataram também a rápida perda de poder germinativo das sementes deixadas em condições ambientais por três a oito dias (TAVARES, 1960; PIMENTEL; SANTOS, 1978).

Gonzaga-Neto et al. (1987) publicaram um dos primeiros estudos do armazenamento das sementes de mangaba, visando prolongar sua durabilidade. 
Diferentes autores observaram perda de viabilidade e vigor após armazenamento por curtos períodos em condições de temperatura ambiente e geladeira (OLIVEIRA; VÁLIO, 1992; QUEIROZ; BIANCHETTI, 2001; VIEIRA et al., 2006). Segundo Salomão (2004), as sementes da espécie não toleram secagem abaixo de $30 \%$ de teor de água e recomendase armazenamento a temperaturas superiores a $10^{\circ} \mathrm{C}$, levando à sua classificação como semente recalcitrante (VIEIRA-NETO, 2001).

Barbedo e Marcos Filho (1998) propõe que uma alternativa para a conservação de sementes recalcitrantes poderia ser obtida através de métodos que visassem à paralisação ou limitação do crescimento do eixo embrionário, mantendo-se a semente sempre hidratada para que a água seja suficiente para evitar a sua desidratação. $O$ uso de reguladores de crescimento vegetal, tais como o ácido abscísico (ABA) foi realizado com algum sucesso para sementes de Inga vera subsp. affinis (DC.) T.D.Penn. (Fabaceae) (BARBEDO; CICERO, 2000), enquanto Andréo, Nakagawa e Barbedo (2006) avaliaram o uso da hidratação controlada com manutenção de embriões da mesma espécie em soluções de polietilenoglicol 6000 (PEG) com potencial osmótico negativo até -2,4 MegaPascal (MPa), com manutenção de germinação elevada até 90 dias de armazenamento a $10^{\circ} \mathrm{C}$.

Soluções de cloreto de cálcio têm sido usadas para o tratamento de sementes ortodoxas de baixa vigor (DANTAS, 2002). Para sementes de soja tratadas com soluções de carbonato de cálcio $\left(\mathrm{CaCO}_{3}\right)$, cloreto de cálcio $\left(\mathrm{CaCl}_{2}\right)$, oxicloreto de cálcio $\left(\mathrm{Ca}(\mathrm{ClO})_{2}\right)$, sulfato de cálcio $\left(\mathrm{CaSO}_{4}\right)$ e hidróxido de cálcio $\left(\mathrm{Ca}(\mathrm{OH})_{2}\right)$ ocorreu diferença de desempenho até a fase de colheita em relação à testemunha, tratada com água (BELUR et al., 2010). Efeito positivo do tratamento pré-semeadura com $\mathrm{CaCl}_{2}$ também foi relatado para amendoim (VENKATESH-BABU et al., 2018) e girassol (NARAYANAREDDY; BIRADARPATIL, 2012).

A adição de cálcio à solução de solo teve efeito positivo sobre a germinação de sementes e outras variáveis para seis espécies arbóreas sujeitas a chuva ácida em floresta do sul da China (LIU et al., 2011). A mangaba é bastante tolerante a solos ácidos, pobres em nutrientes e matéria orgânica (LEDO et al., 2015). A aplicação de calcário não visa à correção da acidez, mas ao fornecimento de cálcio e de magnésio para as plantas (PEREIRA et al., 2016). Vieira-Neto (1995) foi um dos pioneiros no estudo da nutrição mineral da espécie e segundo Rosa, Naves e Oliveira-Junior (2005), as mudas de mangaba que receberam adubação, com ou sem calagem, proporcionaram um maior desenvolvimento a parte aérea das plântulas, enquanto Silva et al. (2009) mencionam a deficiência em cálcio como um fator de mortalidade para as mudas de mangaba. 
O íon cálcio $\left(\mathrm{Ca}^{2+}\right)$ é fundamental para a rigidez da parede celular e permeabilidade da membrana plasmática (HEPLER, 2005). Sua atividade depende da concentração e localização na célula, sendo que uma das principais atividades do $\mathrm{Ca}^{2+}$ nas células vegetais refere-se à transdução de sinais, na qual atua como mensageiro secundário nas respostas das plantas a um número variado de sinais ambientais e hormonais (INÁCIO et al., 2011). A função como mensageiro secundário está baseada em concentrações de 0,1 a 0,2 $\mu \mathrm{M}$ de $\mathrm{Ca}^{2+}$ livre no citossol e alta concentração em outros compartimentos, tais como o retículo endoplasmático. Há evidências de que o cálcio se liga à proteína calmodulina e proteínas quinases dependentes de $\mathrm{Ca}^{2+}$, ativando-as (BETHKE et al., 1995; GASPAR et al., 2003).

Uma das possibilidades para a conservação de sementes recalcitrantes é a criopreservação. Diferentes protocolos foram propostos com variado grau de sucesso, com diferentes espécies. A fase de descongelamento mostrou-se crucial na recuperação e desenvolvimento posterior de embriões de algumas delas (BERJAK et al., 2000). Berjak e Mycock (2004) foram bem sucedidos no resgate de eixos embrionários de sementes de Trichilia dregeana Sond. (Meliaceae) após descongelamento em soluções de $\mathrm{CaCl}_{2}$ e $\mathrm{MgCl}_{2}$ (cloreto de magnésio).

Soluções de cálcio e magnésio a 1,0 mM mostraram-se benéficas para germinação de sementes baixo vigor de Eugenia pyriformis Camb. (Myrtaceae), armazenadas por até 180 dias (JUSTO, 2006), enquanto Bensi (2016) não observou diferença de desempenho germinativo para sementes de E. dysenterica DC. (Myrtaceae) tratadas com solução $10 \mathrm{mM}$ de $\mathrm{CaCl}_{2}$ após dessecação controlada.

A partir da hipótese de que a aplicação exógena de $\mathrm{CaCl}_{2}$ contribui para a integridade e permeabilidade das membranas celulares na semente (HEPLER, 2005) e considerando que não há estudo anterior a respeito da aplicação de sais de cálcio no tratamento de sementes de mangaba, realizou-se este trabalho com o objetivo de avaliar o efeito do cloreto de cálcio $\left(\mathrm{CaCl}_{2}\right)$ sobre a germinação de sementes de $H$. speciosa e o desenvolvimento das plântulas após armazenamento por diferentes períodos.

\section{MATERIAIS E MÉTODOS}

Coletou-se frutos "de vez" e maduros na zona rural dos municípios de Barra do

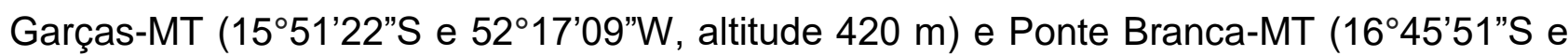
$52^{\circ} 50^{\prime} 00^{\prime \prime} \mathrm{W}$, altitude $424 \mathrm{~m}$ ), durante a primeira quinzena do mês de dezembro de 2016 . $\mathrm{O}$ 
clima da região é tropical semiúmido (Aw, segundo Köppen-Geiger) e caracteriza-se por duas estações bem definidas: uma chuvosa (outubro a abril) e outra seca (maio a setembro), com precipitação média de $1500 \mathrm{~mm}$ e temperatura média de $25,5^{\circ} \mathrm{C}$ em ambas as localidades (PIRANI; SANCHEZ; PEDRONI, 2009; THOMÉ FILHO; CRÓSTA; PAULA, 2012).

Os frutos foram coletados diretamente de diversas matrizes em cada local, com um número variável de frutos por matriz. Reuniram-se os frutos das duas coletas. Os frutos "de vez" foram armazenados por três dias à sombra e despolpados a medida que apresentavam amolecimento da polpa à pressão manual. Para evitar a fermentação, escoou-se periodicamente o líquido que exsudava dos frutos.

Após despolpamento manual, seguido de lavagem em peneira sob água corrente, tratou-se as sementes com fungicidas (Carbendazim, Tiram) e inseticidas (Fipronil, Clorantraniliprole), com imersão na solução de tratamento durante 30 minutos. Escorreuse essa solução, envolveu-se as sementes em papel Germitest seco para absorver água resultante de condensação e armazenou-se à temperatura de $(12,0+1,0){ }^{\circ} \mathrm{C}$ em geladeira em embalagens plásticas não-lacradas.

Após cada tempo de armazenamento ( $0,3,8,15,30,45,60$ e 75 dias), determinouse o teor de água em base úmida (b.u.) de acordo com as Regras de Análise de Sementes (BRASIL, 2009) e conduziu-se testes de germinação em rolos de papel Germitest $\AA^{\circledR}$ autoclavado, nos tratamentos:

- "Com cálcio": papel umedecido com $\mathrm{CaCl}_{2} 100$ mMolar, denominado "CC" a partir deste ponto e

- "Sem cálcio": papel umedecido com $\mathrm{H}_{2} \mathrm{O}$ destilada, denominado "SC".

Ambos na razão de 2,5 vezes a massa do papel seco, o qual foi trocado de acordo com a deterioração das fibras do papel ao longo do experimento e reumedecido com a mesma solução inicial.

O experimento foi conduzido em câmara para germinação de sementes tipo Mangelsdorf com aquecimento (modelo SL 207, Solab®), programada a uma temperatura de $(30,0 \pm 2,0){ }^{\circ} \mathrm{C}$ e fotoperíodo de $12 / 12$ horas de claro/escuro. A câmara de germinação era equipada com quatro lâmpadas fluorescentes de $20 \mathrm{~W}$, tipo luz do dia. Os rolos de germinação foram mantidos na vertical em béckeres. 
O experimento foi realizado em delineamento inteiramente casualizado com quatro repetições de 30 sementes sob esquema fatorial $(8 \times 2)$ e o rolo de papel como repetição experimental (N). Determinou-se o valor da germinação (G\%), tempo médio de germinação (TMG), índice de velocidade de germinação (IVG), emergência de parte aérea (E\%), tempo médio de emergência (TME), índice de velocidade de emergência (IVE) de acordo com as fórmulas apresentadas em Cetnarski-Filho e Carvalho (2009).

As sementes foram observadas diariamente até a protrusão de 2,0 $\mathrm{mm}$ de radícula para registro como germinadas e mantidas nos rolos para acompanhar a emergência de parte aérea definida como 2,0 mm de epicótilo.

Após 30 dias da montagem de cada teste de germinação tomou-se aleatoriamente cinco plantas em cada rolo de papel, totalizando 20 plântulas por tratamento/tempo de armazenamento para avaliação do comprimento das plântulas, relação raiz/parte aérea e massa fresca (MF). O comprimento da parte aérea e da raiz foi avaliado com paquímetro analógico, com precisão de 0,02 mm. A massa foi obtida em balança analítica (GEhaka, modelo AG 200), com precisão de 0,0001 g.

As variáveis analisadas foram testadas quanto à distribuição normal de acordo com o teste de Shapiro-Wilk, procedeu-se à análise de variância por meio do teste $F$, considerando os fatores tempos de armazenamento $(T)$ e presença ou ausência de $\mathrm{CaCl}_{2}$ na solução de umedecimento no papel de germinação (Ca). Para o teor de água, avaliouse apenas o tempo de armazenamento. Efetuou-se o desdobramento quando a interação entre os fatores se mostrou significativa. Realizou-se comparação entre médias a 5\% de probabilidade pelo teste Scott-Knott e análise de regressão em função do tempo de armazenamento. Utilizou-se o programa estatístico SISVAR (FERREIRA, 2011) para realização da análise de variância e comparação entre médias e as funções estatísticas de planilha eletrônica Windows para análise de regressão.

Calculou-se o potencial osmótico da solução de $100 \mathrm{mMolar}$ de $\mathrm{CaCl}_{2}$ através da fórmula de Van't Hoff corrigida para a osmolaridade efetiva (FEHER, 2017):

$$
\psi=-R \cdot T \cdot C_{o s}
$$

Onde $\mathrm{R}=0,0082 \mathrm{~kg} \cdot \mathrm{MPa} \cdot(\mathrm{mol} . \mathrm{K})^{-1}, \mathrm{~T}=303 \mathrm{~K}$, considerando $\mathrm{t}=30^{\circ} \mathrm{C}$ na câmara de germinação. Como o $\mathrm{CaCl}_{2}$ dissocia-se em meio aquoso, resultando em três íons $\left(\mathrm{Ca}^{2+}\right.$ e $\left.2 \mathrm{Cl}-\right)$, a osmolaridade efetiva $\left(C_{o s}=\sum C_{s} . \varphi_{s}\right)$ da solução corresponde a $\sum C_{s .} \varphi_{s}=100 \mathrm{mMolar}$ (x3 íons). $0,85=255$ mosMolar= 0,255 osM, onde o coeficiente osmótico para o $\mathrm{CaCl}_{2}\left(\varphi_{s}=0,85\right)$. O potencial osmótico calculado foi de -0,642 MPascal. O potencial da água destilada foi considerado nulo. Assumiu-se que o $\mathrm{CaCl}_{2}$ é um sal neutro (VON HIPPEL; WONG, 1964), no entanto o pH das soluções não foi medido. 


\section{RESULTADOS E DISCUSSÃO}

O teor de água inicial das sementes foi de $63,9 \%$, declinando até 50,0\% após 75 dias de armazenamento. Houve diferença significativa entre tempos de armazenamento ( $F=$ $33,17, n=32, p<0,0001)$, com regressão também significativa $(F=44,33, n=8, p<0,001$, Figura $1 \mathrm{~A})$.
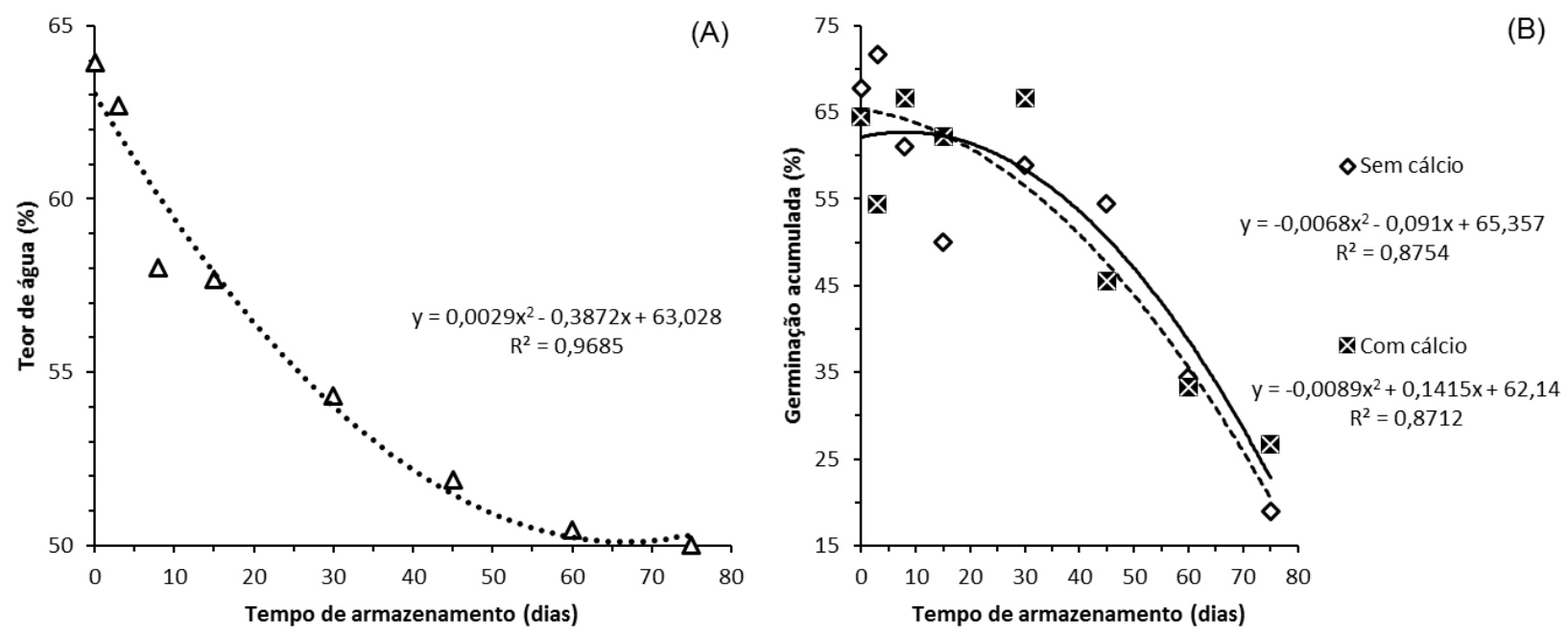

Figura 1. Variação do teor de água das sementes (A), germinação (G\%) de sementes de mangaba $(H$. speciosa) em função do tempo de armazenamento e do uso de solução de $\mathrm{CaCl}_{2} 100$ mMolar na embebição do papel de germinação.

A germinação (G\%) foi de $66 \%$ para sementes recém-colhidas, mantendo-se superior a $50 \%$ até 45 dias de armazenamento e atingindo níveis inferiores a $20 \%$ aos 75 dias. Houve perda de G\% superior a $0,5 \% \cdot$ dia $^{-1}$ de armazenamento, embora a relação não seja linear (Figura 1B). O fator Ca não foi significativo (Tabela 1).

Houve correlação positiva entre a queda do teor de água e a queda da germinação, para ambos os tratamentos ( $r=0,87, F=6,12, n=8$ e $p=0,048$, para "CC") e $(r=0,92, F=$ $12,77, n=8$ e $p=0,012$, para "SC"). 
Tabela 1. Quadrados médios da análise de variância para Germinação (\%), Tempo Médio de Germinação (TMG) e Índice de Velocidade de Germinação (IVG) de sementes de mangaba ( $H$. speciosa) armazenadas por diferentes períodos de tempo e tratadas ou não com solução de $\mathrm{CaCl}_{2} 100 \mathrm{mMolar}$ no teste de germinação. $\mathrm{N}=48$. Fonte de variação $\quad$ Graus de $\quad$ Germinação (\%) $\quad$ TMG (dias) $\quad$ IVG (dia ${ }^{-1}$ ) liberdade

\begin{tabular}{lcccc}
\hline Cálcio (Ca) & 1 & $5,7893^{\text {ns }}$ & $236,1294^{* * * *}$ & $7,8247^{* * * *}$ \\
Tempo de & & $1502,4436^{* * * *}$ & $55,9104^{* * * *}$ & $10,1445^{* * * *}$ \\
armazenamento (T) & 7 & $128,0021^{\text {ns }}$ & $6,4526^{* * *}$ & $0,3367^{*}$ \\
Ca ${ }^{*} \mathrm{~T}$ & 7 & 57,4127 & 1,3827 & 0,1148 \\
Resíduo & 32 & 14,53 & 13,01 & 13,53 \\
CV (\%) & &
\end{tabular}

$\mathrm{CV}=$ coeficiente de variação, $\mathrm{N}=$ número de parcelas. * Significativo a $5 \%$ de probabilidade $(p<0,05)$, ** Significativo a $1 \%$ de probabilidade $(p<0,01),{ }^{* \star \star}$ Significativo a $0,1 \%$ de probabilidade $(p<0,001)$, ${ }^{* * * *}$ Significativo a $0,01 \%$ de probabilidade ou mais $(\boldsymbol{p}<0,0001)$, ns = não significativo.
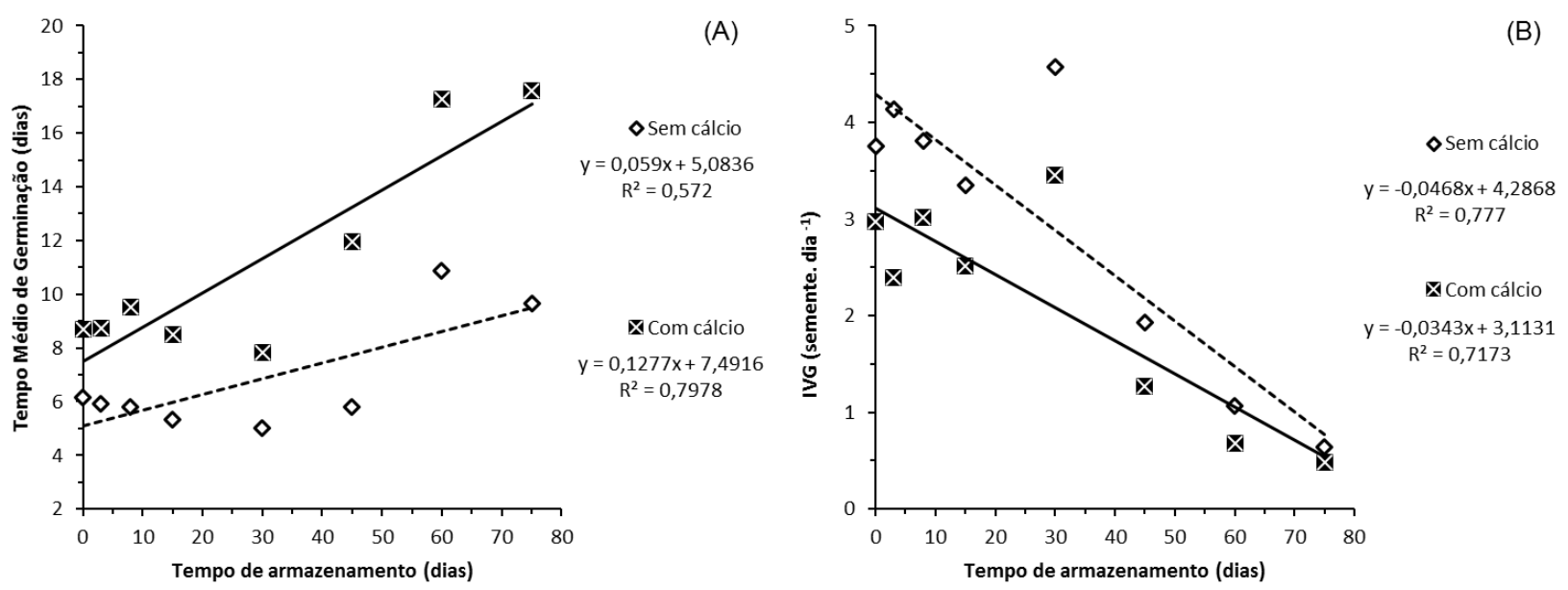

Figura 2. Variação do tempo médio de germinação e do IVG de sementes de mangaba (H. speciosa) em função do tempo de armazenamento e do uso de solução de $\mathrm{CaCl}_{2} 100$ mMolar na embebição do papel de germinação.

A interação entre os fatores Ca e T foi significativa para as variáveis TMG e IVG (Tabela 1). A germinação foi mais lenta no tratamento "CC", observou-se aumento do TMG e diminuição do IVG durante $O$ armazenamento. Ajustou-se regressões lineares significativas em função do tempo tanto para "CC" como para "SC" (Figuras 2A e 2B).

Para a emergência de parte aérea ( $E \%)$, a interação foi significativa entre os fatores Ca e T (Tabela 2). De modo geral, observou-se redução da emergência para sementes armazenadas por períodos mais longos. Para o tratamento "CC", o valor inicial foi de $50 \%$, reduzindo-se para $7,8 \%$ aos 75 dias, enquanto no tratamento "SC" diminuiu de $66,7 \%$ para 
16,7\% (Figura 3A). A regressão linear em função do tempo foi significativa para os dois tratamentos $(F=43,198, n=24$ e $p<0,0001$ para "CC" e $F=60,139, n=24$ e $p<0,0001$ para "SC").

Para o tempo médio de emergência (TME), os fatores $\mathrm{Ca}$ e $\mathrm{T}$ foram significativos, mas a interação entre eles não foi significativa (Tabela 2). Os valores de TME foram mais elevados para o tratamento "CC", com valores entre 22,0 e 25,9 dias, enquanto para "SC" variou entre 17,1 e 21,4 dias. A regressão linear em função do tempo foi significativa apenas para "CC" ( $F=12,28, n=24, p=0,002$, Figura 3B).

O índice de velocidade de emergência (IVE) apresentou interação significativa entre os fatores (Tabela 2). Para os dois tratamentos ocorreu redução do IVE para sementes armazenadas por períodos mais longos. O valor inicial para o tratamento "SC" foi de 1,03, decrescendo para 0,26 aos 75 dias de armazenamento. Para o tratamento "CC", o valor para o tempo zero foi de 0,64 , reduzindo-se para 0,09 (Figura 3C). A regressão linear em função do tempo foi significativa para os dois tratamentos $(F=62,05, n=24, p<0,0001$ para "SC") e ( $F=40,51, n=24, p<0,0001$ para "CC").

Quanto ao comprimento de plântulas, houve interação significativa entre Ca e T (Tabela 3). As plântulas do tratamento "CC" apresentaram comprimento entre 8,7 e 11,4 cm, enquanto as "SC" variaram entre 19,2 e 26,6 cm (Figura 4A). A regressão linear em função do tempo não foi significativa.

Tabela 2. Quadrados médios resultantes da análise de variância para Emergência da parte aérea (\%), Tempo médio de emergência da parte aérea (TME) e Índice de velocidade de emergência (IVE) de sementes de mangaba $(H$. speciosa) armazenadas por diferentes períodos de tempo e tratadas ou não com solução de $\mathrm{CaCl}_{2}$ no teste de germinação. $\mathrm{N}=48$.

\begin{tabular}{lcccc}
\hline Fonte de variação & $\begin{array}{c}\text { Graus de } \\
\text { liberdade }\end{array}$ & $\begin{array}{c}\text { Emergência da } \\
\text { parte aérea (\%) }\end{array}$ & $\begin{array}{c}\text { TME } \\
\text { (dias) }\end{array}$ & IVE (dia $\left.{ }^{-1}\right)$ \\
\hline Cálcio (Ca) & 1 & $1408,2250^{* * * *}$ & $329,9105^{* * * *}$ & $1,2741^{* * * *}$ \\
Tempo de & & & & \\
armazenamento (T) & 7 & $1929,4681^{* * * *}$ & $12,0055^{* * * *}$ & $0,4894^{* * * *}$ \\
Ca ${ }^{*}$ T & 7 & $155,9790^{*}$ & $1,5351^{14 s}$ & $0,0325^{*}$ \\
Resíduo & 32 & 53,7095 & 1,6725 & 0,0125 \\
CV (\%) & & 16,75 & 6,11 & 16,72 \\
\hline CV
\end{tabular}

$\overline{C V}=$ coeficiente de variação. $N=$ número de parcelas. ${ }^{*}$ Significativo a $5 \%$ de probabilidade $(p<0,05)$, ${ }^{* *}$ Significativo a $1 \%$ de probabilidade $(p<0,01),{ }^{* * *}$ Significativo a $0,1 \%$ de probabilidade $(p<0,001)$, $* * \star \star$ Significativo a $0,01 \%$ de probabilidade ou mais $(p<0,0001)$, ns = não significativo. 
Para a relação raiz/parte aérea também houve interação entre os fatores (Tabela 3). Valores maiores do que 1,0 indicaram que a raiz prevaleceu sobre a parte aérea, isso ocorreu tanto para "CC" quanto "SC" nos tempos zero e três dias de armazenamento. Nas demais datas, os valores de "SC" foram superiores aos de "CC". As regressões lineares não foram significativas (Figura 4B). Na comparação entre tratamentos, só não houve diferença significativa para o tempo de 75 dias.
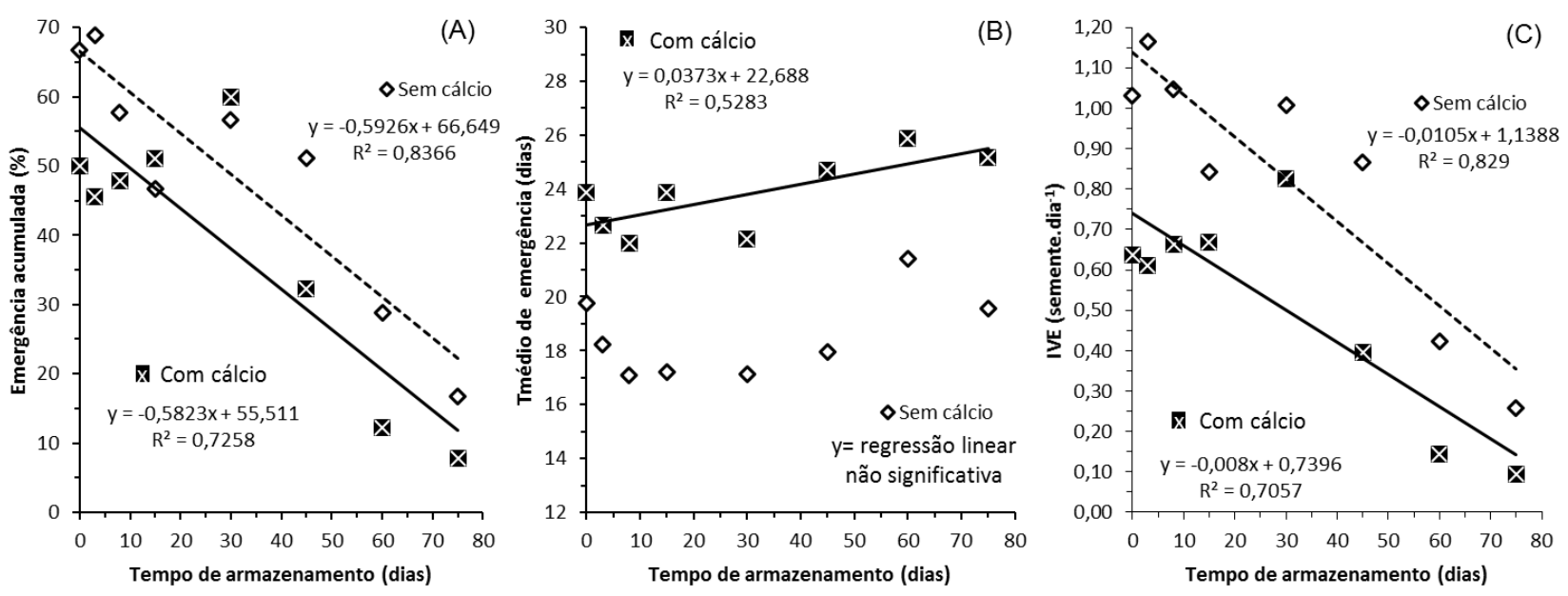

Figura 3. Variação dos parâmetros de emergência da parte aérea de sementes de mangaba (H. speciosa) em função do tempo de armazenamento e do uso de solução de $\mathrm{CaCl}_{2} 100$ mMolar na embebição do papel de germinação.

Tabela 3. Quadrados médios resultantes da análise de variância do comprimento de plântulas, Razão raiz/parte aérea e massa fresca de plântulas resultantes da germinação de sementes de mangaba $(H$. speciosa) armazenadas por diferentes períodos de tempo e tratadas ou não com solução de $\mathrm{CaCl}_{2}$ no teste de germinação.

$$
\mathrm{N}=320 \text {. }
$$

\begin{tabular}{lcccc}
\hline Fonte de variação & $\begin{array}{c}\text { Graus de } \\
\text { liberdade }\end{array}$ & $\begin{array}{c}\text { Comprimento de } \\
\text { plântulas }(\mathrm{cm})\end{array}$ & $\begin{array}{c}\text { Razão } \\
\text { raiz/parte aérea }\end{array}$ & $\begin{array}{c}\text { Massa fresca de } \\
\text { plântulas }(\mathrm{g})\end{array}$ \\
\hline Cálcio $(\mathrm{Ca})$ & 1 & $13305,9639^{* * * *}$ & $2,6701^{* *}$ & $2,3871^{* * * *}$ \\
Tempo de & & & & \\
armazenamento $(\mathrm{T})$ & 7 & $126,4785^{* * *}$ & $5,8688^{* * * *}$ & $0,2078^{* * * *}$ \\
Ca ${ }^{*} \mathrm{~T}$ & 7 & $39,7061^{*}$ & $2,7476^{* * * *}$ & $0,0634^{* * *}$ \\
Resíduo & 304 & 15,0050 & 0,2518 & 0,0176 \\
CV (\%) & & 23,50 & 51,37 & 23,64 \\
\hline CV & & &
\end{tabular}

$\mathrm{CV}=$ coeficiente de variação. $\mathrm{N}=$ número de parcelas. * Significativo a $5 \%$ de probabilidade $(p<0,05)$, ** Significativo a $1 \%$ de probabilidade $(p<0,01),{ }^{* \star *}$ Significativo a $0,1 \%$ de probabilidade $(p<0,001)$,

**** Significativo a $0,01 \%$ de probabilidade ou mais $(p<0,0001)$, ns = não significativo.

Houve interação significativa entre os fatores para a massa fresca das plântulas

(Tabela 3), cujos valores reduziram-se ligeiramente ao longo do armazenamento. 
Plântulas do tratamento "CC" apresentaram massa significativamente menor em todas as datas, exceto para 30 dias de armazenamento (Figura 4C). A regressão linear foi significativa para os dois tratamentos $(F=5,99, n=8, p<0,05$ para "SC") e $(F=10,16$, $\mathrm{n}=8, \mathrm{p}<0,05$ para "CC").
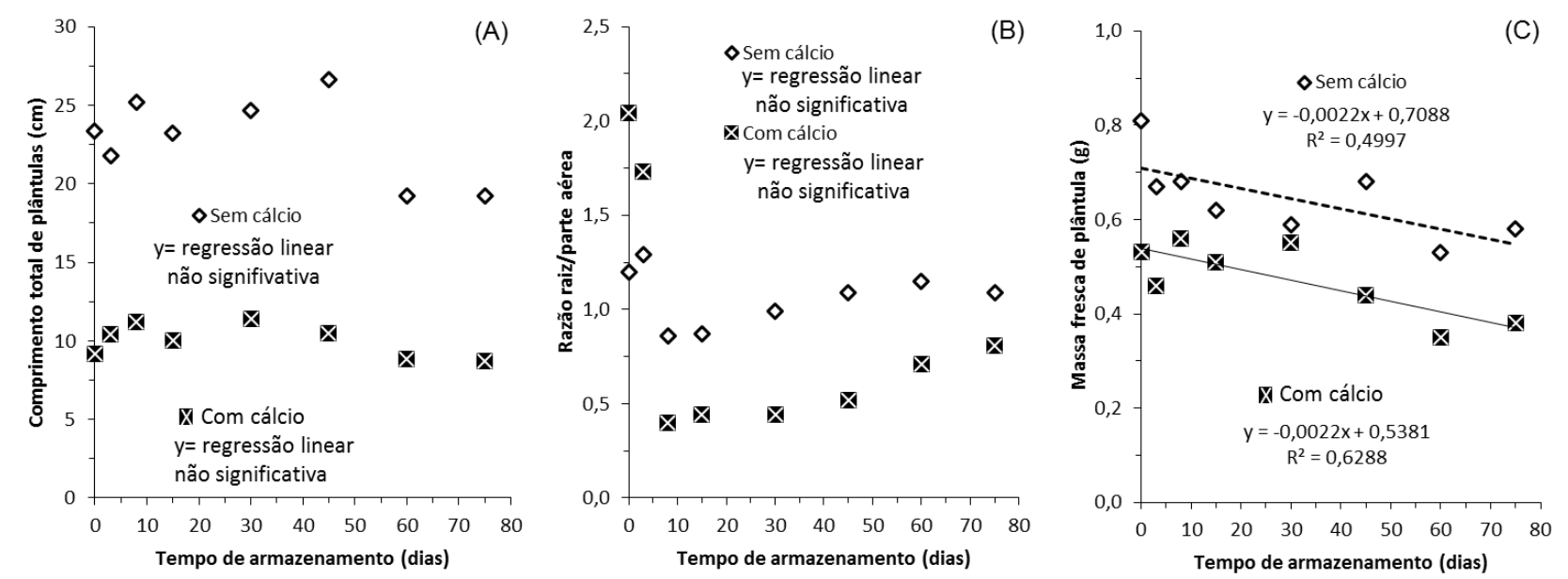

Figura 4. Variação do crescimento de plântulas resultantes de sementes de mangaba $(H$. speciosa) em função do tempo de armazenamento e do uso de solução de $\mathrm{CaCl}_{2}$ a 100 mMolar na embebição do papel de germinação.

O conteúdo de água relatado para as sementes recém colhidas de $H$. speciosa variou entre 43,3\% (BARROS, 2006) e mais de 80\% (TAVEIRA et al., 2017), com valor intermediário obtido neste trabalho. Um aspecto interessante foi observado por Salomão, Santos e Mundim (2004), o teor de água dos eixos embrionários (77,5 a 78,1\%) foi bem mais elevado do que o do endosperma (45,6 a 48,7\%).

A perda do poder germinativo durante o armazenamento foi observada por diversos autores (OLIVEIRA; VÁLIO, 1992; QUEIROZ; BIANCHETTI, 2001; VIEIRA et al., 2006; este trabalho). O tempo de manutenção da viabilidade das sementes variou entre 30 dias (QUEIROZ; BIANCHETTI, 2001); 75 dias (este trabalho), 100 dias (NUNES 2018) e 180 dias de armazenamento (SALOMÃO; SANTOS; MUNDIM, 2004), em função do teor de água das sementes, tipo de embalagem, temperatura de armazenamento e outros tratamentos.

O armazenamento a baixa temperatura baseia-se em regras empíricas, segundo as quais a longevidade de sementes é duplicada para cada $5,5^{\circ} \mathrm{C}$ de diminuição da temperatura de armazenamento no intervalo entre 0 e $40^{\circ} \mathrm{C}$ (VILELA; PERES, 2004). No 
entanto, observa-se perda de viabilidadede sementes de $H$. speciosa após algumas semanas, mesmo em geladeira $\left(7\right.$ a $\left.12^{\circ} \mathrm{C}\right)$ ou câmara fria $\left(5^{\circ} \mathrm{C}\right)$ (OLIVEIRA; VÁLIO, 1992; QUEIROZ E BIANCHETTI, 2001; SALOMÃO, 2004; TAVEIRA et al., 2017; este trabalho).

Taveira et al. (2017) realizaram armazenamento com imersão em solução de polietiilenoglicol (PEG 6000) a -0,8 MPa em câmara fria à 10 C e observaram aumento da condutividade elétrica com o passar do tempo, relacionado com a deterioração das sementes (VIEIRA, 1994). Nunes (2018) também usou soluções osmocondicionantes a 0,8 MPa, no entanto não especifica os componentes de tais soluções, o que dificulta a comparação.

Evitou-se a secagem das sementes e a taxa de perda de água durante o armazenamento foi baixa $(0,18 \%$. dia-1 $)$, enquanto Oliveira e Valio (1992) observaram uma perda ainda mais lenta (0,04\% dia $^{-1}$ de armazenamento), mas a manutenção do teor de água não garantiu a viabilidade, por isso questiona-se a relação causal estabelecida por diversos autores entre teor de água e germinabilidade para as sementes de $H$. speciosa (OLIVEIRA; VÁLIO, 1992; SALOMÃO, 2004; SALOMÃO; SANTOS; MUNDIM, 2005; BARROS, 2006; SANTOS et al., 2010).

Segundo Pammenter, Berjak e Walters (2000), a secagem rápida evita que o dano oxidativo se acumule e que as sementes morram por processos biofísicos que ocorrem com menor teor de água. Santos et al. (2010) e Soares et al. (2014) realizaram secagem das sementes de $H$. speciosa à taxa de 0,30 e $0,37 \%$. hora ${ }^{-1}$ respectivamente, ocorrendo concomitante declínio de emergência de plântulas, Dresch et al. (2016) argumentam que o poder germinativo pode ser mantido se a taxa de secagem das sementes for superior a 0,90\%. hora ${ }^{-1}$, no entanto Barros (2006) obteve germinação superior a $75 \%$ com secagem das sementes a taxa entre 0,51 e 0,60\%. hora ${ }^{-1}$, verifica-se que os dados da literatura são contraditórios a esse respeito.

O tratamento com fungicida antes do armazenamento encontra paralelo em Salomão, Santos e Mundim (2004) e Nunes (2018), principalmente pelo princípio ativo carbendazim ser sistêmico (SINGH et al., 2016), conforme recomendado por Berjak e Pammenter (2004), para maior longevidade das sementes.

$\mathrm{O}$ uso de $\mathrm{CaCl}_{2}$ na germinação não tem antecedente no estudo de $H$. speciosa e não reverteu a perda de vigor, ao contrário do observado por Justo (2006) para sementes de $E$. pyriformis com solução $10 \mathrm{mMolar}$ de $\mathrm{CaCl}_{2}$. Também se obteve efeito favorável na germinação com a aplicação de soluções de 20 mMolar de $\mathrm{Ca}^{2+}$ para Pinus massoniana Lamb., P. armandii Franch., Castanopsis chinensis Hance, Cryptomeria fortunei Hooibr. ex 
Otto et Dietr., Cunninghamia lanceolata (Lamb.) Hook. e Liquidambar formosana Hance (LIU et al., 2011). Em Haloxylon ammodendron (Chenopidiaceae), os efeitos benéficos do cálcio na germinação de sementes e crescimento de plântulas são resultados do fluxo reduzido de potássio e eventual manutenção de um baixo potencial hídrico celular (TOBE; LI; OMASA, 2004).

O efeito osmótico da solução utilizada sobre a germinação de $H$. speciosa foi pouco pronunciado, mas o crescimento das plântulas foi bastante afetado. Coelho et al. (2010) observaram efeito osmótico do $\mathrm{CaCl}_{2}$ sobre a germinação de sementes de feijão a partir de -0,9 MPa, sobre o desenvolvimento das raízes a partir de -0,6 MPa e para o crescimento da parte aérea abaixo de $-0,3 \mathrm{MPa}$.

Com relação ao excesso de $\mathrm{Ca}^{2+}$, as cálcio-ATPases transferem o íon do citossol para fora da célula ou para o vacúolo (WHITE; BROADLEY, 2003), portanto a aplicação exógena de $\mathrm{CaCl}_{2}$ deve ter sido ser modulada por tais enzimas, Segundo Jefferies e Willis (1964), as plantas calcífugas geralmente crescem bem em baixo nível de $\mathrm{Ca}^{2+}$ na rizosfera e dificilmente respondem ao aumento teor de Ca no solo, que pode até inibir o crescimento. Naves (1999) não encontrou correlação significativa entre o teor de cálcio no solo e área basal e altura de plantas de mangaba, mas o estudo de Bessa (2012) mostrou que a omissão de cálcio na solução nutritiva, resultou em alterações morfológicas, traduzidas como sintomas característicos de deficiência nutricional em $\mathrm{H}$. speciosa.

$\mathrm{O}$ tratamento com $\mathrm{CaCl}_{2}$ retardou o crescimento das plântulas, possivelmente por afetar o alongamento celular (HEPLER, 2005); considerando que a solução apresenta dois íons cloreto $\left(\mathrm{Cl}^{-}\right)$para cada $\mathrm{Ca}^{2+}$, a concentração de $\mathrm{Cl}^{\prime}$ à qual as sementes foram expostas foi de 200 mMolar. Dias e Blanco (2010) ressaltam que o cloreto pode ter efeito tóxico sobre as plantas e que a concentração tóxica para diversas delas está em torno de 25 mMolar, pode-se supor um efeito deletério desse ânion, que não foi considerado anteriormente.

A crioconservação e a manutenção in vitro de $H$. speciosa tem dado os primeiros passos (NOGUEIRA, 2010; SANTOS et al., 2015; PIRES, 2017; SANTANA, 2018), no entanto o sucesso das técnicas é variável e ainda persiste a questão da longevidade e armazenamento das sementes naturais da espécie. 


\section{CONSIDERAÇÕES FINAIS}

O modo de armazenamento retardou a perda de água, mas não a deterioração das sementes. $O$ trabalho não recomenda a aplicação de $\mathrm{CaCl}_{2}$ na concentração usada na germinação de mangaba. A solução utilizada prejudicou o crescimento das plântulas.

\section{REFERÊNCIAS}

ALMEIDA, L.M. de; NOGUEIRA, C.A.; BORGES, P.P.; PRADO, A.D.L. do; GONÇALVES, P.J. State of the art of scientific literature on Hancornia speciosa: trends and gaps. Revista Brasileira de Fruticultura, v. 38, n. 4, e-869, 2016.

ANDRÉO, Y.; NAKAGAWA, J.; BARBEDO, C.J. Mobilização de água e conservação da viabilidade de embriões de sementes recalcitrantes de ingá (Inga vera Willd. subsp. affinis (DC.) T. D. Pennington). Revista Brasileira de Botânica, v. 29, n. 2, p. 309-318, 2006.

BARROS, D.I. Tecnologia de sementes de mangaba (Hancornia speciosa Gomes). (Tese) Doutorado em Agronomia - Universidade Federal da Paraíba, Areia, Paraíba, 2006. $89 \mathrm{p}$.

BARROS D.I.; BRUNO, R. de L.A.; NUNES, H.V.; SILVA, G.C. da; PEREIRA, W.E.; MENDONÇA, R.M.N. Métodos de extração de sementes de mangaba visando à qualidade fisiológica. Revista Brasileira de Fruticultura, v. 28, n. 1, p. 25-27, 2006.

BELUR, B.V.; MERWADE M.N.; CHANNAVEERSWAMI A.S.; KRISHNA A.; RUDRA-NAIK, V.; TIRAKANNAVAR S. Effect of pre-sowing seed treatments with calcium salts and their concentrations on crop growth, seed yield and quality of soybean (Glycine max L.). Karnataka Journal of Agricultural Science, v. 23, n. 4, p. 642-646, 2010.

BENSI, R. S. Germinação de sementes de Eugenia dysenterica (Mart.) DC. (Myrtaceae) tratadas com cloreto de cálcio e sob influência do tempo de dessecação. 2016. 51 p. Monografia (Licenciatura em Ciências Biológicas) - Universidade Federal de Mato Grosso, Pontal do Araguaia, MT. 2016.

BERJAK, P.; PAMMENTER, N.W. Biotechnological aspects of non-orthodox seeds: an African perspective. South African Journal of Botany, v. 70, n. 1, p. 102-108, 2004.

BERJAK, P.; WALKER, M.; MYCOCK, D.J.; WESLEY-SMITH, J.; WATT, P.; PAMMENTER, N.W. Cryopreservation of recalcitrant zygotic embryos. In: ENGELMANN, F.; TAKAGI, H. (Eds.). Cryopreservation of tropical plant germplasm. Rome, IPIGRI, 2000, p. 140-155.

BERJAK, P.; MYCOCK, D. Calcium, with magnesium, is essential for normal seedling development from partially dehydrated recalcitrant axes: a study on Trichilia dregeana Sond. Seed Science Research, v.14, n.2, p.217-231, 2004. 
BESSA, L.A. Crescimento e nutrição mineral de mudas de mangaba (Hancornia speciosa Gomes) e caju-de-árvore-do-cerrado (Anacardium othonianum Rizz.) em solução nutritiva. (Dissertação) Mestrado em ciências Agrárias - Instituto Federal de Educação, Ciência e Tecnologia Goiano, Rio Verde, Goiás, 2012.

BETHKE, P.C.; GILROY, S.; JONES, R.L. Calcium and plant hormone action. In: DAVIES, P.J. Plant Hormones: Physiology, Biochemistry and Molecular Biology. 2 ed. Dorbretch: Kluwer Academic Publishers, 1995. cap. 5. p.298-317.

BRASIL. Regras para análise de sementes. Brasília: MAPA/ACS, 2009. 399 p.

CETNARSKI FILHO, R.; CARVALHO, R. I. N. Massa da amostra, substrato e temperatura para teste de germinação de sementes de Eucalyptus dunnii Maiden. Ciência Florestal, v.19, n.3, p.257-265, 2009.

COELHO, D. L. M.; AGOSTINI, E. A. T.; GUABERTO, L. M.; MACHADO NETO, N. B.; CUSTÓDIO, C. C. Estresse hídrico com diferentes osmóticos em sementes de feijão e expressão diferencial de proteínas durante a germinação. Acta Scientiarum - Agronomy, v. 32, n. 3, p. 491-499, 2010.

DANTAS, B.F. Atividade amilolítica e qualidade de sementes de milho (Zea mays L.) submetidas ao alagamento. 2002. $67 \mathrm{f}$. Tese (Doutorado) -Faculdade de Ciências Agronômicas, Universidade Estadual Paulista "Júlio de Mesquita Filho", Botucatu. 2002.

DIAS, N. Da S.; BLANCO, F.F. Efeito dos sais no solo e na planta. In GHEYI, H.R.; DIAS, N. Da S.; LACERDA, C.F. de (Eds.). Manejo da salinidade na agricultura: Estudos básicos e aplicados. Fortaleza, INCT Sal, 2010. p 129-142.

DRESCH, D. M.; JEROMINI, T. S.; SCALON, S. P. Q.; MUSSURY, R. M.; MASETTO, T. E.; PEREIRA, Z. V. Germination and dessication of Hancornia speciosa Gomes seeds. Bioscience Journal, Uberlândia, v. 32, n. 2, p. 496-504, 2016.

FEHER, J. Osmosis and Osmotic Pressure. In: FEHER, J. (ed.). Quantitative Human Physiology: An Introduction. 2a ed. Academic Press, 2017, p. 182-198. Disponível em: https://books.google.com.br/books. Acesso em: 03 jan. 2020.

FERREIRA, D.F. Sisvar: a computer statistical analysis system. Ciência e Agrotecnologia (UFLA), v. 35, n.6, p. 1039-1042, 2011.

FERREIRA, E.G.; MARINHO, S.J.O. Produção de frutos da mangabeira para consumo in natura e industrialização. Tecnologia \& Ciência Agropecuária, João Pessoa, v.1, n.1, p.914, 2007.

GASPAR, T.; KEVERS, C.; FAIVRE-RAMPANT, O.; CRE VECOEUR, M.; PENEL, C.L.; GREPPIN, H.; DOMMES, J. Changing concepts in plant hormone action. In Vitro Cellular and Developmental Biology - Plant, v. 39, p. 85-106, 2003.

GONZAGA NETO, L.; LEDERMAN, I.E.; BEZERRA, J.E.F.; CANUTO, V.T. Estudo de conservação do poder germinativo de sementes de mangaba. In: Congresso Brasileiro De Fruticultura, 9., 1987, Campinas. Anais... Campinas: Sociedade Brasileira de Fruticultura, 1988. pp. 579-583. 
HAVENS K.; VITT, P.; MAUNDER, M.; GUERRANT JR., E.O.; DIXON, K. Ex Situ Plant Conservation and Beyond. BioScience, v. 56, n. 6, p. 525-531, 2006.

HEPLER, P.K. Calcium: A Central Regulator of Plant Growth and Development.The Plant Cell, v.17, n.8, p.2142- 2155, 2005.

JEFFERIES, R.L.; WILLIS, A.J. Studies on the calcicole-calcifuge habit. 2. The influence of calcium on the growth and establishment of 4 species in soil and sand cultures. Journal of Ecology, v. 52, p. 691-707, 1964.

JUSTO, C.F. Aspectos fisiológicos e anatômicos das sementes e do desenvolvimento inicial de Eugenia pyriformis Camb. Lavras, 2006. 225p. Tese (Doutorado em Fisiologia vegetal). Universidade Federal de Lavras, 2006.

LEDO, A. da S. et al. A cultura da mangaba. Brasília, DF, Embrapa, 2015. 84 p.

LIU, T.-W.; WU, F.-H.; WANG, W.-H.; CHEN, J.; LI, Z.-J.; DONG X.-J.; PATTON, J.; PEI, Z.-M.; ZHENG, H.-L. Effects of calcium on seed germination, seedling growth and photosynthesis of six forest tree species under simulated acid rain. Tree Physiology, v. 31, n. 4, p. 402-413, 2011.

MARCGRAVI, G. Historia Naturalis Brasiliae. Disponível em: <http://etnolinguistica.wdfiles.com/local--files/biblio\%3Amarcgrave-1648-

historia/historianaturali12piso_Getty.pdf>. Acesso em: 02 jan. 2020.

MASETTO T.E.; SCALON S.P.Q. Drying and Osmotic Conditioning in Hancornia speciosa Gomes Seeds. Floresta e Ambiente, v. 21, n. 1, p. 62-68, 2014.

NARAYANAREDDY, A.B.; BIRADARPATIL, N.K. Effect of pre-sowing invigouration seed treatments on seed quality and crop establishment in sunflower hybrid KBSH-1. Karnataka Journal of Agricultural Science, v. 25, n. 1, p. 43-46, 2012.

NAVES, R.V. Espécies frutíferas nativas dos cerrados de Goiás: caracterização e influências do clima e dos solos. (Tese) Douturado em Agronomia - Univeesidade Federal de Goiás, Goiânia, Gioás, 1999. 205 p.

NOGUEIRA, G.F. Crioconservação e produção de sementes sintéticas in vitro de mangabeira. (Dissertação) Mestrado em Fitotecnia - Universidade Federal de Lavras, Lavras, Minas Gerais, 2010. 72 p.

NUNES, V.V. Caracterização e conservação de sementes de mangaba (Hancornia speciosa Gomes). (Dissertação) Mestrado em Agricultura e Biodiversidade - Universidade Federal de Sergipe, São Cristóvão, Sergipe, 2018. 81 f.

OLIVEIRA, L.M.Q.; VALIO, I.F.M. Effects of moisture content on germination of seeds of Hancornia speciosa Gomes (Apocynaceae). Annals of Botany, v. 69, p. 1-5, 1992.

PASSOS, E.E.M.; PASSOS, C.D. Influência da maturação do fruto na germinação da semente da mangaba. Embrapa, Comunicado Técnico n. 34, Aracaju, 2004. 4p.

PAMMENTER, N. W.; BERJAK, P.; WALTERS, C. The effect of drying rate on recalcitrant seeds: 'lethal water contents', causes of damage and quantification of recalcitrance. In: 
BLACK, M.; BRADFORD, K. J.; VAZQUEZ-RAMOS, J. (Eds.). Seed biology: advances and applications. Proceedings of the Sixth International Workshop on Seeds, Merida, Mexico, 2000. pp. 215-221.

PEREIRA, A.V.; PEREIRA, E.B.C.; SILVA-JÚNIOR, J.F.; Da SILVA, D.B. Hancornia speciosa Mangaba. (Capítulo 5 - Alimentícias). In: VIEIRA, R.F.; CAMILLO, J.; CORADIN, L. (Eds.). Espécies Nativas da Flora Brasileira de Valor Econômico Atual ou Potencial Plantas para o futuro - Região Centro-Oeste. Brasília: Ministério do Meio Ambiente. Secretaria de biodiversidade, 2016. p. 237-246.

PIMENTEL, M.L.; SANTOS, E.O. Preservação do poder germinativo de sementes de mangaba (Hancornia speciosa Gomes). Recife: IPA, 1978, 5 p. (Comunicado Técnico, 1).

PIRANI, F. R.; SANCHEZ, M.; PEDRONI, F. Fenologia de uma comunidade arbórea em cerrado sentido restrito, Barra do Garças, MT, Brasil. Acta Botanica Brasilica, v. 23, n. 4, p. 1096-1110, 2009.

PIRES, D.C.M. Conservação in vitro por crescimento lento de mangabeira do Cerrado (Hancornia speciosa Gomes). (Dissertação) Mestrado em Agronomia - Universidade Federal de Uberlândia, Uberlândia, Minas Gerais, 2017. 56 p.

QUEIROZ, J.A.L.; BIANCHETTI, A. Efeito do armazenamento sobre o poder germinativo de sementes de mangaba (Hancornia speciosa Gomes). Embrapa, Comunicado técnico, n. 58, Macapá, 2001. 4p.

ROSA, M.E.C.; NAVES, R.V.; OLIVEIRA JÚNIOR, J.P. Produção e crescimento de mudas de mangabeira (Hancornia speciosa Gomes) em diferentes substratos. Pesquisa Agropecuária Tropical, Goiânia, v. 35, n. 2, p. 65-70, 2005.

SALOMÃO, A. N.; SANTOS, I. R. I.; MUNDIM, R. C. Conservação, manejo e uso de sementes de Hancornia speciosa Gomes (Apocynaceae). Documentos, Embrapa Recursos Genéticos e Biotecnologia, v. 126, 2004. 26 p.

SALOMÃO, A. N. Desiccation, storage and germination of Hancornia speciosa seeds. In: SACANDÉ, M.; JOKER, D.; DULLOO, M.E.; THOMSEN, K.A. (Ed.). Comparative storage: biology of tropical tree seeds. Rome: IPGRI, 2004. p. 270-276. Disponível em: https://www.bioversityinternational.org/uploads/tx_news/1032.pdf. Acesso em: 26 dez. 2019.

SANTANA, F.V. Criopreservação de espécies frutíferas tropicais. (Dissertação) Mestrado em Agricultura e Biodiversidade - Universidade Federal de Sergipe, São Cristóvão, SE, 2018. 44 f.

SANTOS, P.A.A.; PAIVA, R.; SILVA, L.C.; SOUZA, A.C.; SANTANA, M.C.; SILVA, D.P.C. da. Cryopreservation of the mangaba tree (Hancornia speciosa Gomes): a protocol for longterm storage. Acta Scientiarum. Agronomy, v. 37, p. 289-296, 2015.

SANTOS, P. C. G.; ALVES, E.U.; GUEDES, R.S.; SILVA, K.B.; ALMEIDA, C.E.; LIMA, C.R. Qualidade de sementes de Hancornia speciosa Gomes em função do tempo de secagem.

Semina: Ciências Agrárias, v. 31, n. 2, p. 343-351, 2010. 
SILVA, E.A. da; MARUYAMA, W.I.; OLIVEIRA, A.C. de BARDIVIESSO, D.M. Efeito de diferentes substratos na produção de mudas de mangabeira (Hancornia speciosa). Revista Brasileira de Fruticultura, v. 31, n. 3, p. 925-929, 2009.

SILVA-JÚNIOR, J.F. A cultura da mangaba. Revista Brasileira de Fruticultura, v. 26, n. 1, editorial, 2004.

SILVA-JUNIOR, J.F.; MOTA, D.M.; SCHMITZ, H.; RODRIGUES, R.F. A. Mangabeira: uma espécie historicamente pernambucana. Arrudea, v. 3, p. 2-22, 2017.

SINGH, S. et al. Toxicity, monitoring and biodegradation of the fungicide Carbendazim. Environmental Chemistry Letters, v. 14, n. 3, p.31-329, 2016.

SOARES, A. N. R.; SANTANA, J. G. S.; MELO, M. F. de V.; MUNIZ, A. V. C. da S. Germinação de Sementes de Mangaba Submetidas à Secagem. In: IV Seminário de Iniciação Científica e Pós-Graduação da Embrapa Tabuleiros Costeiros, 2014. P. 395403.

TAVEIRA, O. C. D.; FREITAS, B. A. L.; SOUZA, J. L.; ALMEIDA, F. A.; SILVA-MANN, R. Avaliação do vigor de sementes armazenadas de mangaba (Hancornia speciosa Gomes) por meio da condutividade elétrica e envelhecimento acelerado. In: 69o anual de SBPC. Anais... Belo Horizonte: UFMG, 2017.

TAVARES, S. Estudos sobre germinação de sementes de mangaba, Hancornia speciosa Gomes. Arquivos do Instituto de Pesquisas Agronômicas, Recife, v. 5, p. 193-199. 1960.

THOMÉ FILHO, J.J.; CRÓSTA, A.P.; PAULA, T.L.F. de. Geoparque Astroblema de Araguainha- Ponte Branca (GO/MT). - Proposta. In: SCHOBBENHAUS, C. (Org.); SILVA, C. R. da (Org.). Geoparques do Brasil/ Propostas, volume I. Rio de Janeiro: CPRM, 2012. Cap. 6, 6 p. 151- $182 . \quad$ Disponível em: <http://rigeo.cprm.gov.br/xmlui/bitstream/handle/doc/17163/astroblema.pdf?sequence=1 >. Acesso em: 28 dez. 2019.

TOBE, K.; LI, X.; OMASA, K. Effects of five different salts on seed germination and sedling growth of Haloxylon ammodendron (Chenopodiaceae). Seed Science Research, v. 14, n. 4, p. 345-353, 2004.

VENKATESH-BABU, D.; BALAJI NAYAK, S.; SUJATHAMMA, P. Studies on seed priming on seedling vigour, crop growth and yield of groundnut (Arachis hypogaea L.) under rainfed conditons. International Journal of Pure and Applied. Bioscience, v.6, n.5, p. 238-242, 2018.

VIEIRA, R.D. Teste de condutividade elétrica. In: VIEIRA, R.D.; CARVALHO, N.M. (Ed.). Testes de vigor em sementes. Jaboticabal: FUNEP, 1994. p.103-32.

VIEIRA, R.F.; COSTA, T. da S.A.; SILVA, D.B. da; FERREIRA, F.R.; SANO, S.M. (Eds.). Frutas nativas da Região Centro-Oeste do Brasil. Brasília: Embrapa Recursos Genéticos e Biotecnologia, 2006. 320 p. 
VIEIRA-NETO, R.D. Efeito da adubação e calagem no desenvolvimento de mangabeiras. Aracaju: EMBRAPA-EMDAGRO, 1995. 5 p. (EMBRAPA-EMDAGRO. Pesquisa em Andamento). (1995).

VIEIRA-NETO, R.D. Recomendações técnicas para o cultivo da mangabeira. Aracaju: Embrapa Tabuleiros Costeiros, 2001. 26p. (Embrapa Tabuleiros Costeiros. Circular Técnica. 20).

VILLELA, F.A.; PERES, W.B. Coleta, beneficiamento e armazenamento. In: FERREIRA, A.G.; BORGHETTI, F. (Ed.). Germinação: do básico ao aplicado. Porto Alegre: Artmed, 2004. p.265-281.

VON HIPPEL, P.H.; WONG, K.-Y. Neutral salts: The generality of their effects on the stability of macromolecular conformations. Science, v. 145, n. 3632, p. 577-580, 1964.

WHITE, P.J.; BROADLEY, M.R. Calcium in plants. Annals of Botany, v. 92, p. 487-51, 2003. 


\title{
CAPÍTULO 4
}

\section{ARBORIZAÇÃO URBANA EM PRAÇAS DE MARICÁ, RIO DE}

\author{
JANEIRO, BRASIL
}

\author{
Luciana Cavalcante de Moura', George Azevedo de Queiroz ${ }^{2}$, Fernanda Stefany Nunes Costa ${ }^{2}$
}

1. Universidade Estadual do Norte Fluminense Darcy Ribeiro (UENF), graduação em Ciências Biológicas, Campos dos Goytacazes, Rio de Janeiro, Brasil.

2. Programa de Pós-Graduação em Ciências Biológicas (Botânica), Museu Nacional, Universidade Federal do Rio de Janeiro (MN, UFRJ).

\section{RESUMO}

A arborização urbana é definida como o conjunto de vegetação arbórea natural ou cultivada de uma cidade, compondo praças, parques e vias públicas, sendo fundamental no planejamento urbano. O objetivo do estudo foi realizar o inventário florístico das árvores, palmeiras e arbustos presentes em 30 praças de Maricá, RJ. O município de Maricá possui $362,571 \mathrm{~km}^{2}$, localizado na região metropolitana do Rio de Janeiro (22 $55^{\prime} 10^{\prime \prime} \mathrm{S}, 42^{\circ} 49^{\prime} 07^{\prime \prime}$ W). Os indivíduos com circunferência a altura do peito (CAP) superior à $15 \mathrm{~cm}$ foram inventariados e analisados quanto a origem (nativo ou exótico). Foram encontrados 392 indivíduos sendo sete mortas, totalizando 385 distribuídos em 54 espécies, 48 gêneros, dentro de 17 famílias botânicas. As famílias Fabaceae e Arecaceae foram as que apresentaram maior riqueza específica, com 16 e oito espécies, respectivamente. A espécie com maior frequência relativa foi, Roystonea regia (Kunth) O.F. Cook (Arecaceae) com $8,83 \%$ e 34 indivíduos. Do total de espécies 55\% são nativas. Conclui-se que as praças de Maricá são compostas principalmente de Arecaceae, não proporcionando sombra suficiente. Apesar do número de espécies nativas apresentarem a maior proporção, sugerese atenção para o uso de espécies nativas no plantio de novos indivíduos.

Palavras-chave: Área urbana, inventário florístico e espécie arbórea.

\section{ABSTRACT}

An urban afforestation is defined as the set of natural or cultivated tree vegetation in a city, components of squares, parks and public roads, being fundamental in urban planning. The aim of this study was to develop the floristic inventory of trees, palms and shrubs present in 30 squares of Maricá city, RJ. The municipality of Maricá has $362,571 \mathrm{~km}^{2}$, located in the

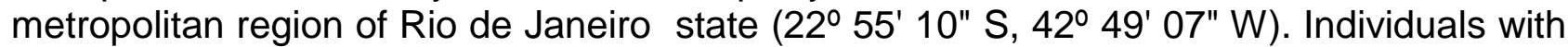
circumference at breast height $(\mathrm{CBH})$ greater than $15 \mathrm{~cm}$ were inventoried and the species were analyzed according to the origin (native or exotic). We found 392 individuals, seven of them dead, a total of 385 distributed in 54 species, 48 genera, within 17 botanical families. The Fabaceae and Arecaceae families showed the highest specific richness, with 16 and 8 species, respectively. Roystonea regia (Kunth) O.F. Cook (Arecaceae) has the higher relative frequency $(8.83 \%)$, with 34 individuals. Of the total species, $55 \%$ are native. It was concluded that the squares of Maricá are mainly composed by Arecaceae, do not provide enough shade. Despite of the native species number has a higher proportion; we suggest attention to the use of native species when planting new individuals.

Keywords: Floristic inventory, tree species and urban area. 


\section{INTRODUÇÃO}

A arborização urbana é definida por Gonçalves; Rocha (2010) como o conjunto de vegetação arbórea natural ou cultivada de uma cidade, compondo praças, parques e vias públicas, sendo fundamental no planejamento urbano. Por sua vez SMAS (2013) considera arborização urbana como sendo o conjunto de vegetação arbórea e arbustiva cultivada e existente nas cidades. Segundo a determinação de Milano (1988), a arborização urbana é, em sua grande maioria, arbórea tanto nas vias públicas, praças, parques e áreas verdes.

Outro conceito utilizado no Brasil para caracterizar o conjunto de vegetação arbórea das cidades é o termo Floresta Urbana. Grey; Deneke (1986) relatam que a definição surgiu no Canadá por Erik Jorgnsen em 1970 que define como um conjunto de toda as árvores das cidades nas ruas, bacias hidrográficas, áreas de recreação. Já Miller (1997), conceitua Floresta urbana como o conjunto de todas as vegetações arbóreas e suas associações dentro e em torno das cidades.

As praças urbanas são lugares destinados a várias funções como lazer, reflexão, refúgio, não só do homem, mas também para interação de pássaros com árvores e arbustos, além disso, são referências históricas e turísticas, portanto o seu planejamento físico e arbóreo é de grande importância. Com base em Demattê (1997), compondo a arborização urbana destaca-se a arborização de praças que são espaços livres urbanos que entre outros tem a função social e de lazer.

As áreas verdes nos centros urbanos trazem uma interação da natureza com a população. De acordo com Graziano (1994), a vegetação urbana tem papel essencial pois produz sombra, diminuem ruídos, melhora a qualidade do ar e proporciona conforto térmico. Há interação também com os animais urbanos como aves e polinizadores como as abelhas que são encontrados em praças e jardins de bairro ninhos de abelhas em troncos e copas das árvores (PIRANI; CORTOPASSI-LAURINO, 1993). Apesar de todos esses benefícios, a arborização pode causar uma série de problemas e prejuízos, caso não seja feita de forma planejada (MILANO; DALCIN, 2000).

Em algumas ocasiões podemos observar a falta de planejamento na implantação da arborização urbana, com o plantio de espécies inadequadas que são incompatíveis com o local e ambiente, portanto é imprescindível a discussão e análise sobre as funções da arborização urbana, remetendo a sua importância no planejamento urbano para que diminua os problemas futuros, tendo as praças e parques como área de reflexão, lazer e 
descanso. É fundamental o resgate das funções sociais desses lugares, que devem ser agradáveis e atraentes a população (SCHUCH, 2006).

Os inventários florísticos em áreas urbanas se tornam importantes quando fornecem uma contínua atualização das informações (TAKAHASHI, 1994). Estudos sobre a arborização são essenciais para o subsídio de informações que auxiliam ações de políticas públicas relacionadas ao planejamento e manutenção de áreas verdes urbanas.

Desse modo, este trabalho teve como objetivo realizar o inventário florístico das árvores, palmeiras e arbustos presentes em 30 praças de Maricá, RJ.

\section{MATERIAIS E MÉTODOS}

\section{1. ÁREA DE ESTUDO}

O município de Maricá (Figura 1) está localizado na região metropolitana do Rio de Janeiro

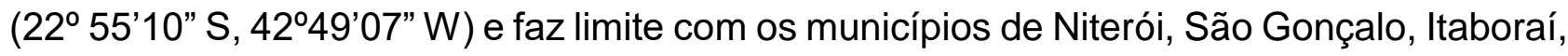
Tanguá e Saquarema. O município de Maricá está dividido entre o meio urbano e rural, possui uma área de unidade territorial de $362,571 \mathrm{Km}^{2}$, densidade de 351,55 habitantes por $\mathrm{Km}^{2}$ e 51 bairros (IBGE, 2018).
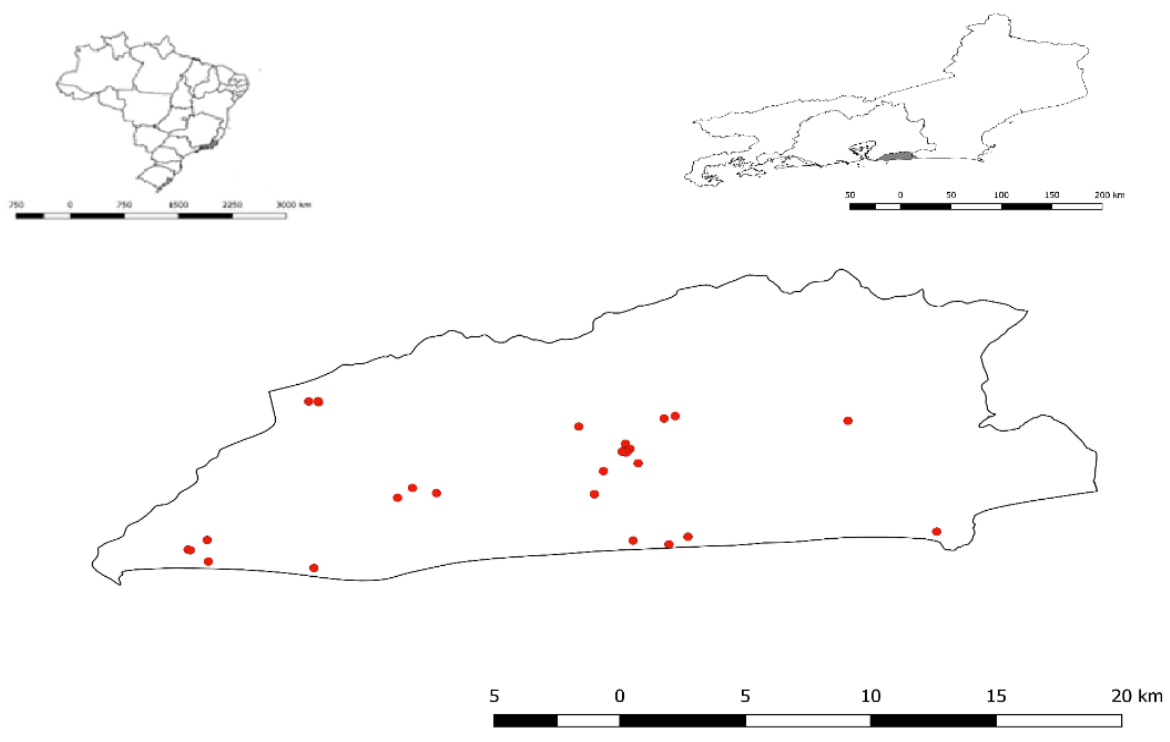

Figura 1: Mapa do Município de Maricá, RJ, Brasil, (software QGis) 
Está inserido no Bioma Mata Atlântica, de acordo com a classificação de Veloso et al. (1991). O clima é do tipo (Aw) tropical chuvoso, com verão quente, chuvoso e inverno subseco, temperatura média anual entre $22^{\circ}$ e $24^{\circ} \mathrm{C}$ e a média da precipitação anual entre 1250 a 1500 mm (NIMER,1977).

Para este estudo foram selecionadas 30 praças em Maricá (Tabela 1):

Tabela 1. Listagem das 30 principais praças do município de Maricá, RJ, cadastradas com os respectivos endereços e coordenadas.

\begin{tabular}{|c|c|c|}
\hline Praça & Endereço & Coordenadas \\
\hline Ana Ferreira & $\begin{array}{l}\text { Rua Dezessete } \\
\text { Rua Assis Coelho da Silva }\end{array}$ & $22^{\circ} 57^{\prime} 19.0^{\prime \prime S} 42^{\circ} 48^{\prime} 42.1 " \mathrm{~W}$ \\
\hline Cinco & Avenida Roberto Silveira & $22^{\circ} 54^{\prime} 19.2^{\prime \prime S} 42^{\circ} 48^{\prime} 08.7^{\prime \prime W}$ \\
\hline $\begin{array}{l}\text { Conselheiro Macedo } \\
\text { Soares }\end{array}$ & $\begin{array}{l}\text { Avenida Roberto Silva } \\
\text { RJ } 114\end{array}$ & $22^{\circ} 54^{\prime} 58.4^{\prime \prime S} 42^{\circ} 49^{\prime} 02.6^{\prime \prime W}$ \\
\hline Córrego Batalha & $\begin{array}{l}\text { Rua Abreu Rangel } \\
\text { Rua Ribeiro de Almeida }\end{array}$ & $22^{\circ} 55^{\prime} 08.9^{\prime \prime S} 42^{\circ} 49^{\prime} 05.1 " \mathrm{~W}$ \\
\hline Da Bandeira & $\begin{array}{l}\text { Avenida Nossa Senhora do Amparo } \\
\text { RJ } 114\end{array}$ & $22^{\circ} 55^{\prime} 23.1^{\prime \prime S} 42^{\circ} 49^{\prime} 05.1^{\prime \prime W}$ \\
\hline Da Estrada & $\begin{array}{l}\text { Rodovia Amaral Peixoto KM } 106 \\
\text { Avenida Prefeito Alcebíades Mendes }\end{array}$ & $22^{\circ} 56^{\prime} 06.8^{\prime \prime S} 42^{\circ} 54^{\prime} 00.9^{\prime \prime W}$ \\
\hline Da Rinha & $\begin{array}{l}\text { Rua Coronel Bitencourt } \\
\text { Rua Professor Digiorgio }\end{array}$ & $22^{\circ} 55^{\prime} 09.6^{\prime \prime S} 42^{\circ} 48^{\prime} 59.5^{\prime \prime W}$ \\
\hline Do Barroco & $\begin{array}{l}\text { Avenida Zumbi dos Palmares } \\
\text { Avenida Carlos Mariguella }\end{array}$ & $22^{\circ} 57^{\prime} 27.4^{\prime \prime S} 42^{\circ} 58^{\prime} 48.2^{\prime \prime W}$ \\
\hline Do Pescador & Avenida Alziro Rodrigues de Moura & $22^{\circ} 57^{\prime} 22.4^{\prime \prime S} 42^{\circ} 47^{\prime} 35.2^{\prime \prime W}$ \\
\hline Do Spar & $\begin{array}{l}\text { Avenida Orestes Vereza Luís } \\
\text { Genésio }\end{array}$ & $22^{\circ} 53^{\prime} 52.8^{\prime \prime S} 42^{\circ} 56^{\prime} 26.1 " \mathrm{~W}$ \\
\hline Escrava Anastácia & $\begin{array}{l}\text { Rua Joaquim Mendes } \\
\text { Rua Ari Spindola }\end{array}$ & 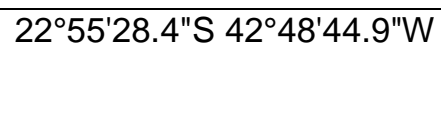 \\
\hline Ferreirinha & $\begin{array}{l}\text { Rua Das Perpétuas } \\
\text { Rua Santa Joana D'Arc }\end{array}$ & $22^{\circ} 57^{\prime} 42.3^{\prime \prime S} 42^{\circ} 59^{\prime} 14.9^{\prime \prime W}$ \\
\hline Gaviões & Rua Antônio Marquês Mathias & $22^{\circ} 58^{\prime} 00.7^{\prime \prime S} 42^{\circ} 58^{\prime} 46.5^{\prime \prime W}$ \\
\hline Gilmar dos Santos & $\begin{array}{l}\text { Estrada Real de Maricá } \\
\text { Estrada da Cachoeira }\end{array}$ & $22^{\circ} 56^{\prime} 14.8^{\prime \prime S} 42^{\circ} 53^{\prime} 27.3^{\prime \prime W}$ \\
\hline Itapeba & $\begin{array}{l}\text { Estrada Velha de Maricá } \\
\text { Rodovia Amaral Peixoto RJ } 106\end{array}$ & $22^{\circ} 54^{\prime} 31.7 " \mathrm{~S} 42^{\circ} 50^{\prime} 08.0^{\prime \prime} \mathrm{W}$ \\
\hline $\begin{array}{l}\text { Joaquim Benedito } \\
\text { Nogueira }\end{array}$ & $\begin{array}{l}\text { Rua Luís Genésio } \\
\text { Rua Nove }\end{array}$ & $22^{\circ} 53^{\prime} 54.2^{\prime \prime} \mathrm{S} 42^{\circ} 56^{\prime} 12.2^{\prime \prime W}$ \\
\hline
\end{tabular}




\begin{tabular}{|c|c|c|}
\hline João Pedro Machado & Rodovia Amaral Peixoto RJ 106 & 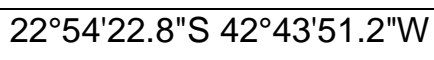 \\
\hline $\begin{array}{l}\text { Lona Cultural Marielle } \\
\text { Franco }\end{array}$ & $\begin{array}{l}\text { Rua João Saldanha } \\
\text { Rua Assis Coelho da Silva }\end{array}$ & $22^{\circ} 57^{\prime} 28.3^{\prime \prime S} 42^{\circ} 48^{\prime} 52.0^{\prime \prime} \mathrm{W}$ \\
\hline Lagoa e Mar & Avenida Maysa & $22^{\circ} 57^{\prime} 36.3^{\prime \prime S} 42^{\circ} 48^{\prime} 16.3^{\prime \prime W}$ \\
\hline Milton Motta & $\begin{array}{l}\text { Avenida Vitória Régia } \\
\text { Rua Walter Favilla da Silva }\end{array}$ & $22^{\circ} 57^{\prime} 43.2^{\prime \prime} \mathrm{S} 42^{\circ} 59^{\prime} 11.8^{\prime \prime} \mathrm{W}$ \\
\hline Manu Manuela & $\begin{array}{l}\text { Rua do Canal } \\
\text { Rua Treze }\end{array}$ & 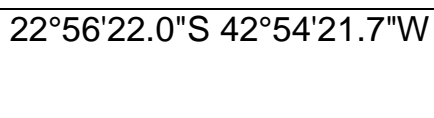 \\
\hline Maria Eugênia Adão & $\begin{array}{l}\text { Avenida Cruzeiro } \\
\text { Rua Luís Genésio }\end{array}$ & $22^{\circ} 53^{\prime} 52.4^{\prime \prime} \mathrm{S} 42^{\circ} 56^{\prime} 13.0^{\prime \prime} \mathrm{W}$ \\
\hline Marquês de Maricá & $\begin{array}{l}\text { Rua Marquês de Sapucaí } \\
\text { Rua Senhor do Bomfim }\end{array}$ & $22^{\circ} 54^{\prime} 15.4^{\prime \prime S} 42^{\circ} 47^{\prime} 53.0^{\prime \prime W}$ \\
\hline $\begin{array}{l}\text { Marilene Rangel da } \\
\text { Cruz Vieira }\end{array}$ & Rua Marilene Rangel da Cruz Vieira & $22^{\circ} 55^{\prime} 06.2^{\prime \prime} \mathrm{S} 42^{\circ} 48^{\prime} 56.2^{\prime \prime} \mathrm{W}$ \\
\hline $\begin{array}{l}\text { Mirene da Silva } \\
\text { Bitencourth }\end{array}$ & Rua Adelaide de Bezerra & $22^{\circ} 55^{\prime} 11.9^{\prime \prime S} 42^{\circ} 49^{\prime} 01.5^{\prime \prime W}$ \\
\hline $\begin{array}{l}\text { Nossa Senhora das } \\
\text { Graças }\end{array}$ & Rua Beira do Canal & $22^{\circ} 57^{\prime} 14.4^{\prime \prime S} 42^{\circ} 41^{\prime} 46.9^{\prime \prime} \mathrm{W}$ \\
\hline $\begin{array}{l}\text { Orlando Barros } \\
\text { Pimentel }\end{array}$ & $\begin{array}{l}\text { Rua Álvaro de Castro } \\
\text { RJ-114 }\end{array}$ & $22^{\circ} 55^{\prime} 10.6^{\prime \prime} \mathrm{S} 42^{\circ} 49^{\prime} 07.4^{\prime \prime} \mathrm{W}$ \\
\hline Pedro Aguiar Coelho & $\begin{array}{l}\text { Rua Alvares de Castro } \\
\text { Avenida Prefeito Ivan Mundim }\end{array}$ & $22^{\circ} 56^{\prime} 16.6^{\prime \prime} \mathrm{S} 42^{\circ} 49^{\prime} 46.2^{\prime \prime} \mathrm{W}$ \\
\hline Setenta & $\begin{array}{l}\text { Rua Setenta } \\
\text { Rua Antônio Marques Mathias }\end{array}$ & $22^{\circ} 58^{\prime} 10.8^{\prime \prime} \mathrm{S} 42^{\circ} 56^{\prime} 18.8^{\prime \prime} \mathrm{W}$ \\
\hline Tiradentes & Rua Álvaro de Castro & $22^{\circ} 55^{\prime} 40.8^{\prime \prime S} 42^{\circ} 49^{\prime} 33.5^{\prime \prime W}$ \\
\hline
\end{tabular}

\subsection{COLETA E ANÁLISE DE DADOS}

Os dados foram coletados entre novembro de 2018 e julho de 2019. Foi realizado o inventário florístico total de árvores, arbustos e palmeiras com circunferência à altura do peito (CAP) maior que $15 \mathrm{~cm}$, sendo que os indivíduos mortos apenas contabilizados. Quando necessário os espécimes férteis foram coletados e depositados no herbário do Jardim Botânico do Rio de Janeiro (RB). Os indivíduos foram identificados utilizando literatura específica como Lorenzi (1994), (1996) e auxílio de especialistas.

Quanto a origem foi utilizada a classificação de nativo e exótico do Brasil, conforme a Flora do Brasil 2020 em construção, Tropicos.org e bibliografias específicas. 
Os dados foram tratados através de estatística básica e os gráficos confeccionados em planilhas no Excel do pacote Microsoft Office Profissional Plus 2016.

\section{RESULTADOS E DISCUSSÃO}

Foram inventariados 392 indivíduos, em que sete se apresentavam mortos. Portanto, foram analisados um total de 385 indivíduos distribuídos em 54 espécies, 48 gêneros e 17 famílias (Tabela 2). Onze espécimes não foram identificados em nível de família por não estarem férteis e três em nível de gênero.

Tabela 2. Listagem das espécies e famílias correspondentes, frequência relativa e origem, que ocorrem nas praças de Maricá, RJ.

\begin{tabular}{|c|c|c|c|c|c|}
\hline Espécie & Família & $\begin{array}{c}\text { Total de } \\
\text { indivíduos }\end{array}$ & $\begin{array}{c}\text { Freq. } \\
\text { Relativa }\end{array}$ & $\mathbf{N}$ & $E$ \\
\hline Albizia lebbeck (L.) Benth & Fabaceae & 2 & $0,52 \%$ & - & $\mathrm{X}$ \\
\hline Anacardium occidentale L. & Anacardiaceae & 5 & $1,28 \%$ & $X$ & - \\
\hline $\begin{array}{l}\text { Anadenathera colubrina (Vell.) } \\
\text { Brenan }\end{array}$ & Fabaceae & 1 & $0,26 \%$ & $\mathrm{X}$ & - \\
\hline Bauhinia forficata Link & Fabaceae & 2 & $0,52 \%$ & $\mathrm{X}$ & - \\
\hline Bauhinia purpurea L. & Fabaceae & 5 & $1,30 \%$ & - & $\mathrm{X}$ \\
\hline Caesalpinia ferrea Mart. ex Tul. & Fabaceae & 5 & $1,30 \%$ & $\mathrm{X}$ & - \\
\hline Cassia sp. & Fabaceae & 1 & $0,26 \%$ & - & - \\
\hline Cassia fistula $\mathrm{L}$. & Fabaceae & 1 & $0,26 \%$ & - & $\mathrm{X}$ \\
\hline Casuarina equisetifolia L. & Casuarinaceae & 14 & $3,64 \%$ & - & $\mathrm{X}$ \\
\hline $\begin{array}{l}\text { Cenostigma pluviosum var. } \\
\text { peltophoroides (Benth.) E. Gagnon } \\
\text { \& G.P. Lewis }\end{array}$ & Fabaceae & 5 & $0,78 \%$ & $X$ & \\
\hline $\begin{array}{l}\text { Clerodendrum quadriloculare } \\
\text { (Blanco) Merr. }\end{array}$ & Lamiaceae & 1 & $0,26 \%$ & - & $\mathrm{X}$ \\
\hline Clitoria fairchildiana R.A. Roward & Fabaceae & 22 & $5,71 \%$ & $X$ & - \\
\hline Cocos nucifera L. & Arecaceae & 5 & $1,30 \%$ & - & $\mathrm{X}$ \\
\hline
\end{tabular}




\begin{tabular}{|c|c|c|c|c|c|}
\hline $\begin{array}{l}\text { Copernicia prunifera (Mill.) H.E. } \\
\text { Moore }\end{array}$ & Arecaceae & 3 & $1,04 \%$ & $\mathrm{X}$ & - \\
\hline Delonix regia (Bojer ex Hook.) Raf. & Fabaceae & 33 & $8,57 \%$ & - & $\mathrm{X}$ \\
\hline Dracaena marginata Lam. & Asparagaceae & 11 & $2,86 \%$ & - & $\mathrm{X}$ \\
\hline $\begin{array}{l}\text { Dypsis decaryi (Jum.) Beentje \& J. } \\
\text { Dransf. }\end{array}$ & Arecaceae & 5 & $1,30 \%$ & - & $\mathrm{X}$ \\
\hline $\begin{array}{l}\text { Dypsis lutescens (H. Wendl.) } \\
\text { Beentje \& J. Dransf. }\end{array}$ & Arecaceae & 32 & $8,31 \%$ & - & $\mathrm{X}$ \\
\hline Erythrina speciosa Andrews & Fabaceae & 1 & $0,26 \%$ & $\mathrm{X}$ & \\
\hline $\begin{array}{l}\text { Corymbia citriodora (Hook.) K.D. } \\
\text { Hill \& L.A.S. Johnson }\end{array}$ & Myrtaceae & 1 & $0,26 \%$ & - & $\mathrm{X}$ \\
\hline Eugenia sp. & Myrtaceae & 1 & $0,26 \%$ & - & - \\
\hline Eugenia uniflora L. & Myrtaceae & 1 & $0,26 \%$ & $x$ & \\
\hline Ficus benjamina $\mathrm{L}$. & Moraceae & 19 & $4,94 \%$ & - & $\mathrm{X}$ \\
\hline Ficus elastica Roxb. ex Hornem. & Moraceae & 1 & $0,26 \%$ & - & $\mathrm{X}$ \\
\hline Grevillea banksii R. Br. & Proteaceae & 1 & $0,26 \%$ & - & $\mathrm{X}$ \\
\hline $\begin{array}{l}\text { Handroanthus chrysotrichus (Mart. } \\
\text { ex DC.) Mattos }\end{array}$ & Bignoniaceae & 1 & $0,26 \%$ & $\mathrm{X}$ & - \\
\hline $\begin{array}{l}\text { Handroanthus heptaphyllus (Vell.) } \\
\text { Mattos }\end{array}$ & Bignoniaceae & 3 & $0,78 \%$ & $\mathrm{X}$ & - \\
\hline Inga laurina (Sw.) Willd. & Fabaceae & 1 & $0,26 \%$ & $\mathrm{X}$ & - \\
\hline $\begin{array}{l}\text { Leucaena leucocephala (Lam.) de } \\
\text { Wit }\end{array}$ & Fabaceae & 1 & $0,26 \%$ & - & $\mathrm{X}$ \\
\hline Licania tomentosa L. & Chrysobalanacea & 8 & $2,08 \%$ & $\mathrm{X}$ & - \\
\hline $\begin{array}{l}\text { Livistona chinensis (Jaq.) R. Br. ex } \\
\text { Mart. }\end{array}$ & Arecaceae & 1 & $0,26 \%$ & - & $\mathrm{X}$ \\
\hline Mimusops coriacea (A. DC.) Miq. & Sapotaceae & 1 & $0,26 \%$ & - & $\mathrm{X}$ \\
\hline Mangifera indica L. & Anacardiaceae & 3 & $0,78 \%$ & - & $\mathrm{X}$ \\
\hline Murraya paniculata (L.) Jack & Rutaceae & 1 & $0,78 \%$ & - & $\mathrm{X}$ \\
\hline Ocotea sp. & Lauraceae & 5 & $1,30 \%$ & - & - \\
\hline Pachira aquatica Aubl. & Malvaceae & 8 & $2,08 \%$ & $X$ & - \\
\hline Pandanus utilis Bory & Pandanaceae & 2 & $0,52 \%$ & - & $\mathrm{X}$ \\
\hline $\begin{array}{l}\text { Paubrasilia echinata (Lam.) } \\
\text { Gagnon, H.C. Lima \& G.P. Lewis }\end{array}$ & Fabaceae & 2 & $0,52 \%$ & $\mathrm{X}$ & - \\
\hline Persea willdenovii Kosterm. & Lauraceae & 1 & $0,26 \%$ & $x$ & - \\
\hline Psidium guajava $\mathrm{L}$. & Myrtaceae & 1 & $0,26 \%$ & - & $\mathrm{X}$ \\
\hline
\end{tabular}




\begin{tabular}{l|l|l|l|l|l}
\hline $\begin{array}{l}\text { Roystonea aff. oleraceae (Jacq.) } \\
\text { O.F. Cook }\end{array}$ & Arecaceae & 30 & $7,33 \%$ & - & $\mathrm{X}$ \\
Roystonea regia (Kunth) O.F. Cook & Arecaceae & 34 & $8,83 \%$ & - & $\mathrm{X}$ \\
\hline Schinus terebinthifolia Raddi & Anacardiaceae & 4 & $1,04 \%$ & $\mathrm{X}$ & - \\
\hline $\begin{array}{l}\text { Senegalia polyphylla (DC.) Britton } \\
\text { \& Rose }\end{array}$ & Fabaceae & 2 & $0,52 \%$ & $\mathrm{X}$ & - \\
\hline $\begin{array}{l}\text { Senna siamea (Lam.) H.S.Irwin \& } \\
\text { Barneby }\end{array}$ & Fabaceae & 11 & $3,06 \%$ & - & $\mathrm{X}$ \\
\hline Spathodea campanulata P. Beauv. & Bignoniaceae & 2 & $0,52 \%$ & - & $\mathrm{X}$ \\
\hline $\begin{array}{l}\text { Syagrus romanzoffiana (Cham.) } \\
\text { Glassman }\end{array}$ & Arecaceae & 6 & $1,56 \%$ & $\mathrm{X}$ & - \\
\hline Syzygium cumini (L.) Skeels & Myrtaceae & 8 & $2,08 \%$ & - & $\mathrm{X}$ \\
\hline Tabebuia gomes ex DC. & Bignoniaceae & 1 & $0,26 \%$ & $\mathrm{X}$ & - \\
\hline $\begin{array}{l}\text { Tabebuia heptaphylla (Vell.) Toledo } \\
\text { Tabebuia impetiginosa (Mart. ex }\end{array}$ & Bignoniaceae & 3 & $0,78 \%$ & $\mathrm{X}$ & - \\
\hline DC.) Standl. & Bignoniaceae & 11 & $2,86 \%$ & $\mathrm{X}$ & - \\
\hline Talipariti tiliaceum (L.) Fryxell & Malvaceae & 12 & $3,06 \%$ & $\mathrm{X}$ & - \\
\hline Tamarindus indica L. & Fabaceae & 5 & $1,30 \%$ & - & $\mathrm{X}$ \\
\hline Tecoma stans (L.) Juss. ex Kunth & Bignoniaceae & 4 & $1,04 \%$ & - & $\mathrm{X}$ \\
\hline Terminalia catappa L. & Combretaceae & 24 & $6,23 \%$ & - & $\mathrm{X}$ \\
\hline Indeterminadas & Indeterminadas & 11 & $2,86 \%$ & - & - \\
\hline Total & & 385 & $100 \%$ & & \\
\hline
\end{tabular}

Legenda: N: origem da espécie nativa; E: origem da espécie exótica.

As oito famílias com maior número de espécies foram Fabaceae (16), Arecaceae (8), Bignoniaceae (7), Myrtaceae (5), Anacardiaceae (3), Moraceae (2), Lauraceae (2) e Malvaceae (2), como mostra a figura 2. As demais famílias apresentaram apenas uma espécie cada.

Fabaceae, Arecaceae, Bignoniaceae, Myrtaceae e Moraceae são as famílias de maior riqueza específica em outros estudos de arborização urbana, como no município de Tianguá - CE realizado por Araújo et al. (2017); e no bairro da Tijuca, Rio de Janeiro - RJ por Freitas; Pinheiro; Abrahão (2015). 


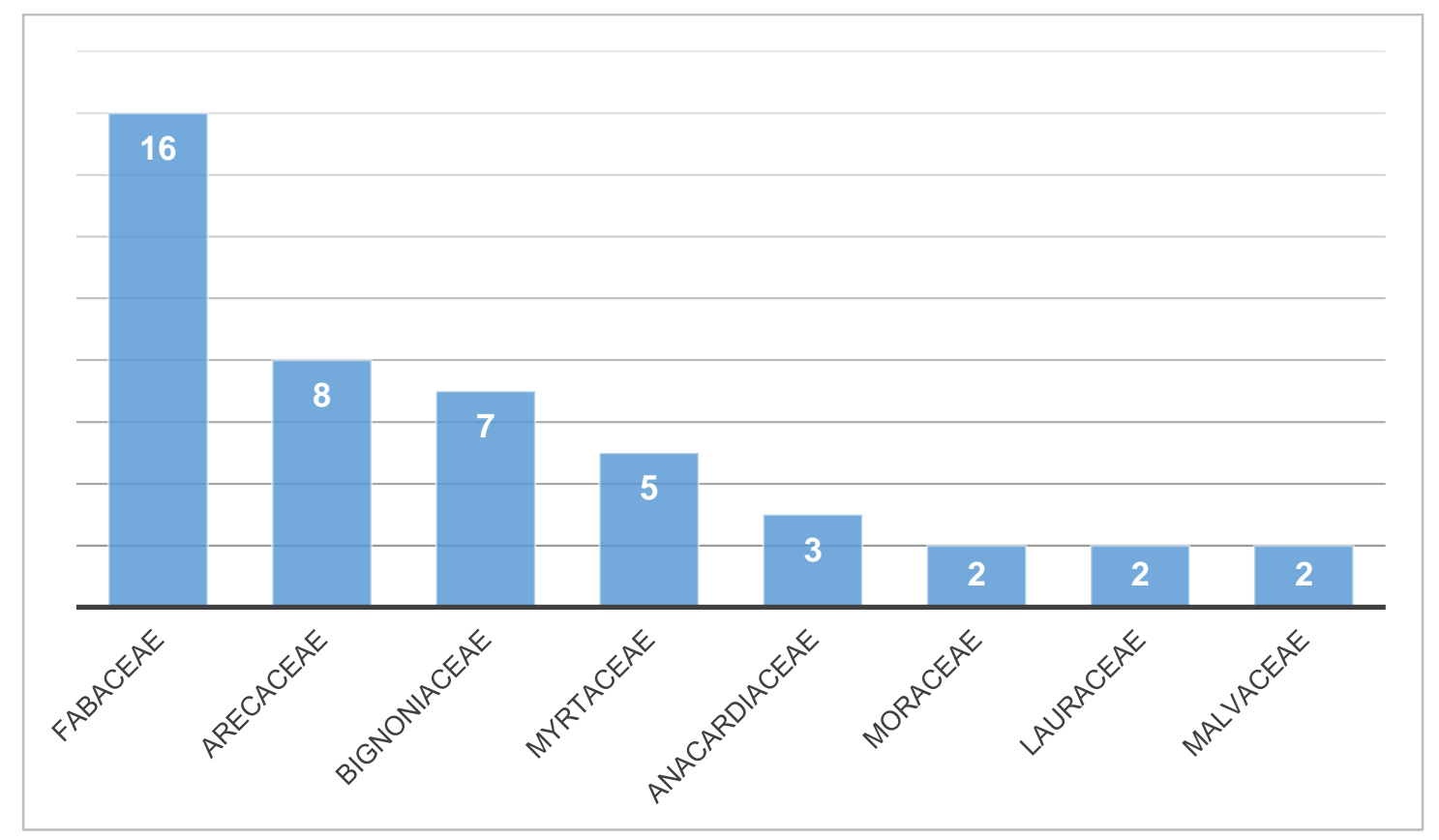

Figura 2. Riqueza de espécies por família nas 30 praças de Maricá, RJ.

A família que apresenta a maior abundância é a Arecaceae, com a frequência relativa de $29,93 \%$, seguido de Fabaceae, com 19,92\%. Esse dado mostra um predomínio de palmeiras na arborização das praças de Maricá.

As espécies que apresentaram maior frequência foram Roystonea regia (Kunth) O.F. Cook, (Arecaceae) com 34 indivíduos, com frequência relativa de 8,83\% (Figura 3), Delonix regia (Bojer ex Hook.) Raf. (Fabaceae) com 33 indivíduos e frequência de 8,57\%, Dypsis lutescens (H. Wendl.) Beentje \& J. Dransf. (Arecaceae) com 32 indivíduos e frequência de $8,31 \%$.

As espécies nativas correspondem $55 \%$ da arborização das praças do município de Maricá, RJ. Apesar desta porcentagem ser superior ao de exóticas, este número ainda é preocupante pois segundo Kulchetscki (2006), o plantio de espécies nativas é uma forma de valorização e divulgação da flora local, preservando a biodiversidade.

No município de Colorado, Rio Grande do Sul, de acordo com as análises de Raber; Rebelato (2010), as plantas nativas com $51 \%$ são mais predominantes na arborização da cidade, porém existe grande número de exemplares exóticos. Já em Campina Grande na Paraíba, Dantas; Souza (2004), registram as frequências de $67,2 \%$ para árvores exóticas e 32,8\% para nativas do Brasil. No entanto, Machado et al. (2006) afirmam que é uma tendência atual a substituição de árvores nativas para exóticas na arborização urbana de cidades brasileiras, uniformizando a paisagem em meios urbanos. 


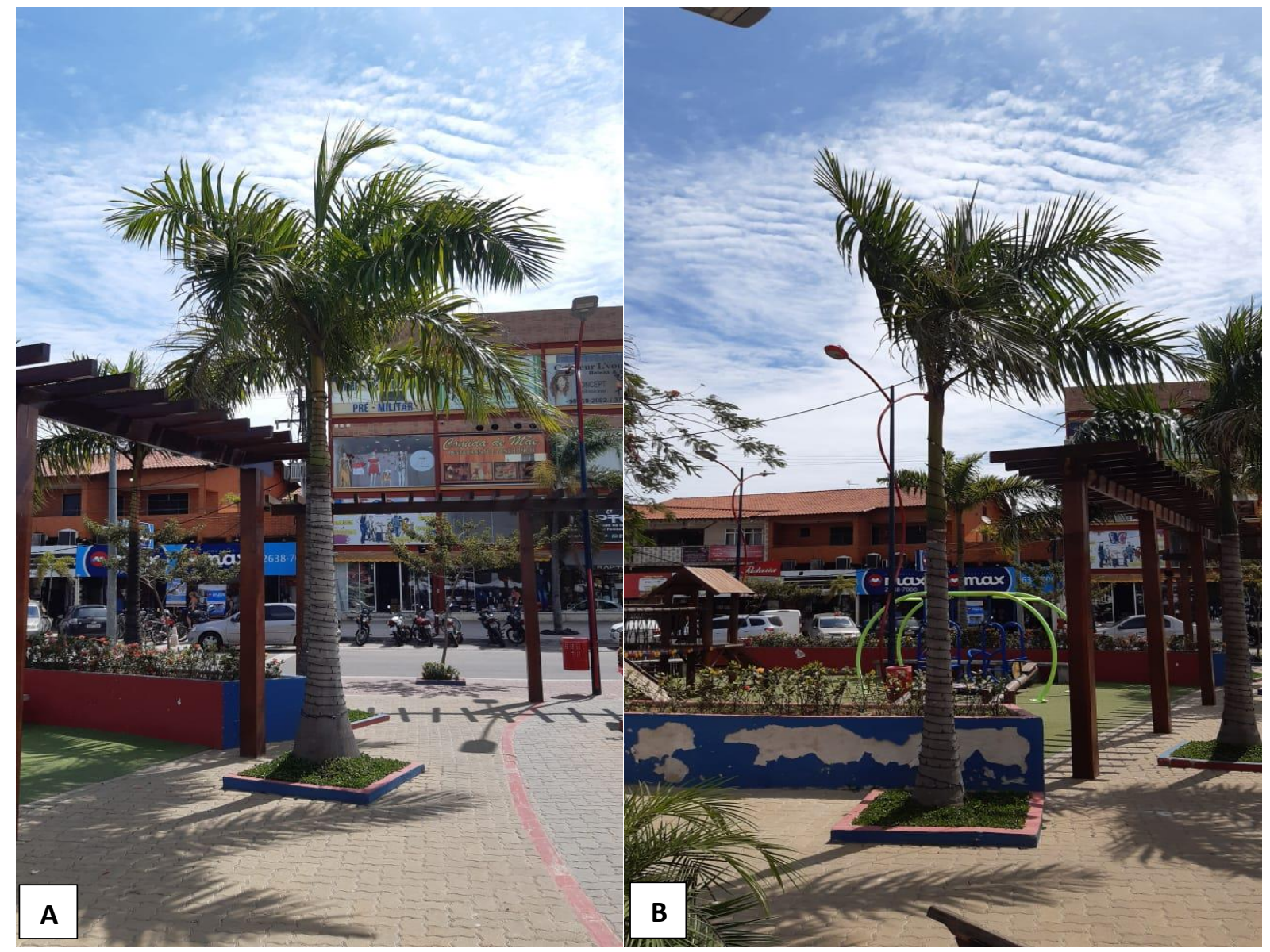

Figura 3. Roystonea regia (Kunth) O.F. Cook (Foto: Luciana Moura).

No entanto, o plantio e a conservação das praças nem sempre é realizado exclusivamente pelo poder público como foi relatado por alguns moradores das praças Ferreirinha, Itapeba e dos Pescadores. Neste levantamento, os moradores relaram com orgulho que muitas árvores foram plantadas e cuidadas por eles como se fosse extensão dos seus quintais dando prioridade a indivíduos frutíferos como Mimusops coriacea (A. DC.) Miq. (abricó), Anacardium occidentale L. (cajueiro), Mangifera indica L. (mangueira) e Syzygium cumini (L.) Skeels (jamelão).

\section{CONCLUSÃO}

Neste trabalho foi possível concluir que a arborização das 30 praças realizada do município de Maricá - RJ apresentou uma grande quantidade de espécies de Arecaceae popularmente conhecida como palmeiras. Roystonea regia (Kunth) O.F. Cook, foi a mais abundante com 34 indivíduos seguido de Dypsis lutescens ( $\mathrm{H}$. Wendl.) Beentje \& J. Dransf., 
com 32. "Nessas praças há um predomínio de palmeiras, que não proporcionam sombra o suficiente, não sendo adequada para a arborização urbana."

As plantas nativas apresentaram um percentual de $55 \%$ o que, apesar de ser a maioria, não é o suficiente para representar a extensão das florestas ao redor dos centros urbanos.

Contudo, Maricá pode ser considerado um município bem arborizado na maioria das suas praças com relação ao número de árvores, arbustos e palmeiras. No entanto, é importante se atentar ao uso de espécies nativas pela importância de preservar a flora nativa do Brasil, evitar o uso excessivo de exóticas à flora brasileira para prevenir conflito entre arborização e também para a substituição dos indivíduos mortos e elaboração de novas praças.

\section{REFERÊNCIAS}

ARAÚJO, F.J.; BRAGA, P.E.T.; SOARES, L.S.P.; FIGUEIREDO, M.F. Essentia, v. 18, n. 2, p. 121-133, 2017.

DANTAS, I.C.; SOUZA, C.M.C. Arborização urbana na cidade de Campina Grande - PB: Inventário e suas espécies. Revista de Biologia e Ciências da Terra, v.4, n.2, p.1-18, 2004.

DEMATTÊ, M.E.S.P. Princípios de paisagismo. Jaboticabal: Funep, 1997.

Flora do Brasil 2020 em construção. Jardim Botânico do Rio de Janeiro. Disponível em: < http://floradobrasil.jbrj.gov.br/ >. Acesso em: 05/12/2018.

FREITAS, W.K.; PINHEIRO, M.A.S.; ABRAHÃO, L.LF. Análise da Arborização de Quatro Praças no Bairro da Tijuca, RJ, Brasil. Floresta e Ambiente, v. 22, n. 1, p. 23-31, 2015.

GONÇALVES, S.; ROCHA, S.T. Caracterização da arborização urbana do bairro de vila Maria baixa. Revista Científica Uninove, São Paulo. v.2, p. 67-7, 2010.

GRAZIANO, T.T. Viveiros Municipais: departamento de horticultura - FCAVJUNESP,1994.

GREY, W.G.; DENEK, F.J. Urban Foresty. 2. New York: Joln Wiley,1986.

IBGE: Web Site do Instituto Brasileiro de Geografia e Estatística. Disponível em: https://cidades.ibge.gov.br/brasil/ri/marica/historico. Acesso em 03/12/2018.

KULCHETSCHI, L.; CARVALHO, P.E.; KELCHETSCHI, S.S.; RIBAS, L.L.F. \& GARDINGO, J.R.; Arborização Urbana com Essência Nativa, Uma Proposta para a Região Centro-Sul Brasileira, Publicações UEPG, v. 12, n. 3, p. 25-32, 2006. 
LORENZI, H. Manual de identificação e controle de plantas daninhas:plantio direto e convencional (4⿳亠丷a . edição). Editora Plantarum Ltda. Nova Odessa, São Paulo, 1994.

LORENZI, H. Palmeiras no Brasil: exóticas e nativas, Nova Odessa, SP: Ed Plantum, 1996.

MACHADO, R.R.B.; MEUNIER, I.M.J.; SILVA, J.A.A. \& CASTRO, A.A.J.F. Árvores Nativas Para Arborização de Teresina, Piauí. Revista da Sociedade Brasileira de Arborização Urbana, v. 1 n.1. p.10-18, 2006.

MILANO, M.S. Avaliação quali-quantitativa e manejo da arborização urbana: exemplo de Maringá - PR. Tese (Doutorado em Ciências Florestais) Curitiba - PR, Universidade Federal do Paraná, 120p.1988.

MILANO, M.S.; Dalcin, E. Arborização de vias públicas. Rio de Janeiro: Light, 2000.

MILLER, R.W. Urban Foresty. Planning and managing urban greenspaces. ed.2. Prentice Hall. 1997.

NIMER, E. Geografia do Brasil: Região Sudeste. SERGRAF- IBGE. Clima Rio de Janeiro, v. 3 , p. $51-89,1977$.

PIRANI, J.R.; M. CORTOPASSI-LAURINO. Flores e abelhas em São Paulo. São Paulo, Edusp, 203 p., 1993.

QGIS. Qgis versão 2.16.3. Disponível em: <www.qgisbrasil.org>. Acessado em: 10/12/2019.

RABER, A.P.; REBELATO, G.S. Arborização Viária do Município de Colorado, RS - Brasil: Análise Quali-quantitativa. REVSBAU, Piracicaba- SP, v.5, n.1, p. 183-199, 2010.

SCHUCH, M.I.S. Arborização Urbana: uma contribuição à qualidade de vida com o uso de geotecnologias. Dissertação (mestrado em Geomática) - programa de pósgraduação em geomática - Santa Marina, Rio Grande do Sul- Universidade Federal de Santa Maria, 2006.

SMAS (2013) Manual de arborização: Orientações e procedimentos técnicos básicos para implantação e manutenção da arborização da cidade do Recife. $1^{1 \mathfrak{a}}$ ed. Secretaria do Meio Ambiente, 2013.

TAKAHASHI, L.Y. Arborização urbana: inventário. Anais do Congresso Brasileiro de Arborização Urbana, 2. São Luís: Sociedade Brasileira de Arborização Urbana., 1994.

TROPICOS.ORG. Missouri Botanical Garden. Disponível em: <http://www.tropicos.org>. Acessado em: 20/12/2019

VELOSO, H.P.; RANGEL FILHO, A. L. R.; LIMA, J. C. A. Classificação da vegetação brasileira, adaptada a um sistema universal. Rio de Janeiro: IBGE - Instituto Brasileiro de Geografia e Estatística. Departamento de Recursos Naturais e Estudos Ambientais. Rio de Janeiro, 1991. 


\title{
CAPÍTULO 5
}

\section{BIOTECNOLOGIA UTILIZANDO O ÓLEO ESSENCIAL DE DUAS} ESPÉCIES DE Capsicum ADAPTADAS NA REGIÃO

\section{AMAZÔNICA PARA O DESENVOLVIMENTO DE DEFENSIVO} AGRÍCOLA NATURAL BIODEGRADÁVEL COM APLICAÇÃO EM ALIMENTOS

\author{
André Luiz dos Santos Oliveira1, Nélio Ranieli Ferreira de Paula², Maicon Gildisnei \\ Alves $^{2}$, Gleison Serafim Justino², Luiza Carvalho Sagrado², Amanda Eloise Machado \\ de Souza ${ }^{2}$, Gabriela Saiki²
}

1. Instituto Federal de Educação, Ciência e Tecnologia de Alagoas (IFAL), Penedo, Alagoas, Brasil;

2. Instituto Federal de Educação, Ciência e Tecnologia de Rondônia (IFRO), Colorado do Oeste, Rondônia, Brasil;

\section{RESUMO}

Diversas pesquisas tem incentivado o desenvolvimento de métodos que permitam a extração de substancias com propriedades inibidoras podendo ser aplicadas na agricultura, visando à produção de alimentos sem agroquímicos. Assim o objetivo deste trabalho foi desenvolver um novo método de controle bacteriológico a partir da extração de óleos essências de duas espécies de pimenta de fácil adaptação da Região Amazônica, Capsicum frutescens (malagueta) e Capsicum chinese (bode), tendo como principal substrato a Capsaicina, princípio ativo de controle sanitário para a produção de alimentos. A escolha das espécies foi justificada por serem bastante difundidas na Amazônia Legal. A metodologia aplicada neste trabalho foram as seguintes: seleção das amostras, lavagem, picagem do fruto (separando-os das sementes), pesagem das amostras, liofilização (retirada de úmidade), extração do óleo essencial (usando etanol PA como solvente) com 0 aparelho extrator soxhlet, determinação de diferentes concentrações de substratos com diluições de: $10 \%, 5 \%, 2,5 \%, 1,25 \%, 0,625 \%$ e $0 \%$. Após esta foram realizados ensaios de microescala em laboratório com cepas bacteriológicas para o controle da Escherichia coli. Todos os grupos de tratamento apresentaram atividade antibacteriana em relação ao controle. Esse resultado sugere o uso da pimenta como agente antibacteriano nas lavouras visando à aplicação de alimentos sem agroquímicos. Apesar dos valores numéricos terem se mostrado diferentes, há indicação de que não houve diferença significativa entre os grupos. Desse modo este estudo atestou que o extrato de óleo essencial possui efeito antibacteriano podendo ser utilizado futuramente para prevenir algumas doenças entéricas veiculadas pelos alimentos. Vale ressaltar que estes testes foram realizados in vitro o que precisará de mais pesquisas para a aplicação e transferência de tecnologia para o produtor, indústria e outras instituições.

Palavras-chave: Óleos essenciais, Capsicum spp e Antimicrobiano. 


\section{ABSTRACT}

Several researches have encouraged the development of methods that allow the extraction of substances with inhibitory properties that can be applied in agriculture, aiming at the production of food without agrochemicals. Thus, the objective of this work was to develop a new method of bacteriological control from the extraction of essential oils from two easily adapted pepper species from the Amazon region, Capsicum frutescens (chilli) and Capsicum chinese (goat), having as its main substrate Capsaicin, active ingredient of sanitary control for food production. The choice of species was justified because they are widespread in the Legal Amazon. The methodology applied in this work were as follows: sample selection, washing, fruit mincing (separating them from seeds), sample weighing, lyophilization (moisture removal), extraction of essential oil (using ethanol PA as solvent) with soxhlet extraction apparatus, determination of different substrate concentrations with dilutions of: $10 \%, 5 \%, 2.5 \%, 1.25 \%, 0.625 \%$ and $0 \%$. After this, microscale assays were performed in the laboratory with bacteriological strains to control the Escherichia coli. All treatment groups showed antibacterial activity, compared to the control. This result suggests the use of pepper as an antibacterial agent in crops that use food applications without pesticides. Although the numerical values have shown different, there is an indication that there was no significant difference between the groups. Thus, this study attested that the essential oil extract has antibacterial effect and can be used in the future to prevent some enteric diseases transmitted by food. It is noteworthy that these tests were performed in vitro which will require further research for the application and transfer of technology to the producer, industry and other institutions.

Keyword: Essencial oils, Capsicum spp and Antimicrobial.

\section{INTRODUÇÃO}

A utilização dos óleos essenciais extraídos de vegetais visa à conservação de alimentos e também podem promover o controle fitossanitário devido aos diversos métodos ecologicamente seguros, proporcionando o desenvolvimento de técnicas que reduzem os efeitos negativos causados pela oxidação, radicais livres e microrganismos deterioradores bem como 0 ataque de pragas que oferecem grandes prejuízos à produção de alimentos.

A pesquisa por novos óleos essenciais, especialmente da Amazônia, tem tido interesse na busca por substâncias inibidoras (ALCÂNTARA et al., 2010). O ecossistema amazônico é conhecido como umas das regiões de maior biodiversidade do planeta, apresentando inúmeras espécies vegetais com propriedades medicinais e outros efeitos terapêuticos que são desconhecidos (MACHADO; FERNENDES, 2011).

Os óleos essenciais são a forma mais concentrada do material resinoso presente nas cascas, flores, rizoma e sementes de plantas. São utilizados em diversas indústrias na fabricação de tintas, borrachas, têxteis, produtos veterinários, inseticidas entre outros. A utilização de compostos resinosos como inseticidas é uma prática cada vez mais difundida no meio agrícola. A capsaicina, componente ativo das espécies capsicum, confere o ardor 
característico de pimentas, o extrato de capsaicina obtido da pimenta pode ser utilizado como um inseticida natural, este atua como uma alternativa saudável e ecologicamente correta ao uso de agrotóxicos. O sabor picante dos frutos provém da ação de uma substância denominada capsaicina que é acumulada pelas plantas no tecido da superfície da placenta e é liberada pelo dano físico às células quando se extraem sementes ou cortase o fruto para qualquer fim. O óleo essencial deste composto químico pode ser obtido por processo mecânico ou procedimentos de destilação e extração. A concentração de capsaicina no óleo dependerá de fatores como solvente utilizado, variedade da pimenta, época de cultivo, secagem e condições de armazenamento.

Assim sendo, o presente trabalho objetivou no desenvolvimento de um defensivo agrícola natural biodegradável com aplicação em alimentos tendo como matéria prima o óleo essencial de pimentas. Vale ressaltar que o desenvolvimento e aplicação do produto ocorreu na Região do Cone Sul do Estado de Rondônia, mais precisamente no município de Colorado do Oeste.

\section{MATERIAIS E MÉTODOS}

O experimento foi conduzido nos laboratórios de Química e Agroindústria do Instituto Federal de Rondônia, Campus Colorado do Oeste, no período de agosto de 2017 a junho de 2018. A ideia inicial teria como "start" o plantio de sementes de pimenta, mas uma infestação de formigas arruinou o cultivo inicial. Visando otmizar o processo foi decidido por comprar 10 quilogramas das amostras de Capsicum frutescens.

\subsection{PREPARAÇÃO DA AMOSTRA}

Após o recebimento das amostras, as mesmas passaram pelo processo de lavagem, logo em seguida foram secas com papel toalha, picadas para aumentar a área específica e separação da polpa das sementes.

\subsection{REMOÇÃO DE UMIDADE DO FRUTO}

A retirada da úmidade das amostras é um dos principais problemas nos processos de extração de óleos essenciais. A mesma além de diminuir o rendimento do processo contribui na diminuição da concentração dos óleos. Pensando nisso optamos pelo processo 
de liofilização (Figura 1). A liofilização se baseia no congelamento do alimento, depois o mesmo é encaminhado para uma câmara de vácuo, onde a temperatura é aumentada gradativamente, reduzindo-se deste modo à pressão circunvizinha, o que permite à água congelada no material passar diretamente da fase sólida para a fase gasosa. Esse método só é possível devido a pressão extremamente baixa a que o alimento é submetido. $A$ pressão reduzida em alimentos altera o ponto de vaporização da água contida nele. Deste modo, quanto menor a pressão a que um alimento é submetido, a água dentro do mesmo terá também um ponto de vaporização menor, tornando mais fácil o processo de sublimação.

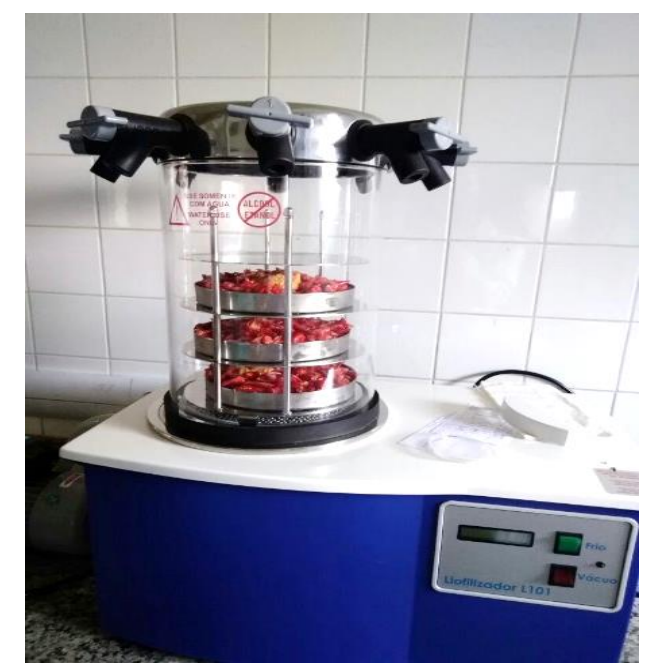

Figura 1. Equipamento de liofilização. Colorado do Oeste, RO, 2017.

Após processo de liofilização as amostras foram acondicionadas em sacos de papel e posteriormente colocadas em dessecadores, ao abrigo de umidade, ficando no aguardo para processo de extração.

\subsection{EXTRAÇÃO DO ÓLEO ESSENCIAL COM O EXTRATOR SOXHLET}

O extrator Soxhlet é utilizado para a extração de lipídios e outras substâncias sólidas que são insolúveis em água ou em solventes polares, mas solúveis em compostos orgânicos. O mesmo é composto por um reservatório de vidro com tubo lateral, esta estrutura fica entre um condensador (parte superior) e um balão (parte inferior). Depois de montar e conectar o equipamento, foi adicionado dez gramas da amostra no reservatório, é importante que este material esteja envolto por um papel filtro. Em seguida colocou-se 300 mililitros de etanol P.A. no balão de fundo redondo de 500 mililitros. Adicionou-se 
também microesferas de vidro para agilizar a ebulição do solvente. A extração aconteceu (Figura 2) devido ao aquecimento do solvente que ficou no balão, este processo ocorreu com o auxílio de uma manta aquecedora. Quando o solvente atingiu a temperatura de ebulição vapor se deslocou para o condensador (parte superior) se transformando em líquido. As gotas que resultante desta transformação caem sobre o papel filtro e enchem o reservatório até o nível do tubo lateral que leva o solvente de volta para o balão junto com as substâncias solúveis da amostra contida no papel filtro e o ciclo é retomado até a obtenção do composto final. Em seguida levamos a mistura, solvente + extrato, para o processo de destilação e determinação o rendimento bruto de extração.

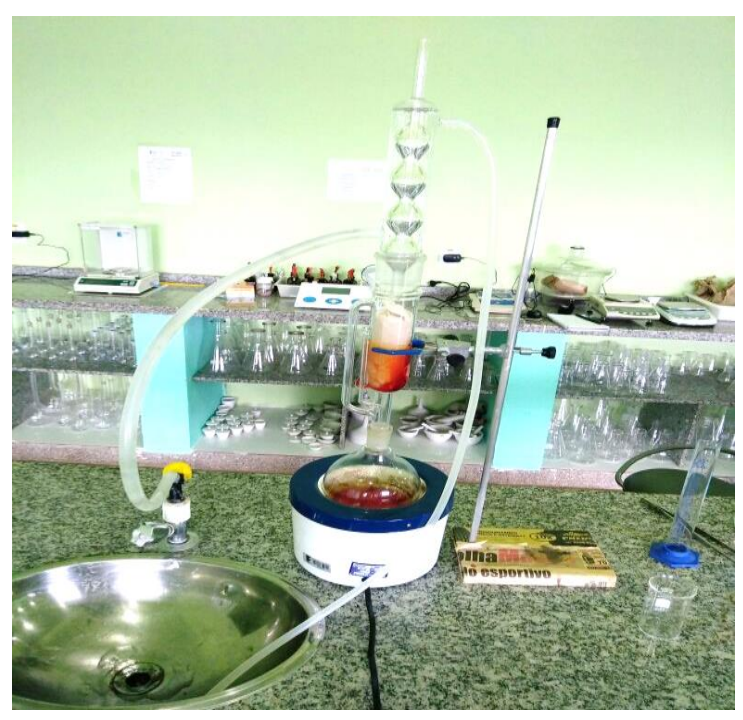

Figura 2. Extração do óleo essencial em extrator soxhlet liofilização. Colorado do Oeste, $\mathrm{RO}, 2017$.

\subsection{DETERMINAÇÃO DA CONCENTRAÇÃO MÍNIMA INIBITÓRIA}

A concentração mínima inibitória dos óleos essenciais foi determinada através da técnica de disco-difusão conforme NCCLS (NCCLS, 2012). Adicionando uma alíquota da suspensão padronizada dos microrganismos ao meio de cultura à temperatura de $45^{\circ} \mathrm{C}$. Foi utilizada $5 \mu \mathrm{L}$ de óleo essencial para na aplicação nos discos de papel filtro, medindo $6 \mathrm{~mm}$ de diâmetro. Os discos foram colocados sobre o meio de cultura contendo os microrganismos. As placas foram incubadas a $37^{\circ} \mathrm{C}$ (temperatura ambiente) por 24 horas. A concentração mínima inibitória foi avaliada utilizando paquímetro para a medição dos halos de inibição. Foram testadas diferentes concentrações de substratos por meio das seguintes diluições: (10\%, 5\%, 2,5\%, 1,25\%, 0,0625\% e 0\%), com propriedades inibitórias, mínimas e máximas. Estas placas foram preenchidas com meio de cultura NUTRIENT 
AGAR. Foi realizado quatro repetições de cada tratamento, totalizando vinte e quatro parcelas. $\mathrm{O}$ aguar foi preparado e autoclavado para evitar contaminações de possíveis microrganismos indesejáveis.

\subsection{TESTE DA ATIVIDADE ANTIBACTERIANA DOS EXTRATOS}

A bactéria utilizada foi da família da enterobactéria a Escherichia coli sendo enterro toxigênica. Para sua ativação, foi preparado o TSB e TSA, onde foram colocados em tubos, após o processo de autoclave foram colocados $30 \mu \mathrm{L}$ da bactéria em um tudo e colocado numa estufa por 12 horas e replicada, colocando $100 \mu \mathrm{L}$ em outro tubo com TSB e colocado na estufa novamente em uma temperatura de $37^{\circ} \mathrm{C}$, estando pronto para realizar o teste 12 horas depois. Utilizando essas substâncias foram preparadas o óleo. Após 12 horas foram realizadas aplicação nas placas Petri, primeiramente realizado a aplicação do extrato de óleo e esperou se absorção e para aplicação da bactéria, esse processo foi realizado dentro de uma capela para evitar contaminação (Figura 3). Após 12 horas foram realizadas a contagem e tabulação para ciclos Log.

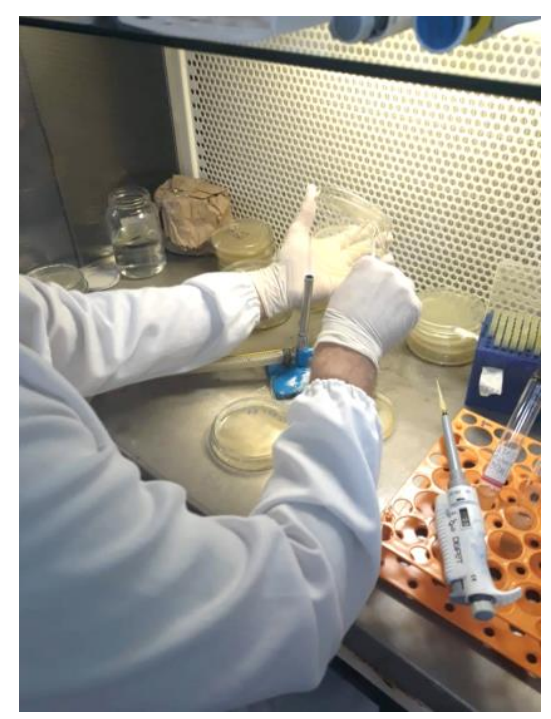

Figura 3. Aplicação do extrato de óleo na bactéria nas placas petri. Colorado do Oeste, RO, 2018.

\section{RESULTADOS E DISCUSSÃO}

De acordo com esta pesquisa verificou que a concentração de $0,062 \mu \mathrm{L} / \mathrm{mL}$ (C1) de extrato etanólico de pimenta apresentou melhor efeito antibacteriano, pois foi observado um log de UFC/g de 2,13. Para a concentração de 1,25 $\mu \mathrm{L} / \mathrm{mL}$ (C2) observou-se um log de 
UFC/g de 2,47, este foi semelhantemente ao encontrado para a concentração de $2,5 \mu \mathrm{L} / \mathrm{mL}$ (C3), pois o valor em log de UFC/g foi de 2,35. A concentração de $5 \mu \mathrm{L} / \mathrm{mL}$ (C4) apresentou um log de UFC/g de 2,88. Da mesma forma para a concentração $10 \mu \mathrm{L} / \mathrm{mL}$ (C5) o valor em log de UFC/g apresentado foi 3,00, verificado um crescimento maior de Escherichia coli toxigências. Já para a concentração $0 \%$ o resultado foi incontável (Tabela 1). Todos os grupos de tratamento apresentaram atividade antibacteriana em relação ao controle. Esse resultado sugere o uso da pimenta como agente antibacteriano nas lavouras visando à aplicação de alimentos sem agroquímicos. Apesar dos valores numéricos terem se mostrado diferentes, há indicação de que não houve diferença significativa entre os grupos (Figura 4).

Tabela 1. Efeito antibacteriano de diferentes concentrações de extrato de pimenta para bactéria Escherichia coli Enterotoxigênica em valores médios de ciclos Logarítmicos.

Colorado do Oeste, RO, 2018.

\begin{tabular}{c|c}
\hline $\begin{array}{c}\text { Tratamentos } \\
\text { Extrato de óleo de pimenta } \\
\boldsymbol{\mu L} / \mathbf{m L}\end{array}$ & $\begin{array}{c}\text { Escherichia coli enterotoxigênica em } \\
\text { ciclos Logarítmico } \\
\text { ( ciclos Log UFC/g) }\end{array}$ \\
\hline Controle (0) & 8,00 \\
C $1-0,062$ & 2,13 \\
C2- 1,25 & 2,47 \\
C3 $-2,5$ & 2,35 \\
C4 - 5 & 2,88 \\
C5 - 10 & 3,00 \\
\hline
\end{tabular}

Esta em ciclos Log representando efeito antimicrobiano de diferentes concentrações de extrato de pimenta em $\mu \mathrm{l} / \mathrm{mL}$ para bactéria Escherichia coli enterotoxigênica.

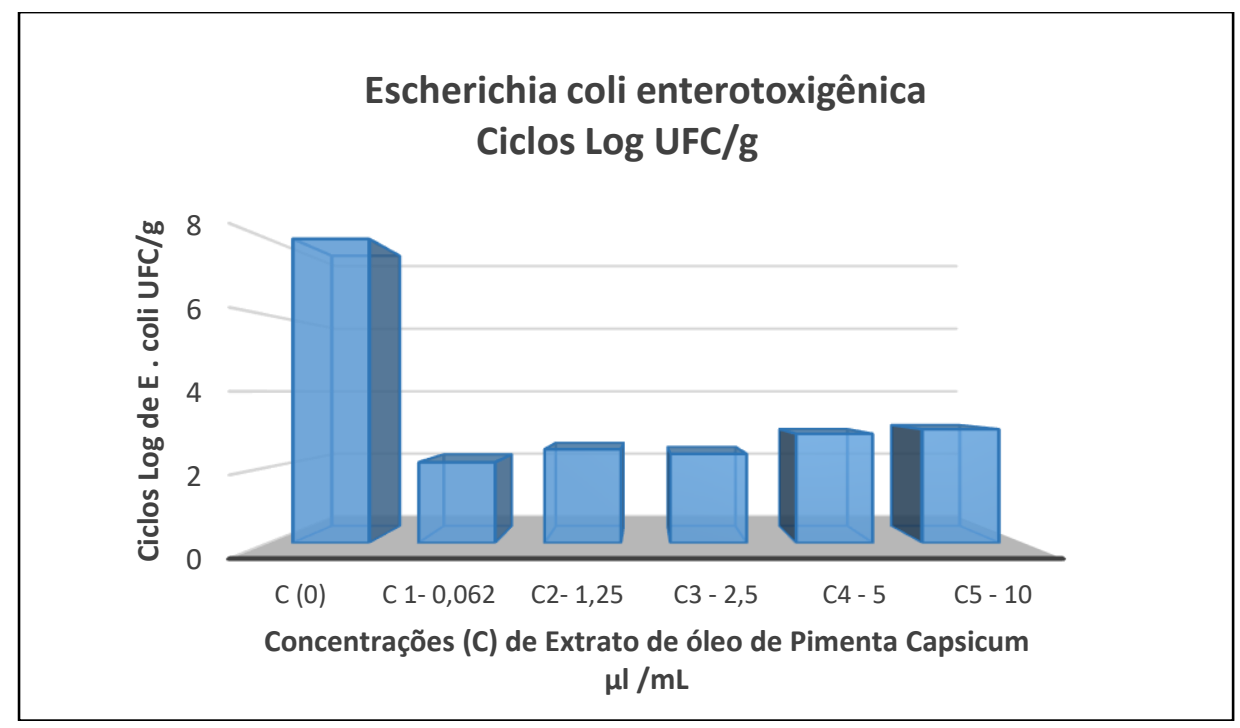

Figura 4. Efeito antimicrobiano de diferentes concentrações de extrato de pimenta para bactéria Escherichia coli Enterotoxigênica em ciclos Logarítmicos. Colorado do Oeste, RO, 2018. 


\section{CONSIDERAÇÕES FINAIS}

Desta forma esta pesquisa mostrou que este produto, o extrato do óleo de possui efeito antibacteriano e futuramente o mesmo poderá ser utilizado para prevenir algumas doenças entéricas veiculadas pelos alimentos e contribuir satisfatoriamente para o ambiente devido ao mesmo ser um produto biodegradável, ou seja, causará menos contaminação ao meio ambiente e não será tóxico ao homem. Podendo assim ser comercializado futuramente. Vale ressaltar que estes testes foram realizados in vitro o que precisará de mais pesquisas para a aplicação e transferência de tecnologia para o produtor, indústria e outras instituições.

\section{REFERÊNCIAS}

ALCÂNTARA, J. M.; YAMAGUCHI, K. K. D. L.; SILVA, J. R. D. A.; VIEGA JR, V. F. D. Composição química e atividade biológica dos óleos essenciais das solhas e caules de Rhodostemono da phneparvifolia Madriñán (Lauraceae). Acta Amazônia, v.40, p.567-572, 2010.

ARAÚJO, J. M. A. Química de alimentos: teoria e prática. 5. ed. Viçosa: UFV, 2011, 601p. GUIMARÕES, L. G. L.; CARDOSO, M. G.; ZACARONI, L. M.; LIMA, R. K. Influência da luz e da temperatura sobre a oxidação do óleo essencial de capim-limão (Cymbopogon citratus (D.C) STAPF). Química Nova, v.31, n.6, p.1476-1480, 2008.

MACHADO, B. F. M.. T.; FERNANDES JUNIOR, A. Óleos essenciais: aspectos gerais e usos em terapias naturais. Cadernos Acadêmicos, v.3, n.2, p.105-127, 2011.

NCCLS (National Committee for Clinical Laboratory Standards). Methods for dilution antimicrobial susceptibility tests for bacteria that grow aerobically.n.2. Wayne, PA, USA: Clinica land Laboratory Standards Institute, 2012. 68p.

PEGORARO, R. L.; FALKENBERG, M. B.; VOLTOLINI, C. H.; SANTOS, M.; PAULILO, M. T. S. Produção de óleos essenciais em plantas de Mentha $x$ piperitaL. var.piperita (Lamiaceae) submetidas a diferentes níveis de luz e nutrição do substrato. Revista Brasileira de Botânica, v.33, n.4, p.631-637, 2010. 


\title{
CAPÍTULO 6
}

\section{CARACTERIZAÇÃO MORFOANATÔMICA DO FOLÍOLO, MESOFILO E CAULE DA ESPÉCIE Lantana camara Linn}

\section{(VERBENACEAE)}

\author{
Thalyta Julyanne Silva de Oliveira1, Jailson Renato de Lima Silva², Elayne Eally Silva \\ de Oliveira Morais ${ }^{2}$, Natália Correia Aguiar ${ }^{2}$, Adrielle Rodrigues Costa ${ }^{3}$, Antonia \\ Eliene Duarte ${ }^{4}$, Luiz Marivando Barros ${ }^{5}$
}

1. Universidade Regional do Cariri (URCA), Laboratório de Ecofisiologia Vegetal (LECOV), Crato, Ceará, Brasil;

2. Universidade Regional do Cariri (URCA), Laboratório de Biologia e Toxicologia (BIOTOX), Crato, Ceará, Brasil;

3. Universidade Regional do Cariri (URCA), Programa de Pós-graduação em Bioprospecção Molecular, Crato, Ceará, Brasil;

4. Universidade Regional do Cariri (URCA), Departamento de Ciências Biológicas (DCBIO), Laboratório de Biologia e Toxicologia (BIOTOX), Crato, Ceará, Brasil;

5. Universidade Regional do Cariri (URCA), Departamento de Ciências Biológicas (DCBIO), Laboratório de Ecofisiologia Vegetal (LECOV), Crato, Ceará, Brasil.

\section{RESUMO}

A espécie Lantana camara Linn é um arbusto aromático, conhecido popularmente como camará-de-cheiro, podendo crescer cerca de 2 metros de altura, considerado uma erva daninha tóxica de importância nacional, ultilizada popularmente para o tratamento de várias enfermidades e comprovada diversas atividades farmacológicas. O diagnóstico da morfoanatomia auxilia no cultivo, compreensão da ecofisiologia e diferenciação de espécimes.O objetivo da pesquisa foi realizar uma caracterização morfoanatômica do folíolo, mesofilo e caule da espécie Lantana camara Linn (Verbenaceae). Foi realizado cortes transversais, a fixação foi realizada com FAA + glutaraldeído, as amostras foram armazenadas em etanol, as lâminas semipermanentes foram coradas e o material foi avaliado sob microscopia de luz e fotografado. A espécie L. camara apresentou no mesofilo, periciclo côncavo, epiderme composta por uma camada de células uniestratificada, feixe vascular colateral, mesofilo homogêneo entre as epidermes, no folíolo uma camada de parênquima paliçádico uniestratificado e de parênquima esponjoso, células parenquimáticas do tipo clorofiliano grandes de paredes delgadas, o caule apresentou forma aproximadamente cilíndrica, feixes vasculares laterais, presença de células parenquimáticas do tipo clorofiliano e células parenquimáticas medular isodiamétricas. Conclui- se que a caracterização morfoanatômica do folíolo, mesofilo e caule da espécie $L$. camara auxilia na mofodiagnose da espécie, servindo de subsídio para novas pesquisas.

Palavras-Chave: Lantana camara, tecido e morfoanatomia. 


\begin{abstract}
The species Lantana camara Linn is an aromatic shrub, popularly known as the scent shrimp, and can grow up to 2 meters tall, considered a toxic weed of national importance, popularly used for the treatment of various diseases and proven various activities. pharmacological The diagnosis of morphoanatomy assists in the cultivation, understanding of ecophysiology and differentiation of specimens. The objective of this research was to perform a morphoanatomic characterization of Lantana camara Linn (Verbenaceae). Crosssections were performed, fixation was performed with FAA + glutaraldehyde, samples were stored in ethanol, semipermanent slides were stained and the material was evaluated under light microscopy and photographed. The species L. camara presented in the mesophyll, concave pericycle, epidermis composed of a uniestratified cell layer, collateral vascular bundle, homogeneous mesophyll between epidermis, in the follicle an uniestratified palisadic parenchyma layer and spongy parenchyma, large parenchymal chlorophyllian cells Thin-walled, the stem had an approximately cylindrical shape, lateral vascular bundles, presence of chlorophyll-like parenchyma cells and isodiametric medullary parenchyma cells. It can be concluded that the morphoanatomic characterization of the $L$. camara leaflet, mesophyll and stem helps in the mofodiagnosis of the species, serving as subsidy for further research.
\end{abstract}

Keywords: Lantana camara, tissue and morfoanatomy.

\title{
1. INTRODUÇÃO
}

A espécie Lantana camara Linn é um arbusto perene nativo da América subtropical e tropical, sendo algumas espécies indígenas da Ásia tropical e da África (KETKI et al., 2018), pertencente a ordem Lamiales e família Verbenaceae (VERMA, 2018; PATIL; KUMBHAR, 2017). Conhecida popularmente como camará-de-cheiro, camara de espinho, planta de chá do suriname e bandeira espanhola (KALITA et al., 2012; DAY et al., 2003).

L. camara é um arbusto aromático com espinhos, ereto, meio escalado e peludo, podendo crescer até cerca de 2 metros de altura (AJITHAET al., 2015; FAYAZ et al., 2017) possui flores pequenas, normalmente alaranjadas mas frequentemente brancas a vermelho escuro, com brácteas conspícuas e persistentes, os frutos são pequenos possuindo cerca de $5 \mathrm{~mm}$ de diâmetro, azul-esverdeado, enegrecido, drupáceo sendo dispersos por aves (VENKATACHALAM et al., 2011), as folhas são ovais ou ovais oblongas, aguda ou subaguda $3-8 \mathrm{~cm}$ de comprimento por $3-6 \mathrm{~cm}$ de largurade cor verde, coberta de pêlos ásperos (SASTRI, 1962).

É considerada uma erva daninha tóxica de importância nacional devido sua ação altamente invasiva, apresentando perigo para a biodiversidade (RAWAT et al., 2014; PATEL; SIDDAIAH, 2018), considerando esses aspectos, tornou-se necessário encontrar meios para o uso desta planta onde ela é utilizada na ornamentação e realizado estudos 
para descobrir potenciais terapêuticos, (GWALANI et al., 2018). Utilizado popularmente suas folhas na forma de decocção para o tratamento da tosse, tétano, reumatismo, malária e como loção para feridas, suas folhas batidas são utilizadas em cortes, úlcera e inchaços (WATT; BREYER; BRANDWIJK, 1962).

Comprovada suas diversas atividades farmacológicas como, atividade anticancerígena, anti-inflamatória, anti-séptica, atividade antidiabética, anti-helmíntica, antileishimania, anti-trypanossoma; antibacteriana, antifúngica e outras (DAY et al., 2003; BRAGA et al., 2007; SANJEEB et al., 2012; BARROS et al., 2016), alguns autores exploram a capacidade da espécie L.camara atuar na síntese biomimética de nanopartículas de ouro, prata e platina, fitoextração, absorção de poluentes, transferência de calor e extração de produtos químicos (ABBASI et al., 2018).

O diagnóstico da morfoanatomia auxilia no ajuste das condições de cultivo visando melhorar a taxa de sobrevivência (RODRIGUES et al., 2015), fitopatologia (MENDONÇA et al., 2008), na compreesão dos aspectos ecofisiológicos (TRIPPLETT; KIRCHOFF, 1990) sendo de suma importância quando se vai utilizar o vegetal como medicamento (TOLEDO et al., 2006), permitindo assim, saber a diferenciação de espécies botanicamente muito próximas (DI STASI, 1996; SOUZA et al., 2005)

O objetivo da pesquisa foi realizar uma caracterização morfoanatômica do folíolo, mesofilo e caule da espécie Lantana camara Linn.

\section{MATERIAIS E MÉTODOS}

\subsection{MATERIAL VEGETAL}

As folhas da espécie Lantana camara foram coletadas no horto do Padre Cicero, localizado em Juazeiro do Norte-Ceará, Brasil, em junho de 2012. O material vegetal foi depositado e identificado no Herbário Caririense Dárdano de Andrade-Lima localizado na Universidade Regional do Cariri-URCA, sob o número 7518. 


\subsection{MORFOANATOMIA}

A fixação foi feita com FAA + glutaraldeído (LERSTENEE; CURTIS, 1988; JÚNIOR et al., 2017; FRANCO; ALBIEIRO, 2018) por um período de 18 a 24 horas. Depois da fixação, as amostras foram armazenadas em etanol a 50\%. Na avaliação microscópica do material botânico, cortes transversais foram realizados com uma lâmina de barbear. As lâminas temporárias foram preparadas utilizando 50\% de água glicerina (KRAUS; ARDUIN, 1997; BERLYN, 1976). As seções foram clarificadas em solução de hipoclorito de sódio a 5\% e coradas com astra azul + fucsina básica (LUQUE et al., 1996; ROSER, 1962). As lâminas semipermanentes foram preparadas com as secções branqueadas em solução de hipoclorito de sódio a 33\%, lavadas com água destilada, coradas com 1\% de safranina e 1\% de solução de astra azul, com gelatina de glicerol (1: 1) (SASS, 1951). O material foi avaliado sob microscopia de luz e fotografado com uma câmera acoplada no microscópio Zeiss / Axioplan com filme Kodak Gold 100.

\section{RESULTADOS E DISCUSSÃO}

A nervura central do corte transversal do folíolo da espécie L. camara apresenta-se circundada pela endoderme onde está o periciclo apresentando forma côncava (Fig.1.A) e pela epiderme que é composta por uma camada de células uniestratificada com as células da parede pouco espessadas (Fig.1.B). Segundo Scatena et al. (2004), o periciclo apresenta forma estrelada e está presente internamente a endoderme nas espécies, Syngonanthus paepalophyllus sub sp. paepalophyllus e Syngonanthus niveus (Eriocaulaceae). Segundo Pires et al. (2015) a espécie Schinusmolle L em um corte transversal apresenta uma epiderme composta por células tabulares com espaçamento das paredes periclinais. A epiderme da espécie Catopsis berteroniana apresenta forma retangular com paredes periclinais espessas (MARCONDES et al., 2018).

O feixe vascular do tipo colateral distribuído na região mediana do mesofilo sendo rodeado homogêneo por células parenquimáticas e endoderme (Fig.1.B). Segundo Lima et al. (2019) o feixe vascular presente na folha da espécie Diploon Cronquist (Sapotaceae) é do tipo plano-convexo. O mesofilo é do tipo homogêneo e está posicionado entre as epidermes superior e inferior (Fig.1.C). Segundo Faria; Vihalva (2016), numa análise 
anatômica foliar da espécie Plectranthus barbatus (Lamiaceae), o mesofilo é homogêneo ou isodiamétrico apresentando tricomas glandulares. As células glandulares recobrem o folíolo (Fig.1.D), sendo estas células as responsáveis pela presença de óleos essenciais, encontrados em variadas famílias, bem como na família Lamiales (ASCENÇÃO; MARQUES; PAIS, 1995; METCALF; CHALK, 1983).
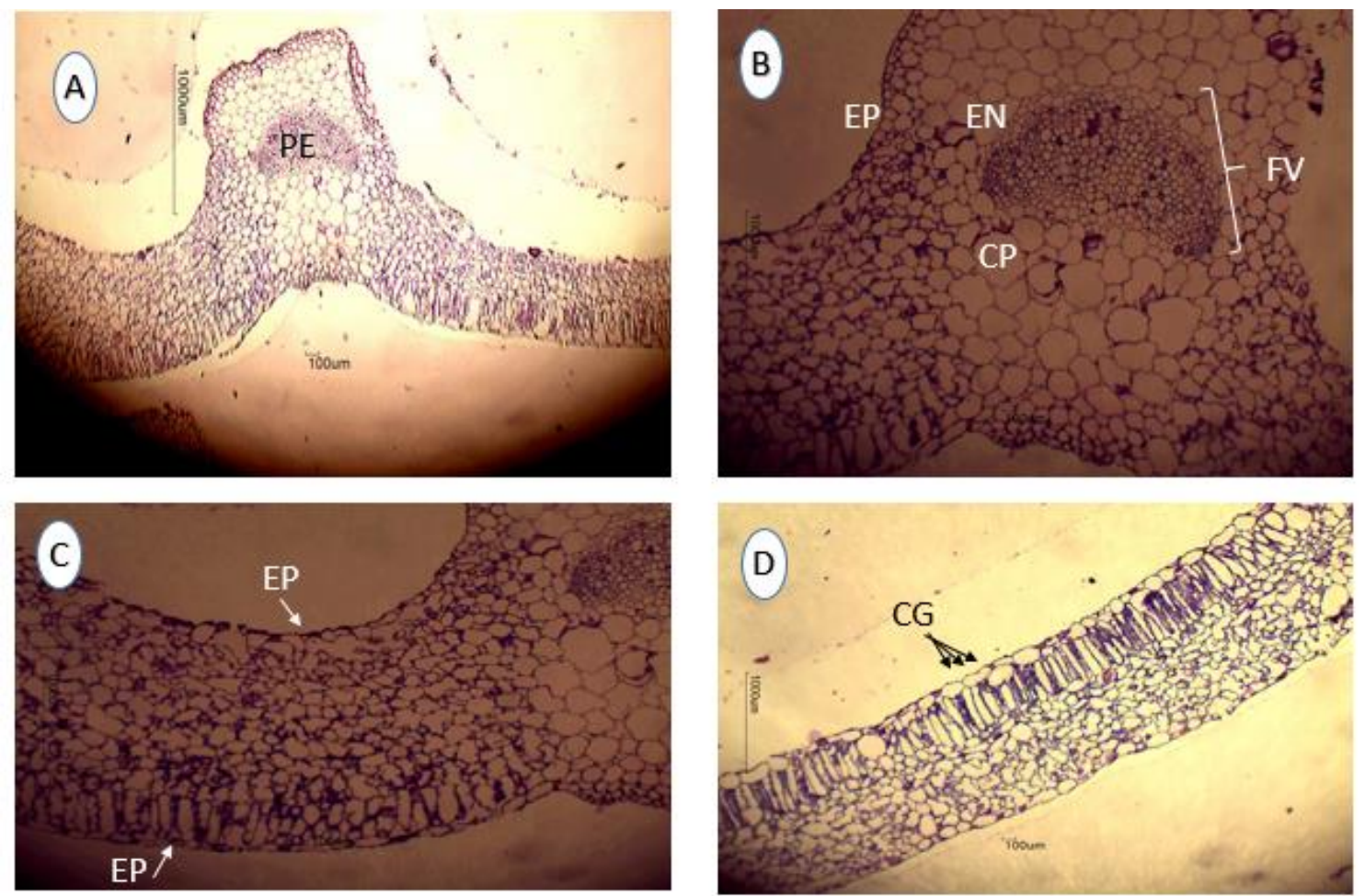

Figura 1. Lantana camara. Folíolo em seção transversal: A. Nervura central; B. Detalhe da nervura central; C. Mesofilo; D. Detalhes do mesofilo. Abreviações: EP: epiderme, EN: endoderme, PC: periciclo, FV: Feixes vasculares, CG: Células glandulares. Bar $=1000$ $\mu \mathrm{m}$ e $100 \mu \mathrm{m}$.

No detalhe do mesofilo foliar da espécie $L$. camara apresenta-se uma camada de parênquima paliçádico uniestratificado, longo e fino e uma de parênquima esponjoso apresentando espaços intercelulares (Fig.2.A). Na espécie Oxalis latifólia o parênquima paliçádico apresenta uma camada (Oxalidaceae) (REIS; ALVIM, 2015). O parênquima paliçádico na seringueira apresenta duas camadas, uma superior com células mais alongadas e uma inferior com células mais baixas, (MEDRI, 1983). Bündchen et al. (2015) relata que a espécie Lantana brasiliensis (Verbenaceae) contém grande porcentagem relativa de ar no parênquima esponjoso e grande espessura. Segundo Martins (2002), no 
seu trabalho de anatomia foliar das espécies Mentha spicata e Mentha suaveolens (Lamiaceae) o parênquima paliçádico apresenta-se com células mais curtas e mais largas

Segundo Schwarz e Furlan (2002), envolvendo o núcleo das células parenquimáticas das espécies Oxypetalum confusum e Oxypetalum obtusifolium permitiram chegar à verificação que em todas há presença de células secretoras em paliçadas. As células parenquimáticas do tipo clorofiliano são grandes de paredes delgadas (Fig.2.B). No mesofilo da espécie Brachiaria brizantha (Poaceae) o parênquima clorofiliano apresenta-se com células grandes, poliédricas e de paredes delgadas (BRITO; RODELLA, 2002).
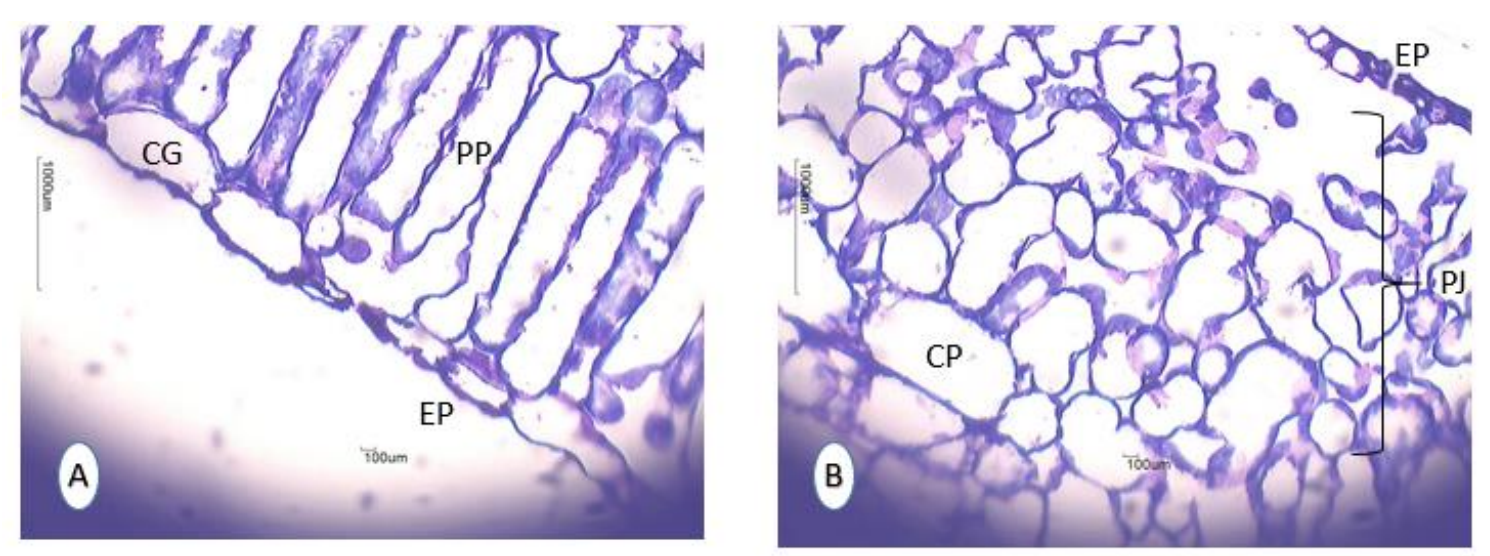

Figura 2. Lantana camara. Detalhes do mesofilo foliar. Abreviações: EP. Epiderme, CG: Células glandulares; PP: parênquima paliçádico, PJ: parênquima esponjoso, CP: Células parenquimáticas do tipo clorofiliano. Bar $=1000 \mu \mathrm{m}$ e $100 \mu \mathrm{m}$.

$\mathrm{Na}$ (Fig.3.A) no corte em seção transversal do caule da espécie L. camara observase o caule de forma aproximadamente cilíndrica, feixes vasculares e as células parenquimáticas medular. O caule da espécie Lepismium cruciforme mostrou-se com formato triangular em secção transversal (CURY et al., 2018), Lepismium warmingianum formato achatado (DETTKE; MILANEZE-GUTIERRE, 2008) e em nove variedades da espécie Cucurbita maxima o caule mostrou-se arredondado e angular (PRIORI et al., 2018). O xilema e o floema se mostram cilíndricos (Fig.3.B).

Apresentar feixes vasculares laterais, não são típicos como observado na espécie Tanacetum vulgare estudada no trabalho de Guerreiro et al. (2016), onde o floema é localizado centrifugamente e o xilema centripetamente. Na espécie Smilax polyantha os feixes vasculares são também laterais (MARTINS; APPEZZATO; DA GLÓRIA, 2006). O 
feixe vascular da espécie Microlicia hatschbachii (Melastomataceae) apresenta o floema externamente e o xilema internamente (CASSIANO et al., 2010). A espécie Piper gaudichaudianum (Piperaceae) apresenta os feixes vasculares na medula do caule (ALBIERO et al., 2005). Na (Fig.3.C) a presença de células parenquimáticas do tipo clorofiliano. A espécie Phoradendron mucronatum (Viscaceae) apresenta de três a sete camadas de células parenquimáticas do tipo clorofiliano homogêneo (DETTKE; MILANEZE-GUTIERRE, 2007).

$\mathrm{Na}$ (Fig.3.D) há a presença de células parenquimáticas medular isodiamétricas pela qual corresponde boa parte do conteúdo caulinar. $\mathrm{Na}$ espécie Elephantopus mollis (Asteraceae) o volume caulinar é composto em sua grande parte por células parenquimáticas isodiamétricas (EMPINOTTI; DUARTE, 2008). As células parenquimáticas da espécie Pyrostegia venusta (Bignoniaceae) é lignificada correspondendo cerca de $30 \%$ do conteúdo caulinar (DUARTE; JURGENSEN, 2007).
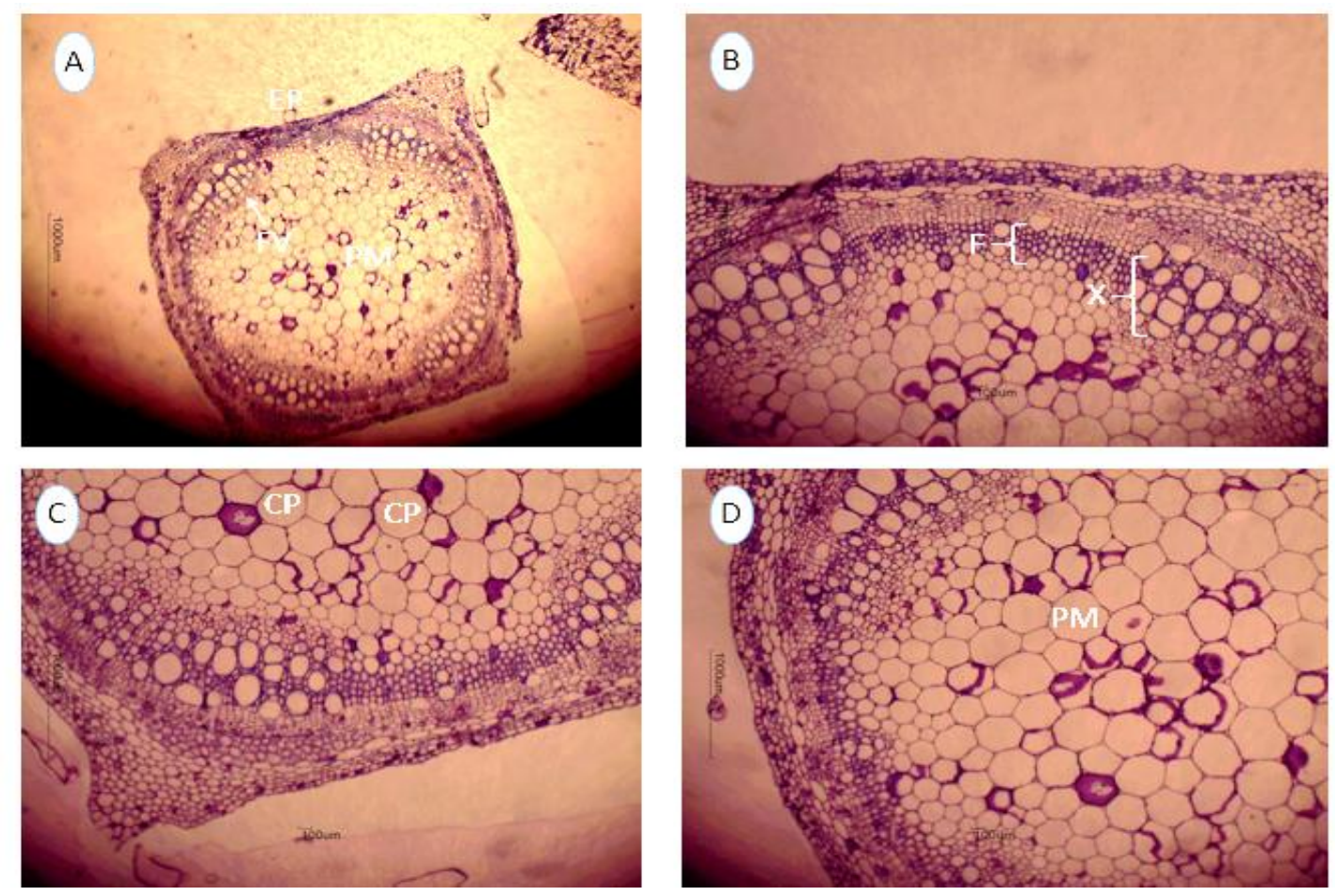

Figura 3. Lantana camara. Corte em seção transversal do caule: A. Imagem central; B-D. Ampliação do corte central. Abreviações: EP: epiderme, FV: Feixes vasculares, CP: Células parenquimáticas do tipo clorofiliano, PM: Células parenquimáticas medular. $\mathrm{Bar}=$ $1000 \mu \mathrm{m}$ e $100 \mu \mathrm{m}$. 


\section{CONCLUSÃO}

Conclui-se que a espécie $L$. camara apresentou o folíolo circundado pela endoderme onde o periciclo apresenta forma côncava, e epiderme composta por uma camada de células uniestratificada com as células da parede pouco espessadas, o feixe vascular do tipo colateral distribuído na região mediana do mesofilo do tipo homogêneo e posicionado entre as epidermes superior e inferior. No detalhe do mesofilo foliar apresentou uma camada de parênquima paliçádico uniestratificado, longo e fino e uma de parênquima esponjoso apresentando espaços intercelulares. As células parenquimáticas do tipo clorofiliano grandes de paredes delgadas. O caule apresentou forma aproximadamente cilíndrica, o xilema e o floema se mostram cilíndricos compondo feixes vasculares laterais, presença de células parenquimáticas do tipo clorofiliano e presença de células parenquimáticas medular isodiamétricas pela qual corresponde boa parte do conteúdo caulinar.

Portanto, a caracterização morfoanatômica do folíolo, mesofilo e caule da espécie $L$. camara auxilia na mofodiagnose da espécie, servindo de subsídio para novas pesquisas, tendo em vista que a identificação de caracteres é de extrema relevância quando se trata de plantas medicinalmente utilizadas para diversas enfermidades.

\section{AGRADECIMENTOS}

A Universidade Regional do Cariri-URCA, ao Laboratório de Ecofisiologia Vegetal (LECOV), Laboratório de Biologia e Toxicologia (BIOTOX) e a agência de fomento Fundação Cearense de Apoio ao Desenvolvimento Científico e Tecnológico -FUNCAP.

\section{REFERÊNCIAS}

ABBASI, A.S.; BANUPRIYA, D. Initiatives and options for utilizing the dreaded weeds lantana (Lantana camara), parthenium (Partheniumhysterophorus) and salvinia (Salviniamolesta). International Journal of Engineering \& Scientific Research, v.6, n.1, p.95-145, 2018.

AJITHA, B.; ASHOK, K.R.Y.; SREEDHARA, R.P.; Green synthesis and characterization of silver nanoparticles using Lantana camara leaf extract. Materials Science and Engineering C, v.49, p.373-381, 2015. 
ALBIERO, A.L.M.; MOURÃO, K.S.M.; SOUZA, L.A.; ALMEIDA, O. Morfo-anatomia do caule e da folha de Piper gaudichaudianum Kuntze (Piperaceae). Acta Farmacéutica Bonaerense, v.24, n.4, p.550-554, 2005.

BARROS, L.M.; DUARTE, A.E.; MORAIS-BRAGA, M.F.B.; WACZUK, E.P.; VEGA, C.; LEITE, N.F.; MENEZES, I.R.A. et al. Chemical Characterization and Trypanocidal, Leishmanicidal and Cytotoxicity Potential of Lantana camara L. (Verbenaceae) Essential Oil. Molecules, v.21, n.2, p.209, 2016.

BERLYN, G.P.; MIKSCHE, J.P. Microtécnica e citoquímica botânica. A lowa State University Press, Ames; 1976. 326 p.

BÜNDCHEN, M.; BOEGER, M.R.T.; REISSMANN, C.B. Estrutura foliar de espécies lenhosas de dossel e sub-bosque em uma floresta subtropical do sul do Brasil. Iheringia, v.70, n.1, p.105-114, 2015.

BRAGA, F.G.; BOUZADA, M.L.M.; FABRI, R.L.; MATOS, M.O.; MOREIRA, F.O.; SCIO, E. et al. Antileishmanial and antifungal activity plant used in traditional medicine in Brazil. Journal of Ethnopharmacology, v.111, p.396-402, 2007.

CASSIANO, D.S.A.; BRANCO, A.; SILVA, T.R.S.; SANTOS, A.K.A. Caracterização morfoanatômica de folhas e caules de Microlicia hatschbachii Wurdack, Melastomataceae. Revista Brasileira de Farmacognosia, v.20, n.4, p.529-535, 2010.

BRITO, C. J.; RODELLA, R. A. Caracterização morfo-anatômica da folha e do caule de Brachiaria brizantha (Hochst. ex A. Rich.) Stapf e B. humidicola (Rendle) Schweick. (Poaceae). Revista Brasileira Botânica, v.25, n.2, p.221-228, 2002.

CURY, R.K.; RANDI, A.M.; SANTOS, M. Germinação, desenvolvimento inicial e morfoanatomia de cactáceas epifíticas. Rodriguésia, v.69, n.4, p.2119-2135, 2018.

DAY, M.D.; WILEY, C.J.; PLAYFORD, J.; ZALUCKI, M.P. Lantana: Current Management Status and Future Prospects; [monography] 102, Canberra, Australia. ACIAR Australian Centre for International Agricultural Research; 2003.

DETTKE, G.A.; MILANEZE-GUTIERRE, M.A. Estudo anatômico dos órgãos vegetativos da hemiparasita Phoradendron mucronatum (DC.) Krug\& Urb. (Viscaceae). Revista Brasileira de Biociências, v.5, n.1, 534-536, 2007.

DETTKE, G.A.; MILANEZE-GUTIERRE, M.A. Anatomia caulinar de espécies epífitas de Cactaceae, subfamília Cactoideae. Hoehnea, v.35, n.4. p.583-595, 2008.

DI STASI, LC. “Plantas medicinais: Arte e ciência” Unesp, São Paulo. 1996.

DUARTE, M.R.; JURGENSEN, I. Diagnose Morfoanatômica de Folha e Caule de Pyrostegiavenusta (KerGawl.) Miers, Bignoniaceae. Latin American Journal of Pharmacy, v.26, n.1, p. 70-75, 2007.

EMPINOTTI, C.B.; DUARTE, M.R. Estudo anatômico de folha e caule de Elephantopusmollis Kunth (Asteraceae). Revista Brasileira de Farmacognosia, v.18, n.1, p.108-116, 2008. 
FARIA, M.T.; VILHALVA, D.A.A. Importância das aulas práticas na disciplina de anatomia vegetal: descrição da anatomia foliar e histoquimica de Plectranthusbarbatusandrews (Lamiaceae). Revista Eletrônica De Educação Da Faculdade Araguaia, v.10, p.214-223, 2016.

FAYAZ, M.; BHAT, M.H.; FAYAZ, M.; KUMAR, A.; JAIN, A.K. Antifungal Activity of Lantana camara L. Leaf Extracts in Different Solvents Against Some Pathogenic Fungal Strains. Pharmacologia. v.8, n.3, p.105-112, 2017.

FRANCO, M.J.C.S.; ALBIERO, A.L.M. Estruturas secretoras em folha e caule de Esenbeckiafebrifuga (A.St.-Hil.) A. Juss. ex Mart. e Esenbeckiagrandifl ora Mart. (Rutaceae). Hoehnea, v.45, n.3, 468-483, 2018.

GAUTAM, R.K.; GAUTAM, P.K.; BANERJEE, S.; RAWAT, V.; SONI, S.; SHARMA, S.K et al. Removal of tartrazine by activated carbon biosorbents of Lantana camara: Kinetics, equilibrium modeling and spectroscopic analysis. Journalof Environmental ChemicalEngineering, v.3, n.1, p.79-88, 2015.

GUERREIRO, K.K.; BOBEK, V.; SANTOS, V.L.P.; FRANCO, C.R.C.; PAULA, J.P.; FARAGO, P.V et al. Análise farmacobotânica de folha e caule de Tanacetumvulgare (L.). Revista Brasileira de Plantas Medicinais, v.18, n.1, p.89-95, 2016.

GWALANI, K.; NASHIKKAR, N.; BUNDALE, S.; UPADHYA, A. Avaliação da erva tóxica Lantanacamara como planta medicinal potente. Revista Internacional de Pesquisa em Farmácia e Ciências Farmacêuticas, v.3, n.5, p.16-20, 2018.

JÚNIOR, N.G.R.; SILVA, I.V.; ARAÚJO, C.F.; FAGUNDES, O.S.; GERVAZIO, W. Anatomia e morfometria de raízes e folhas de Urochloabrizantha cv. Marandu em diferentes estádios de acometimento da síndrome da morte das pastagens. Iheringia, v.72, n.1, p.127-132, 2017.

KATIA, S.; KUMAR, G.; KARTHIK, L.; VENKATA, K.; RAO, B.A. A Review on Medicinal Properties of Lantana camara Linn. Research Journal of Pharmacy and Technology, v.5, n.6, p. 711-715, 2012;

KRAUS, J.E.; ARDUIN, M. Manual básico de métodos em morfologia vegetal, Ed. EDUR, Rio de Janeiro; 1977.

LERSTEN, N.R.; CURTIS, J.L. Secretory Reservoir (ducts) of two kinds in giant ragweed (Ambrosia trifida, Asteraceae). American Journal of Botany, v.75, n.9, p.1313-1323, 1988.

LIMA, R.G.V.N.; LIMA, L.F.; FERREIRA, A.C.; ARAÚJO, J.S.; ZICKEL, C.S. Morfoanatomia foliar de Diploon Cronquist (SapotaceaeJuss.). Biota Neotropica, v.19, n.1, p. e20180600, 2019;

LUQUE, R.; SOUZA, H.C.; KRAUS, J.E. Métodos de Coloração de Roeser (1972): modificado - e Kropp (1972) visando a substituição do azul de astra por azul de alcião 8GS ou 8GX. Acta Botânica Brasilica, v.10, p.1-14, 1996.

MARCONDES, J.P.B.A.C.; TARDIVO, R.C.; KOWALSKI, V.K.; COSTA, M.G. O gênero Catopsis (Bromeliaceae: Tillandsioideae) no estado do Paraná: aspectos taxonômicos e anatômicos. Rodriguésia, v.69, n.2, p.649-662, 2019. 
MARTINS, A.R.; APPEZZATO, G.B. Morfoanatomia dos órgãos vegetativos de Smilaxpolyantha Griseb. (Smilacaceae). Revista Brasileira Botânica, v.29, n.4, p.555567, 2006.

MARTINS, M.B.G. Estudos de microscopia óptica e de microscopia eletrônica de varredura em folhas de Menthaspicata e de Menthaspicata $x$ suaveolens(Lamiaceae). Bragantia, v.61, n.3, p.205-218, 2002.

MEDRI, M.E.; LLERAS, E. Quantificação e uso de caracteres anatômicos e fisiológicos de folhas de seringueira na determinação da eficiência hídrica em cultivares de Hevea spp. Acta Amazonica, v.13, p.261-288, 1983.

MENDONÇA, M.S.; OLIVEIRA, A.B.; ARAÚJO, M.G.P.; ARAÚJO, L.M. Morfo-anatomia do fruto e semente de Oenocarpusminor Mart. (Arecaceae). Revista Brasileira de Sementes, v.30, p.90-99, 2008.

N SB. The WealthofIndia.In: A Dictionary of Indian Raw Material sand Industrial Products. 6th ed. Council of Scientific and Industrial Research. 1962. 483 p.

PATEL, A.P.; SIDDAIAH, M. A brief review of some important medicinal plants used in the treatment of asthma. Journal of Drug Delivery \& Therapeutics, v.8, n.6-s, p.347-349, 2018.

PATIL, S.P.; KUMBHAR, S.T. Antioxidant, antibacterial and cytotoxic potential of silver nanoparticles synthesized using terpenes rich extract of Lantana camara L. leaves. BiochemistryandBiophysicsReports, v.10, p.76-81, 2017.

PIRES, M.F.; PEREIRA, M.P.; CASTRO, E.M.; BARBOSA, S.; PEREIRA, F.J. Micromorfometria foliar de Schinusmolle L. (anacardiaceae) em diferentes alturas na copacerne. Revista Brasileira de Farmacognosia, v.21, n.1, 17-25, 2015.

PRIORI, D.; BARBIERI, R.L.; MISTURA, C.C.; VILLELA, J.C.B. Caracterização morfológica de variedades crioulas de abóboras (Cucurbita maxima) do sul do Brasil. Revista Ceres, v.65, n.4, p. 337-345, 2018.

REIS, R.E.; ALVIM, M.N. Anatomia foliar comparada de três espécies do gênero Oxalis L. (Oxalidaceae). Periódico Científico do Núcleo de Biociências Centro Universitário Metodsitalzabela Hendrix, v.3, n.6, p.59-72, 2013.

RODRIGUES, J.K.; MENDONCA, M.S.; GENTIL, D.F.O. Aspectos biométricos, morfoanatômicos e histoquímicos do pirênio de Bactrismaraja (Arecaceae). Rodriguésia, v.66, n.1, p.75-85, 2015.

ROESER, K.R. Die Nadel der Schwarzkiefer-Massenprodukte Und Kunstwerk der Natur. Mikrokosmos, v.61, n.2, p.33-36, 1962.

SASS, J.E. Botanical Microtechnique (2nd. ed.) Ames, lowa StateCollege Press. 1951. $228 \mathrm{p}$.

SOUZA, T.J.T.; MANFRON, M.P.; ZANETTI, G.D.; HOELZEL, S.C.S.M.; PAGLIARIN, V.P. Análise morfo-histológica e fitoquímica de Verbena litoralisKunth. Acta Farmacéutica Bonaerense, v.24, n.2, p.209-214, 2005. 
SCATENA, V.L.; VICH, D.V.; PARRA, L.R. Anatomia de escapes, folhas e brácteas de Syngonanthus sect. Eulampis (Bong. exKoern.) Ruhland (Eriocaulaceae). Acta Botânica Brasilica, v.18, n.4, p.825-837, 2004.

SCHWARZ, E.A.; FURLAN, A. Coléteres foliares de Oxypetalum R. Br. (Asclepiadoideae, Apocynaceae) - Aspectos ultraestruturais e anatômicos úteis à taxonomia das espécies do Paraná (Brasil). Acta Biológica Paranaense, v.31, p.79-97, 2012;

TOLEDO, A.C.O.; DUARTE, M.R.; NAKASHIMA, T. Caracterização morfoanatômica de raiz e rizoma de Symphytumofficinale L. (Boraginaceae). Revista Brasileira de Farmacognosia, v.16, n.2, p.185-191, 2006.

TRIPPLETT, J.; KIRCHOFF, B. Lamine architecture and anatomy in the Heliconiaceae and Musaceae. Canadian Journal of Botany, v.69, p.887-900, 1990.

VENKATACHALAM, T.; KUMAR, V.K.; SELVI, P.K.; MASKE, A.O.; KUMAR, N.S. Physicochemical and preliminary phytochemical studies on the Lantana camara (L.) Fruits. International Journal of Pharmacy and Pharmaceutical Sciences, v.3, n.1, p.52-54, 2011.

WATT, J.M.; BREYER-BRANDWIJK, M.G. The Medicinal and Poisonous Plants of Southern and Eastern Africa being an Account of their Medicinal and other Uses, Chemical Composition, Pharmacological Effects and Toxicology in Man and Animal. $2^{\mathrm{a}}$ ed, 1962. 


\title{
CAPÍTULO
}

\section{COMPOSIÇÃO FLORÍSTICA DE PLANTAS RUDERAIS EM UMA ÁREA DO SEMIÁRIDO NORDESTINO}

\author{
Antônio Reis de Sousa1, Maria do Socorro Meireles de Deus², Thiago Pereira \\ Chaves $^{1}$, Maria Carolina de Abreu², Kairo Michel Lima Borges ${ }^{1}$, Andreia de Moura \\ Araújo', Fernanda Beatriz do Nascimento'
}

1. Universidade Federal do Piauí (UFPI), Curso de Graduação em Ciências Biológicas, Picos, Piauí, Brasil; 2. Universidade Federal do Piauí (UFPI), Núcleo de Pesquisa em Ciências Naturais do Semiárido do Piauí, Picos, Piauí, Brasil;

\section{RESUMO}

Plantas ruderais são espécies típicas de processos de sucessão secundária que apresentam características mais rústicas que favorecem seu crescimento em condições adversas e incorporação à paisagem urbana. Neste capítulo apresentamos um checklist da flora ruderal do município de Picos, Piauí. Foram realizadas coletas em três bairros da zona urbana e uma localidade da zona rural do referido munícipio. O processo de herborização e identificação foi realizado no laboratório de Botânica da Universidade Federal do Piauí - CSHNB. Posteriormente, as espécies foram categorizadas quanto ao seu hábito de crescimento e importância. O levantamento florístico resultou na identificação de 97 espécies, distribuídas em 64 gêneros e 28 famílias. As famílias com maior riqueza específica foram Fabaceae, Poaceae, Malvaceae, Euphorbiaceae, Asteraceae e Cyperaceae. A zona urbana contribuiu com o maior número de espécies, das quais 58 são exclusivas. A maioria das espécies foi considerada de importância negativa, com destaque para aquelas potencialmente infestantes para a região, que representaram $50 \%$ das espécies levantadas. Entretanto, para as demais espécies, importantes usos foram atribuídos, como os usos medicinal (25\%), ornamental (16\%) e apícola (11\%). O hábito herbáceo foi o predominante para essa vegetação. Dessa forma, os resultados obtidos são de grande relevância, pois podem contribuir para criação de novas formas de manejo, controle, bem como otimizar o uso das plantas ruderais e dos espaços urbanos.

Palavras-chave: Plantas Daninhas, Zona urbana e Ambientes antropizados.

\begin{abstract}
Rudimentary plants are typical species of secondary succession processes that present more rustic characteristics that favor their growth in adverse conditions and incorporation into the urban landscape. In this chapter we present a checklist of the ruderal flora of the municipality of Picos, Piauí. Collections were carried out in three neighborhoods in the urban area and one in the rural area of that municipality. The herborization and identification process was carried out at the Botany laboratory of the Federal University of Piauí - CSHNB. Subsequently, the species were categorized according to their growth habit and importance. The floristic survey resulted in the identification of 97 species, distributed in 64 genera and 28 families. The families with the highest specific wealth were Fabaceae, Poaceae,
\end{abstract}


Malvaceae, Euphorbiaceae, Asteraceae and Cyperaceae. The urban area contributed with the largest number of species, of which 58 are exclusive. Most species were considered of negative importance, with emphasis on those potentially infesting for the region, which represented $50 \%$ of the surveyed species. However, for other species, important uses have been attributed, such as medicinal (25\%), ornamental (16\%) and bee (11\%). The herbaceous habit was predominant for this vegetation. Thus, the results obtained are of great relevance, as they can contribute to the creation of new forms of management, control, as well as optimizing the use of ruderal plants and urban spaces. Keywords: Weed plants, Urban area and Anthropized environments.

\section{INTRODUÇÃO}

Ao longo do tempo a expansão das áreas urbanas, bem como a intensa atividade antrópica nesses locais, tem resultado em elevados níveis de alteração no ambiente natural, como por exemplo, a retirada da vegetação nativa, além de diversas alterações no solo. Esses fatores possibilitaram a formação de novos ecossistemas onde se desenvolve uma flora adaptada a sobreviver em ambientes antropizados, se estabelecendo às margens de estradas, próximo a habitações abandonadas, loteamentos urbanos e terrenos baldios. Essa vegetação típica de processos de sucessão secundária apresenta maior rusticidade que proporciona maior adaptação a ambientes modificados (SOUSA; MACHADO FILHO; ANDRADE, 2012). Essas plantas, denominadas de ruderais, constituem um grupo especializado em se estabelecer de forma extraordinária, em áreas urbanizadas.

As plantas ruderais apresentam atributos que favorecem a adaptação às áreas citadas, tais como: mecanismo $\mathrm{C}_{4}$ para 0 processo de fotossíntese, que as tornam bastantes agressivas na ocupação do espaço, grande produção de sementes com longo período de longevidade e facilidade de dispersão, o que as torna extremamente hábeis a sobreviverem em ambientes muito adversos. Em determinadas circunstâncias, essas plantas são as únicas encontradas nesses ambientes, sendo, as responsáveis pela proteção do solo contra a erosão provocada pela chuva e pelo vento (SOUZA; LORENZI, 2008; PALEARI, 2012).

Os centros urbanos geralmente apresentam grande riqueza de espécies, que pode ser até maior que os seus entornos (GUO et al., 2018). Esse fato pode estar relacionado com a movimentação de humanos, que pode contribuir com o transporte de propágulos de novas espécies (LOPEZ-MORENO; DIAZ-BETANCOURT, 1995). Cerca de 50\% da população humana atualmente vive nas cidades. No Brasil esse percentual é maior que 
80\% (LUNDHOLM; MARLIN, 2006; KNAPP et al., 2008). O aumento populacional nessas áreas reduz o contato das pessoas com ambientes naturais conservados. Nesse contexto, as plantas que se estabelecem nas zonas urbanas passam a ser as mais vistas e, por conseguinte, as mais conhecidas, o que faz com que elas desempenhem um papel importante no contato das populações urbanas com a natureza (MILLER, 2005; THOMPSON; MCCARTHY, 2008).

A riqueza de espécies nesses ambientes é também favorecida pela heterogeneidade de micro-habitat, provenientes dos diferentes usos da terra e das instabilidades do habitat, como resultado do distúrbio contínuo nas áreas urbanas. Por estarem expostas a grande influência do homem, muitos autores não consideram as áreas urbanas como um verdadeiro ecossistema, considerando a forma como estas áreas se desenvolvem e que alguns processos e relações ecológicas são alterados e mais intensos nas áreas urbanas, como por exemplo, as relações de competição, mutualismo e sucessão ecológica. Em geral, a abundância de muitas espécies é uma resposta ao grau de antropização do ambiente (BIONDI; PEDROSA-MACEDO, 2008).

Ultimamente, tanto a vegetação introduzida como a remanescente nas cidades dependem e têm grande influência da administração municipal no que se refere às áreas públicas (praças, parques, jardins de instituições públicas e arborização de ruas), e da população local nas áreas particulares e de calçadas. Além desses fatores políticos e culturais, o fator econômico também pode influenciar na quantidade e na qualidade da vegetação urbana (BIONDI; PEDROSA-MACEDO, 2008). Dessa maneira, é importante investir em métodos que auxiliem no conhecimento das comunidades urbanas acerca do potencial das espécies vegetais (ERASMO; PINHEIRO; COSTA, 2004).

São poucas as referências bibliográficas da ocorrência de plantas ruderais em áreas urbanas no Brasil, há uma carência bastante significativa. No entanto, alguns trabalhos podem ser destacados, como por exemplo: Gavilanes e D'angieri Filho (1991), Pedrotti e Guarim Neto, (1998) Carneiro e Irgang (2005), Schneider (2007), Souza, Machado Filho e Andrade (2012) e Soares Filho et al., (2016). A literatura, até o momento, não registra referências sobre essa temática para o estado do Piauí, em especial, para a região semiárida do estado. Diante deste cenário, o estudo de plantas ruderais pode contribuir para novas formas de manejo, controle, bem como otimizar o uso dos espaços urbanos. $O$ presente estudo teve como objetivo identificar a composição florísticas da comunidade de plantas ruderais, em áreas urbana e rural do município de Picos, Piauí. 


\section{MATERIAL E MÉTODOS}

\subsection{LOCAL DE ESTUDO}

O município de Picos está localizado na região Centro/Sul do estado do Piauí (Figura 1), à margem direita do Rio Guaribas, a uma latitude de $7^{\circ} 04^{\prime} 37^{\prime \prime}$ Sul e uma longitude de 41²8'01" Oeste. O clima é caracterizado segundo Köppen, como sendo do tipo Bsh quente e semiárido, com estações chuvosas no verão.

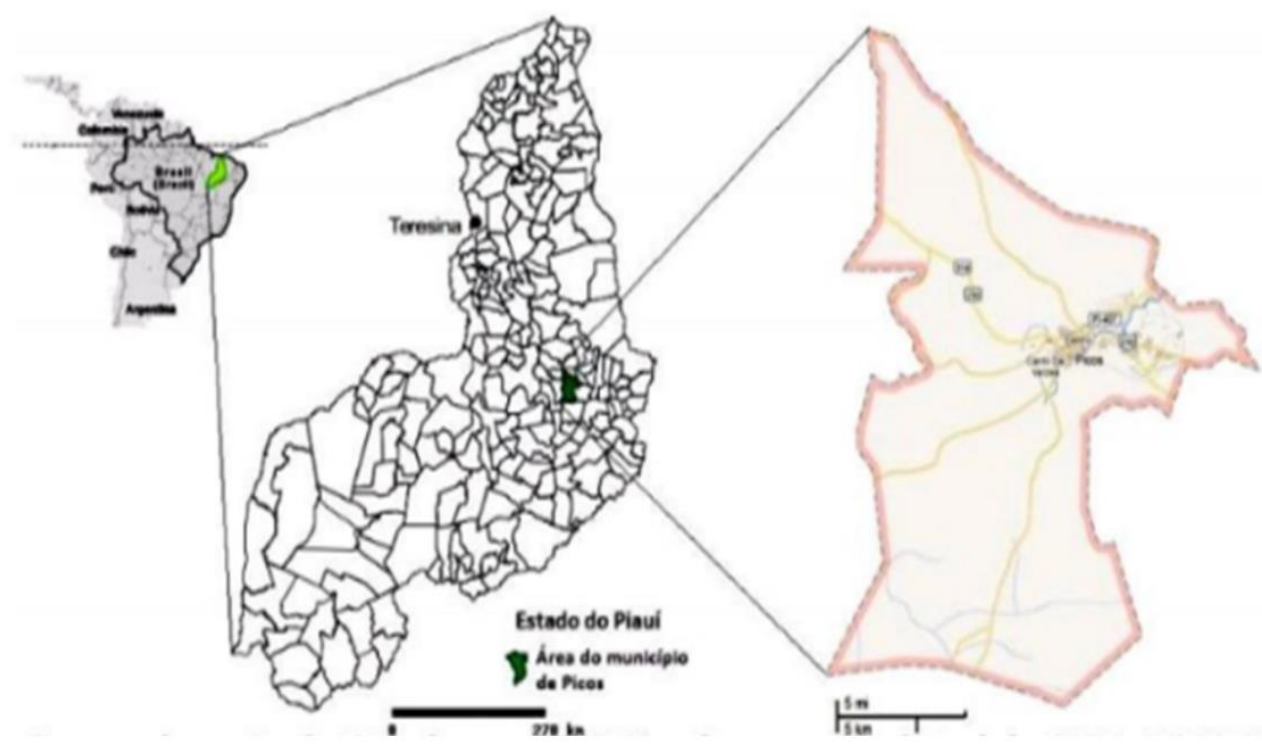

Figura 1: Mapa com a localização do município de Picos, Piauí.

Fonte: Adaptação do Google Maps (2012) e CPRM (2004)

A precipitação média anual é $679 \mathrm{~mm}$ por ano e a umidade relativa do ar permanece em torno de $60 \%$ com decréscimo no período de estiagem. O período chuvoso se estende de janeiro a junho. Geralmente, os rios da região apresentam elevado volume de água nesse período, porém são de curta duração, já que as maiores precipitações ocorrem nos meses de fevereiro e março. Nos outros meses do ano o volume de água diminui consideravelmente, quando em muitas regiões percorridas pelos rios a água desaparece totalmente.

A formação vegetacional que predomina na região é a Caatinga, ocorrendo pequenas manchas de Cerrado a noroeste, revestindo o platô mais dissecado. Nas áreas 
de várzeas, próximo aos rios, o juazeiro, o umbu e a carnaúba oferecem à fisionomia um aspecto de caatinga arbórea (BARBOSA et al. 2007).

\subsection{COLETA DE DADOS}

O material de estudo foi coletado em três bairros da zona urbana da cidade de Picos, sendo estes: Parque de Exposição, Jardim Natal e Pedrinhas, e uma localidade na zona rural, denominada de Cipaúba. As coletas ocorreram em excursões quinzenais durante 0 período de outubro de 2017 a junho de 2018. Para o levantamento florístico foram coletados espécimes da vegetação arbustiva, herbácea, epífita, trepadeira, suculenta e parasita, através de caminhadas aleatórias pelas áreas.

A identificação taxonômica foi realizada por comparações diretas com exsicatas dos herbários virtuais, além do uso de bibliografia especializada como, Lorenzi (2008), Moreira (2011) e Souza e Lorenzi (2012). Foram realizadas as conferências dos nomes científicos e a autoria dos epítetos específicos no banco eletrônico no site Flora do Brasil 2020.

As espécies encontradas foram classificadas em termos de importância para o homem com base no método proposto por Soares Filho et al., (2016), como segue: positivas: $\mathbf{A p}=$ Apícola; $\mathbf{A l}=$ Alimentícia; $\mathbf{A v}=$ Adubação Verde; Fo = Plantas forrageiras; Me = Medicinal; Vt = Veterinária; Or = ornamental. Negativos: In = infestante (daninhas); Tx = tóxicas para humanos e animais; e Ni = não identificada. Para verificar a importância de cada espécie foram utilizadas as seguintes literaturas: Vidal, Santana e Vidal (2008), Lorenzi (2008), Soares Filho et al., (2016) e Vichiato e Vichiato (2016). As espécies também foram agregadas quanto ao local de coleta: $\mathrm{Zu}=$ zona urbana; $\mathrm{Zr}=$ zona rural e por fim, foi confeccionada uma lista (checklist) das espécies coletadas.

\section{RESULTADOS E DISCUSSÃO}

Um total de 106 espécimes de plantas ruderais foi coletado nas áreas, destas, 72 foram identificadas em nível de espécie e quinze ao nível de gênero (Tabela 1). As plantas identificadas foram distribuídas em 64 gêneros e 28 famílias. 
Tabela 1. Plantas ruderais registradas no município de Picos-PI, com informações sobre o local de coleta (LC), nome popular (NP), hábito (HB) e sua importância (IP): Alimentícia (Al); Apícola (Ap);

Adubação verde (Av); Forrageira (Fo); Farmacológica (Fa); Medicinal (Me); Veterinária (Vt); Ornamental (Or); Infestação (In); Tóxica (Tx); Não identificada (Ni).

\begin{tabular}{lcccc}
\hline FAMÍLIA/ESPÉCIE & NP & HB & IP & LC \\
\hline ACANTHACEAE & & & & \\
Ruellia bahiensis (Nees) Morong & Ruélia-azul & Erva & Or & Zu
\end{tabular}

\section{AMARANTHACEAE}

Alternanthera brasiliana (L.) Kuntze

Alternanthera tenella Colla

Amaranthus deflexus L.

Froelichia Humboldtiana Seub.

\section{ASTERACEAE}

Aspilia pascalioides Griseb.

Bidens pilosa L.

Bidens subalternans DC.

Jaegeria hirta (Lag.) Less.

Melampodium divaricatum (Rich.) DC.

Pluchea sagittalis (Lam.) Cabrera

Tridex procumbens $\mathrm{L}$.

\section{BORAGINACEAE}

Heliotropium indicum L.

Heliotropium laceolatum Ruiz \&

Pav.

\section{CLEOMACEAE}

Cleome spinosa Jacq.

Physostemon guianense (Aubl.) Malme
Carrapichinho

Carrapicho

Bredo

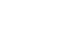

Erva

$\mathrm{Or} / \mathrm{In}$

$\mathrm{Zr}$

Picão-preto

Erva

Picão

Botão-de-ouro

Erva

Erva

Flor-de-ouro

Erva

$\mathrm{Me} / \mathrm{Vt} / \mathrm{F} / \mathrm{Ap}$

$\ln / \mathrm{Ap}$

$\mathrm{Zu}$

$\mathrm{Ni}$

$\mathrm{Zr}$

\section{Lucera}

Erva-de-touro

Erva

Erva

Crista-de-galo

Subarbustiva

Jacuacanga

Subarbustiva

In/Or

$\mathrm{Me} / \mathrm{ln}$

$\mathrm{Zu} / \mathrm{Zr}$

$\mathrm{Zu}$

Subarbustiva
Erva

$\mathrm{Me} / \mathrm{Or}$

$\mathrm{Ni}$

$\mathrm{Zu}$

$\mathrm{Zu}$

\section{COMMELINACEAE}

Commelina erecta L.

Murdannia cf. nudiflora (L.) Brenon

\begin{abstract}
Santa-luzia
trapoerabinha
\end{abstract}

Erva
Erva

$\begin{array}{cc}\text { Or/Ap/Me } & \mathrm{Zu} \\ \mathrm{Ni} & \mathrm{Zr}\end{array}$




\section{CONVOLVULACEAE}

Ipomoea carnea Jacq.

Canudo

Arbustiva

Tx/Or

$\mathrm{Zu} / \mathrm{Zr}$

Ipomoea ramosissima (Poir.)

Jitirana

Erva

In/Or

$\mathrm{Zu} / \mathrm{Zr}$

Choisy

\section{CUCURBITACEAE}

Momordica charantia L.

Melão de São

Erva

$\underset{\text { /Or }}{\mathrm{Me} / \mathrm{Vt} / \mathrm{Ap} / \mathrm{Al} \quad \mathrm{Zu}}$

CYPERACEAE

Cyperus iria L.

Cyperus lanceolatus Poir

Cyperus surinamensis Rottb.

Junquinho

Erva

In

Zu

Cyperus sp

$\begin{array}{cc}\text { Junça } & \text { Erva } \\ ------ & \text { Erva } \\ \text { Junquinho } & \text { Erva } \\ & \text { Erva } \\ ---- & \text { Erva }\end{array}$

$\mathrm{Ni}$

$\mathrm{Zr}$

Kyllinga brevifolia Rottb.

Rhynchospora sp.

Erva

$\mathrm{Zu}$

$\mathrm{Ni} \quad \mathrm{Zu}$

In $\mathrm{Zu}$

$\mathrm{Ni} \quad \mathrm{Zu}$

\section{EUPHORBIACEAE}

Chamaesyce hirta (L.) Millsp

$$
\text { Erva-de-santa- }
$$
luzia

Chamaesyce hyssopifolia (L.)

Small

Erva-andorinha

Erva

In

$\mathrm{Zu}$

Chamaesyce prostrata (Ailton)

Small

Quebra-pedra

Erva

$\mathrm{Zu}$

Chamaesyce sp

Cansanção
Velame
----
----

Erva

Erva

$\mathrm{Me}$

$\mathrm{Zu} / \mathrm{Zr}$

Cnidoscolus urens (L.) Arthur

Arbustiva

$\mathrm{Ni}$

$\mathrm{Zu}$

Croton glandulosus $\mathrm{L}$

Subarbustiva

Croton sp1

Subarbustiva

Croton sp2

Subarbustiva

$\mathrm{In} / \mathrm{Me} \quad \mathrm{Zr}$

FABACEAE

Bauhinia sp

Chamaecrista nictitans (L.)

Moench

Chamaecrista rotundifolia (Perss.)

Greene

Crotalaria spectabilis Rotth

Stylosanthes $s p$

---- Arbória

Peninha

Subarbustiva

$\mathrm{Ni}$

$\mathrm{Zr}$

Glycine wightii (Graham ex Wight \& Arn.) Verdc.

Matapasto

Chocalho

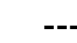

Soja-perene
Erva

Subarbustiva

Erva

Trepadeira
$\mathrm{In} / \mathrm{Me} \quad \mathrm{Zr} / \mathrm{Zu}$

$\mathrm{Ni} \quad \mathrm{Zu} / \mathrm{Zr}$

$\mathrm{Ni} \quad \mathrm{Zu}$ 
Indigofera truxillensis Kunth

Anileira

Erva

In

Zu

Macroptilium lathyroides (L.) Urb.

Feijão-de-rôla

Erva

Av

$\mathrm{Zu} / \mathrm{Zr}$

Mimosa sp1

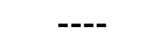

Subarbustiva

$\mathrm{Ni}$

$\mathrm{Zu} / \mathrm{Zr}$

Mimosa sp2

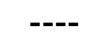

Fedegoso

Subarbustiva

$\mathrm{Ni}$

$\mathrm{Zu}$

Senna obtusifolia (L.) H. S. Irwin \& Barneby

Senna occidentalis (L.) Link

Fedegoso

Subarbustiva

$\ln / T x$

$\mathrm{Zu} / \mathrm{Zr}$

Senna uniflora (Mill.) H. S. Irwin \& Barneby

Matapasto

Arbustiva

In/Me/Tx/Or

Zu

Subarbustiva

In

$\mathrm{Zu}$

\section{LAMIACEAE}

Mesosphaerum suaveolens (I.)

Kuntze

Bamburral Subarbustiva

$\mathrm{Ni}$

$\mathrm{Zu} / \mathrm{Zr}$

\section{LOGANIACEAE}

Spigelia anthelmia L.

Pimenta-daágua

Erva

$\mathrm{In} / \mathrm{Me}$

$\mathrm{Zu}$

\section{LYTRACEAE}

Cuphea campestris (Mart.)

Koehne

\section{MALVACEAE}

Corchorus olitorius L.

Gaya pilosa K. Schum

Herissantia tiubae (K.Schum.)

Brizicky

Melochia pyramidata L.

Pavonia concellata (L.) Cau.

Sida sp.

Waltheria douradinha A.St. Hill

Waltheria indica $\mathrm{L}$.

Waltheria tomentosa $\mathrm{H}$. St. John

\section{MOLLUGINACEAE}

Mollugo verticillata $\mathrm{L}$.

Molugo

Erva

In

$\mathrm{Zu} / \mathrm{Zr}$

\section{NYCTAGINACEAE}

Boerhavia diffusa L.

Boerhavia sp.
Juta-azul

Guaxima

Melosa

Guaxuma-roxa

Mala-rasteira

Doradinha

Malva-branca

Malva-roxa

Subarbustiva

Erva

Subarbustiva

Subarbustiva

Subarbustiva
$\mathrm{Ni}$ $\mathrm{Zu}$

Erva

$\mathrm{Al} / \mathrm{In}$

$\mathrm{Zu}$

In

$\mathrm{Zu}$

In

ZR

In/Me

Zu

$\mathrm{Ap} / \mathrm{Me} / \mathrm{Or} \quad \mathrm{Zu}$

$\mathrm{Ni}$

$\mathrm{Zu} / \mathrm{Zr}$

In/Me

$\mathrm{Zu}$

$\ln / \mathrm{Ap} / \mathrm{Me}$

$\mathrm{Zu} / \mathrm{Zr}$

In

$\mathrm{Zr}$

Pega-pinto

Erva
Erva

$\ln / \mathrm{Me}$

$\mathrm{Zu} / \mathrm{Zr}$

$\mathrm{Ni}$

$\mathrm{Zu}$ 
ONAGRACEAE

Ludwigia octovalvis (Jacq.) P.H. Cruz-de-malta $\quad$ Erva $\quad$ In/Or $\quad$ Zu

Raven

PHYTOLACACEAE

Microtea paniculata Moq.

Capim-névoa

Erva

$\ln$

$\mathrm{Zr}$

\section{PLANTAGINACEAE}

Seoparia dulcis L.

Vassourinha

Erva

$\ln / \mathrm{Me}$

$\mathrm{Zu}$

POACEAE

Cynodon dactylon (L.) Pers.

Grama-seda

Erva

In

$\mathrm{Zu} / \mathrm{Zr}$

Dactyloctenium aegyptium (L.)

Willd.

Pé-de-galo

Erva

$\mathrm{Zu} / \mathrm{Zr}$

Digitaria horizontalis Wildd

Digitaria sanguinalis (I.) Scop.

Capim-tinga

Erva

In

Zu/Zr

Capim-

anguinário

Erva

$\mathrm{Zu} / \mathrm{Zr}$

Capim-arroz

Erva

Erva

In

$\mathrm{Zu}$

Echinochloa colona (L.) Link

----

Erva

$\mathrm{Zu} / \mathrm{Zr}$

Eragratis sp.

Pastinho-d’água

$\mathrm{Zr}$

Luziola peruviana Juss. Ex J. F. Gmel.

Panicum cf. aquaticum Poir

Paspalum cf. urvillei Steud

Erva

Erva

Pennisetum setosum (SW.) Rich

Capim-oferecido

Erva

$\mathrm{Zu} / \mathrm{Zr}$

\section{POLYGALACEAE}

Polygala sp.

Erva

$\mathrm{Ni}$

$\mathrm{Zu} / \mathrm{Zr}$

PORTULACACEAE

Portulaca hirsutíssima Cambess sp.

\section{RUBIACEAE}

Diodella teres (Walter) Small

Richardia grandiflora (Cham \&

Schltdl) Steud.

$\begin{array}{cc}\text { Mata-pasto } & \text { Erva } \\ \text { Poaia-rasteira } & \text { Erva }\end{array}$

In

$\mathrm{Zu} / \mathrm{Zr}$

Ap $\quad Z u / Z r$

\section{SAPINDACEAE}

Urvillea sp.

\section{TURNERACEAE}


Turnera subulata Sm

Turnera sp.

Turnera $s p$.

\section{VERBENACEAE}

Stachytarpheta elatior Schrad. Ex Schult

\section{ZYGOPHYLLACEAE}

Kallstroemia maxima (L.) Hook. \& Arn

Kallstroemia tribuloides (Mart.) Steud.
Chanana

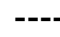

$---$

Erva-de-grilo
Erva

Erva

Erva

Subarbustiva

$\ln / \mathrm{Me} / \mathrm{Or}$

$\mathrm{Zu}$
$\mathrm{Ap} / \mathrm{In} / \mathrm{Me} / \mathrm{Or} \quad \mathrm{Zu} / \mathrm{Zr}$

$\mathrm{Ni} \quad \mathrm{Zu}$

$\mathrm{Ni} \quad \mathrm{Zu}$ 
2000). Uma das características mais importantes da família Fabaceae é a propriedade da fixação biológica de $\mathrm{N}_{2}$ quando em associação com bactérias do solo do grupo dos rizóbios (SOUZA, 2010). Esse fato as torna bem adaptadas à primeira colonização e exploração de diversos ambientes, sendo dessa forma de grande importância ecológica (GOMES; SILVA; CONCEIÇÃO, 2017).

A família Poaceae é formada por cerca de 700 gêneros e 10.000 espécies que se distribuem amplamente em todas as regiões do globo (GPWG, 2001). A importância ecológica e econômica desta família é indiscutível, pela dominância em vários ecossistemas vegetais, pela utilização na alimentação dos animais e pelo uso dos cereais no regime alimentar do homem (WELKER; LONGHI-WAGNER, 2007).

A família Malvaceae é representada por 243 gêneros e 4.300 espécies distribuídas principalmente nas regiões tropicais e subtropicais e, mais raramente, nas regiões temperadas (BAYER; KUBITZKI, 2003). No Brasil, a família está representada por 70 gêneros e 765 espécies, 406 destas endêmicas (BFG, 2015).

A família Euphorbiaceae é representada por cerca de 310 gêneros e 6.900 espécies distribuídas principalmente nos trópicos e subtrópicos (OLIVEIRA; GIMENEZ; GODOY, 2007). É considerada uma das famílias típicas da Caatinga devido à sua grande representatividade no semiárido nordestino (ZAPPI, 2008). As espécies de Euphorbiaceae têm grande destaque na atividade econômica, através da alimentação humana e na medicina a partir do conhecimento popular (TRINDADE, 2015). Muitas espécies de Croton L. crescem, predominantemente, em locais perturbados, tais como beira de estradas, margem de rios e clareiras de matas. Essas e outras características ecológicas, como a produção massiva de flores e frutos durante a maior parte do ano, fazem dos membros do gênero candidatos ideais para a restauração de florestas degradadas (LIMA; PIRANI, 2008). São reputadas como plantas medicinais (RODRIGUES, 2007), onde apresentam metabólitos secundários como alcalóides, terpenóides e cocarcinógenos (LIMA; PIRANI, 2008). A espécie Chamaesyce hirta (L) Millsp., por exemplo, é amplamente utilizada como xarope para tosse e para crise asmática, além de muitas plantas dessa família movimentar a economia no mercado de plantas ornamentais pela beleza das brácteas ou folhas (RODRIGUES, 2007).

Asteraceae é uma das maiores famílias de plantas e compreende cerca de 1.600 gêneros e 23.000 espécies (ANDENBERG et al., 2007). No Brasil, existem aproximadamente 2.000 espécies e 250 gêneros (SOUZA; LORENZI, 2008). Na Caatinga, estão representadas por cerca de 100 gêneros e 262 espécies (NAKAJIMA et al., 2014). 
As Asteraceae apresentam distribuição cosmopolita, encontrando-se disseminadas por todos os continentes, com exceção da Antártica, porém com representação mais ampla nas regiões temperadas e semiáridas dos trópicos e subtrópicos (ROQUE; BATISTA, 2008). É constituída por representantes de hábito herbáceo, subarbustivo, lianas, e eventualmente, por arbustos ou pequenas árvores, ocorrendo em praticamente todos os biomas brasileiros (DA SILVA; BARBOSA; DE BARROS, 2014). Roque; Batista, (2008), supõem que o desenvolvimento de um sistema químico de defesa que inclui a produção combinada de compostos secundários muito derivados, do tipo poliacetilenos e lactonas sesquiterpênicias, seja o principal responsável pela importância econômica da família na medicina tradicional, além dos propósitos medicinais, várias espécies são utilizadas como produtos alimentícios, na produção de cosméticos ou, ainda, como plantas ornamentais. $\mathrm{O}$ gênero Bidens apresenta diversas espécies, entre as quais Bidens pilosa L. se destaca em todo o mundo, por ser uma planta daninha bastante agressiva e, ao mesmo tempo, espécie vegetal de elevado valor medicinal, em razão de suas propriedades farmacêuticas (SANTOS; CURY, 2011). Ainda segundo esses autores, nos últimos anos, considerado número de trabalhos tem dado destaque a $B$. pilosa, por suas propriedades fitotóxicas a outras plantas e a microrganismos, além disso, nos campos agrícolas, ela apresenta ampla disseminação, devido às características de rusticidade tanto na produção de propágulos como no uso eficiente dos recursos, principalmente água e nutrientes, e condições edáficas e ambientais.

Para a família Cyperaceae são reconhecidas cerca de 5.500 espécies, distribuídas em 104 gêneros no mundo (GOVAERST et al., 2007) e no Brasil são registradas aproximadamente 600 espécies, distribuídas em cerca de 40 gêneros (SOUZA; LORENZI, 2012). Embora as espécies da família sejam frequentemente associadas a ambientes alagadiços, como margens de rios e corpos d'água, estas também ocorrem em ambientes mais drenados, como topos de morro, além de constituírem importante elemento florístico e ecológico na composição sucessional de áreas sujeitas à ação antrópica (TREVISAN; DE ABREU FERREIRA; BOLDRINI, 2008). Destaca-se como sendo uma das famílias de algumas das mais agressivas espécies invasoras de culturas, conhecidas como tiririca ou tiriricão (Cyperus spp.).

Do total de espécies registradas, 58 foram identificadas como exclusivas para zona urbana $(\mathrm{Zu}), 20$ ocorreram apenas na zona rural $(\mathrm{Zu})$ e 28 em ambos os locais, demostrando que a zona urbana do município apresenta maior diversidade de espécies do 
que a zona rural, com 50,6\% das espécies ocorrentes com exclusividade a esta área (Figura 1)

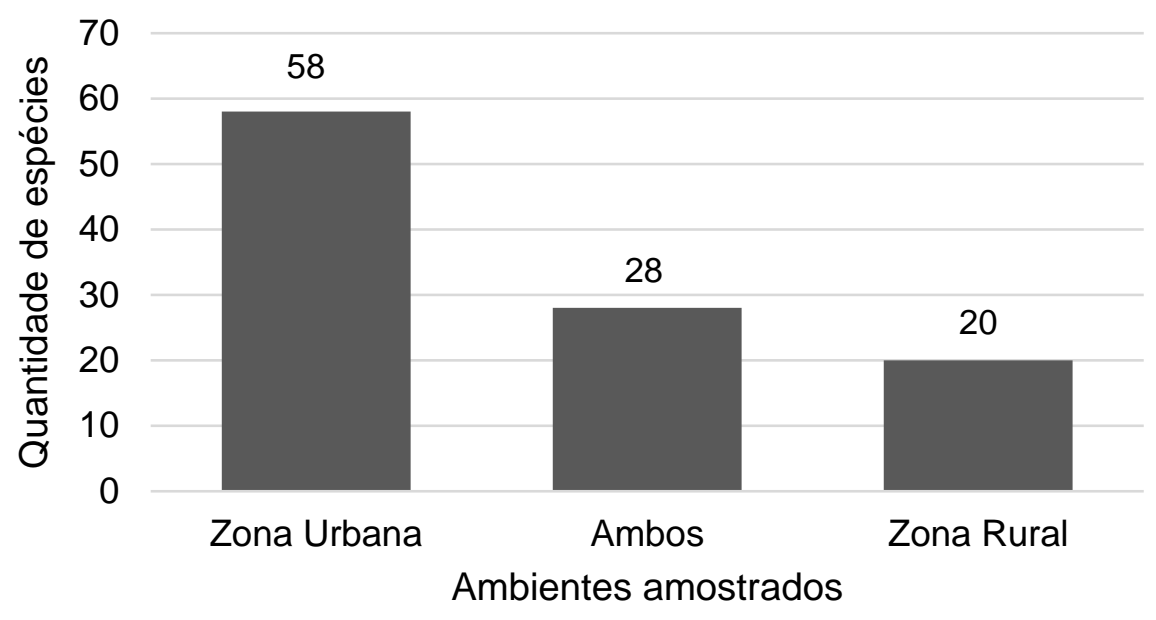

Figura 1. Número de plantas ruderais por ambiente amostrado no semiárido nordestino.

Os centros urbanos geralmente apresentam grande riqueza de espécies, que pode ser até maior que os seus entornos (GUO et al., 2018). Esse fato pode estar relacionado com o processo de antropização, que pode contribuir com a mudança das características do ambiente, favorecendo o estabelecimento de espécies invasoras, e com o transporte de sementes de novas espécies (LOPEZ-MORENO; DIAZ-BETANCOURT, 1995). A adversidade das condições ambientais, comum a distintos centros urbanos, favorece a sobrevivência de espécies com características fisiológicas e morfológicas semelhantes, mesmo em localidades distantes geograficamente. De modo que a grande riqueza florística encontrada no ambiente urbano, não afeta positivamente a diversidade em nível global (CARNEIRO; IRANG, 2005).

Contatou-se que $77 \%$ das espécies ruderais do município de Picos-PI apresenta hábito herbáceo, onde foram registradas 82 ervas, 18 plantas subarbustivas, 3 arbustivas, 2 trepadeiras e 1 arbórea (Figura2). As herbáceas normalmente são plantas que apresentam ciclo de vida curto, característica comum às plantas angiospermas, que produzem semente mais rapidamente e mais precoce que as gimnospermas, o que pode considerar-se uma vantagem evolutiva (VICHIATO; VICHIATO, 2016). 


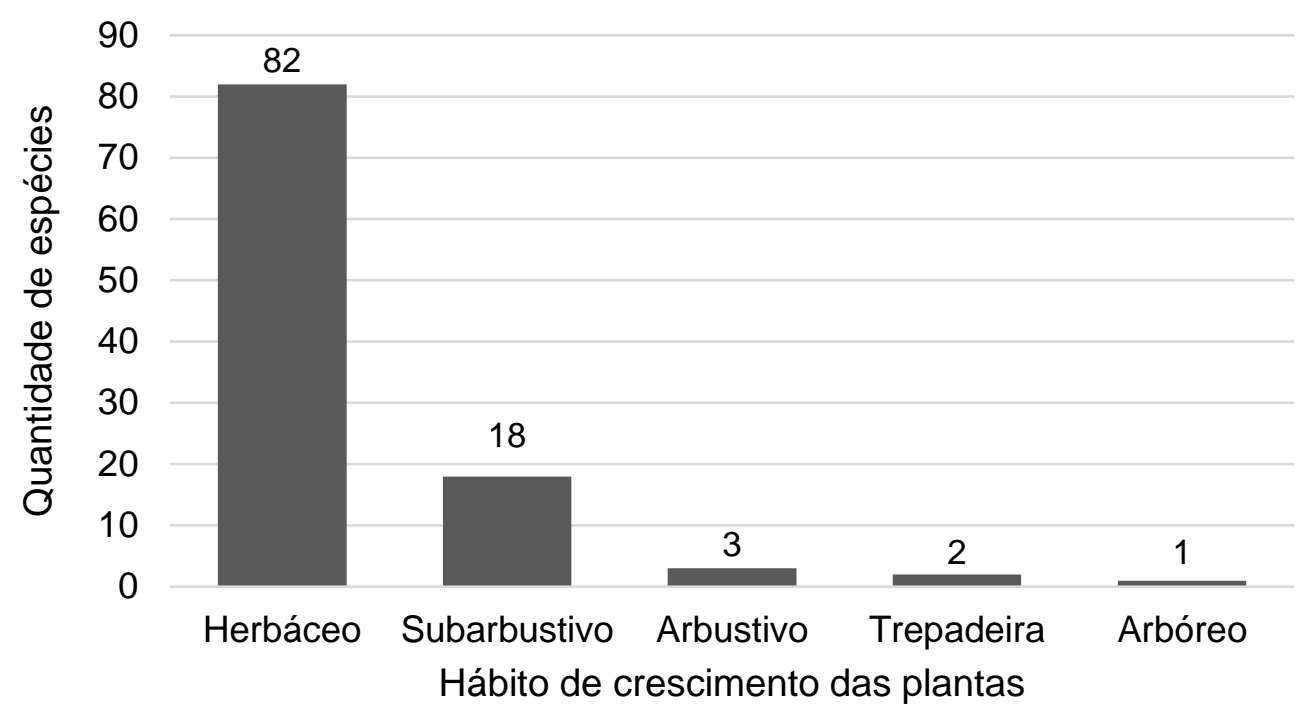

Figura 2. Hábito das plantas registradas no levantamento da diversidade de plantas ruderais no semiárido nordestino

Em termos de importância, $61 \%$ das plantas ruderais possuem algum potencial positivo ou negativo. Os outros 39\% não foi possível caracterizar o seu potencial, uma parcela por ter sido identificado somente ao nível de família ou gênero e o restante por não ter sido encontrado na literatura pesquisada. Dos $61 \%$ de plantas com algum tipo de potencial, $59 \%$ apresentaram potencial negativo, enquanto $41 \%$ das espécies apresentaram potencial positivo. Destes o uso medicinal obteve o maior índice com cerca de $30 \%$ das espécies, seguido pelo potencial ornamental com $16 \%$ e o potencial apícola com $11 \%$. Além disso, ainda constatou-se que as plantas ruderais possuem potencial como forrageiras, adubação verde, alimentícia e veterinária. As espécies Bidens pilosa L. e Momordica charantia L. se apresentaram com o maior potencial de uso.

Entretanto, 55\% das espécies apresentaram algum potencial negativo. No qual, a infestação se sobressaiu com o maior índice, em que cerca de 50\% das espécies podem apresentar algum tipo de infestação. No entanto, segundo Soares Filho et al., (2016), não se pode pensar na maioria das ervas como simplesmente daninhas, logo é preciso repensar conceitos e em vista disso, sugere-se que o termo mais apropriado para as plantas espontâneas em culturas, pastagens e áreas em regeneração, seja 'ruderal', a fim de evitar a associação de características negativas a essas plantas.

Esses dados, para a região estudada, chamam atenção o potencial apícola dessas plantas, pois o município de Picos-PI vem se destacando pela elevada produção de mel de excelente qualidade, sendo considerada a capital do mel no estado. O Piauí ocupa o quarto 
lugar na produção nacional de mel, tendo atingido $3.262 \mathrm{t}$ de mel em 2010, enquanto o município de Picos é o maior produtor do estado do Piauí e um dos maiores do Brasil, ocupando o décimo terceiro lugar na cadeia nacional (IBGE, 2010).

\section{CONCLUSÃO}

No sentido estritamente florístico o município de Picos-PI apresenta flora ruderal que pode ser considerada medianamente rica em espécies. Com espécies de grande utilidade para a sociedade em geral, principalmente o potencial apícola dessas plantas devido à importância econômica da produção do mel para a região.

Dessa forma, sugere-se que para a melhoria da utilização das plantas ruderais são necessários incentivos às pesquisas sobre interações ecológicas, capacidade infestação e deteç̧ão de variedades com características aproveitáveis, estratégias de domesticação baseadas em melhoramento genético, prospectar conhecimentos sobre usos das plantas ruderais e divulgá-los, e, por fim, estabelecer estratégias para aproveitar o potencial das espécies ruderais, incorporando-as aos diversos sistemas, ao invés de somente combatêlas. Portanto, os resultados obtidos são de grande relevância, pois podem contribuir para criação de novas formas de manejo, controle, bem como otimizar o uso dos espaços urbanos.

\section{REFERÊNCIAS}

ANDENBERG, A. A., BALDWIN, B.G., BAYER, R.G., BREITWIESER, J., JEFFREY, C., DILLON, M.O., ELDEÑAS, P., FUNK, V., GARCIA-JACAS, N., HIND, D.J.N., KARIS, P.O., LACK, H.W., NESON, G., NORDENSTAM, B., OBERPRIELER, CH., PANERO, J.L., PUTTOCK, C., ROBINSON, H., STUESSY, T.F., SUSANNA, A., URTUBEY, E., VOGT, R., WARD, J. \& WATSON, L.E. Compositae. Pg. 61- 588. In: KADEREIT, J. W.; JEFFREY, C. (Eds.). Flowering Plants Eudicots Asterales, Vol. VIII. The Families and Genera of Vascular Plants, K. Kubitzki (Ed.). Springer - Verlag, 2007.

BARBOSA, R. I.; CAMPOS, C.; PINTO, F.; FEARNSIDE, P. M. Os "Lavrados" de Roraima: Biodiversidade e Conservação de Savanas Amazônicas Brasileiras. Functional Ecosystems and Communities, v. 1, p. 30-42, 2007.

BAYER, C.; KUBITZKI, K. Malvaceae. In: Flowering Plants- Dicotyledons. Springer, Berlin, Heidelberg, p. 225-311, 2003. 
BFG (The Brazilian Flora Group). Growing knowledge: an overview of Seed Plant diversity in Brazil. Rodriguésia. v. 66, n. 4, p. 1085-1113, 2015.

BIONDI, D.; PEDROSA-MACEDO, J. H. Plantas invasoras encontradas na área urbana de Curitiba (PR). Floresta, v. 38, n. 1, p. 129-144, 2008.

CARNEIRO, A. M.; IRGANG, B. E. Origem e distribuição geográfica das espécies ruderais da Vila de Santo Amaro, General Câmara, Rio Grande do Sul. Iheringia. Série Botânica., v. 60, n. 2 , p. $175-188,2005$.

CARVALHO, S. L.; PITELLI, R. A. Levantamento e análise fitossociológica das principais espécies de plantas daninhas de pastagens da região de Selvíria (MS). Planta Daninha, v.10, n. 1-2, p. 25-32, 1992.

DA SILVA, A. M. A.; COELHO, I. D.; DE MEDEIROS, P. R. Levantamento florístico das plantas daninhas em um parque público de Campina Grande, Paraíba, Brasil. Biotemas, v.21, n. 4, p. 7-14, 2008.

DA SILVA, M. P.; BARBOSA, F. S. Q.; DE BARROS, R. F. M. Estudo taxonômico e etnobotânico sobre a família Asteraceae (Dumortier) em uma comunidade rural no Nordeste do Brasil. Gaia Scientia, v. 8, n. 2, 2014.

VIDAL, M. G.; SANTANA, N. S.; VIDAL, D. Flora apícola e manejo de apiários na região do recôncavo sul da Bahia. Revista Acadêmica: Ciência Animal, v. 6, n. 4, p. 503-509, 2008.

ERASMO, E. A. L.; PINHEIRO, L. L. A.; COSTA, N. V. Levantamento fitossociológico das comunidades de plantas infestantes em áreas de produção de arroz irrigado cultivado sob diferentes sistemas de manejo. Planta daninha, p. 195-201, 2004.

Flora do Brasil 2020. Jardim Botânico do Rio de Janeiro. Disponível em <http://floradobrasil.jbrj.gov.br>. Acesso em: 02 de Out. de 2018.

GAVILANES, M. L.; D'ANGIERI FILHO, C. N. Flórula ruderal da cidade de Lavras, MG. Acta Botanica Brasilica, v. 5, n. 2, p. 77-88, 1991.

GOMES, G. S.; SILVA, G. S.; CONCEIÇÃO, G. M. diversidade de Leguminosas no cerrado do município de São João do Sóter, Maranhão, Brasil. Agrarian Academy, Centro Científico Conhecer - Goiânia, v.4, n.7; p. 2017.

GOVAERTS, R.; SIMPSON, D. A.; GOETGHEBEUR, P.; WILSON, K. L.; EGOROVA, T.; BRUHL, J. World checklist of Cyperaceae. Kew: The Board of Trustees of the Royal Botanical Garden, 2007.

GPWG (Grass Phylogeny Working Group). Phylogeny and subfamilial classification of the grasses (Poaceae). Annals of the Missouri Botanical Garden, v. 88, n. 3, p. 373-457, 2001.

GUO, P.; YU, F.; REN, Y.; LIU, D.; LI, J.; OUYANG, Z.; WANG, X. Response of ruderal species diversity to an urban environment: implications for conservation and management. International journal of environmental research and public health, v. 15, n. 12, p. 28-32, 2018. 
IBGE, Diretoria de Pesquisas, Coordenação de Agropecuária, Pesquisa da Pecuária Municipal 2010.

KNAPP, S.; KÜHN, I.; SCHWEIGER, O.; KLOTZ, S. Challenging urban species diversity: contrasting phylogenetic patterns across plant functional groups in Germany. Ecology Letters, v.11, p.1054-1064, 2008.

LARA, J. F. R.; MACEDO, J. F.; BRANDÃO, M. Plantas daninhas em pastagens de várzeas no Estado de Minas Gerais Meadow holm pasture weeds in fields in the State of Minas Gerais. Planta Daninha, v. 21, n. 1, p. 11-20, 2003.

LEWIS, G. P.; SCHRIRE, B. D.; MACKINDER, B. A.; LOCK, J. M. Legumes of the World. Royal Botanic Gardens, Kew. p. 577, 2005.

LIMA, H. C. Leguminosas arbóreas da Mata Atlântica - uma análise da riqueza, padrões de distribuição geográfica e similaridades florísticas em remanescentes florestais do estado do Rio de Janeiro. Tese de Doutorado. Universidade Federal do Rio de Janeiro, Rio de Janeiro, p.122, 2000.

LIMA, L. R.; PIRANI, J. R. Taxonomic revision of Croton sect. Lamprocroton (Müll. Arg.) Pax (Euphorbiaceae ss). Biota Neotropica, v. 8, n. 2, p. 177-231, 2008.

LÓPEZ-MORENO, I. R. L.; DÍAZ-BETANCOURT, M. E. El estudio de la biodiversidad en ecosistemas urbanos. Arbor, n. 596, p. 63-86,1995.

LORENZI, H. Plantas daninhas do Brasil: terrestres, aquáticas, parasitas e tóxicas. Instituto Plantarum, Nova Odessa, 2008.

LUNDHOLM, J. T.; MARLIN, A. Habitat origins and microhabitat preferences of urban plant species. Urban Ecosystems n. 9, p.139-159. 2006.

MILLER, J. R. Biodiversity conservation and the extinction of experience. Trends in Ecology \& Evolution, v. 20, n. 8: p. 430-434. 2005.

NAKAJIMA, JN.et al. Asteraceae in Lista de Espécies da Flora do Brasil. Jardim Botânico do Rio de Janeiro. Disponível em: <http://floradobrasil.jbrj.gov.br> acesso em: 02 out. 2018.

OLIVEIRA, R. B. de; GIMENEZ, V. M. M.; GODOY, S. A. P. de. Intoxicações com espécies da família Euphorbiaceae. Revista Brasileira de Biociências, v. 50, n. 01, 2007.

PALEARI, L. M. Plantas ruderais: o mato que alimenta, protege e embeleza o ambiente. Rede Sans, 2012.

PEDROTTI, D. E.; GUARIM NETO, G.. Flora ruderal da cidade de Cuiabá, Mato Grosso, Brasil. Acta botanica brasilica, p. 135-143, 1998.

RODRIGUES, A. S. As tribos Dalechampieae Müll. Arg. e Manihoteae Melchior (Euphorbiaceae) no Distrito Federal, Brasil. 2007. 
ROQUE, N.; BAUTISTA, H. P. Asteraceae: caracterização e morfologia floral. Edufba, 2008.

SANTOS, J. B.; CURY, J. P. Picão-preto: uma planta daninha especial em solos tropicais. Planta daninha, v. 29, n. spe, p.1159-1172, 2011.

SCHNEIDER, A. A. A flora naturalizada no estado do Rio Grande do Sul, Brasil: herbáceas subespontâneas. Biociências, v. 15, n. 2, p. 257-268, 2007.

SOARES FILHO, A. O.; DE PAULA, A.; DOS SANTOS, A.A.; DE OLIVEIRA, C.V.; D'SOARES, C.S.; DOS SANTOS, F.S.; CARVALHO, R.C.F.; PEREIRA, JE.S. Plantas ruderais no Planalto Conquistense, Bahia e sua importância. Natureza on line, v. 14, n. 2, p. 027-043, 2016.

SOUSA, V. S.; MACHADO FILHO, H. O.; ANDRADE, T. M. de. Similaridade de vegetação ruderal entre regiões do Brasil. Revista Geonorte, v. 01, n. 04, p 274-283, 2012.

SOUZA, L. A. G. Levantamento da habilidade nodulífera e fixação simbiótica de $\mathrm{N}_{2}$ nas Fabaceae da região amazônica. Enciclopédia Biosfera, Goiânia, v. 6, n. 10, p. 1-11, 2010.

SOUZA, R. S. S.; MACHADO FILHO, H. O.; ANDRADE, T. M. Levantamento preliminar da vegetação ruderal da cidade de João Pessoa-PB. Revista Geonorte, v. 3, n. 4, p. 200-207, 2012.

SOUZA, V. C.; LORENZI, H. Botânica sistemática: guia ilustrado para identificação das famílias de fanerógamas nativas e exóticas no Brasil, baseado em APG II. Nova Odessa: Instituto Plantarum, 2008.

SOUZA, V. C.; LORENZI, H. Botânica sistemática: guia ilustrado para identificação das famílias fanerógamas nativas e exóticas no Brasil, baseado em APG III. 3. Ed. - Nova Odessa, SP: Instituto Plantarum, 2012.

THOMPSON, K. McCARTHY, M. A. Traits of British alien and native urban plants. Journal of Ecology, v. 96, p. 853-859, 2008.

TREVISAN, R.; DE ABREU FERREIRA, P. M.; BOLDRINI, I. I. A família Cyperaceae no Parque Estadual de Itapuã, Viamão, Rio Grande do Sul, Brasil. Revista Brasileira de Biociências, v. 6, n. 3, p. 217-244, 2008.

TRINDADE, M. T. Espécies úteis da família Euphorbiaceae no Brasil. Revista Cubana de Plantas Medicinales, v. 19, n. 4, p. 292-309, 2015.

VICHIATO, M. R. M; VICHIATO, M. Flora ruderal da cidade de Belo Horizonte, Minas Gerais. Tecnologia \& Ciência Agropecuária. v.10, n.5, p.7-15, 2016.

WELKER, C. A. D.; LONGHI-WAGNER, H. M. A família Poaceae no Morro Santana, Rio Grande do Sul, Brasil. Revista Brasileira de Biociências, v. 5, n. 4, p. 53-92, 2007.

ZAPPI, D. Fitofisionomia da Caatinga associada à Cadeia do Espinhaço. Megadiversidade, v. 4, n. 1-2, p. 34-37, 2008. 


\title{
CAPÍTULO 8
}

\section{EFEITOS DAS MUDANÇAS CLIMÁTICAS EM PLANTAS} CULTIVADAS E NATIVAS: ATUAL ESTADO DAS PESQUISAS BRASILEIRAS

\author{
Eduardo Habermann1, Daniele Ribeiro Contin², Dilier Olivera Viciedo³, Rafael \\ Ferreira Barreto ${ }^{3}$, Marcela Aparecida de Moraes' ${ }^{1}$, Eduardo Augusto Dias de \\ Oliveira ${ }^{4}$, Carlos Alberto Martinez ${ }^{1}$
}

1. Universidade de São Paulo (USP-FFCLRP), Departamento de Biologia, Laboratório de Fisiologia Vegetal, Ribeirão Preto, São Paulo, Brasil;

2. Universidade de São Paulo (USP- FCFRP), Laboratório de Farmacognosia, Ribeirão Preto, São Paulo, Brasil;

3. Universidade Estadual Paulista (UNESP), Laboratório de Nutrição de Plantas, Departamento de Solos e Adubos, Jaboticabal, São Paulo, Brasil;

4. Universidade de Illinois em Chicago (UIC), Laboratório de Isótopos Estáveis, Chicago, Illinois, Estados Unidos da América;

\section{RESUMO}

As alterações globais de origem antrópica e as consequentes mudanças climáticas estão entre os principais desafios para a humanidade nas próximas décadas. Essas alterações já estão afetando tanto os ecossistemas naturais, quanto os ecossistemas manejados, visto que as plantas são intimamente dependentes das condições edafoclimáticas para seu crescimento e sobrevivência. Nesse capítulo, compilamos as principais respostas de plantas nativas e cultivadas de experimentos realizados no Brasil sob condições previstas de temperatura, disponibilidade de água e concentração atmosférica de $\mathrm{CO}_{2}$ no futuro próximo. Ao final do capítulo, identificamos as principais lacunas ainda existentes no cenário brasileiro e sugerimos algumas orientações para futuras pesquisas.

Palavras-Chave: Aquecimento global, gases estufa e fisiologia vegetal.

\section{ABSTRACT}

Human-induced global changes and the consequent climatic changes are amongst the biggest challenges to humanity in the near future. These changes are already impacting both natural and managed ecosystems, because plants are intimately dependent on edaphoclimatic conditions for growth and survival. In this chapter, we compiled the main responses of native and cultivated plant species from experiments carried out in Brazil under predicted conditions of temperature, water availability and atmospheric $\mathrm{CO}_{2}$ concentration for the near future. At the end of the chapter we have identified the mains gaps of Brazilian research and suggested new directions to future research programs.

Keywords: Greenhouse gases, human-induced global warming and plant physiology. 


\section{INTRODUÇÃO}

Nas últimas décadas, o aquecimento global de origem antrópica tornou-se o principal tema de estudo das ciências ambientais. Existem fortes evidencias (IPCC, 2014) que a emissão de gases estufa (GES) a partir da Revolução Industrial (por volta de 1850) e seu acúmulo na atmosfera são os principais responsáveis pelo aumento da temperatura média da superfície terrestre nos últimos anos. Dentre os gases emitidos por atividades humanas os mais comumente citados são o dióxido de carbono $\left(\mathrm{CO}_{2}\right)$, o óxido nitroso $\left(\mathrm{N}_{2} \mathrm{O}\right)$, 0 hexafluoreto de enxofre $\left(\mathrm{SF}_{6}\right)$ e o metano $\left(\mathrm{CH}_{4}\right)$ (IPCC, 2014). Medições da concentração atmosférica de $\mathrm{CO}_{2}\left(\left[\mathrm{CO}_{2}\right]\right)$, por exemplo, mostram que a atual [CO $]$, acima de 400 ppm, é a maior concentração registrada nos últimos 2 milhões de anos (YAN et al. 2019). Como a concentração dos GES na atmosfera e a temperatura média da superfície terrestre são variáveis intimamente relacionadas, modelos climáticos são capazes de prever as futuras condições de temperatura de acordo com estimativas previstas de emissões de GES. Um exemplo disso são os modelos climáticos que foram criados em 1970 e que conseguiram prever, de forma acurada, o aumento de temperatura de $0.9{ }^{\circ} \mathrm{C}$ observado até 2019 (HAUSFATHER et al. 2019). Atualmente, os modelos climáticos são ainda mais robustos e precisos, visto que compreendemos com mais detalhes a dinâmica climática do planeta. Além do aumento da temperatura nas últimas décadas, também foi observado um aumento significativo na intensidade e duração de eventos climáticos extremos como secas, ondas de calor e inundações (ALEXANDER et al. 2006; COUMOU; RAHMSTORF, 2012). Devido a esta precisão dos modelos climáticos, enxergou-se a necessidade de um acordo internacional entre diversos países (Tratado de Paris; UNCC, 2018) com o objetivo de frear as mudanças climáticas de origem antrópica e manter a futura variação de temperatura abaixo de $1,5^{\circ} \mathrm{C}$.

Essas alterações climáticas influenciam fortemente a vida humana, a biodiversidade e a segurança alimentar. Nas últimas décadas, muitos estudos avaliaram como as plantas poderiam ser afetadas pelas diferentes variáveis dessas mudanças. No entanto, a maioria desses estudos foram conduzidos em países de clima temperado do hemisfério norte, enquanto que em países tropicais do hemisfério sul como o Brasil, esses estudos são mais escassos e recentes. De forma geral, o aumento da [ $\left.\mathrm{CO}_{2}\right]$ na atmosfera resulta em efeitos positivos na fotossíntese e no crescimento das plantas. Além disso, o aumento da [ $\mathrm{CO}_{2}$ ] habitualmente reduz a abertura estomática, resultando em menor taxa transpiratória e 
consequentemente em maior eficiência do uso da água. No entanto, variações encontradas nessas respostas são em grande parte dependentes do metabolismo fotossintético da espécie ( $C_{3}, C_{4}$ ou CAM) e de outros fatores ambientais (AINSWORTH; LONG, 2015). Já o aumento da temperatura, resulta em uma maior diversidade de efeitos nas plantas, desde o aumento de produtividade para espécies em regiões abaixo de sua temperatura ótima de crescimento, até reduções de produtividade. Temperaturas elevadas podem aumentar a demanda evaporativa das plantas, e como consequência, intensificar efeitos de déficit hídrico (SAGE; KUBIEN, 2007), que por sua vez é reconhecida como o fator abiótico que mais limita a produtividade vegetal (BOYER, 1982). É importante salientar que todas essas variáveis estão sendo alteradas em conjunto. Dessa forma, estudos que avaliam as respostas das plantas à um dos fatores climáticos somente, devem ser analisados com cautela, visto que interações entre os diferentes fatores climáticos podem dar origem a efeitos emergentes inesperados.

Este capítulo visa compilar algumas das principais respostas de espécies nativas e cultivadas no Brasil sob condições futuras de [ $\left.\mathrm{CO}_{2}\right]$, temperatura e disponibilidade de água, tanto sob condições experimentais, quanto por meio de modelagens matemáticas. Para isso, consultamos a produção cientifica de diversos grupos de pesquisa nacionais a fim de elucidar o atual estado do nosso conhecimento e destacar quais os principais desafios ainda existentes.

\section{REVISÃO DA LITERATURA}

\subsection{EFEITOS DAS MUDANÇAS CLIMÁTICAS EM ESPÉCIES CULTIVADAS}

\subsubsection{Culturas estimulantes e frutíferas}

Estudos realizados em diversos cultivares de café (Coffea arabica L.) demonstraram que sob elevada concentração atmosférica de $\mathrm{CO}_{2}(\mathrm{eC})$, por meio do sistema FACE (FreeAir Carbon dioxide Enrichment), as plantas apresentaram maior taxa fotossintética, maior altura e maior número de frutos por ramo (GHINI et al. 2015). No entanto, o conteúdo foliar de nitrogênio $(\mathrm{N})$ foi reduzido, indicando uma necessidade de aumentar a recomendação de adubação dessa espécie no futuro. Em outro experimento, realizado em câmara de topo 
aberto (OTC), foi demonstrado que a [ $\left.\mathrm{CO}_{2}\right]$ de $760 \mathrm{ppm}$ pode mitigar parcialmente os efeitos da seca na fotossíntese e no acúmulo de carboidratos nas folhas do cafeeiro (SANCHES et al. 2017). Ainda, utilizando câmaras de crescimento, Ramalho et al. (2018) avaliaram a qualidade dos frutos do cafeeiro sob elevada $\left[\mathrm{CO}_{2}\right]$ na atmosfera $(700 \mathrm{ppm})$ desta vez em combinação com elevada temperatura. Os autores observaram que $\circ \mathrm{CO}_{2}$ mitigou os efeitos negativos do aquecimento na qualidade dos frutos. Dessa maneira, os frutos do cafeeiro mantiveram suas características nutricionais (coloração, conteúdo de compostos fenólicos, cafeína, lipídeos e minerais). Utilizando modelagens matemáticas, Tavares et al. (2017) estudaram na região Sul-Sudoeste de Minas Gerais a interferência na produtividade de café

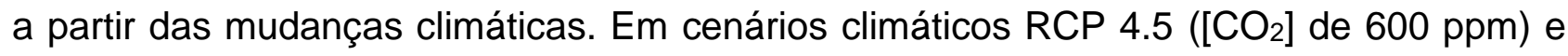
RCP8.5 ( $\left[\mathrm{CO}_{2}\right]$ de $1000 \mathrm{ppm}$ ) previstos até o final do século XXI foi estimado que a produtividade do cafeeiro será reduzida em cerca de $25 \%$ se o aumento médio da temperatura for de $4^{\circ} \mathrm{C}$ a $8^{\circ} \mathrm{C}$ no cenário RCP8.5. Sabe-se que o café, uma espécie $C_{3}$, necessita de temperaturas médias anuais entre $18^{\circ} \mathrm{C}$ e $22^{\circ} \mathrm{C}$ para apresentar boa produtividade e qualidade. A ocorrência frequente de temperaturas máximas acima de $28^{\circ} \mathrm{C}$ causa queda na produção de folhas e consequentemente na fotossíntese, e a partir de $34^{\circ} \mathrm{C}$ causa o abortamento de flores e assim a perda dramática da produtividade (DRINNAN; MENZEL, 1995).

Além do café, em estudos realizados em goiabeira (Psidium guajava L.) em câmaras de topo aberto (OTCs) não foi encontrado aumento de biomassa aérea ou alteração na concentração de açúcares solúveis em folhas das plantas sob 780 ppm de $\mathrm{CO}_{2}$. No entanto, as plantas apresentaram aumento na concentração foliar de amido e taninos. Ambos esses compostos são utilizados como defesa e podem representar maior capacidade de proteção dessa espécie contra herbívoros (REZENDE et al., 2015). Gateau-Rey et al. (2018) estudaram o efeito da seca relacionada ao El Niño na produtividade do cacau (Theobroma cacao L.) na Bahia entre 2015-2016. Foi observado um aumento na mortalidade das plantas de cacau, além de significativa perda na produtividade. Esse estudo é importante, pois existe uma discussão na literatura cientifica a respeito dos possíveis efeitos do aquecimento global antrópico na intensidade e frequência do EI Niño. Isso porque os modelos climáticos apresentam respostas discrepantes que vão desde aumentos na frequência e na intensidade desses eventos (CAl et al., 2014), redução de sua previsibilidade (JIA et al., 2019), ou ainda a uma ausência de alterações (CHUNG; POWER, 2016). 


\subsubsection{Culturas de cereais e oleaginosas}

Silva et al. (2012) submeteram plantas de milho (Zea mays L.) à [CO $\left.\mathrm{CO}_{2}\right]$ de $700 \mathrm{ppm}$ e não observaram diferenças na produção de massa seca da parte aérea ou na produtividade de grãos. No entanto, Renato et al. (2018) avaliaram a influência de diferentes [CO $\left.\mathrm{CO}_{2}\right]$ combinadas ao aumento da temperatura na produção de milho, encontrando alterações na produtividade. Para a construção do modelo adotado no estudo foi utilizado o programa Model Maker (ModelKinetix), baseado no modelo bioquímico de Graham Farquhar. Foram simulados cenários com uma $\left[\mathrm{CO}_{2}\right]$ de 700 ppm combinado com quatro níveis de aumentos na temperatura: $1^{\circ} \mathrm{C}, 2^{\circ} \mathrm{C}, 3^{\circ} \mathrm{C}$ e $5^{\circ} \mathrm{C}$ acima da temperatura média atual. Nos dois primeiros cenários de aumento da temperatura houve um aumento da produtividade de massa seca do milho, que por se tratar de uma planta $\mathrm{C}_{4}$, presumivelmente foi beneficiada pelo aumento moderado na temperatura. Entretanto, na simulação dos acréscimos de $3^{\circ} \mathrm{C}$ e $5^{\circ} \mathrm{C}$, a produtividade diminuiu devido principalmente à aceleração da fenologia e redução do ciclo da cultura, apresentando uma queda de até $65 \%$ de produção de massa seca no último cenário. Camilo et al. (2018) simularam os impactos das mudanças climáticas na produtividade de milho no estado de Minas Gerais a partir de modelagem matemática. Utilizaram-se de dois modelos de circulação global, HadGEM2ES e MIROC5 acoplados ao modelo regional Eta, para gerar dados climáticos futuros. Cada modelo simulou dois cenários: RCP4.5 e RCP8.5. Os autores observaram diferenças entre os dois modelos utilizados, com projeções de aumento na temperatura de $4,5^{\circ} \mathrm{C}$ para 0 cenário RCP4.5 e de $6^{\circ} \mathrm{C}$ para o cenário RCP8.5, usando o modelo HadGEM2-ES. Para o modelo MIROC5 o aumento de temperatura foi de $2^{\circ} \mathrm{C}$ e $4,5^{\circ} \mathrm{C}$ para os cenários RCP4.5 e RCP8.5, respectivamente. Ambos os modelos também indicaram mudanças nos padrões médios de precipitação com predominância de redução dos totais mensais de pluviosidade. Consequentemente, houve redução de $5 \%$ a $26 \%$ de produtividade da cultura do milho na safra de verão no cenário RCP4.5 pelos modelos HadGEM2-ES e MIROC5.

Em um experimento realizado com feijão (Phaseolus vulgaris L.), sob elevada $\left[\mathrm{CO}_{2}\right]$ (700 ppm) combinada ao estresse hídrico, foi observado que a taxa fotossintética e a produção de massa seca aumentaram sob elevada $\left[\mathrm{CO}_{2}\right]$ e adequada disponibilidade de água. No entanto, a massa total de grãos não foi alterada. Reduções nas concentrações foliares de $\mathrm{N}$ e $\mathrm{P}$ ocorreram em plantas cultivadas sob elevada $\left[\mathrm{CO}_{2}\right]$ resultando em maior quantidade de $\mathrm{CO}_{2}$ assimilado por unidade de $\mathrm{N}$ foliar. Nesse estudo, os efeitos do estresse hídrico foram predominantes e tanto a massa seca da parte aérea quanto a massa total de 
grãos foram reduzidos mesmo quando as plantas cresceram sob elevada [CO 2 ] (SILVA et al., 2014).

Em um outro estudo realizado com soja (Glycine max L.), foi observado que a $\left[\mathrm{CO}_{2}\right]$ elevada $(800 \mathrm{ppm})$ aumentou a produtividade de grãos, enquanto o aumento da temperatura $\left(4^{\circ} \mathrm{C}\right.$ acima da temperatura ambiente) diminuiu a produtividade dessas plantas (Palacios et al., 2019). Mas, quando o aumento de temperatura e da $\left[\mathrm{CO}_{2}\right]$ foram combinados, os efeitos positivos do $\mathrm{CO}_{2}$ foram predominantes e mitigaram os efeitos deletérios do aquecimento na produtividade dos grãos de soja. Respostas similares foram observadas em plantas de soja cultivadas sob três condições de temperatura (dia/noite) $20 / 15^{\circ} \mathrm{C} ; 25 / 20^{\circ} \mathrm{C}$ e $30 / 25^{\circ} \mathrm{C}$ e $\left[\mathrm{CO}_{2}\right.$ ] elevada (BRYAN et al., 2006). Contudo, outro estudo demonstrou um aumento na severidade da doença oídio (Microsphaera difusa Cke. \& Pk) quando quatro cultivares de soja foram cultivados sob [ $\mathrm{CO}_{2}$ ] elevada (504 ppm) (LESSIN; GHINI, 2009). Outros resultados similares foram encontrados no estudo realizado por Gória, Ghini e Bettiol (2013), no qual três cultivares de arroz (Oryza sativa L.) foram expostos ao aumento da $\left[\mathrm{CO}_{2}\right]$ (de 100 a $300 \mathrm{ppm}$ acima da [CO 2 ambiente). Nesse estudo, a severidade do fungo da brusone do arroz (Magnaporthe oryzae, anteriormente Magnaporthe grisea (T.T. Hebert) M.E. Barr), foi maior sob $\left[\mathrm{CO}_{2}\right]$ elevada.

\subsubsection{Culturas energéticas}

A cana-de-açúcar (Saccharum officinarum L.) é uma planta de metabolismo tipo $\mathrm{C}_{4}$, cuja temperatura ambiente é o fator mais limitante no seu desenvolvimento. Tayt-Sohn (2014) utilizando o modelo CropWat 8.0 da FAO, e o programa de georreferenciamento ArcGIS 10.0 para estimar a produtividade da cana-de-açúcar na região da bacia hidrográfica do Paranaíba frente aos cenários RCP 4.5 e RCP 8.5. Os autores observaram que o único fator limitante para a produtividade da cultura foi a restrição hídrica, em ambos os cenários, sendo a região totalmente apta para o cultivo da cana-de-açúcar sob condições de adequada irrigação. Entretanto, a demanda de água seria alta, o que causaria aumento elevado nos custos de produção de etanol. Renato (2009) fez simulações de produtividade da cana-de-açúcar nas cidades de Ribeirão Preto - SP e Piracicaba - SP utilizando o modelo matemático ECHAM5/MPI-OM, desenvolvido no Instituto Max Planck de Meteorologia em Hamburgo, Alemanha. O cenário adotado foi o A1B, projetado de 2005 a 2020 pelo Painel Intergovernamental de Mudanças Climáticas (IPCC). O aumento da temperatura média anual fez com que o ciclo da cultura diminuísse, ocasionando queda de produtividade. Em 
Ribeirão Preto a temperatura média anual no período de 2005 a 2011 aumentou $1,3^{\circ} \mathrm{C}$ diminuindo em $24 \%$ a produtividade. Em Piracicaba, neste mesmo período, o aumento da temperatura média anual foi de $1,8^{\circ} \mathrm{C}$ e a produtividade de etanol diminuiu em $49 \%$. Os autores concluíram que o aumento da temperatura aumenta a taxa fotossintética, a taxa respiratória e o acúmulo de massa seca, entretanto a aceleração da fenologia da cultura não permite que a produtividade atinja seu potencial. Em experimentos realizados com plantas de cana de açúcar cultivadas em câmaras de topo aberto, sob boas condições de disponibilidade hídrica, De Souza et al. (2008), observaram aumento de biomassa e fotossíntese das plantas sob elevada $\left[\mathrm{CO}_{2}\right]$ e inibição de genes da síntese de lignina e maiores quantidades de celulose nas folhas nas plantas sob elevada $\left[\mathrm{CO}_{2}\right]$.

\subsubsection{Raízes e Tubérculos}

Cruz et al. (2018) estudaram a produtividade da mandioca (Manihot esculenta Crantz) quando cultivada sob 750 ppm de [CO 2 , tanto sob irrigação quanto sob deficiência hídrica. Os autores observaram que a $\left[\mathrm{CO}_{2}\right]$ elevada mitigou os efeitos negativos da deficiência hídrica sobre a transpiração, e em todas as medidas de crescimento e índice de colheita. Dessa forma, foi sugerido que a produção de raízes da mandioca pode ser resistente a mudanças na precipitação, que acompanharão o aumento da $\left[\mathrm{CO}_{2}\right]$. Olivo et al. (2002), determinaram efeitos positivos da elevada $\left[\mathrm{CO}_{2}\right]$ em duas espécies de batata (Solanum tuberosum e Solanum curtilobum), cultivadas sem restrições hídricas nem nutricionais em câmaras de topo aberto. $O$ rendimento da massa seca de tubérculos aumentou em $40 \%$ e $85 \%$ em S. tuberosum e S. curtilobum, respectivamente.

\subsubsection{Espécies florestais de interesse econômico}

Pirovani et al. (2018) utilizaram os modelos climáticos MCG e MRI-CGCM2.3.2 para avaliar os impactos das mudanças climáticas sobre o cultivo de oito espécies arbóreas no Estado do Espírito Santo: nim (Azadirachta indica A.Juss.), pupunha (Bactris gasipaes Kunth), pinus (Pinus caribaea var. hondurensis, Pinus elliottii var. elliottii, Pinus oocarpa e Pinus taeda), teca (Tectona grandis L.) e cedro Australiano (Toona ciliata M.Roem). Os resultados mostraram que a diminuição da pluviosidade será responsável por diminuir drasticamente as áreas de cultivo dessas espécies. Já na região norte do Estado do Espírito Santo e sul da Bahia, Baesso, Ribeiro e Silva (2010) utilizando o modelo Physiological 
Principles for Predicting Growth (3-PG), para estudar os impactos das mudanças climáticas na produtividade de madeira do eucalipto (Eucalyptus grandis W. Hill ex Maiden). Os autores determinaram que sob os cenários A2 (alta emissão) o incremento médio anual (IMA) de madeira diminuiu até 40\% para algumas áreas no período de 2070-2100, e sob o cenário B2, o IMA diminuiu até $24 \%$ no período de $2070-2100$. Esta queda na produtividade foi explicada a partir do aumento da temperatura e diminuição da precipitação que atuaram no modelo 3-PG dentro do processo fotossintético, ou seja, a temperatura afetou de forma direta e a precipitação de forma indireta (água disponível no solo).

\subsubsection{Culturas forrageiras}

Uma série de estudos conduzidos em Ribeirão Preto - SP utilizando a instalação Trop-T-FACE que combina os sistemas FACE e T-FACE (Temperature Free-Air Controlled Enhancement) avaliaram em condições de campo os efeitos do aumento da concentração atmosférica de $\mathrm{CO}_{2}(600 \mathrm{ppm})$, aumento da temperatura $\left(+2^{\circ} \mathrm{C}\right)$ e do déficit hídrico na fisiologia, anatomia e produtividade de espécies forrageiras tropicais. Sob elevada $\left[\mathrm{CO}_{2}\right] \mathrm{o}$ capim-Mombaça (Panicum maximum Jacq. cv. Mombaça - $\mathrm{C}_{4}$ ) apresentou um aumento na taxa de fotossíntese liquida, acompanhado por uma redução na abertura estomática e taxa transpiratória. Como consequência, a quantidade de carbono fixado por unidade de água transpirada aumentou de maneira substantiva, o que contribuiu para a conservação da umidade do solo. No entanto, quando o aumento da $\left[\mathrm{CO}_{2}\right]$ foi combinado com um aquecimento $\left(+2^{\circ} \mathrm{C}\right)$, os efeitos do $\mathrm{CO}_{2}$ na conservação de água do solo foram suprimidos pelos efeitos do aquecimento (HABERMANN et al., 2019a). De forma geral, o aquecimento não alterou a estrutura do fotossistema Il e não afetou a capacidade fotossintética do capimmombaça ou a velocidade de carboxilação das enzimas fotossintéticas (HABERMANN et al., 2019 a,b). Também foi observado que as plantas sofreram aclimatação à temperatura elevada, produzindo folhas mais finas, cutículas mais espessas, e menores cilindros vasculares e células buliformes (HABERMANN et al., 2019a). Outros mecanismos de aclimatação dessa espécie em resposta ao aumento da temperatura como a produção de enzimas antioxidantes (BORJAS-VENTURA et al., 2020) e o acúmulo de aminoácidos relacionados à defesa contra estresses térmicos e hídricos (WEDOW et al., 2019) também foram observados. De forma geral, a produtividade do capim-mombaça sob aquecimento se mostra dependente das condições de água do solo, ou seja, se umidade é elevada a produtividade aumenta, enquanto que dependendo da intensidade do déficit hídrico, a 
produtividade é reduzida ou se mantem inalterada (OLIVERA-VICIEDO et al., 2019). No entanto, a qualidade nutricional e a digestibilidade dessa pastagem foram drasticamente reduzidas independentemente das alterações climáticas, o que pode amplificar 0 aquecimento global por um 'feedback' positivo devido a maior emissão de metano pelos ruminantes (HABERMANN et al., 2019b).

No estudo realizado por Pezzopane et al. (2017), utilizando os modelos matemáticos PRECIS e ETA, para analisar o efeito que as mudanças do clima teriam sobre o crescimento da cultivar Tanzânia de P. maximum, observaram que nas regiões Sul, Sudeste e Centrooeste espera-se um aumento na produtividade dessa cultivar, enquanto que na região Nordeste do país é esperada uma redução na produção de forragem. Andrade et al. (2014) utilizando esses mesmos modelos para avaliar os efeitos das mudanças climáticas na gramínea Brachiaria brizantha (cv. Marandu), estimaram um aumento de produtividade do capim-marandu em todo o estado de São Paulo, e devido ao aumento da temperatura, pode ser esperado um aumento da demanda hídrica em algumas regiões do estado, o que segundo demonstrado por Olivera-Viciedo et al. (2019) pode trazer alguns prejuízos ao cultivo das pastagens.

Em outra série de estudos utilizando o sistema Trop-T-FACE, Habermann et al. (2019c) mostraram que Stylosanthes capitata Vogel, uma leguminosa forrageira $\mathrm{C}_{3}$, aumenta sua fotossíntese tanto pelo aumento da [ $\left.\mathrm{CO}_{2}\right]$ na atmosfera, quanto pelo aumento da temperatura. Ambos fatores climáticos beneficiaram o funcionamento do fotossistema II dessa espécie (MARTINEZ et al., 2014; HABERMANN et al., 2019c).

\subsection{EFEITOS DAS MUDANÇAS CLIMÁTICAS EM ESPÉCIES NATIVAS FLORESTAIS}

Dias de Oliveira et al. (2012) avaliaram as respostas da sangra d'água (Croton urucurana Baill., arbórea pioneira) e do jequitibá-rosa (Cariniana legalis (Mart.) Kuntze, sucessional tardia) ao incremento de $\left[\mathrm{CO}_{2}\right]$ atmosférico (570 ppm e 760 ppm) utilizando OTCs. Os autores observaram que sob 760 ppm de [ $\left.\mathrm{CO}_{2}\right]$ ambas as espécies apresentaram um aumento na fotossíntese liquida, na velocidade de carboxilação e uma diminuição da fotorrespiração. Além disso, foi observado que a transpiração foi reduzida, aumentando proporção de carbono fixado por volume de água transpirado e consequentemente houve um aumento na biomassa da parte aérea. No entanto, as respostas de ambas as espécies à elevada $\left[\mathrm{CO}_{2}\right]$ foram dependentes da disponibilidade de nutrientes no solo, ou seja, as 
respostas das plantas ao aumento da $\left[\mathrm{CO}_{2}\right]$ só foram positivas quando não havia limitação nutricional.

Arenque et al. (2014) submeteram plantas de mangerioba grande (Senna reticulata (Willd.) H. S. Irwin \& Barneby), uma espécie que cresce em regiões de planícies de inundação, a condições de [CO $]$ elevado (760 ppm) utilizando OTCs. Houve um aumento na taxa de fotossíntese liquida e na concentração foliar de açúcares solúveis e amido sob $\left[\mathrm{CO}_{2}\right]$ elevada. Não foram observados aumentos na biomassa total, folhas e raízes ao final do experimento. No entanto, foi constatado que durante o crescimento inicial sob elevada [ $\left.\mathrm{CO}_{2}\right]$, a biomassa foi alocada para as folhas, enquanto ao final a biomassa foi realocada para as raízes. A biomassa de raízes adventícias em alagamento duplicou sob elevada $\left[\mathrm{CO}_{2}\right]$ quando comparada à $\left[\mathrm{CO}_{2}\right]$ ambiente e alagamento. O aumento na fotossíntese durante o início do crescimento promoveu um incremento na biomassa devido à degradação do amido das folhas. Durante o alagamento, a elevada $\left[\mathrm{CO}_{2}\right]$ reduziu o impacto do alagamento na diminuição da biomassa total, sugerindo uma melhora no desempenho fisiológico dessa espécie sob condições alagadas.

Plantas de tamanqueiro (Alchornea glandulosa Casar) foram submetidas ao incremento de $\left[\mathrm{CO}_{2}\right]$ atmosférico $(800 \mathrm{ppm})$ e temperatura elevada em $1,5^{\circ} \mathrm{C}$. A abertura estomática não foi alterada pela $\left[\mathrm{CO}_{2}\right]$, mas foi reduzida pelo aquecimento de $1,5^{\circ} \mathrm{C}$. Os autores sugerem que essa espécie possui alto potencial de aclimatação às mudanças previstas (FAUSET et al. 2019). Rosa, Souza e Pereira (2019) submeteram plantas de macaúba (Acrocomia aculeata Jacq. Lodd. ex Mart), uma palmeira nativa brasileira, ao incremento de $\left[\mathrm{CO}_{2}\right]$ atmosférico $(700$ ppm) e três ciclos de estresse hídrico. Nesse estudo, foi observado um efeito mitigador da elevada $\left[\mathrm{CO}_{2}\right]$ nos efeitos deletérios da seca. A elevada $\left[\mathrm{CO}_{2}\right]$ acelerou a recuperação das plantas reidratadas e manteve maiores conteúdos de água foliar durante os ciclos de estresse, impedindo perda da biomassa total. Souza et al. (2019) estudaram o efeito da $\left[\mathrm{CO}_{2}\right]$ elevada (700 ppm) nas respostas de plantas de dedaleiro (Lafoensia pacari A. St.-Hil) ao estresse hídrico. Essa espécie encontrada no Cerrado brasileiro também teve os efeitos da seca mitigados pela $\left[\mathrm{CO}_{2}\right]$ elevada, fazendo com que as plantas apresentassem uma maior eficiência do uso da água. O efeito mitigador do [ $\left.\mathrm{CO}_{2}\right]$ também foi estudado por Souza et al. (2016) em três espécies nativas do Cerrado brasileiro, jatobá (Hymenaea stigonocarpa Mart. ex Hayne), ipê-amarelo-do-cerrado (Tabebuia aurea Benth. \& Hook. F. Ex S. Moore.) e lobeira (Solanum lycocarpum A.St.-Hil.). Sob 700 ppm de $\left[\mathrm{CO}_{2}\right]$ as plantas que passaram sob estresse hídrico apresentaram maiores concentrações de clorofila, além de diversas outras alterações ecofisiológicas que sugerem 
um efeito mitigador do $\left[\mathrm{CO}_{2}\right]$ sob a seca. No estudo realizado por Silva et al. (2017) na Caatinga, sob $\left[\mathrm{CO}_{2}\right]$ elevado (550 ppm) a germinação de sementes da catingueiraverdadeira (Poincianella pyramidalis (Tul.) L.P. Queiroz) e da aroeira (Myracrodruon urundeuva Fr. All.) não são alteradas.

Como observado, os estudos com espécies arbóreas nativas e florestais foram realizados em quase sua totalidade dentro de câmaras de crescimento ou OTCs. Embora esse método seja muito importante para a compreensão de mecanismos fisiológicos, ele possui algumas limitações como a alteração da radiação incidente, fluxo de vento, temperatura e umidade. Além disso, devido ao grande porte dessas espécies, as mesmas não podem ser cultivadas durante todo seu ciclo de vida nas condições climáticas testadas. Dessa forma, os estudos são realizados com plantas jovens ou até que o tamanho das câmaras limite o crescimento aéreo dessas espécies. Além disso, o tamanho dos vasos também limita o crescimento das raízes, o que pode alterar as respostas dessas espécies ao incremento de $\left[\mathrm{CO}_{2}\right]$, temperatura e seca. Assim, estudos a longo prazo tornam-se inviáveis.

Estudos que foram realizados em condições de campo a longo-prazo no Brasil evidenciaram como algumas respostas só podem observadas após muitos anos de experimento. Em um estudo de longo-prazo, Rownland et al. (2015) reduziram a incidência de chuvas em uma região de 1 hectare da floresta amazônica utilizando painéis próximos ao solo e um sistema de calhas para captação da água da chuva. Nos primeiros anos de experimento, as espécies arbóreas não mostraram quaisquer respostas à seca experimental. No entanto, após 13 anos de experimento foi observado uma morte súbita das maiores árvores da área experimental devido a um colapso no sistema hidráulico das plantas. Nepstad et al. (2007) utilizando um método similar, também demonstraram uma elevada mortalidade de lianas e grandes arvores após um período de seca experimental na floresta de Tapajós, no Pará. Estudos recentes demonstraram ainda que as mudanças climáticas antrópicas estão sendo responsáveis por aumentar o déficit de pressão de vapor (DPV) da atmosfera na floresta amazônica nos meses mais secos. Consequentemente, a demanda evaporativa da região será maior, e quando somada aos eventos de seca mais intensos e frequentes, podem reduzir a quantidade de $\mathrm{CO}_{2}$ sequestrado pela floresta (BARKHORDARIAN et al., 2019). Além disso, Brando et al. (2020) demonstraram que o aquecimento global de origem antrópica irá amplificar as queimadas no sul da Amazônia, liberando mais de 17 bilhões de toneladas de $\mathrm{CO}_{2}$ para a atmosfera até 2050. 


\section{CONSIDERAÇÕES FINAIS}

Nessa breve revisão bibliográfica, observamos alguns padrões e pontos importantes a serem destacados. Primeiro, de forma geral, observa-se um efeito positivo do incremento do [ $\left.\mathrm{CO}_{2}\right]$ atmosférico na mitigação dos efeitos da seca e do aquecimento nas plantas. No entanto, esse efeito não se faz presente em condições mais intensas de aumento da temperatura e déficit hídrico. Esses resultados são preocupantes visto que a temperatura do ar e os eventos de seca aumentaram nas ultimas décadas e os modelos atmosféricos indicam que essa tendência será mantida nas próximas décadas. Segundo, a vasta maioria dos experimentos foram realizados utilizando câmaras fechadas ou OTCs na avaliação dos impactos das variáveis climáticas em plantas. Como já discutido anteriormente, esses métodos possuem algumas limitações, principalmente quando consideramos o estudo de espécies de grande porte e ciclo de vida longo. Enquanto estruturas que permitem estudos ao ar livre como o FACE e T-FACE estarem disponíveis desde 1990 nos Estados Unidos, no Brasil essas tecnologias ainda são escassas, devido principalmente ao alto custo de construção e manutenção. No Brasil temos apenas três sistemas FACE disponíveis para pesquisa: na Embrapa localizada em Jaguariúna - SP construído em 2011, onde são realizados estudos com café; na Universidade de São Paulo em Ribeirão Preto - SP construído em 2011, onde são realizadas pesquisas com espécies forrageiras e mais recentemente o AmazonFACE, construído na floresta amazônica. Até o momento, sistemas de aquecimento ao ar livre como o T-FACE estão disponíveis apenas na USP em Ribeirão Preto - SP. Esses sistemas ao ar livre são fontes importantes de dados para a construção e aprimoramento de modelos climáticos e de produtividade. Como pode ser observado ao longo do capítulo, o uso da modelagem matemática como uma representação da realidade futura tornou-se promissor. Estes modelos integram diferentes fatores na produtividade e têm sido utilizados para determinar o potencial de produção e a otimização do manejo para quantificar perdas no campo. Além disso, esses modelos são empregados no estudo dos impactos das mudanças climáticas na agricultura e na sobrevivência de espécies florestais. No entanto, a escassez de dados, principalmente no campo, limita a capacidade dos modelos matemáticos de simularem o crescimento, fisiologia e produtividade das espécies em resposta às condições climáticas futuras. Dessa forma, destaca-se a necessidade de maior quantidade de estudos conduzidos a longo-prazo e de mais estruturas físicas que 
permitam avaliar as respostas das plantas em condições de campo, ampliando nosso conhecimento em diferentes espécies, condições edafoclimáticas e biomas brasileiros.

\section{REFERÊNCIAS}

AINSWORTH, E.A.; LONG, S.P. What have we learned from 15 years of free-air $\mathrm{CO}_{2}$ enrichment (FACE)? A meta-analytic review of the responses of photosynthesis, canopy properties and plant production to rising CO2. New Phytologist., v. 165, n. 2, p. 351-371, 2005.

ALEXANDER, L.V.; ZHANG, X.; PETERSON, T.C.; CAESAR, J.; GLEASON, B.; KLEIN TANK, A.M.G.; HAYLOCK, M.; COLLINS, D.; TREWIN, B.; RAHIMZADEH, F.; TAGIPOUR, A.; RUPA KUMAR, K.; REVADEKAR, J.; GRIFFITHS, G.; VINCENT, L.; STEPHENSON, D.B.; BURN, J.; AGUILAR, E.; BRUNET, M.; TAYLOR, M.; NEW, M.; ZHAI, P.; RUSTICUCCI, M.; VAZQUEZ-AGUIRRE, J.L. Global observed changes in daily climate extremes of temperature and precipitation. Journal of Geophysical Research., v. 111, n. 5, p. 213-219, 2006.

ANDRADE, AS.; SANTOS, P.M.; PEZZOPANE, J.RM.; BETTIOL, G.M.; EVANGELISTA, S.R.M. Climate change and future scenarios for palisade grass production in the state of São Paulo, Brazil. Pesquisa Agropecuária Brasileira., v. 49, n. 10, p. 745-753, 2014.

ARENQUE, B.C.; GRANDIS, A.; POCIUS, O.; SOUZA, A.P.; BUCKERIDGE, M.S. Responses of Senna reticulata, a legume tree from the Amazonian floodplains, to elevated atmospheric $\mathrm{CO}_{2}$ concentration and waterlogging. Trees., v. 28, n. 4, p. 1021-1034, 2014.

BAESSO, R.C.; RIBEIRO, A.; SILVA, M.P. Impacto das mudanças climáticas na produtividade do eucalipto na região norte do Espírito Santo e sul da Bahia. Ciência Florestal., v. 20, n. 2, p. 335-344, 2010.

BARKHORDARIAN, A.; SAATCHI, S.S.; BEHRANGI, A.; LOIKITH, P.C.; MECHOSO, C.R. A Recent Systematic increase in Vapor Pressure Deficit over Tropical South America. Scientific Reports., v. 9, n. 15331, p. 1-12, 2019.

BORJAS-VENTURA, R.; FERRAUDO, A.S.; MARTINEZ, C.A.; GRATAO, P.L. Global warming: antioxidant responses to deal with drought and elevated temperature in Stylosanthes capitata, a forage legume. Journal of Agronomy and Crop Science., v. 206, n. 1, p. 13-27, 2020.

BOYER, J.S. Plant productivity and environment. Science., v. 218, n. 4571, p. 443-448, 1982.

BRANDO, P.M.; SOARES-FILHO, B.; RODRIGUES, L.; ASSUNÇÃO, A.; MORTON, D.; TUCHSCHNEIDER, D.; FERNANDES, E.C.M.; MACEDO, M.N.; OLIVEIRA, U.; COE, M.T. The gathering firestorm in southern Amazonia. Science Advances., v. 6, n. 2, p. 1-10, 2020. 
BRYAN, A.; MAIA, A.D.H.N.; DOURADO-NETO, D.; INGRAM, K.T.; HOOGENBOOM, G. Soybean (Glycine max (L.) Merr.) growth and development response to $\mathrm{CO}_{2}$ enrichment under different temperature regimes. European Journal of Agronomy., v. 24, n. 1, p. 52$61,2006$.

CAI, W.; BORLACE, S.; LENGAIGNE, M.; VAN RENSCH, P.; COLLINS, M.; VECCHI, G.; TIMMERMANN, A.; SANTOSO, A.; MCPHADEN, M.J.; WU, L.; ENGLAND, M.H.; WANG, G.; GUILYARDI, E.; JIN, F. Increasing frequency of extreme El Niño events due to greenhouse warming. Nature Climate Change., v. 4, n.2, p. 111-116, 2014.

CAMILO, J.A.; ANDRADE, C.L.T.; AMARAL, T.A.; CHOU, S.C.; TIGGES, C.H.P.; MELO, M.L.A.; GARCIA, A.G. Mudanças Climáticas Futuras Afetarão a Produtividade de Milho em Minas Gerais. Boletim de Pesquisa e Desenvolvimento., v. 1, n. 180, p. 1-29, 2018.

CHUNG, C.T.Y.; POWER, S.B. Modelled impact of global warming on ENSO-driven precipitation changes in the tropical Pacific. Climate Dynamics., v. 47, n. 3-4, p. 1303-1323, 2016.

COUMOU, D.; RAHMSTORF, S. A. A decade of weather extremes. Nature Climate Change., v. 2, n.7, p. 491-496, 2012.

CRUZ, J.L.; LECAIN, D.R.; ALVES, A.A.C.; FILHO, M.A.C.; COELHO, E.F. Elevated $\mathrm{CO}_{2}$ reduces whole transpiration and substantially improves root production of cassava grown under water deficit. Archives of Agronomy and Soil Science., v. 64, n. 12, p. 1623-1634, 2018.

DE SOUZA, A.P.; GASPAR, M.; DA SILVA, E.A.; ULIAN, E.C.; WACLAWOVSKY, A.J.; NISHIYAMA, M.Y.JR.; DOS SANTOS, R.V.; TEIXEIRA, M.M.; SOUZA, G.M.; BUCKERIDGE, M.S., Elevated $\mathrm{CO}_{2}$ increases photosynthesis, biomass and productivity, and modifies gene expression in sugarcane. Plant, Cell and Environment., v. 31, p. 11161127, 2008.

DIAS DE OLIVEIRA, E.A.; APPROBATO, A.U.; LEGRACIE, J.R.; MARTINEZ, C.A. Soilnutrient availability modifies the response of young pioneer and late successional trees to elevated carbon dioxide in a Brazilian tropical environment. Environmental and experimental Botany., v. 77, n. 1, p. 53-52, 2012.

DRINNAN, J.E.; MENZEL, C.M. Temperature affects vegetative growth and flowering of coffee (Coffea arabica L.). Journal of Horticultural Science., v.70, n. 1, p. 25-34, 1995.

FAUSET, S.; OLIVEIRA, L.; BUCKERIDGE, M.S.; FOYER, C.H.; GALBRAITH, D.; TIWARI, R.; GLOOR, M. Contrasting responses of stomatal conductance and photosynthetic capacity to warming and elevated $\mathrm{CO}_{2}$ in the tropical tree species Alchornea glandulosa under heatwave conditions. Environmental and Experimental Botany., v. 158, n. 1, p. 28-39, 2019.

GATEAU-REY, L.; TANNER, E.V.J.; RAPIDEL, B.; MARELLI, J-P.; ROYAERT, S. Climate change could threaten cocoa production: Effects of 2015-16 El Niño-related drought on cocoa agroforests in Bahia, Brazil. PLoS ONE., v. 13, n. 7, p. 1-14, 2018.

GHINI, R.; TORRE-NETO, A.; DENTZIEN, A.F.M.; GUERREIRO-FILHO, O.; IOST, R.; PATRÍCIO, F.R.A.; PRADO, J.S.M.; THOMAZIELLO, R.A.; BETTIOL, W.; DAMATTA, F.M. 
Coffee growth, pest and yield responses to free-air $\mathrm{CO}_{2}$ enrichment. Climatic Change., v. 132, n.2, p. 307-320, 2015.

GÓRIA, M.M.; GHINI, R.; BETTIOL, W. Elevated atmospheric $\mathrm{CO}_{2}$ concentration increases rice blast severity. Tropical Plant Pathology., v. 38, v. 3, p. 253-257, 2013.

HABERMANN, E.; SAN MARTIN, J.A.B.; CONTIN, D.R.; BOSSAN, V.P.; BARBOZA, A.; BRAGA, M.R.; GROPPO, M.; MARTINEZ, C.A. Increasing atmospheric $\mathrm{CO}_{2}$ and canopy temperature induces anatomical and physiological changes in leaves of the $\mathrm{C}_{4}$ forage species Panicum maximum. PLoS ONE., v. 14, n. 2, p. 1-25, 2019 a.

HABERMANN, E.; DIAS DE OLIVEIRA, E.A.; CONTIN, D.R.; DELVECCHIO, G.; VICIEDO, D.; MORAES, M. A.; PRADO, R.M.; COSTA, A.P.; BRAGA, M.R.; MARTINEZ, C.A. Warming and water deficit impact leaf photosynthesis and decrease forage quality and digestibility of a $\mathrm{C}_{4}$ tropical grass. Physiologia Plantarum., v. 165, n. 2, p. 383-402, 2019b.

HABERMANN, E.; DIAS-DE-OLIVEIRA, E.A.; CONTIN, D.R.; SAN MARTIN, J.A.B.; CURTARELLI, L.; GONZALEZ-MELER, M.A.; MARTINEZ, C.A. Stomatal Development and Conductance of a Tropical Forage Legume Are Regulated by Elevated [ $\mathrm{CO}_{2}$ ] Under Moderate Warming. Frontiers in Plant Science., v. 10, n. 1, p. 1-17, 2019c.

HAUSFATHER, Z.; DRAKE, H.F.; ABBOTT, T.; SCHMIDT, G.A. Evaluating the Performance of Past Climate Model Projections. Geophysical Research Letters., v. 47, n. 1, p. 1-10, 2019.

IPCC. Climate Change 2014 Synthesis Report. Disponível em <http://www.ipcc.ch/report/ar5/syr/> Acessado em 27/01/2020.

JIA, F.; CAI, Q.; GAN, B.; WANG, G.; KUCHARSKI, F.; CHANG, P.; KEENLYSIDE, N. Weakening Atlantic Nino-Pacific connection under greenhouse warming. Science Advances., v. 5, n. 8, p. 1-9, 2019.

LESSIN, R.C.; GHINI, R. Efeito do aumento da concentração de $\mathrm{CO}_{2}$ atmosférico sobre o oídio e o crescimento de plantas de soja. Tropical Plant Pathology., v. 34, n. 6, p. 385392, 2009.

MARTINEZ, C.A.; BIANCONI, M.; SILVA, L.; APPROBATO, A.; LEMOS, M.; SANTOS, L.; CURTARELLI, L.; RODRIGUES, A.; MELLO, T.; MANCHON, F. Moderate warming increases PSIl performance, antioxidant scavenging systems and biomass production in Stylosanthes capitata Vogel. Environmental and Experimental Botany., v. 102, n. 6, p. 58-67, 2014.

OLIVERA-VICIEDO, D.; PRADO, R.M.; MARTINEZ, C.A.; HABERMANN, E.; PICCOLO, M.C. Short-term warming and water stress affect Panicum maximum Jacq. stoichiometric homeostasis and biomass production. Science of the Total Environment., v. 681, n. 1, p. 267-274, 2019.

OLIVO, N.; MARTINEZ, C.A.; OLIVA, M. A. The photosynthetic response to elevated $\mathrm{CO}_{2}$ in high altitude potato species (Solanum curtilobum). Photosynthetica., v. 40, n.2, p. 309313, 2002. 
PALACIOS, C.J.; GRANDIS, A.; CARVALHO, V.J.; SALATINO, A.; BUCKERIDGE, M.S. Isolated and combined effects of elevated $\mathrm{CO}_{2}$ and high temperature on the whole-plant biomass and the chemical composition of soybean seeds. Food Chemistry., v. 275, n. 2, p. 610-617, 2019.

PEZZOPANE, J.R.M.; SANTOS, P.M.; EVANGELISTA, S.R.M.; BOSI, C.; CAVALCANTE, A.C.R.; BETTIOL, G.M.; GOMIDE, C.A.M.; PELLEGRINO, G.Q. Panicum maximum cv. Tanzania: climate trends and regional pasture production in Brazil. Grass and Forage Science., v. 72, n. 1, p. 104-117, 2017.

PIROVANI, D.B.; PEZZOPANE, J.E.M.; XAVIER, A.C.; PEZZOPANE, J.R.M.; JÚNIOR, W.C.J.; MACHUCA, M.A.H.; SANTOS, G.M.A.D.A.; SILVA, S.E.; ALMEIDA, S.L.H.; PELUZIO, T.M.O.; EUGENIO, F.C.; MOREIRA, T.R.; ALEXANDRE, R.S.; SANTOS, A.R. Climate change impacts on the aptitude area of forest species. Ecological Indicators., v. 95, n. 1, p. 405-416, 2018.

RAMALHO, J.C.; PAIS, I.P.; LEITAO, A.E.; GUERRA, M.; REBOREDO, F.H.; MAGUAS, C.M.; CARVALHO, M.L.; SCOTTI-CAMPOS, P.; RIBEIRO-BARROS, A.I.; LIDON, F.J.C.; DAMATTA, F.M. Can Elevated Air [ $\mathrm{CO}_{2}$ ] Conditions Mitigate the Predicted Warming Impact on the Quality of Coffee Bean? Frontiers in Plant Science., v. 9, n. 287, p. 1-14, 2018.

RENATO, N. S. Fotossíntese em cenários de mudanças climáticas: adaptação de modelo para a produtividade potencial da cana-de-açúcar. (Dissertação) Mestrado em Meteorologia Agrícola, Universidade Federal de Viçosa, Viçosa, 2009.

RENATO, N.S.; SEDIYAMA, G.C.; SILVA, J.B.L.; PEREIRA, E.G. Modelo fotossintético para simulação da produtividade do milho em condições de temperatura e $\mathrm{CO}_{2}$ elevados. Revista de Ciências Agrárias., v. 41, n. 4, p. 1067-1074, 2018.

REZENDE, F.M.; SOUZA, A.P.; BUCKERIDGE, M.S.; FURLAN, C.M. Is guava phenolic metabolism influenced by elevated atmospheric $\mathrm{CO}_{2}$ ? Environmental Pollution., v. 196, n. 1, p. 483-488, 2015.

ROSA, B.L.; SOUZA, J.P.; PEREIRA, E.G. Increased atmospheric $\mathrm{CO}_{2}$ changes the photosynthetic responses of Acrocomia aculeata (Arecaceae) to drought. Acta Botanica Brasilica., v. 33, n. 3, p. 486-497, 2019.

ROWLAND, L.; COSTA, A.C.L.; GALBRAITH, D.R.; OLIVEIRA, R.S.; BINKS, O.J.; OLIVEIRA, A.A.R.; PULLEN, A.M.; DOUGHTY, C.E.; METCALFE, D.B.; VASCONCELOS, S.S.; FERREIRA, L.V.; MALHI, Y.; GRACE, J.; MENCUCCINI, M.; MEIR, P. Death from drought in tropical forests is triggered by hydraulics not carbon starvation. Nature., v. 528, n. 1, p. 119-122, 2015.

SAGE, R.F.; KUBIEN, D.S. The temperature response of $\mathrm{C}_{3}$ and $\mathrm{C}_{4}$ photosynthesis. Plant Cell and Environment., v. 30, n. 9, p. 1086-1106, 2007.

SANCHES, R.F.E.; CATARINO, I.C.A.; BRAGA, M.R.; SILVA, E.A. Influência da alta concentração atmosférica de $\mathrm{CO}_{2}\left(\uparrow\left[\mathrm{CO}_{2}\right] a t m\right) \times$ disponibilidade hídrica nas relações hídricas, trocas gasosas e acúmulo de carboidratos em Coffea arabica L. Hoehnea., v. 44, n. 4, p. 635-643, 2017. 
SILVA, F.F.S.; OLIVEIRA, G.M.; ARAÚJO, M.N.; ANGELOTTI, F.; MOURA, M.S.B.; DANTAS, B.F. Rainfall events, high $\mathrm{CO}_{2}$ concentration, and germination of seeds in Caatinga. Journal of Environmental Analysis and Progress., v. 2, n. 3, p. 258-265, 2017.

SILVA, J.B.L.; FERREIRA, P.A.; PEREIRA, E.G.; COSTA, L.C.; MIRANDA, V. Development of experimental structure and influence of high $\mathrm{CO}_{2}$ concentration in maize crop. Engenharia Agrícola., v. 32, n. 2, p. 306-314, 2012.

SILVA, J.B.S.; FERREIRA, P.A.; JUSTINO, F.; PIRES, L.C.; TOLEDO, A.S. Leaf concentrations of nitrogen and phosphorus in Phaseolus vulgaris $\mathrm{L}$. plants under high $\mathrm{CO}_{2}$ concentration and drought stress. Engenharia Agrícola., v. 34, n. 5, p. 935-944, 2014.

SOUZA, J.P.; MELO, N.M.J.; HALFELD, A.D.; VIEIRA, K.I.C.; ROSA, B.L. Elevated atmospheric $\mathrm{CO}_{2}$ concentration improves water use efficiency and growth of a widespread Cerrado tree species even under soil water deficit. Acta Botanica Brasilica., v. 33, n. 3, p. 425-436, 2019.

SOUZA, J.P.; MELO, N.M.J.; PEREIRA, E.G.; HALFELD, A.D.; GOMES, I.N.; PRADO, C.H.B.A. Responses of woody Cerrado species to rising atmospheric $\mathrm{CO}_{2}$ concentration and water stress: gains and losses. Functional Plant Biology., v. 43, n. 12, p. 1183-1193, 2016.

TAVARES, P. S.; GIAROLLA, A.; CHOU, S.C.; SILVA, A.J.P.; LYRA, A.A. Climate change impact on the potential yield of Arabica coffee in southeast Brazil. Regional Environmental Change., v. 18, n. 3, p. 873-883, 2017.

TAYT-SOHN, F. C. O. Avaliação dos impactos das mudanças climáticas na aptidão para o cultivo da cana-de-açúcar na região da bacia hidrográfica do Paranaíba. (Dissertação) Mestrado em Planejamento Energético, Universidade Federal do Rio de Janeiro, Rio de Janeiro, 2014.

UNCC (United Nations Climate Change). The Paris Agreement. Disponível em $<$ https://unfccc.int/process-and-meetings/the-paris-agreement/the-paris-agreement>. Acessado em 30/01/2020.

WEDOW, J.M.; YENDREK, C.R.; MELLO, T.R.; CRESTE, S.; MARTINEZ, C.A.; AINSWORTH, E.A. Metabolite and transcript profiling of Guinea grass (Panicum maximum Jacq) response to elevated $\left[\mathrm{CO}_{2}\right]$ and temperature. Metabolomics., v. 15, n. 4, p. 1-13, 2019.

YAN, Y.; BENDER, M.L.; BROOK, E.J.; CLIFFORD, H.M.; KEMENY, P.C.; KURBATOV, A.V.; MACKAY, S.; MAYEWSKI, P.A.; NG, J.; SEVERINGHAUS, J.P.; HIGGINS, J.A. Twomillion-year-old snapshots of atmospheric gases from Antarctic ice. Nature., v. 574, n. 7780, p. 663-666, 2019. 


\title{
CAPÍTULO 9
}

\section{ESTRUTURA POPULACIONAL DE ESPÉCIES EXÓTICAS} INVASORAS EM SÍTIOS DE MATA ATLÂNTICA, ITABAIANA, SERGIPE, BRASIL

\author{
Thieres Santos Almeida1, Rony dos Santos Nascimento1, Kelianne Carolina Targino \\ de Araújo1, Laina Caroline de Santana Pereira², Janisson da Costa Silva ${ }^{3}$, Diego de \\ Andrade Mendonça ${ }^{1}$, Fabiana Jesus Tavares ${ }^{3}$, Jackeline Santos da Silva ${ }^{3}$, Mércia \\ Passos da Cruz $^{3}$, Daniel Oliveira Reis ${ }^{1}$, Juliano Ricardo Fabricante ${ }^{1}$
}

1. Universidade Federal de Sergipe, Laboratório de Ecologia e Conservação da Biodiversidade, Itabaiana, Sergipe, Brasil;

2. Universidade Federal de Sergipe, Laboratório de Liquenologia, Itabaiana, Sergipe, Brasil;

3. Universidade Federal de Sergipe, Itabaiana, Sergipe, Brasil.

\section{RESUMO}

A invasão biológica, segunda maior causa de perda de biodiversidade mundial, acontece quando uma espécie exótica se estabelece, se dispersa e passa a causar danos à comunidade local. Diante da ameaça da invasão biológica, o presente estudo teve como objetivo avaliar a estrutura populacional das exóticas invasoras Cenchrus polystachios (L.) Morrone, Cosmos caudatus Kunth. e Megathyrsus maximus (Jacq.) B.K.Simon \& S.W.L.Jacobs. no município de Itabaiana, Sergipe, Brasil. O estudo foi realizado em três sítios de Mata Atlântica. Nesses locais foram plotadas parcelas de $1 \mathrm{~m}^{2} \mathrm{e}$ todos os indivíduos das espécies mencionadas foram contabilizados, classificados em adultos ou regenerantes e tiveram seu diâmetro a altura do solo (DAS) aferido. Com esses dados foram calculadas a densidade e o índice de dispersão espacial de Morisita. Ainda foram realizadas análises de correlação entre estádios ontogenéticos e construído um gráfico de densidade estimada da frequência de DAS. As espécies apresentaram altas densidades em comparação com outras exóticas já estudadas no Brasil. Esse dado, associado a grande quantidade de indivíduos nas classes iniciais de DAS sugerem que as espécies se encontram estáveis o que é bastante preocupante pois tratam-se de espécies que causam vários impactos negativos

Palavras-chave: Invasão biológica, ervas e espécies alóctones.

\section{ABSTRACT}

The biological invasion, the second biggest cause of worldwide biodiversity loss, happens when an exotic species establishes, disperses and starts to damage the local community. Faced with threat of the biological invasion, this study aimed to evaluate the population structure of exotic invaders Cenchrus polystachios (L.) Morrone, Cosmos caudatus Kunth. 
and Megathyrsus maximus (Jacq.) B.K.Simon \& S.W.L.Jacobs. in municipality of Itabaiana, Sergipe, Brazil. The study was carried out in three Atlantic Forest sites. In these places, plots of $1 \mathrm{~m}^{2}$ were plotted and all individuals of mentioned species were counted, classified into adults or seedlings and had their diameter at ground height (DGH) measured. With these data, density and morisita index of dispersion were calculated. Correlation analyzes were carried out between ontogenetic stages and a estimated density graph of DGH frequency was constructed. The species showed high densities in comparison with other exotic species already studied in Brazil. This data, associated with large number of individuals in the initial DGH classes, suggests that the species are settled, which is quite worrying because they are species that cause several negative impacts.

Keywords: biological invasion, herbs and alien species.

\section{INTRODUÇÃO}

Uma população é definida como "um grupo de indivíduos de mesma espécie que está sob investigação" (TOWNSEND; BEGON; HARPER., 2006), ou ainda "qualquer grupo de organismos da mesma espécie que ocupa um espaço particular e funciona como parte de uma comunidade biótica" (ODUM; BARRET, 2007). Segundo Peroni e Hernández (2011), trabalhos com populações envolvem relações como: distribuição, abundância, crescimento e reprodução (PERONI; HERNÁNDEZ, 2011), sendo uma das ferramentas utilizadas para o estudo com espécies exóticas invasoras (ANDRADE et al., 2010; FABRICANTE et al., 2012).

Considerada como a segunda principal causa de perda de biodiversidade mundial (BELLARD et al., 2016), a Invasão Biológica (IB) é o processo onde ocorre a adaptação de espécies não nativas em um novo ambiente (WILLIAMSON, 1996; ZILLER, 2000; ZILLER, 2001), diminuindo sua biodiversidade e causando mudanças no seu funcionamento como: alterações no ciclo hidrológico, no regime de incêndio e nas características do solo (ZILLER, 2000; ZILLER, 2001; ANDRADE; FABRICANTE; OLIVEIRA, 2009; FABRICANTE et al., 2012). O estabelecimento e dispersão desses táxons é facilitado em ecossistemas que possuem alto grau de perturbação, com nichos vagos e baixa diversidade biológica (WILLIAMSON, 1996; ZILLER, 2000; ZILLER, 2001; ANDRADE; FABRICANTE et al., 2012).

Segundo a base de dados da I3N-Brasil (2020) existem 201 espécies de plantas exótica invasora no Brasil. Dentre essas espécies, este trabalho irá destacar duas herbáceas: Morrone, Cosmos caudatus Kunth e Megathyrsus maximus (Jacq.) B.K.Simon \& S.W.L.Jacobs e fazer o registro de uma nova espécie: Cenchrus polystachios (L.). 
A espécie Cenchrus polystachios (L.) Morrone, conhecida popularmente como capim-custodio ou capim-mandante, é uma Poaceae nativa da África, introduzida em alguns países devido ao seu potencial forrageiro ( $C A B I, 2020)$. Estudos desenvolvidos nas Austrália relatam que a espécie tem capacidade de intensificar incêndios e de competir por água e nutrientes com outras espécies (PANTON, 1993; FAIZ, 1999). No Brasil não foram encontrados estudos sobre a ecologia de C. polystachios.

Já Cosmos caudatus Kunth., que apresenta o nome vernacular de cosmosselvagem, é uma Asteraceae nativa da América Central (CHAN; WONG; CHAN, 2016). Trata-se de uma planta anual, subarbustiva, introduzida em diversos países devido suas características ornamentais e aplicações medicinais e alimentícias (MOSHAWIH et al., 2017). No entanto, é considerada daninha em culturas agrícolas no Oeste da Índia e América Central (MANSFELD, 2001). No Brasil a espécie já foi observada nas Regiões Centro-Oeste, Nordeste e Sudeste (MONDIN, 2020), contudo, esse é o primeiro registro da espécie no Estado de Sergipe.

Por fim a espécie Megathyrsus maximus (Jacq.) B.K.Simon \& S.W.L.Jacobs. conhecida popularmente como capim-colonião ou capim-mombaça, é uma Poaceae nativa da África. M. maximus foi introduzida no Brasil com o intuito de servir de alimento para os animais (FERREIRA; MAIA-BARBOSA, 2014; SCIAMARELLI; GUGLIERI-CAPORAL; CAPORAL, 2013), mas vem apresentando comportamento invasor, formando densas populações que dificultam o recrutamento e estabelecimento de outas espécies (FERREIRA; MAIA-BARBOSA, 2014).

Diante dos fatos mencionados e da falta de estudos sobre a estrutura populacional dessas espécies, o presente trabalho teve como objetivo avaliar esse aspecto para as exóticas invasoras C. polystachios, C. caudatus e M. maximus no munícipio de Itabaiana, Sergipe.

\section{MATERIAIS E MÉTODOS}

\section{1 ÁREA DE ESTUDO}

Os sítios estudados (Figura 1) se localizavam em Itabaiana, SE. O município se encontra numa região de transição entre Mata Atlântica e a Caatinga (DANTAS et al., 2010). O clima regional é do tipo As' (Tropical com verão seco e moderado e inverno chuvoso), 
segundo a classificação de Köeppen-Geiger, a precipitação varia de 1.100 a $1.300 \mathrm{~mm}$ por ano (DANTAS; RIBEIRO, 2010), com uma evapotranspiração de 800mm (VICENTE, 1999). Os solos predominantes são os neossolos litólicos distróficos.

Destaca-se que as espécies $C$. caudatus e $C$. polystachios foram estudadas em sítios situados dentro dos limites do Parque Nacional Serra de Itabaiana (PARNASI), importante unidade de conservação brasileira.

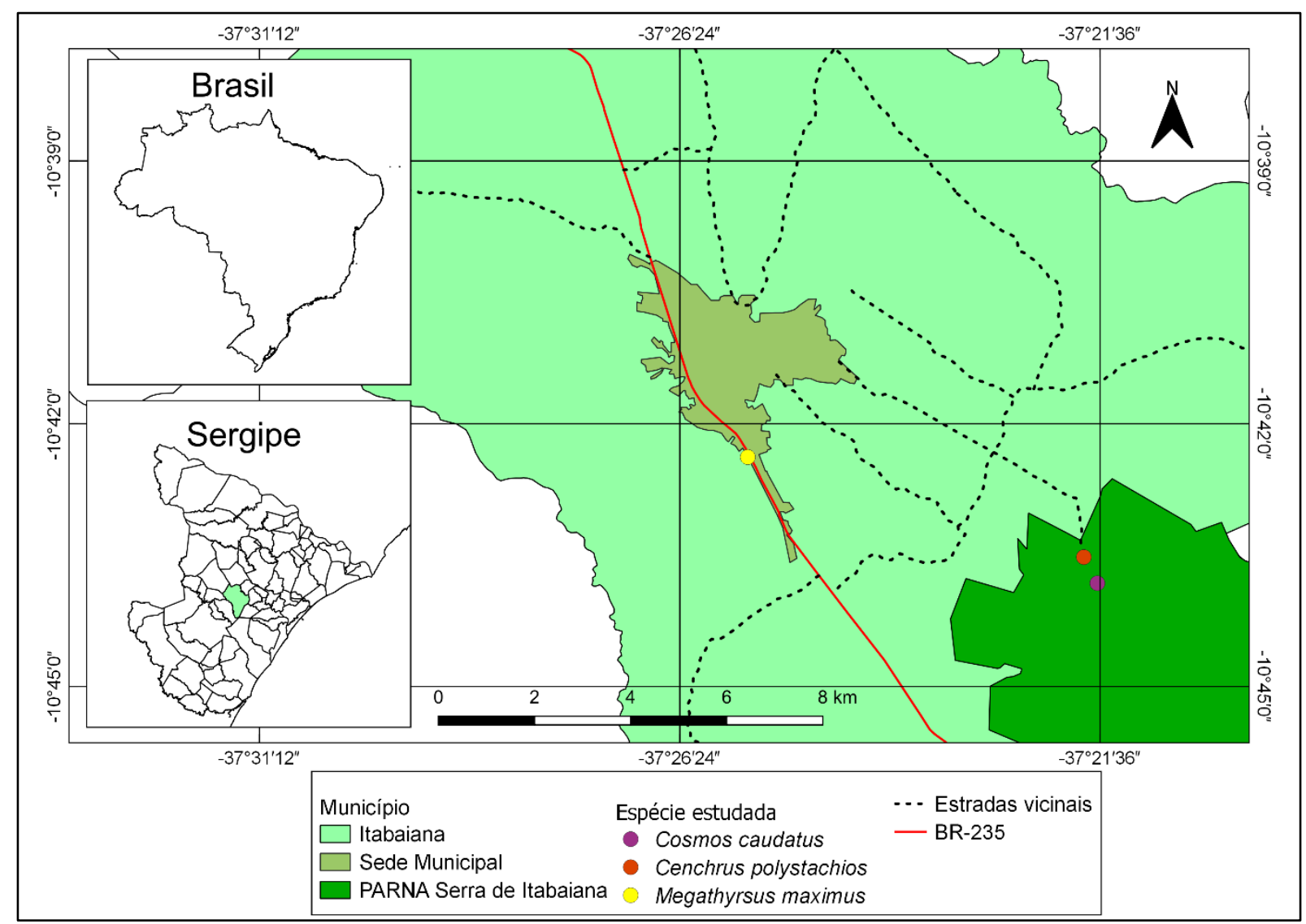

Figura 1. Pontos de localização das populações estudadas de três exóticas invasoras no munícipio de Itabaiana, Sergipe, Brasil.

\subsection{COLETA E ANÁLISE DE DADOS}

Para cada espécie foram plotadas 20 parcelas de $1 \mathrm{~m}^{2}$ onde todos os indivíduos presentes no interior das unidades amostrais foram contabilizados e tiveram seus diâmetros a altura do solo (DAS) aferidos por meio de um paquímetro. Os indivíduos ainda foram classificados quanto ao seu estádio ontogenético em adultos (quando havia a presença ou 
resquício de material reprodutivo) e regenerantes (quando os órgãos reprodutores estivessem ausentes) (FABRICANTE; OLIVEIRA; SIQUEIRA-FILHO, 2013; FABRICANTE et al., 2015).

Com os dados obtidos foram calculados os valores de densidade total, densidade dos regenerantes e densidade dos adultos (RECHENMACHER; SCHMITT; BUDKE, 2007), e o Índice de Dispersão Espacial de Morisita (Id) para as três situações (Id total, Id regenerantes e Id adultos), onde valores superiores, iguais ou inferiores a 1 indicam respectivamente dispersão agregada, uniforme e aleatória (MORISITA, 1959, 1962; PAESDANTAS; RIBEIRO, 2010). A correlação entre os estádios ontogenéticos, foi avaliada pelo Índice de Correlação Linear de Pearson (RODGERS; NICEWANDER, 1988; LIRA; NETO, 2006; FABRICANTE et al., 2009; JYOTHI et al., 2015). Essas análises foram realizadas utilizando os softwares BioEstat 5.0 e Microsoft Excel (AYRES et al. 2007; MATIELO et al., 2016).

Ainda, os dados de diâmetro das populações de cada espécie foram utilizados para a construção de um gráfico de densidade estimada através da função geom_density(), que gera pequenas distribuições normais em cada ponto de dado construindo uma linha suavizada (WICKHAM, 2016). Para a geração do gráfico de densidade foi utilizado o pacote ggplot2 (WICKHAM, 2016) no software R (R CORE TEAM, 2020).

\section{RESULTADOS E DISCUSSÃO}

Para a espécie $C$. caudatus foram amostrados 342 indivíduos com densidade total de 17,1 ind. $\mathrm{m}^{2}$, densidade de adultos de $11,4 \mathrm{ind} / \mathrm{m}^{2}$ e $5,7 \mathrm{ind} / \mathrm{m}^{2}$ para a densidade de regenerantes. Já $M$. maximus obteve valores de densidade total de $16,6 \mathrm{ind} / \mathrm{m}^{2}$, densidade de adultos $11,6 \mathrm{ind} / \mathrm{m}^{2}$ e $5 \mathrm{ind} / \mathrm{m}$ para densidade de regenerantes e a espécie $C$. polystachios obteve valores de $7,85 \mathrm{ind} / \mathrm{m}^{2}$ para a densidade total,3,6 ind $/ \mathrm{m}^{2}$ para a densidade de adultos e 4,25 ind/ $\mathrm{m}^{2}$ para a densidade de regenerantes (Tabela 1 ).

As densidades obtidas no presente estudo foram maiores que as apresentadas por outras exóticas invasoras herbáceas, a exemplo de Cenchrus ciliares L. (ARAÚJO et al., 2013a), Cenchrus echinatus L. (ARAÚJO et al., 2013b) e Sorghum arundinaceum (Desv.) Stapf (SILVA et al., 2013). Altas densidades parecem ser uma característica comum entre muitas espécies exóticas invasoras (ANDRADE et al., 2009; BOURSCHEID; REIS, 2010; 
FABRICANTE et al., 2012). Esses resultados podem ser explicados pelos atributos intrínsecos dessas espécies como a maturação precoce e produção de grandes quantidades de sementes durante praticamente todo o ano (ZILLER, 2001). Outro aspecto que pode explicar essa alta densidade é a dispersão das espécies, associada à grande longevidade das sementes (SILVA, 1969; SOUZA; GANDOLF; RODRIGUES, 2017) possibilitando que a espécie forme densas populações em sítios favoráveis (MEDEIROS; FOCHT, 2007).

Associado a isso, as condições ambientais de degradação e antropização onde as espécies ocorrem contribuem para as altas densidades, segundo Williamson (1996), exóticas invasoras tendem a ter sua dispersão e estabilidade facilitada em ambientes degradados e antropizados, uma vez que estes formam nichos vagos.

Com relação ao índice de dispersão espacial (Id) os valores da espécie $C$. caudatus foi de 1,76 para a população total, 1,29 para adultos e 9,42 para regenerantes. Já para $C$. echinatus foi de 1,18 para a população total, 1,12 para os adultos e 1,45 para regenerantes. Enquanto aos valores de M. maximus foram 1,19 no total, 1,24 para adultos e 1,23 para regenerantes (Tabela 1), todas as dispersões obtiveram valores superiores à 1 , indicando dispersão agregada para todos os casos (MORISITA, 1959, 1962), assim, todos os resultados demonstram existir convergência atrativa em sítios específicos (SILVA, 1991).

Esse tipo de dispersão espacial está de acordo com o modelo proposto por Janzen (1970) em que a proximidade com a planta-mãe favorece a taxa de recrutamento de indivíduos regenerantes. Nota-se ainda, que para os regenerantes nas espécies $M$. maximus e $\mathrm{C}$. caudatus, os valores do Id foram superiores ao dos adultos, isso demonstra que os indivíduos regenerantes tendem a se agruparem com mais intensidade que os indivíduos adultos (HUTCHINGS, 1996). O padrão de dispersão da espécie é determinado por ações bióticas e abióticas (LEITE, 2001), uma das condições abióticas, é a convergência atrativa das espécies à sítios que apresentam ótimas condições para 0 desenvolvimento das espécies, promovendo uma distribuição agregada (BEGON; HARPER; TOWNSEND, 1990).

Além disso, segundo Nasi (1993), espécies pioneiras e que ocorrem em ambientes antropizados, como no caso das exóticas invasoras, são agressivas e adaptadas a diversas condições ecológicas, endendo a formar agregados populacionais. Um outro fator que influência na distribuição agregada é o fato das espécies do presente estudo serem autocóricas e zoocóricas (GALLAGHER et al., 2012; CABI, 2020), já que os diásporos são 
liberados próximo a planta mãe ou carregados por animais e depositado em locais onde os animais permanecem mais tempo (NEGRINI et al., 2012).

Tabela 1. Valores de densidade e do Índice de dispersão espacial de Morisita para as espécies Cosmos caudatus, Cenchrus echinatus e Megathyrsus maximus, munícipio de Itabaiana, Sergipe, Brasil.

\begin{tabular}{lcccccc}
\hline \multicolumn{1}{c}{ Espécie } & DT & DA & DR & IdT & IdA & IdR \\
\hline Cosmos caudatus Kunth & 17,1 & 11,4 & 5,7 & 1,76 & 1,29 & 9,42 \\
Cenchrus polystachios (L.) Morrone & 7,85 & 3,6 & 4,25 & 1,19 & 1,24 & 1,23 \\
Megathyrsus maximus (Jacq.) B.K.Simon \& & 16,6 & 11,6 & 5 & 1,18 & 1,12 & 1,45 \\
S.W.L.Jacobs. & & & & &
\end{tabular}

DT - Densidade da população total (ind. $m^{2}$ ); DA - Densidade dos adultos (ind. $m^{2}$ ); DR - Densidade dos regenerantes (ind. $\mathrm{m}^{2}$ ); IdT - Índice de dispersão para a população total; IdA - Índice de dispersão para adultos; IdR - Índice de dispersão para regenerantes.

A espécie $M$. maximus apresentou correlação positiva e significativa entre os estádios ontogenéticos $(P=0,557, t=28,453, p=0,0107)$, indicando que a medida que há um aumento na densidade de um estágio há um aumento no outro. Já para as demais espécies, os resultados não foram significativos, sendo a correlação positiva em $C$. polystachios $(P=0,3056, t=13,618, p=0,19)$ e negativa em $C$. caudatus $(P=-0,3684, t=$ $-16,814, p=0,1099)$.

A correlação positiva entre os estágios ontogenéticos de $M$. maximus indica uma população "density-dependent" (HUTCHINGS, 1996), como o resultado encontrado por Fabricante et al. (2009) com a espécie pioneira Caesalpinia pyramidalis Tul. Em ambos os casos a densidade das plântulas da estão positivamente correlacionados à densidade de adultos, gerando uma maior taxa de sobrevivência de regenerantes próximos à adultos (HUTCHINGS, 1996).

$\mathrm{Na}$ representação gráfica das classes diamétricas, os resultados foram similares para as três espécies (Figura 2). Todas as espécies possuíram mais indivíduos em classes diamétricas menores e uma tendência decrescente na quantidade de indivíduos com maiores diâmetros, formando deste modo curvas do tipo "J-invertido". 


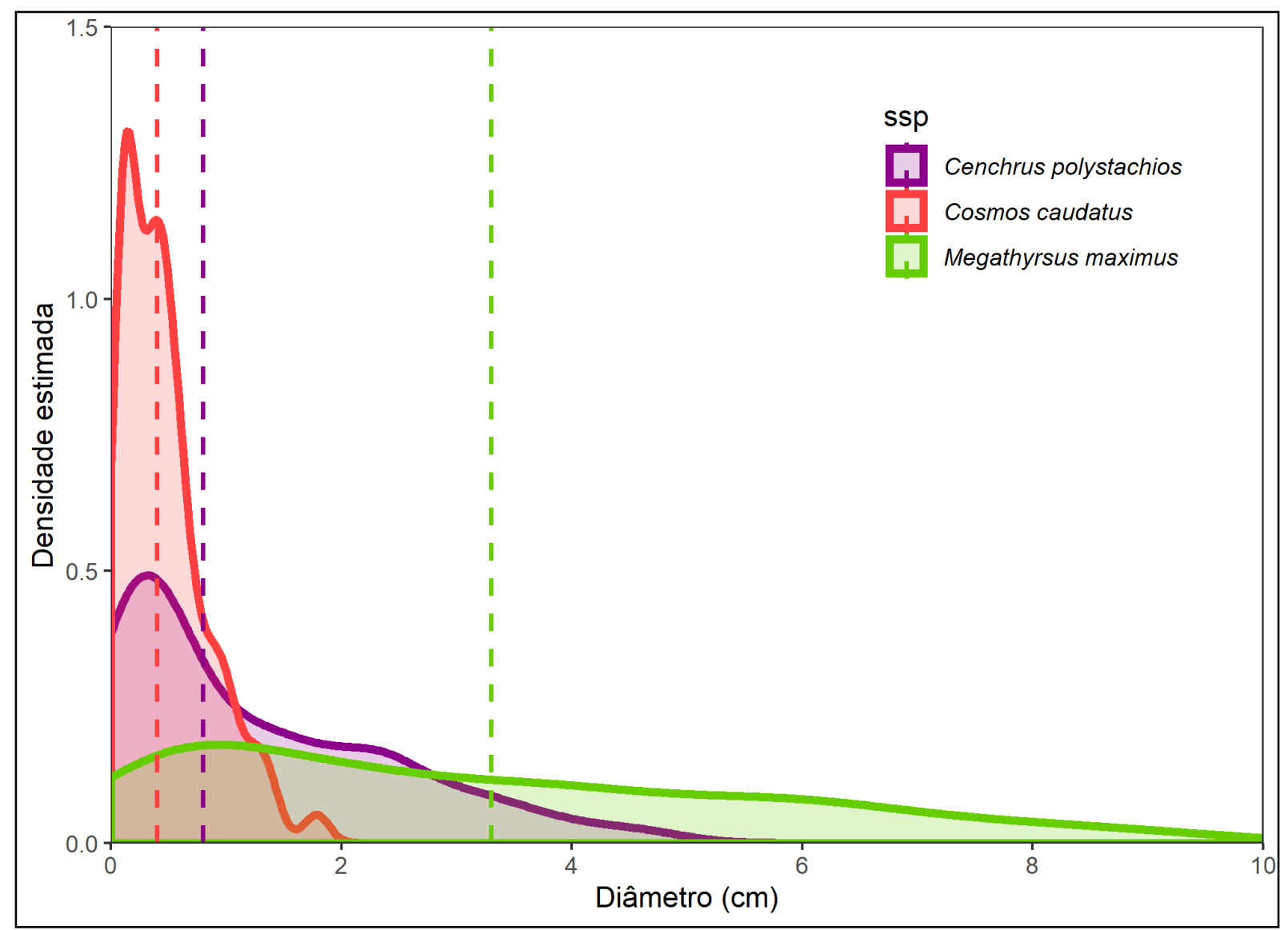

Figura 2. Gráfico de densidade estimada da frequência de diâmetro nas populações de três espécies exóticas invasoras no município de Itabaiana, Sergipe, Brasil. Legenda: Linhas tracejadas indicam a média dos valores de diâmetro da espécie de cor correspondente.

O padrão de "J-invertido" observado indica que à medida que ocorre um aumento no diâmetro dos indivíduos, ocorre uma diminuição na abundancia, ou seja, existem mais indivíduos jovens. Em adição, esse padrão demonstra que a população está estável e apresenta potencial regenerativo constante (AGREN; ZARACKINSON, 1990; SILVERTOWN, 1987). Essa estabilidade populacional ocorre devido às condições favoráveis que as espécies encontraram para seu estabelecimento e permanência, como ausência de predadores, vantagens na competição e reprodução rápida com alta produção e longevidade de sementes (SILVA, 1969; ZILLER, 2001).

\section{CONCLUSÃO}

Os resultados apresentados demonstram claramente que as espécies alóctones estudadas estão estabilizadas, com populações auto regenerantes e formando maciços populacionais que provavelmente estão causando problemas à comunidade de espécies 
nativas e sucessão ecológica. Diante da atual situação, estudos de comunidade para a compreensão dos impactos dessas espécies e a erradicação das mesmas tornam-se ações urgentes para a recuperação das áreas estudadas.

\section{REFERÊNCIAS}

ANDRADE, L.A.; FABRICANTE, J.R.; OLIVEIRA, F.X. Invasão biológica por Prosopis julifI ora (Sw.) DC.: impactos sobre a diversidade e a estrutura do componente arbustivo-arbóreo da caatinga no estado do Rio Grande do Norte, Brasil. Acta Botânica Brasilica., v. 23, n. 4, p. 935-943, 2009.

ANDRADE, L.A.; FABRICANTE, J.R.; OLIVEIRA, F.X. Impactos da invasão de Prosopis juliflora (sw.) DC.(Fabaceae) sobre o estrato arbustivo-arbóreo em áreas de Caatinga no Estado da Paraíba, Brasil. Acta Scientiarum. Biological Sciences., v. 32, n. 3, p. 249255, 2010.

ARAÚJO, K.C.T.; FABRICANTE, J.R.; CASTRO, R.A.; FURTADO, M.D.G.; SIQUEIRAFILHO, J.A. Plantas Exóticas e Exóticas Invasoras da Caatinga. In: Fabricante, J.R. Cenchrus echinatus L. Editora Bookess. p. 20-27, 2013.

ARAÚJO, K.C.T.; FABRICANTE, J.R.; CASTRO, R.A.; SIQUEIRA-FILHO, J.A. Plantas Exóticas e Exóticas Invasoras da Caatinga. In: Fabricante, J.R. Cenchrus ciliares L. Editora Bookess. p. 37-43, 2013.

AYRES, M.; AYRES, M.J.; AYRES, D.L. \& SANTOS, S.A. Bioestat 5.0: aplicações estatísticas nas áreas das Ciências Biomédicas. Belém, Mamirauá/CNPq., 2007.

BEGON, M; HARPER, J. L.; TOWNSEND, C. R. Ecology. Individuals, Populations and Communities. Victoria: Blackwell Sci. p. 886, 1990.

BELLARD, C.; CASSEY, P.; BLACKBURN, T.M. Alien species as a driver of recent extinctions. Biology letters., v. 12, n. 2, p. 1-4, 2016.

BOURSCHEID, K.; REIS, A. Dinâmica da invasão de Pinus elliottii Engelm. em restinga sob processo de restauração ambiental no Parque Florestal do Rio Vermelho, Florianópolis, SC. Biotemas., v. 23, n. 3, p. 23-30, 2010.

CABI. Invasive Species Compedium. Disponível em: < https://www.cabi.org/isc/>. Acesso em: 30/01/2020.

CARVALHO, F. A.; JACOBISON T. K. B. Invasão de plantas daninhas no Brasil - uma abordagem ecológica. Anais do Simpósio brasileiro sobre espécies exóticas invasoras. Brasília: MMA; 2005.

CHAN, E.W.C.; WONG, S.K.; CHAN, H.T. Ulam Herbs of Oenanthe Javanica and Cosmos caudatus: An Overview on their Medicinal properties. Journal of Natural Remedies. v. 16; n. 4, p. 137-147, 2016.

CRAWLEY, M.J. Plant Ecology. Oxford: Blackwell Scientific Publications, 1986. 
DANTAS, T.V.P.; NASCIMENTO-JÚNIOR, J.E.; RIBEIRO, A.S.; PRATA, A.P.N. Florística e estrutura da vegetação arbustivo-arbórea das Areias Brancas do Parque Nacional Serra de Itabaiana/Sergipe, Brasil. Revista Brasil. Bot., v. 33, n. 4, p. 575-588, 2010.

DANTAS, T.V.P.; RIBEIRO, A.S. Caracterização da Vegetação no Parque Nacional Serra de Itabaiana, Sergipe - Brasil. Biotemas, Vol. 23, n4, p. 9-18, 2010.

DAVY, A.J.; HUTCHINGS. M.J.; WATKINSON, A.R. Plant population ecology. Londres: Blackwell Scientific Publications. p. 478, 1988.

DIAS, J.; SURIAN, T.; MANTOANI, M.C.; PEREIRA, L.C.S.M.; TOREZAN, J.M.D. Crescimento de Megathyrsus maximus (Capim-colonião) e duas espécies nativas arbóreas em diferentes condições ambientais. Revista floresta., v. 46, n. 3, p. 325- 333, 2016.

FABRICANTE, J.R.; CASTRO, R.A.; ARAÚJO, K.C.T.; SIQUEIRA-FILHO, J.A. Atributos ecológicos da bioinvasora Nicotiana glauca Graham (Solanaceae) e avaliação da susceptibilidade de sua ocorrência no Brasil. Ciência Florestal., v. 25, n. 4, p. 959-967, 2015.

FABRICANTE, J.R.; ARAÚJO, K.C.T.; ANDRADE, L.A.; FERREIRA, J.V.A. Invasão biológica de Artocarpus heterophyllus Lam. (Moraceae) em um fragmento de Mata Atlântica no Nordeste do Brasil: impactos sobre a fitodiversidade e os solos dos sítios invadidos. Acta Botânica Brasilica., v. 26, n. 2, p. 399-407, 2012.

FABRICANTE, J.R.; ARAÚJO, K.C.T.; ANDRADE, L.A.; FERREIRA, J.V.A. Invasão biológica de Artocarpus heterophyllus Lam. (Moraceae) em um fragmento de Mata Atlântica no Nordeste do Brasil: impactos sobre a fitodiversidade e os solos dos sítios invadidos. Acta Botânica Brasilica., v. 26, n. 2, p. 399-407, 2012.

FABRICANTE, J.R.; FEITOSA, S.S.; BEZERRA, F.T.C.; FEITOSA, R.C.; XAVIER, R.F. Análise populacional de Caesalpinia pyramidalis Tul. (Fabaceae Lindl.) na caatinga da região do Seridó nordestino. Revista Brasileira de Biociências. v. 7, n. 3, p. 285-290, 2009.

FABRICANTE, J.R.; OLIVEIRA, M.N.A.; SIQUEIRA-FILHO, J.A. Aspectos da ecologia de Calotropis procera (Apocynaceae) em uma área de Caatinga alterada pelas obras do Projeto de Integração do Rio São Francisco em Mauriti, CE. Rodriguésia, v. 64, n. 3, p. 647-654, 2013.

FAIZ, M.A.A. Effects of Herbicides on Seed Germination and Control of Pennisetum polystachion (L.) Schult. Journal of Rubber Research, v. 2, n. 2, 1999.

FERREIRA, M.T.S.; MAIA-BARBOSA, P.M. O fogo como facilitador da invasão biológica por Megathyrsus maximus (Poaceae: Panicoideae) na Terra Indígena Maxakali (MG): propostas para um manejo agroecológico integrado e adaptativo. Biodiversidade Brasileira., v. 3, n. 2, p. 159-174, 2014.

Gallagher, R.V.; Duursma, D.E.; O'Donnell, J.; Wilson, P.D.; Downey, P.O.; Hughes, L.; Leishman, M.R. The grass may not always be greener: projected reductions in climatic suitability for exotic grasses under future climates in Australia. Biological Invasions, v. 15, n. 5, p. 961-975, 2013.

HARPER, J. L. Population biology of plants. Londres: Academic Press. p. 892, 1977.

HUTCHINGS, M.J. The structure of plant population. In: Crawley, M.J. Plant Ecology. Blackwell Scientific Publ., Oxford., 1996. 
I3N-Brasil. Espécies. Disponível em: <http://bd.institutohorus.org.br/www>. Acesso em: 29/01/2020

ICMBIO. Parna Serra de Itabaiana- Ministério do Meio Ambiente. Disponível em: $<w w w . i c m b i o . g o v . b r>$. Acesso em: 29/01/2020.

JANZEN, D.H. Herbivores and the number of tree species in tropical forests. American Naturalist, v. 104, n. 940, p. 501-528, 1970.

JYOTHI, H.J.; VIDYADHAR, D.J.; MAHADEVA, A.; PHILIP, M.; PARMAR, S.K.; MANOHARI, S.G.; SHANKAR, S. K.; RAJU, T. R. E ALLADI, P. A. Aging causes morphological alterations in astrocytes and micróglia in human substantia nigra pars compacta. Elsevier., v. 36, n. 1, p. 3321-3333, 2015.

LEITE, E.J. Spatial distribution patterns of riverine Forest taxa in Brasília, Brazil. Forest Ecology and Management., v. 140, p. 257-264, 2001.

LIRA, S.A.; NETO, A.C. Coeficientes de correlação para variáveis ordinais e dicotômicas derivados do coeficiente linear de Pearson. Revista Recie., v. 15, n 1/2, p. 45-53, 2006.

LOPES, M.A. Population structure of Eschweilera coriacea (DC.) S. A. Mori in forest fragments in eastern Brazilian Amazonia. Revista Brasileira de Botânica., v. 30, n. 3, p. 509-519, 2007.

MANSFELD, R. Mansfeld's encyclopedia of agricultural and horticultural crops:(except ornamentals). Springer Science \& Business Media, 2001.

MATIELO, M.D.; SAUZA, T.B.; MENDONÇA P.P.; SELVATICI, P.D.C.; JUNIOR, L.P.G. A população do mexilhão Perna perna no costão rochoso de Piúma-ES, e sua utilidade para agricultura. Arquivo de Ciências do Mar., v. 49, n.1, p.38-42, 2016.

MEDEIROS, R.B.; FOCHT, T. Invasão, prevenção, controle e utilização do capim-annoni-2 (Eragrostis plana Nees) no Rio Grande do Sul, Brasil. Pesquisa Agropecuária Gaúcha., v.13, n.1-2, p.105-11, 2007.

MODRO, A.F.H.; MESSAGE, D.; LUZ, C.F.P.; MEIRA-NETO, J.A.A. Flora de importância polinífera para Apis mellifera (L.) na região de Viçosa, MG. Revista Árvore., v. 35, n. 5, p. 1145-1153, 2011.

MONDIN, C.A. Cosmos in Lista de Espécies da Flora do Brasil. Jardim Botânico do Rio de Janeiro. Disponível em: <http://floradobrasil.jbrj.gov.br/jabot/floradobrasil/FB114896>. Acesso em: 29/01/2020.

MOREIRA, H.D.C.; BRAGANÇA, H.B.N. Manual de identificação de plantas infestantes. FMC, SP, 326, 2011.

MORISITA, M. Measuring of the dispersion of individuals and analysis of the distributional patterns. Mem. Fac. Sci. Kyushu Univ. Ser. E., v. 2, n. 21, p. 5-23, 1959.

MORISITA, M. la-index, a measure of dispersion of individuals. Researches on population ecology. v. 4, n. 1, p. 1-7, 1962.

MOSHAWIH, S.; CHEEMA, M.; AHMAD, Z.; ZAKARIA, Z.A.; HAKIM, M.N.A comprehensive review on Cosmos caudatus (Ulam raja): pharmacology, ethnopharmacology, and phytochemistry. International Research Journal of Education and Sciences, v. 1, n. 1, 14-31, 2017. 
NASI, R. Analysis of the spatial structure of a rattan population in a mixed dipterocarp forest of Sabah (Malaysia). Acta oecologica, v. 34, n.1, p. 73-85, 1993.

Negrini, M.; Aguiar, M.D.D.; Vieira, C.T.; Silva, A.C.D.; Higuchi, P. Dispersão, distribuição espacial e estratificação vertical da comunidade arbórea em um fragmento florestal no Planalto Catarinense. Revista Árvore, v. 36, n. 5, p. 919-930, 2012.

NRCS. Pennisetum polystachion (L.) Schult. mission grass. Disponível em: <https://plants.sc.egov.usda.gov/core/profile?symbol=PEPO14>. Acesso em: 29/01/2020.

ODUM, E.P.; BARRETT, GW. Fundamentos de Ecologia. Tradução da 5. ed. Norte americana. São Paulo: Cengage Learning. 612p, 2007.

PAES-DANTAS, T.V.; RIBEIRO, A.S. Estrutura populacional de Kielmeyera rugosa Choisy (Clusiaceae) no Parque Nacional Serra de Itabaiana, Estado do Sergipe. Maringá, actascibiolsci; v. 32, n. 2, p. 141-146, 2010.

PANTON, W.J. Changes in post World War II distribution and status of monsoon rainforests in the Darwin area. The Australian Geographer., v. 24, n. 2, p. 50-59, 1993.

PERONI, N.; HERNÁNDEZ, M.I.M. Ecologia de populações e comunidades. Universidade Aberta do Brasil., p. 13-14, 2011.

PETERSON, G; ALLEN, C.R; HOLLING, C.S. Ecological resilience, biodiversity, and scale. Ecosystems., v. 1, n. 1, p. 6-18, 1998.

PRATA, A.P.N.; AMARAL, M.C.E.; FARIAS, M.C.V.; ALVEZ, M.V. Flora de Sergipe. Aracaju. Gráfica e Editora Triunfo., v.1, p.26, 2013.

PRIETO, R.O.; OLIVA, L.G. Lista nacional de plantas invasoras y potencialmente invasoras en la República de Cuba. Bissea., v. 9, n. 2, p. 1-8, 2015.

TEAM, R. C. A language and environment for statistical computing. Vienna, Austria: R Foundation for Statistical Computing; 2012. Disponível em: <https://www. R-project. org>. Acesso em: 29/01/2020.

TOWNSEND C.R.; BEGON M.; HARPER J.P. Fundamentos em Ecologia. Editora ARTMED, Porto Alegre 2 ed, 2006.

RECHENMACHER, C.; SCHMITT, J.L.; BUDKE, J.C. Estrutura e distribuição espacial de uma população de Blechnum tabulare (thunb.) kuhn (Pteridophyta, blechnaceae) em um mosaico floresta-campo no Sul do Brasil. Pesquisas, Botânica., n. 58, p.177-186, 2007.

REFLORA. Megathyrsus maximus. Disponível em: $<$ http://reflora.jbrj.gov.br/reflora/floradobrasil/FB86869>. Acesso em: 29/01/2020.

RODGERS, J.L.; NICEWANDER, W.A. Thirteen ways to look at the correlation coefficient. The American Statistician., v. 42, n. 1, p. 59-66, 1988.

ROSA D.M.; FORTES, A.M.T.; MAULI, M.M.; MARQUES, D.S.; PALMA, D. Potencial Alelopático de Panicum maximum JACQ sobre a Germinação de Sementes de Espécies Nativas. Floresta e Ambiente., v. 18 n. 2, p. 198-203, 2011.

SCIAMARELLI, A.; GUGLIERI-CAPORAL, A.; CAPORAL, F.J.M. Variação temporal de dados espectrais na elaboração de modelos de distribuição potencial geográfica de gramíneas invasoras "capim-bermuda”,"capim-jaraguá" e "capim-colonião" em Mato Grosso do Sul, Brasil. XVI Simpósio Brasileiro de Sensoriamento Remoto., p. 2735, 2013. 
SILVA, D.M. Estrutura de tamanho e padrão espacial de uma população de Esterpe edulis Mart. (Arecaceae) em mata mesofila semidecidua no municipio de Campinas. (Dissertação) Mestrado em Biologia Vegetal - Universidade Federal de Campinas, 1991.

SILVA, H.A.; REIS, L.B.O.; ALVES, J.S.; FABRICANTE, J.R. Plantas Exóticas e Exóticas Invasoras da Caatinga. In: Fabricante, J.R. Sorghum arundinaceum (Desv.) Stapf. Editora Bookess. p. 35-42, 2013.

SILVA, S.A.F. Contribuição ao estudo do "capim-colonião" (Panicum maximum Jacq. var. maximum). II - Considerações sobre sua dispersão e seu controle. Vellozia., Rio de Janeiro, v. 7, p. 3-21, 1969.

SOUZA, S.C.P.M.; GANDOLF, S.; RODRIGUES, R.R. A influência da cobertura vegetal e da distância do remanescente florestal no processo de regeneração natural na Floresta Ombrófila Densa Montana. Hoehnea, v. 45, n. 1, p. 55-68, 2017.

VICENTE, A.; ARAÚJO, G.M.M.; LÍRIO, G.P.; SANTOS, S.C. Descrição parcial e preliminar dos hábitats da Serra de Itabaiana, Sergipe. Publicações Avulsas do Centro Acadêmico Livre de Biologia - Universidade Federal de Sergipe, n. 1, p.23-27, 1997.

WICKHAM, Hadley. ggplot2: elegant graphics for data analysis. Springer, 2016.

WILLIAMSON, M. Biological Invasions. London: Chapman e Hall., 1996.

YODZIS, P. Lecture Notes in Biomathematics Competition for Space and the Structure. Springer Verlag., 1978.

ZILLER, S.R. A estepe gramíneo-lenhosa no segundo planalto do paraná: Diagnostico ambiental com enfoque à contaminação biológica. (Tese) Doutorado em Engenharia Florestal - Universidade Federal do Paraná, Curitiba, 2000.

ZILLER, S.R. Plantas exóticas invasoras: a ameaça da contaminação biológica. Ciência hoje., v. 30, n.1, p.77-79, 2001.

ZILLER, S.R. Os processos de degradação ambiental originados por plantas exóticas invasoras. Ciência hoje, v.30, n.178, 2001. 


\title{
CAPÍTULO 10
}

\section{AGRODIVERSIDADE FLORÍSTICA EM QUINTAIS URBANOS DE ITACOATIARA, ESTADO DO AMAZONAS}

\author{
Luís Enrique Gainette Prates ${ }^{1}$
}

1. Universidade do Estado do Amazonas (UEA), Centro de Estudos Superiores de Itacoatiara (CESIT), Itacoatiara, Amazonas, Brasil.

\section{RESUMO}

Os quintais urbanos são fontes de uma gama de plantas que podem ser alternativas à suplementação alimentar de populações das cidades da Amazônia. O objetivo do trabalho fo investigar a ocorrência de árvores frutíferas em quintais urbanos de Itacoatiara, Estado do Amazonas. Foram inventariadas 356 residências em oito bairros: Iraci, São Francisco, Jauari I, Santa Luzia, Santo Antônio, São Cristovão, Colônia, Pedreiras. A coleta de dados ocorreu de outubro (2016) a maio (2017). Foram encontrados 6.887 indivíduos de 53 espécies (24 famílias). Das espécies encontradas, 28 são exóticas (52,8\%) e 25 são nativas $(47,2 \%)$. As espécies mais frequentes foram: mangueira (Mangifera indica L.) (148 residências), bananeira (Musa paradisiaca L.) (135), aceroleira (Malpighia glabra L.) (104), goiabeira (Psidium guajava L.) (96), mamoeiro (Carica papaya L.) (72). Já as espécies mais abundantes foram: bananeira (632 indivíduos), açaizeiro (Euterpe spp.) (534), cupuaçuzeiro (Theobroma grandiflorum K. Schum.) (210) e mangueira (210). As famílias taxonômicas com maior número de indivíduos foram Arecaceae (7) e Myrtaceae (5). O bairro São Cristovão (680) apresntou o maior número de árvores frutíferas, enquanto que Santo Antônio (189) teve a menor quantidade. O cultivo de frutíferas em quintais urbanos de Itacoatiara concentra a escolha em poucas espécies, tanto nativas quanto exóticas, com espécies frotemente associadas a usos tradicionais que tradicionalmente transitam intra e inter-regiões brasileiras.

Palavras-chave: Amazônia Ocidental, Silvicultura Urbana e Espécies Frutíferas.

\section{ABSTRACT}

The home gardens are sources of a range of plants that can be alternatives to food supplementation for populations in Amazonian cities. The objective of the work was to investigate the occurrence of fruit trees in urban yards in Itacoatiara, State of Amazonas. 356 homes were inventoried in eight neighborhoods: Iraci, São Francisco, Jauari I, Santa Luzia, Santo Antônio, São Cristovão, Colônia, Pedreiras. Data collection occurred from October (2016) to May (2017). 6,887 individuals of 53 species (24 families) were found. Of the species found, 28 are exotic $(52.8 \%)$ and 25 are native $(47.2 \%)$. The most frequent species were: mango (Mangifera indica L.) (148 residences), banana (Musa paradisiaca L.) (135), aceroleira (Malpighia glabra L.) (104), guava (Psidium guajava L.) (96), papaya (Carica papaya L.) (72). The most abundant species were: banana (632 individuals), açaizeiro (Euterpe spp.) (534), cupuaçuzeiro (Theobroma grandiflorum K. Schum.) (210) 
and mango (210). The taxonomic families with the largest number of individuals were Arecaceae (7) and Myrtaceae (5). The São Cristovão neighborhood (680) had the largest number of fruit trees, while Santo Antônio (189) had the lowest number. The cultivation of fruit trees in urban backyards in Itacoatiara concentrates the choice on a few species, both native and exotic, with species that are strongly associated with traditional uses that traditionally transit within and between Brazilian regions.

Keywords: Western Amazon, Urban Forestry and Fruit Species.

\section{INTRODUÇÃO}

Os quintais domésticos são sistemas agroflorestais caracterizados pela complexidade da estrutura e funções múltiplas que incluem ervas, arbustos e árvores situadas dentro de um limite residencial, envolvendo o manejo e o trabalho familiar (COOMES; BAN, 2004).

Outros termos podem ser utilizados para este espaço como home garden, huerto casero, sítio, pomar caseiro ou terreiro (MARTINS et al., 2003). Do ponto de vista cultural, a reunião de plantas e animais próximos de habitações humanas pode revelar muito da história cultural dos lugares e das decisões de manejo dos proprietários individuais (BLANCKAERT et al., 2004). De forma geral, podem satisfazer alguns requerimentos básicos de alimentação, medicamentos, construção e recreação (WINKLERPRINS, 2002), além de contribuir com a captação de carbono da atmosfera (ALBRECHT; KANDJI, 2003).

Em regiões tropicais, o cultivo de uma diversificada gama de plantas em quintais caseiros favorece a deposição de resíduos orgânicos e auxilia com a melhoria da qualidade do solo ao redor das moradias (PINHO et al., 2010). Nos trópicos, os quintais são encontrados em zonas rurais e urbanas, com a organização do seu espaço compreendendo as partes de trás, lateral e frontal da casa (MARTINS et al., 2003).

Na Amazônia, os quintais residenciais também têm grande importância tanto na vida rural como na urbana, expressando o contínuo rural-urbano (WINKLERPRINS, 2002). Este contínuo simboliza um intercâmbio de material genético que associa a diversidade contida nos ecossistemas naturais às tradições das populações humanas locais (CLEMENT et al., 2001), alcançando a vida urbana através da abertura de espaço na complementação alimentar dos habitantes das cidades (MARTINS, 1998).

Estudos que atentem para o entendimento do aproveitamento deste espaço como forma de subsídio de parte da vida urbana são ainda escassos e de pouca expressão na Amazônia. Entretanto, a FAO (2004) alerta que os pomares caseiros estão se 
transformando em uma importante fonte de alimento e renda em áreas urbanas, mitigando parcialmente a falta de alimentos das populações destes centros.

Este aspecto tem grande importância no Brasil, visto que a população brasileira vem se caracterizando por uma dieta com alto consumo de calorias e baixo aproveitamento de frutas e produtos hortícolas, destacadamente nos centros urbanos (LEVY-COSTA et al., 2005). Desta forma, os quintais domésticos urbanos podem assumir papeis importantes relacionados à segurança alimentar, melhorando a qualidade da alimentação nos centros urbanos através de fontes suplementares de vitaminas e carboidratos vegetais.

$\mathrm{Na}$ região amazônica, as adaptações das populações humanas em ambientes urbanos podem acarretar diferenças no uso destes recursos (MARTINS, 1998). Fatores como migração, incorporam uma bagagem cultural externa no uso dos recursos regionais, fazendo com que variedades não-existentes na localidade (exóticas) sejam incorporadas e/ou maximizadas aos hábitos locais. No sentido ampliar o entendimento acerca do uso dos quintais urbanos na Amazônia Central, este estudo teve por objetivo descrever a composição florística referente às espécies frutíferas cultivadas em quintais urbanos de Itacoatiara, Estado do Amazonas.

\section{MATERIAL E MÉTODOS}

\section{1 ÁREA DE ESTUDO}

O Estado do Amazonas é a maior unidade federativa do Brasil, possuindo $1.570 .745,680 \mathrm{~km}^{2}$. Segundo o IBGE (2016), sua população era de 3.994 .371 habitantes, distribuídos por 62 municípios. A maior parte da população está concentrada na Região Metropolitana de Manaus, onde residem cerca de 2.006.870 pessoas, representando uma taxa de urbanização de 62,3\% (BRASIL, 2009). A Região Metropolitana de Manaus foi criada pela Lei Complementar 52/2007 e abrange oito municípios (AMAZONAS, 2007): Manaus, Careiro da Várzea, Iranduba, Itacoatiara, Manacapuru, Novo Airão, Presidente Figueiredo, Rio Preto da Eva.

O município de Itacoatiara tem uma área de $8.891,903 \mathrm{~km}^{2}$ e uma população de 98.503 habitantes (IBGE, 2016). Está situado na porção Nordeste do Amazonas, limitandose com os municípios de Itapiranga, Silves, Urucurituba, Boa Vista do Ramos, Maués, Nova 
Olinda do Norte, Autazes, Careiro da Várzea, Manaus e Rio Preto da Eva (SILVA, 2003). A zona urbana do município está dividida em 24 bairros divididos em quatro zonas: norte, sul, leste, oeste.

\subsubsection{Coleta de Dados}

A coleta de dados ocorreu de setembro de 2016 a maio de 2017. Foram selecionados aleatoriamente oito bairros $(n=30 \%)$ que tinham tempo de existência superior a 15 anos, sendo dois bairros em cada zona da cidade: zona norte - bairro Iraci (37) e São Francisco (49); zona sul - Jauari I (47) e Santa Luzia (47); zona leste - Santo Antônio (40) e São Cristóvão (41); zona oeste - Colônia (38) e Pedreiras (47).

Para a coleta de dados, utilizou-se como técnica de pesquisa a entrevista com auxílio de questionário semiestruturado e a turnê guiada.

Reconheceu-se como quintal a área residencial formada por um ou mais espaços aos fundos, laterais e frente da área construída, além das cercanias, como muros e calçadas.

Foram anotados as espécies arbóreo-frutíferas e o número de indivíduos que cada espécie. A definição de árvore frutífera seguiu dois aspectos. O primeiro considerou as plantas de porte arbóreo ou similar; e o segundo levou em conta se a planta é tradicionalmente comestível pela população humana. Também foram consideradas os indivíduos sob domínio da residência, como as plantadas nas calçadas. Apenas os indivíduos com porte visível de produção frutífera foram contabilizados, descartando-se os juvenis.

A maioria das identificações taxonômicas foi feita através de conhecimento prévio do autor e por consulta à literatura (CAVALCANTE, 1991; SHANLEY et al., 1998; MIRANDA et al., 2001), pois quase todas as plantas observadas são de uso comum. Os nomes científicos das plantas e dos autores foram checados nos portais do Missouri Botanical Garden e Flora do Brasil 2020.

\subsubsection{Análise dos Dados}

Para cada bairro amostrado, foram verificadas a composição, riqueza e abundância das plantas observadas. A composição referiu-se à listagem geral das espécies e famílias botânicas encontradas com nome botânico. 
A riqueza foi medida a partir da soma do número de espécies e famílias botânicas. Associado a estes dados foi verificado a abundância total de indivíduos por bairro.

Para entender a preferência de cultivo das espécies nos quintais de cada bairro, foi gerado um índice de valor de preferência (IVP) para o total das espécies. Este índice é a soma relativizada da densidade de indivíduos (Den) com a frequência de ocorrência (Fre) das espécies por unidade amostral (IVP = \%Den + \%Fre) (SEMEDO; BARBOSA, 2007).

$O$ teste de normalidade foi aplicado em cada conjunto de dados para a verificação de distinções entre abundância de indivíduos, número de famílias, riqueza total e densidade média de espécies entre os bairros. Todos os testes foram realizados com o programa BioEstat 5.3.

\section{RESULTADOS E DISCUSSÃO}

Foram registrados 2.972 indivíduos de 53 espécies pertencentes a 24 famílias botânicas (tabela 1). Do total de espécies encontradas, 14 (26,4\%) eram comuns aos oito bairros, mostrando diferenças significativas entre o número de espécies presentes em cada bairro $\left(X^{2}=0,0217\right)$. Desta forma, os quintais dos bairros podem ser considerados heterogêneos quanto ao número de espécies.

Das espécies observadas, 28 são exóticas (52,8\%) e 25 são nativas da Amazônia $(47,2 \%)$.

Tabela 1. Famílias Botânicas, Espécies Frutíferas, Origem

\begin{tabular}{lll}
\hline Família & Nome Científico & Origem \\
\hline \multirow{4}{*}{ Anacardiaceae } & Anacardium occidentale L. & Nativa \\
& Spondias mombin L. & Nativa \\
& Spondias venulosa Engl. & Nativa \\
& Mangifera indica L. & Exótica \\
\hline \multirow{4}{*}{ Annonaceae } & Rollinia mucosa Bail., & Nativa \\
& Annona crassiflora Mart. & Nativa \\
& Annona squamosa L. & Exótica \\
& Annona muricata Vell. & Exótica \\
\hline Apocynaceae & Aspidosperma polyneuron Müll.Arg. & Nativa \\
\hline & Astrocaryum vulgare Mart. & Nativa \\
& Euterpe precatoria Mart. & Nativa \\
Arecaceae & Bactris gasipaes Kunth & Nativa \\
& Cocos nucifera L. & Exótica \\
& Euterpe oleracea Mart. & Nativa \\
& Mauritia flexuosa L.f. & Nativa
\end{tabular}


Oenocarpus bacaba Mart.

Nativa

\begin{tabular}{|c|c|c|}
\hline Bignoniaceae & Crescentia cujete L. & Exótica \\
\hline Bixaceae & Bixa orellana L. & Nativa \\
\hline Caricaceae & Carica papaya L. & Exótica \\
\hline Clusiaceae & Platonia insignis Mart. & Nativa \\
\hline Combretaceae & Terminalia catappa L. & Exótica \\
\hline \multirow{3}{*}{ Fabaceae } & Caesalpinia ferrea Mart. & Nativa \\
\hline & Inga edulis Mart. & Nativa \\
\hline & Tamarindus indica L. & Exótica \\
\hline Lamiacea & Vitex polygama Cham. & Nativa \\
\hline Lauraceae & Persea americana Mill. & Exótica \\
\hline Malpighiaceae & Malpighia glabra L. & Exótica \\
\hline \multirow{2}{*}{ Malvaceae } & Theobroma cacao L. & Exótica \\
\hline & Theobroma grandiflorum K.Schum. & Nativa \\
\hline \multirow{3}{*}{ Moraceae } & Artocarpus sp. & Exótica \\
\hline & Artocarpus heterophyllus Lam. & Exótica \\
\hline & Morus nigra L. & Exótica \\
\hline Musaceae & Musa paradisiaca L. & Exótica \\
\hline \multirow{5}{*}{ Myrtaceae } & Eugenia uniflora L. & Nativa \\
\hline & Plinia cauliflora (Mart.) Kausel & Nativa \\
\hline & Psidium guajava L. & Exótica \\
\hline & Syzygium jambos Alston & Nativa \\
\hline & Eugenia stipitata McVaugh & Exótica \\
\hline Oxalidaceae & Averrhoa carambola L. & Exótica \\
\hline Punicaceae & Punica granatum L. & Exótica \\
\hline \multirow{4}{*}{ Rubiaceae } & Alibertia edulis A.Rich. & Nativa \\
\hline & Genipa americana L. & Nativa \\
\hline & Coffea arabica L. & Exótica \\
\hline & Morinda citrifolia L. & Exótica \\
\hline \multirow{4}{*}{ Rutaceae } & Citrus aurantiifolia Swingle & Exótica \\
\hline & Citrus reticulata Blanco & Exótica \\
\hline & Citrus $x$ limon Osbeck & Exótica \\
\hline & Citrus $x$ sinensis Osbeck & Exótica \\
\hline \multirow{2}{*}{ Sapindaceae } & Nephelium lappaceum L. & Exótica \\
\hline & Talisia esculenta (Cambess.) Radlk. & Nativa \\
\hline \multirow{2}{*}{ Sapotaceae } & Manilkara zapota P. Royen & Exótica \\
\hline & Pouteria caimito Radlk. & Nativa \\
\hline Vitaceae & Vitis vinifera L. & Exótica \\
\hline
\end{tabular}

As famílias taxonômicas com maior número de espécies foram Arecaceae (7) e Myrtaceae (5). Já as espécies mais frequentes foram a mangueira (Mangifera indica L.) (148 residências), bananeira (Musa paradisiaca L.) (135), aceroleira (Malpighia glabra L.) (104), goiabeira (Psidium guajava L.) (96) e o mamoeiro (Carica papaya L.) (72) (figura 1). 


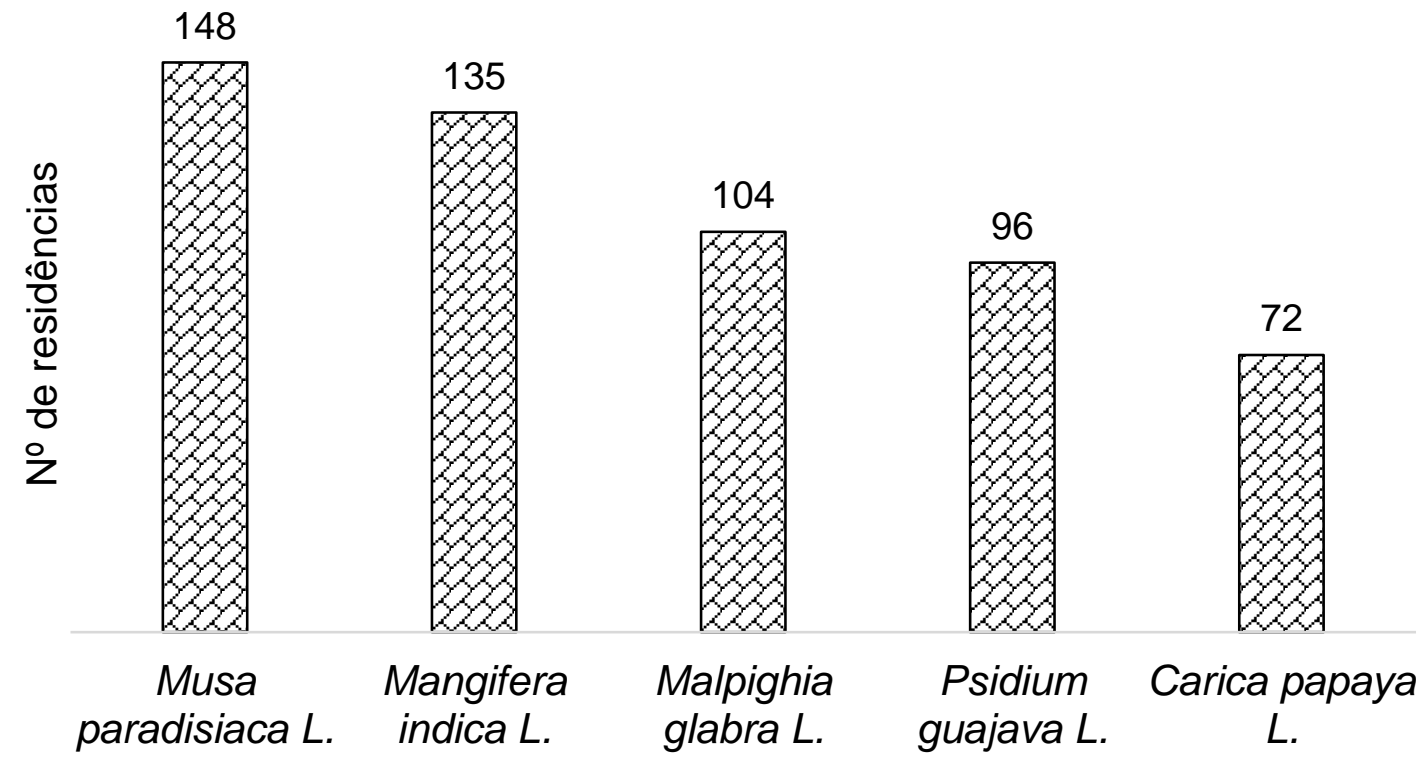

Figura 1. Espécies mais frequentes dentre os bairros estudados.

As espécies mais abundantes foram a bananeira (Musa paradisiaca L.), com 1714 indivíduos, representando $24,9 \%$ da abundância; o açaizeiro-do-pará (Euterpe oleraceae Mart.), com 1109 indivíduos e 16,1\% da abundância; e a mangueira (Mangifera indica L.), com 402 indivíduos e 5,8\% da abundância (figura 2).

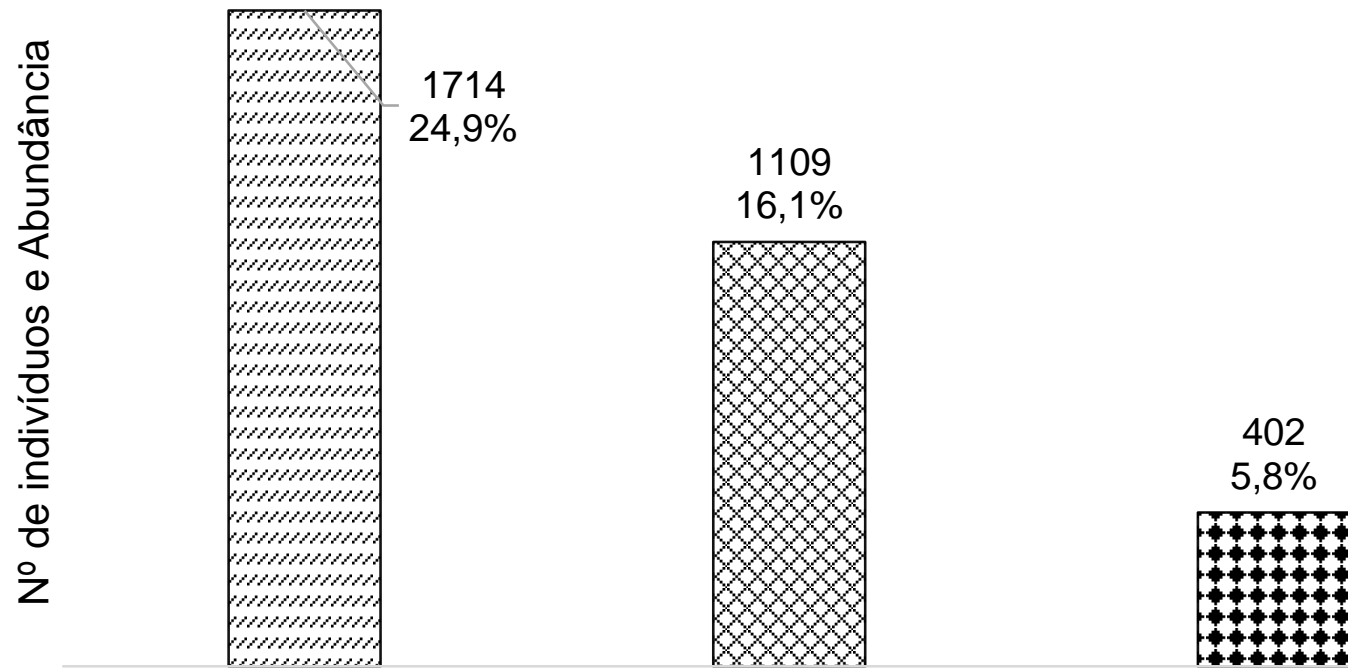

Musa paradisiaca L. $\quad$ Euterpe oleraceae Mart. Mangifera indica $L$.

Figura 2. Espécies mais abundantes dentre os bairros estudados. 
O bairro São Cristovão (680) apresntou o maior número de árvores frutíferas, enquanto que Santo Antônio (189) teve a menor quantidade.

As espécies frutíferas exclusivas de apenas um bairro foram pitombeira (Talisia esculenta Radlk.) (Colônia), sirigueleira (Spondias purpurea L.) (Colônia), buritizeiro (Mauritia flexuosa L.f.) (São Cristóvão), cafeeiro (Coffea arabica L.) (São Cristóvão), jucazeiro (Caesalpinia ferrea Mart.) (São Cristóvão), videira (Vitis vinifera L.) (São Cristóvão), perobeira (Aspidosperma polyneuron Müll. Arg.) (Santa Luzia), araticunzeiro (Annona crassiflora Mart.) (Iraci), araçazeiro (Eugenia stipitata McVaugh) (Jauari I), açaizeiro-do-pará (Euterpe oleracea Mart.) (Pedreiras), romãzeiro (Punica granatum L.) (Santo Antônio).

Os maiores IVP foram anotados para Mangifera indica L. (22,4\%); Musa paradisiaca L. (19,6\%) e Malpighia glabra L. (14,4\%). Todas estas espécies são exóticas da Amazônia e somam conjuntamente $56,4 \%$ do IVP. Estas espécies fazem parte da lista das principais espécies citadas por Martins et al. (2003) para um bairro de Manaus (AM), por Siviero et al. (2011) em Rio Branco (AC) e por Semedo e Barbosa (2007) para bairros de Boa Vista (RR). Algumas destas frutas arbóreo-arbustivas são domesticadas há séculos e foram introduzidas desde a época dos grandes descobrimentos. Possuem baixo custo em seu manejo diário, alta produção de frutos e baixo custo de insumos. Portanto, se tornam atrativas em termos de uso preferencial doméstico em relação a espécies tipicamente amazônicas.

Smith et al. (2006) indicaram que a grande riqueza observada em áreas residenciais urbanas é atribuída à forte predominância do grupo de espécies exóticas. Esta observação também é comum em outras regiões do Brasil. Em quintais urbanos do Pantanal de Mato Grosso (CARNIELLO et al., 2010) e os caiçaras da Mata Atlântica (HANAZAKI et al., 2000), que se utilizam majoritariamente de plantas exóticas em detrimento das nativas.

Com relação à Amazônia, este estudo confirma que a maior parte de frutíferas cultivadas e consumidas pela população urbana de Itacoatiara tem preferência por espécies exóticas, como havia sido detectado para o grupo das plantas arbóreas frutíferas por Semedo e Barbosa (2007), concordando com o padrão observado em outras cidades da região amazônica, como Belém (MADALENO, 2000), Santarém (WINKLERPRINS, 2002), Manaus (MARTINS et al., 2003), Rio Branco (SIVIERO et al., 2011) e Boa Vista (SEMEDO; BARBOSA, 2007; BATISTA; BARBOSA, 2014). 
Na maioria das vezes, a escolha pelo cultivo de plantas exóticas está relacionada à sua longa domesticação temporal que pode estar associada à maior facilidade de manejo, sabor e beleza.

Os resultados do presente estudo diferem do padrão encontrado por Costa e Mitja (2010) em quintais de zonas rurais florestais amazônicas, em que havia o predomínio de espécies nativas.

Plantas comestíveis são muito comuns nos quintais urbanos da Amazônia, além de abundantemente observadas nas zonas rurais (LOURENÇO et al., 2009) e são encontradas em grande número em diferentes condições socioeconômicas urbanas (SIVIERO et al., 2011). Por outro lado, Winklerprins (2002) registrou a predominância de plantas medicinais em Santarém, revelando uma configuração mais farmacêutica para aqueles quintais". "O uso destas plantas é muito dependente da bagagem de conhecimento tradicional que, em geral, é dominado por mulheres com mais idade (VOEKS, 2007).

Também chamou atenção como os quintais têm perdido espaço para a área construída da residência, principalmente no bairro Santo Antônio, pois em alguns locais que as frutíferas foram observadas, estas se limitavam a poucos indivíduos, considerando, sobretudo, a falta de espaço livre para o cultivo de espécies arbóreas de grande porte.

Quando comparado com outros estudos, pode-se afirmar que os quintais urbanos de Itacoatiara possuem pequena riqueza de árvores frutíferas. Winklerprins (2002) contabilizou 98 espécies em 41 quintais (urbanos e rurais) de Santarém. Em outro estudo, Winklerprins e Souza (2005) indicaram um total de 182 espécies de plantas nos quintais de Santarém. Martins et al. (2003) contabilizaram 202 espécies distribuídas em 77 famílias em quintais do bairro Jorge Teixeira, da cidade de Manaus. Batista e Barbosa (2014) registraram 221 espécies pertencentes a 65 famílias botânicas nos quintais de Boa Vista. Oliveira (2015) registrou 297 espécies em três bairros de Manaus.

Uma explicação para a baixa riqueza de espécies pode ser a complementação da dieta alimentar, em que há o investimento no cultivo de poucas espécies, mas em grandes quantidades (p. ex. banana). Contudo, a diversificação produz melhores efeitos nutricionais do que o cultivo de uma grande quantidade de uma ou duas espécies (BATISTA; BARBOSA, 2014). 


\section{CONCLUSÃO}

O cultivo de frutíferas em quintais urbanos de Itacoatiara concentra a escolha em poucas espécies, tanto nativas quanto exóticas, com espécies que também estão presentes nas demais regiões brasileiras.

Os quintais urbanos dos bairros estudados podem ser considerados heterogêneos em função da sua área, mas não do seu tempo de formação; com os bairros maiores (Iraci e São Cristóvão) se constituindo em sistemas mais abundantes e ricos em relação aos menores bairros (Jauari I e Santo Antônio).

Os maiores índices de valor de preferência foram observados em plantas tradicionalmente utilizadas em diferentes partes da Amazônia, revelando um padrão preferencial que não se distancia dos demais quintais urbanos regionais, indicando que a agrobiodiversidade urbana de Itacoatiara está associada a usos tradicionais que transitam pelas regiões brasileiras.

O cultivo de árvores frutíferas nos quintais domésticos de Itacoatiara possivelmente esteja contribuindo com a suplementação alimentar da população de baixa renda familiar.

\section{AGRADECIMENTOS}

À Universidade do Estado do Amazonas pela concessão de gratificação produtividade que custeou os custos e a logística do projeto de pesquisa.

\section{REFERÊNCIAS}

ALBRECHT, A.; KANDJI, S.T. Carbon sequestration in tropical agroforestry systems. Agriculture, Ecosystems and Environment, v. 99, p. 15-27, 2003.

AMAZONAS. Lei Complementar 52, de 30 de maio de 2007. Institui a Região Metropolitana de Manaus e dá outras providências. Manaus: ALEAM, 2007.

BATISTA, D.L.; BARBOSA, R.I. Agrobiodiversidade urbana: composição florística, riqueza e diversidade de plantas nos quintais de Boa Vista, Roraima. Revista Brasileira de Agroecologia, v. 9, n. 2, p. 130-150, 2014. 
BLANCKAERT, I. et al. Floristic composition, plant uses and management practices in homegardens of San Rafael Coxcatlán, Valley of Tehuacán-Cuicatlán, Mexico. Journal of Arid Environments, v. 57: 39-62, 2004.

BRASIL. Ministério do Planejamento, Orçamento e Gestão. Territórios simultaneamente beneficiados por programas federais e por pagamentos de royalties decorrentes da exploração de gás natural. Brasília: MPOG, 2009.

CARNIELLO, M.A. et al. Quintais urbanos de Mirassol D'Oeste-MT, Brasil: uma abordagem etnobotânica. Acta Amazonica, v. 40, n. 3, p. 451-470, 2010.

CAVALCANTE, P.B. Frutas comestíveis da Amazônia. Belém: Museu Paraense Emílio Goeldi, 1991.

CLEMENT, C.R. et al. Recursos frutícolas na várzea e na terra firme em onze comunidades rurais do Alto Solimões, Amazonas, Brasil. Acta Amazonica, v. 31, n. 3, p. 521-527, 2001.

COOMES, O.T.; BAN, N. Cultivated plant species diversity in home gardens of an Amazonian peasant village in northeastern Peru. Economic Botany, v. 58, n. 3, p. 420434, 2004.

COSTA, R.J.; MITJA, D. Uso dos recursos vegetais por agricultores familiares de Manacapuru (AM). Acta Amazonica, v. 40, n. 1, p. 49-58, 2010.

FAO. Food and Agriculture Organization of the United Nations. Household food security and community nutrition. Roma: FAO, 2004.

HANAZAKI, N. et al. Diversity of plant uses in two Caiçara communities from the Atlantic Forest coast, Brazil. Biodiversity and Conservation, v. 9, p. 597-615, 2000.

IBGE. Fundação Instituto Brasileiro de geografia e Estatística. Projeção da população do Brasil e das unidades da federação: Amazonas 2016. Disponível em: $<$ http//:www.ibge.gov.br/populacao>. Acessado em 08/09/2018.

LEVY-COSTA, R.B. et al. Household food vailability in Brazil: distribution and trends (19742003). Revista de Saúde Pública, v. 39, n. 4, p. 530-540, 2005.

LOURENÇO, J.N.P. et al. Agrobiodiversidade nos quintais agroflorestais em três assentamentos na Amazônia Central. Revista Brasileira de Agroecologia, v. 4, n. 2, p. 965-969, 2009.

MADALENO, I. Urban agriculture in Belém, Brazil. Cities, v. 17, n. 1, p. 73-77, 2000.

MARTINS, A.L.U.; NODA. H.; NODA, S.N. Quintais Urbanos de Manaus. In: OLIVEIRA, J.A.; ALECRIM, J.D.; GASNIER, T.R.J. (Orgs.). Cidade de Manaus: visões interdisciplinares. Manaus: EDUA, 2003.

MARTINS, A.L.U. Quintais urbanos em Manaus: organização, espaço e recursos naturais. (Dissertação) Mestrado em Ciências do Ambiente - Centro de Ciências do Ambiente, Universidade do Amazonas, Manaus, Amazonas, 1998. 
MIRANDA, I.P.A. et al. Frutos de Palmeiras da Amazônia. Manaus: INPA, 2001.

OLIVEIRA, D.N. Etnobotânica de quintais de três bairros urbanos de Manaus, Amazonas. (Dissertação) Mestrado em Ciências Biológicas, Botânica - Instituto Nacional de Pesquisas da Amazônia, Manaus, Amazonas, 2015.

PINHO, R.C. et al. Islands of fertility: soil improvement under indigenous homegardens in the savannas of Roraima, Brazil. Agroforestry Systems, v. 81, p. 235-247, 2010.

SEMEDO, R.J.C.G.; BARBOSA, R.I. Árvores frutíferas nos quintais urbanos de Boa Vista, Roraima, Amazônia brasileira. Acta Amazonica, v. 37, n. 4, p. 497-504, 2007.

SHANLEY, P.; CYMERYS, M.; GALVÃO, J. Frutíferas da mata na vida Amazônica. Belém: Supercores, 1998.

SILVA, J.M. Solos do município de Itacoatiara Amazonas. Belém: Embrapa Oriental, 2003.

SIVIERO, A. et al. Cultivo de espécies alimentares em quintais urbanos de Rio Branco, Acre, Brasil. Acta Botanica Brasilica, v. 25, n. 3, p. 549-556, 2011.

SMITH, R.M. et al. Urban domestic gardens (IX): Composition and richness of the vascular plant flora, and implications for native biodiversity. Biological Conservation, v. 129, p. 312322, 2006.

VOEKS, R.A. Are women reservoirs of traditional plant knowledge? Gender, ethnobotany and globalization in northeast Brazil. Singapore Journal of Tropical Geography, v. 28, p. 7-20, 2007.

WINKLERPRINS, A.M.G.A.; SOUZA, P.S. Surviving the city: Urban home gardens and the economy of affection in the Brazilian Amazon. Journal of Latin American Geography, v. 4, n. 1, p. 107-126, 2005.

WINKLERPRINS, A.M.G.A. House-lot gardens in Santarém, Pará, Brazil: Linking rural with urban. Urban Ecosystems, v. 6, n. 1-2, p. 43-65, 2002. 


\title{
CAPÍTULO 11
}

\section{HERBÁRIO DIDÁTICO COMO FERRAMENTA PARA O ENSINO DE BOTÂNICA NA EDUCAÇÃO SUPERIOR A DISTÂNCIA}

\author{
Renata Maria Almeida da Silva Biango', George Azevedo de Queiroz², Fernanda \\ Stefany Nunes Costa ${ }^{2}$
}

1. Universidade Estadual do Norte Fluminense Darcy Ribeiro (UENF), Campos dos Goytacazes, Rio de Janeiro, Brasil.

2. Museu Nacional, Universidade Federal do Rio de Janeiro (MN/UFRJ), Programa de Pós-graduação em Ciências Biológicas (Botânica), Rio de Janeiro, Rio de Janeiro, Brasil.

\section{RESUMO}

O ensino de Botânica é de grande importância na construção de conhecimentos, porém vem se tornando desestimulante e descontextualizado. Com isso torna-se necessário o uso de estratégias de ensino que despertem o interesse dos alunos. Como por exemplo, o herbário didático, que compreende em uma coleção botânica utilizada no processo do ensino-aprendizagem. Este estudo objetiva implementar um herbário didático no polo de São Gonçalo da Universidade Estadual do Norte Fluminense/Cederj e analisar a concepção dos alunos quanto à importância do mesmo para o Ensino de Botânica. Para a criação do herbário, as amostras botânicas foram coletadas, herborizadas e montadas as exsicatas. Posteriormente, foram aplicados dois questionários: um antes da prática de morfologia foliar da Disciplina de Botânica I e outro após. Todos os 24 alunos que participaram da pesquisa assinaram o termo de consentimento livre e esclarecido. Foram montadas 36 exsicatas, representando 12 espécies, sendo utilizadas durante a aula prática de morfologia foliar. No pré-questionário, nove entrevistados consideravam Botânica interessante e 16 alunos afirmaram gostar desta área. Antes da prática, apenas dez alunos sabiam o que era uma exsicata e 18 conheciam um herbário. Após a atividade 22 alunos afirmaram que sabiam o que era uma exsicata, enquanto todos tinham conhecimento do que era um herbário. Para todos os entrevistados, o herbário didático ajudou nas aulas práticas e foi considerado importante para o polo. Conclui-se que a implementação do herbário didático no polo de São Gonçalo UENF/Cederj constitui uma ferramenta importante para o ensino-aprendizado. Palavras-chave: Coleção botânica, ensino-aprendizagem e recurso didático.

\footnotetext{
ABSTRACT

Botany teaching is very importance for the construction of the knowledge; however it has been taught in a discouraging and decontextualized way. Thus, it is necessary to use teaching strategies that stimulates the students. For example, the didactic herbarium, which comprises a botanical collection used in the teaching and learning process. This study aims to implement a didactic herbarium at the pole of São Gonçalo of the Universidade Estadual do Norte Fluminense/ Cederj and analyze the students' studies regarding about its importance. In order to create herbarium, plants were collected, herborized and assembled
} 
as exsiccates. Subsequently, two questionnaires were applied: one before the practice of leaf morphology of the Discipline of Botany and another after. All 24 students who participated in the research signed an informed consent form. 36 exsiccates were assembled, representing 12 species, being used during a leaf morphology class. In the prequestionnaire, nine respondents considered Botany interesting and 16 students said they liked this field. Before practice, only ten students knew what an exsiccate is and $18 \mathrm{knew}$ an herbarium. After an activity of 22 students, who knew what an exsiccate is, while everyone was aware of what an herbarium is. For all respondents, the didactic herbarium helped in practical classes and was considered important for the pole. It was concluded that the implementation of the didactic herbarium at the pole of São Gonçalo, UENF/ Cederj, was an important tool for teaching and learning.

Keywords: Botanical collection, teaching and learning and didactic resource.

\section{INTRODUÇÃO}

\subsection{EDUCAÇÃO A DISTÂNCIA}

A educação a distância é caracterizada como o processo de: "Ensino-aprendizagem onde professores e alunos não estão normalmente juntos, fisicamente, mas podem estar conectados, interligados por tecnologias, principalmente as telemáticas, como a Internet" (MORAN, 2002).

Para Oliveira (2007) é considerado como uma modalidade de ensino que facilita a auto-aprendizagem, com a ajuda de recursos didáticos organizados, apresentados em diferentes suportes de informação, que pode ser utilizada por diversos meios de comunicação. Sendo assim, pode ser definida como um aprendizado planejado que se sucede em um local diferente do local de ensino, e que requer técnicas de criação de curso e de instrução, comunicação por meio das diferentes tecnologias e disposições organizacionais e administrativas (MOORE; KEARSLEY, 2008).

Essa modalidade de ensino é resultado da combinação de processos de educação e de comunicação em massa, o que faz com que um grande número de pessoas seja alcançado através da utilização de vários recursos tecnológicos (OLIVEIRA, 2007). Além do mais, é uma grande beneficiadora da sociedade, pois é capaz de promover a inclusão digital e social (LOPES et al., 2010). Também é responsável por tornar as pessoas mais comprometidas socialmente, conhecedoras de sua autossuficiência racional e aptas para assumirem uma posição crítica em diferentes situações (VIDAL; MAIA, 2010). Esse método de ensino permite que os alunos aprendam a estudar sozinhos, o que ajuda no desenvolvimento de habilidades, independência, iniciativa e autodidatismo (VIDAL; MAIA, 2010). 


\subsection{CONSÓRCIO CENTRO DE EDUCAÇÃO SUPERIOR A DISTÂNCIA DO ESTADO DO RIO DE JANEIRO (CEDERJ)}

O Consórcio Centro de Educação Superior a Distância do Estado do Rio de Janeiro, mais conhecido como CEDERJ, é uma instituição de ensino especializada em educação a distância (MENEZES, 2007). Foi planejado em 1999, na Secretaria de Estado de Ciência e Tecnologia, porém não concretizado, tendo como fonte inspiradora as ideias de Darcy Ribeiro, que pensava em um dia construir uma universidade aberta no Brasil, mediante a junção de várias universidades federais do país (BIELSCHOWSKY, 2017). O consórcio surgiu de uma parceria entre o Governo e as Prefeituras do Estado do Rio de Janeiro, a Secretaria de Ciência e Tecnologia e as Universidades Públicas consorciadas: UERJ, UFF, UENF, UFRJ, UNIRIO e UFRRJ e foi incorporado à Fundação Centro de Ciências e Educação Superior a Distância do Rio de Janeiro em 2002 e projetado para propiciar a democratização de acesso ao ensino superior público de qualidade (SPÍNDOLA; MOUSINHO, 2012).

O CEDERJ possui um modelo semi-presencial de estrutura, integrando momentos presenciais e momentos a distância. Sua estrutura é composta por cinco pilares tidos como essenciais que são: material didático elaborado para educação a distância de apoio digital e impresso; tutorias a distância e presencial; estágios supervisionados; realização de avaliação presencial e aulas práticas em laboratórios nos polos regionais. A sua plataforma conta com o contato discente e docente, fórum, debates, mensagem para os participantes, além dos avisos, planos de aula, avaliação, trabalhos, acompanhamento de participação e download como recursos de comunicação. Cada polo tem o seu diretor, que é assessorado pelos coordenadores. Em cada universidade consorciada, o atendimento é feito individualmente e realizado pelos mediadores a distância por telefone, por fax e pela sala de tutoria da plataforma (SPÍNDOLA; MOUSINHO, 2012).

\subsection{ENSINO DE BOTÂNICA}

A Botânica está presente na vida de todas as pessoas, de forma direta ou indireta. O seu aprendizado é considerado de grande importância na construção de conhecimentos necessários à formação dos cidadãos. Entretanto, muitas dificuldades têm sido apontadas no ensino da Botânica, nos diferentes níveis de ensino (SANTOS et al., 2015). 
Entre essas dificuldades, Sipavicius e Cerati (2017) destacam a complexidade dos conteúdos de fisiologia vegetal e dos ciclos reprodutivos das plantas, a fotossíntese, a sistemática e a taxonomia, além da grande quantidade de vocabulário específico. Além do mais, a utilização de metodologias tradicionais e livros didáticos que possuem conteúdos teóricos específicos de grande complexidade, desestimula não só os alunos, mas também os professores que precisam fazer com que eles aprendam a matéria (GONÇALVES; MORAES, 2011).

O conhecimento da Botânica não é só prejudicado pela falta de estímulos em observar e interagir com as plantas, mas também pela precariedade dos equipamentos, dos métodos e das tecnologias que poderiam auxiliar no aprendizado (MENEZES et al., 2008).

Neste contexto, a cegueira botânica tem um papel fundamental na concepção errônea acerca das plantas como sendo inferiores aos animais. A cegueira botânica é um termo utilizado para se referir a dificuldade em perceber as plantas no seu ambiente e compreender a importância que elas possuem para a biosfera e para o ser humano (KATON; TOWATA; SAITO, 2013).

Para reverter esse cenário, é de grande importância que os professores sejam conscientizados a não se prenderem apenas nas informações contidas nos livros didáticos para ensinar Botânica, mas que eles possam utilizar as aulas práticas e de campo para fazer com que os alunos percebam e recuperem a relação homem-natureza (MATOS et al., 2015).

As aulas práticas permitem que o professor consiga explorar temas mais relevantes, através da associação dos conteúdos teóricos com o cotidiano dos alunos. As aulas expositivas, os jogos, os debates, as discussões e os modelos, também são de grande importância para a aprendizagem do ensino de Botânica, pois a utilização dessas atividades concede aos alunos o contato com outros tipos de conhecimento (KATON; TOWATA; SAITO, 2013).

O ensino de Botânica, quando desenvolvido por meio de atividades que utilizem instrumentos e saberes cotidianos, possibilita uma aprendizagem mais eficaz, pois o contato do aluno com o objeto de estudo de sua realidade o envolve muito mais do que em aulas convencionais em que, geralmente, a ênfase é o conteúdo abordado teoricamente (VINHOLI JÚNIOR, 2011).

A utilização de coleção botânica como material didático nas aulas práticas é uma boa opção para tentar resolver o problema do desinteresse e da dificuldade de aprendizado, 
uma vez que a utilização de materiais botânicos em aulas expositivas é capaz de atingir o seu objetivo, mostrando ser uma ferramenta excelente na construção do conhecimento, na motivação dos alunos e na melhoria da qualidade do ensino e aprendizagem (BESSA, 2011).

\subsection{HERBÁRIO}

Herbário é o conjunto de plantas secas e prensadas, conservadas e organizadas de forma a serem utilizadas em pesquisas científicas e também no ensino da Botânica. Essas amostras de plantas são provenientes de diferentes regiões e ecossistemas e podem ser doadas e recebidas de herbários de todo o mundo (ROTTA; CARVALHO; ZONTA, 2008).

De acordo com Gadelha Neto et al. (2013), o herbário possui diversas finalidades como por exemplo: identificar espécimes de vegetais e fungos desconhecidos, através da comparação com outros espécimes da coleção herborizada, devidamente identificada por especialistas; realizar inventário da flora ou da micota de uma certa área; reconstituir a vegetação e a micota de uma região; avaliar a ação do homem, da poluição e das perturbações naturais na vegetação e na micota de uma certa área.

\subsection{HERBÁRIO DIDÁTICO}

Herbário didático é uma coleção de plantas, fungos e algas que é utilizado no processo de ensino-aprendizagem. As coleções didáticas não requerem tanto cuidado na organização e na manutenção quanto as coleções científicas, pois elas têm uma duração muito curta, em função do frequente manuseio (SANTOS, 2013).

O herbário constitui uma importante fonte de ensino, extensão e pesquisa (ARAÚJO; MIGUEL, 2013). Além disso, ele é um ótimo aliado no processo de ensino aprendizagem, pois ele torna a aula mais dinâmica. O seu uso no ensino fundamental, médio e graduação, faz com que os alunos conheçam o seu funcionamento, a sua coleção, a metodologia empregada na manutenção e na preservação dos espécimes conservados, destacando a importância das coleções científicas (ARAÚJO; MIGUEL, 2013).

O contato dos alunos com a coleção, estimula no estudo da flora e da biodiversidade regional e serve para demonstrar a importância de se conservar as áreas naturais (SANTOS, 2013). Além do mais, todo o material da coleção que é produzido, serve como documento didático científico (ALBUQUERQUE; ZÁRATE, 2017). 
Alguns estudos implementaram herbário didático em suas instituições de ensino. Uns no Ensino Fundamental e Médio, como Fagundes e Gonzalez (2006), no Colégio Estadual Deputado Arnaldo Faivro Busato, no Paraná; Martins et al. (2010), em duas escolas do Paraná, uma pública e outra privada; Santos (2013), no Herbário Cap-UERJ (Colégio de Aplicação); Silva e Lopes (2014), em uma escola particular de São Paulo; Alves et al. (2017), na Escola Estadual Benjamin Constant no Amazonas; Pereira et al. (2017), no Herbário HIFPA no Pará, que realiza atividades práticas no seu Campus com alunos do Ensino Médio. Outros trabalhos se dedicaram ao Ensino Superior, como Nunes e Alves (2016), no Herbário HUEMG; Pires, Santos e Junior (2017), no Herbário MAR; Costa e Fonseca (2017), no Herbário HIFPA. Todos obtiveram êxito no estudo e comprovaram que um herbário didático é capaz de contribuir de forma positiva na formação dos alunos e dos docentes. Além disso, o herbário didático mostrou-se capaz de transformar a visão da botânica, de dinamizar as aulas de Ciências e Biologia, de envolver alunos, licenciandos e professores nas atividades realizadas, de estimular o interesse pela pesquisa, de ajudar na assimilação dos conteúdos, de facilitar a construção do conhecimento e de melhorar a percepção de diversidade.

Este estudo tem como objetivo analisar a percepção dos alunos quanto à importância do herbário didático para o Ensino de Botânica na Educação Superior a Distância.

\section{MATERIAIS E MÉTODOS}

\section{1. ÁREA DE ESTUDO}

O Polo Regional UAB (Universidade Aberta do Brasil) - CEDERJ - São Gonçalo, foi criado através de uma parceria com a Prefeitura do município e o Consórcio Cederj, conforme a Lei municipal de № 400, de 6 de novembro de 2011 (BRASIL, 2011).

O polo São Gonçalo/ Cederj está localizado na Rua Visconde de Itaúna, s/noำ, Gradim, nas dependências do CIEP 250 - Rosendo Rica Marcos e oferece os cursos de ensino superior à distância em Administração, Segurança Pública, Ciências Contábeis, Computação, Engenharia de Produção, Licenciatura em Ciências Biológicas, Física, Matemática, Química e Turismo, que são administrados pelas universidades parceiras: UENF, UERJ, UFF, UFRJ, UFRRJ e UNIRIO. 


\subsection{MONTAGEM DO HERBÁRIO DIDÁTICO}

A montagem do Herbário Didático consiste nas seguintes etapas: coleta dos espécimes vegetais; herborização; montagem das exsicatas e identificação do material coletado; conservação do herbário didático (GADELHA NETO et al., 2013).

A coleta dos espécimes vegetais foi realizada com o auxílio do facão e da tesoura de poda. Após coletados, os exemplares foram colocados em folhas de jornal dobradas ao meio, até o momento de serem herborizados. O caderno de campo foi utilizado para realizar anotações que possam ajudar no processo de identificação da planta, como a cor, o aroma e outras informações que se perdem no processo de secagem da planta (GADELHA NETO et al., 2013).

As amostras foram selecionadas conforme a variedade morfológica das folhas e coletadas na área do Polo São Gonçalo - Cederj e em um sítio no município de Itaboraí.

$\mathrm{Na}$ herborização, os exemplares coletados foram colocados sobre a prensa de madeira com a placa de alumínio e o papelão juntos e depois amarrados com barbante. Em seguida, o material foi desidratado em estufa durante 2 a 5 dias em uma temperatura entre $60^{\circ}$ e $70^{\circ} \mathrm{C}$ aproximadamente.

Para a montagem das exsicatas, foram utilizadas camisa e saia de cartolina. As plantas foram fixadas nas camisas com o auxílio de uma fita adesiva. A etiqueta com informações sobre o local, a data de coleta, o nome do coletor e a identificação dos espécimes, foi colada no canto inferior direito da cartolina e no canto superior esquerdo, foi colado um pequeno envelope com fragmentos do material. Depois de montado, o material recebeu uma saia com o nome da família, gênero e espécie e depois foram colocadas em sacos plásticos com naftalinas, amarradas e guardadas em uma caixa plástica com tampa devidamente identificada.

\subsection{APLICAÇÃO E ANÁLISE DOS QUESTIONÁRIOS}

O público-alvo desta pesquisa foram os alunos da disciplina de Botânica I do curso de Licenciatura em Ciências Biológicas do CEDERJ - Polo São Gonçalo. A atividade foi realizada durante a prática IV desta disciplina que tem como tema morfologia das folhas.

Anteriormente à aplicação dos questionários, os 24 alunos, que concordaram em colaborar com a pesquisa, assinaram o termo de consentimento livre-esclarecido. Os alunos responderam o pré-questionário, e após a prática utilizando o herbário didático, foi 
aplicado o pós-questionário. Ambos os questionários apresentavam questões abertas e fechadas.

Os dados foram analisados através da estatística básica e gráficos foram confeccionados utilizando o programa Excel.

\section{RESULTADOS E DISCUSSÕES}

A coleção botânica didática montada produziu um total de 36 exsicatas, onde foram representadas 12 espécies, distribuídas em nove famílias como descrita na tabela 1.

Tabela 1. Tabela das plantas coletadas para a criação do herbário didático do polo São Gonçalo - Cederj/UENF

\begin{tabular}{l|l|l}
\hline Família & Gênero e Espécie & Nome popular \\
\hline Apocynaceae & Nerium oleander L. & Espirradeira \\
\hline Asparagaceae & Sansevieria trifasciata Prain & Espada-de-São-Jorge \\
\hline Bignoniaceae & Handroanthus chrysotrichus (Mart. ex DC.) Mattos & Ipê-amarelo \\
\hline Bignoniaceae & Tecoma stans (L.) Juss. ex Kunth & Sinos amarelos \\
\hline Fabaceae & Cassia fistula L. & Cássia-imperial \\
\hline Fabaceae & Caesalpinia pulcherrima (L.) Sw. & Flamboyant-de jardim \\
\hline Fabaceae & Bauhinia forficata Link. & Pata-de-vaca \\
\hline Loranthaceae & Struthanthus marginatus (Desr.) G.Don. & Erva-de-passarinho \\
\hline Malvaceae & Hibiscus rosa-sinensis L. & Hibisco \\
\hline Myrtaceae & Psidium guajava L. & Goiabeira \\
\hline Lamiaceae & Plectranthus barbatus Andr. & Boldo \\
\hline Rubiaceae & Uncaria tomentosa (Willd. Ex Schult.) DC. & Unha-de-gato \\
\hline
\end{tabular}

A análise do pré-questionário revelou que grande parte dos alunos tinham preferência pelas áreas de Zoologia, Botânica e Biologia Molecular respectivamente (Figura 1). Esse resultado pode ser explicado pelo fato do ensino de Botânica no Cederj ser baseado em tutorias com atividades práticas. Dessa forma, os alunos possam participam ativamente, o que faz com que eles se interessem cada vez mais pela disciplina.

Santos et al. (2015) encontraram um resultado parecido em que os alunos de cinco universidades presenciais públicas de Goiás também gostavam de Botânica, sendo 37\% 
gostavam, $36 \%$ gostavam muito e $23 \%$ gostava pouco e apenas $4 \%$ não gostam. Contrapondo o estudo de Fonseca e Ramos (2018), que afirmam que os alunos, em grande parte, não têm interesse por Botânica.

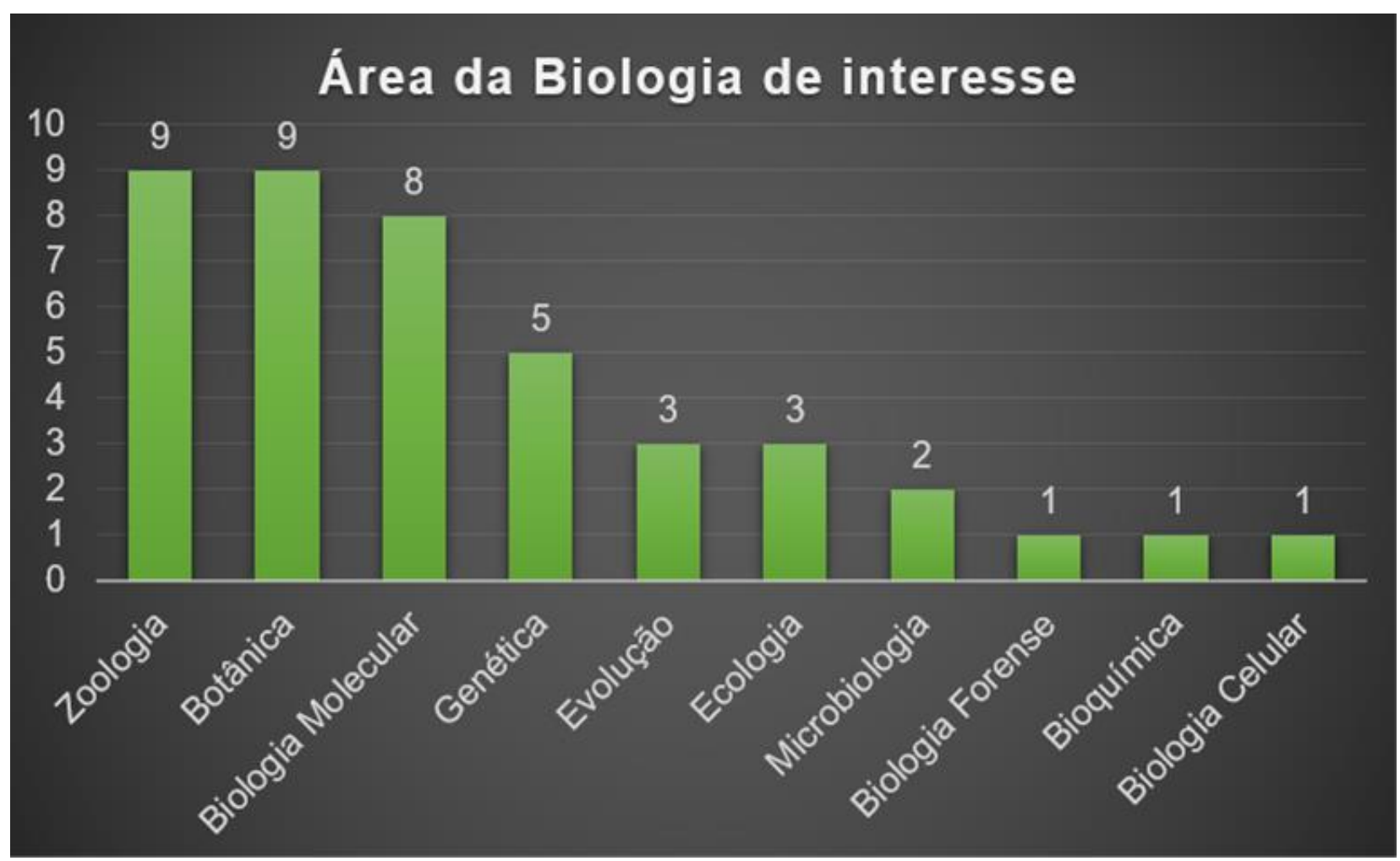

Figura 1. Gráfico da área da Biologia de interesse dos alunos de Licenciatura do polo Cederj/ São Gonçalo.

Quando questionados se gostavam da disciplina de Botânica, 67\% afirmaram que sim, enquanto $33 \%$ responderam que um pouco. Ninguém marcou que não gostava. $O$ resultado encontrado foi diferente do trabalho de Costa e Spinelli (2017), sobre conteúdos botânicos na formação de professores de Ciências e Biologia, realizado com licenciandos do curso presencial de Biologia da UFPB. Esse trabalho tinha como objetivo, descobrir quais eram as principais dificuldades em lecionar os conteúdos de Botânica e quais eram os principais obstáculos na aprendizagem desses conteúdos. O resultado desse estudo apontou que 36,4\% dos licenciandos tinham afinidade pela disciplina de Botânica, 21,2 \% um pouco e $6,1 \%$ nenhuma.

Em relação às dificuldades enfrentadas na disciplina, 67\% apontaram a nomenclatura e terminologia, $25 \%$ morfologia e $8 \%$ outros temas (Figura 2). O mesmo 
resultado pode ser encontrado no trabalho de Nunes et al. (2015) em uma escola de Ensino médio no município de Parnaíba, Piauí, onde foi construído um herbário didático para ser utilizado como uma ferramenta diferenciada para a aprendizagem. O resultado encontrado nesse estudo, mostra que $55 \%$ dos alunos têm mais dificuldades na nomenclatura e na terminologia do que em outros temas. Segundo esses autores, a dificuldade estaria relacionada com a "difícil pronúncia e a imensidade de termos", considerado pelos alunos como desnecessários para se entender a Botânica.

No entanto, em um curso de Ensino Superior em Biologia, a nomenclatura e a terminologia são de extrema importância para o estudo de Botânica. Sendo cada vez mais necessárias estratégias de ensino que permitam superar as dificuldades em relação aos termos científicos.

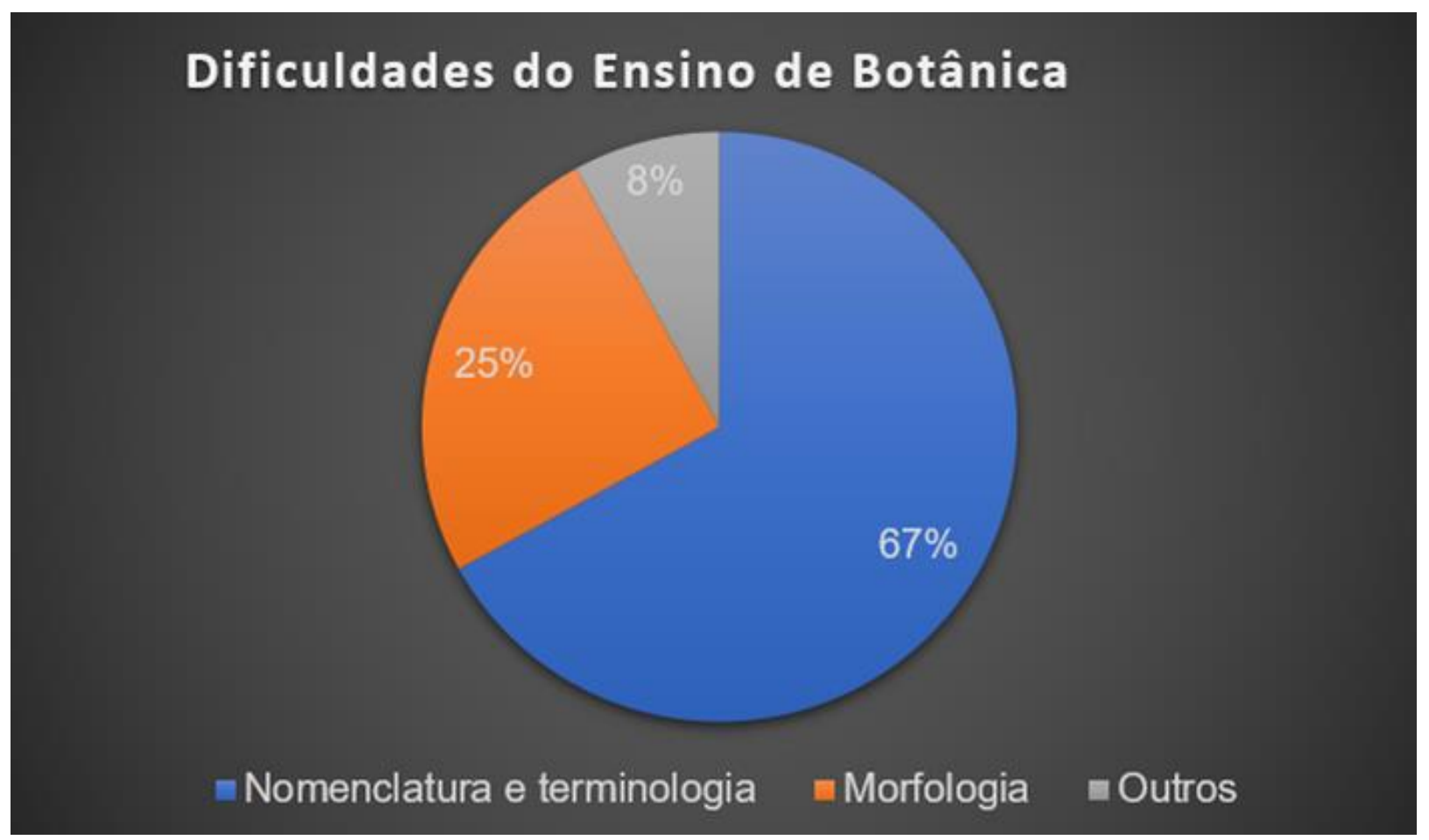

Figura 2. Gráfico das dificuldades do Ensino de Botânica citadas pelos alunos de Licenciatura do polo Cederj/ São Gonçalo.

No que se refere a questões 3 e 4 do questionário aplicado antes da prática, apenas dez alunos sabiam o que era uma exsicata e 18 conheciam um herbário. Após a atividade, 22 alunos afirmaram que sabiam o que era uma exsicata, enquanto todos tinham conhecimento do que era um herbário (Figura 3). 
Para Fagundes e Gonzalez (2006), saber o que é um herbário e uma exsicata é algo essencial na vida de um aluno de Graduação em Ciências Biológicas, porém não basta apenas ter a informação do que se trata, é preciso que se aprenda como os conhecimentos foram produzidos.

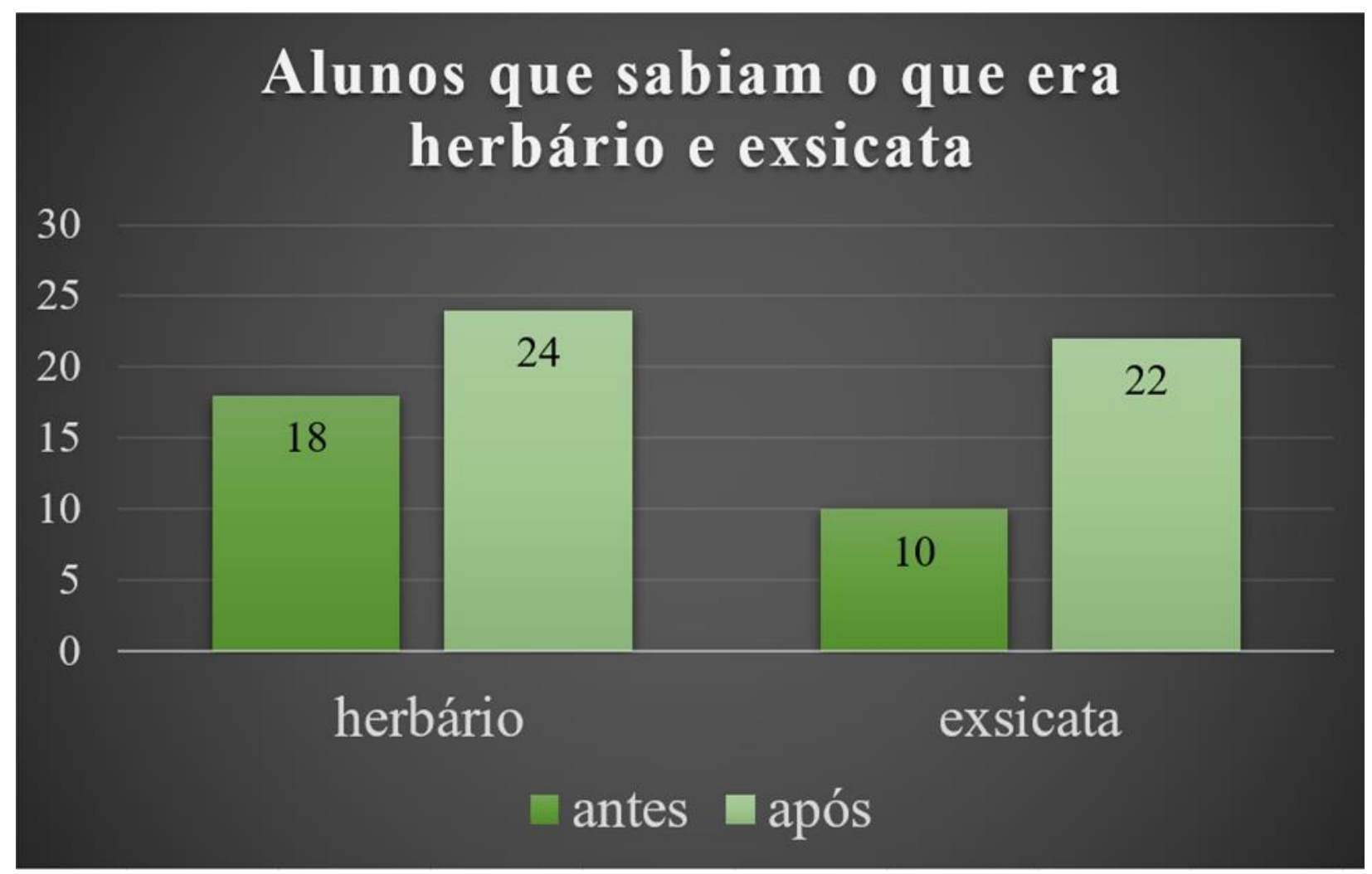

Figura 3. Gráfico dos alunos de Licenciatura do polo Cederj/ São Gonçalo que sabiam o que era herbário e exsicata.

Todos os alunos acharam que a implementação do herbário didático no polo auxiliou nas aulas práticas de Botânica tornando mais interessante. Um resultado muito parecido pode ser observado no trabalho de Silva et al. (2019), em uma escola de Ensino Médio no município de Jaguaribe, Ceará. Neste estudo, também foi utilizado o questionário para saber a opinião dos alunos. Os autores destacam, que a maioria dos alunos acharam o processo de produção de exsicatas muito importante por utilizar plantas de seus cotidianos e que esta produção facilitou o reconhecimento das estruturas vegetais que eram estudadas durante as aulas teóricas e que o material produzido deixou a aula mais interessante e dinâmica. 
É possível perceber a efetividade da utilização do herbário didático através das respostas dos alunos, pois segundo eles, a implementação de um herbário didático no polo é importante: "porque as aulas ficam mais dinâmicas e o conteúdo mais fácil de ser entendido"; "porque ajuda na identificação de plantas e suas estruturas"; "as aulas se tonam mais interativas".

Além disso, a maior contribuição que o herbário didático pode dar para as aulas práticas de Botânica é o fato que ele: "facilita a visualização das estruturas, além de aguçar a percepção, favorecendo a aprendizagem"; "os alunos tornam-se mais participativos e trocam informações com o docente"; "auxilia muito na fixação do conteúdo e na visualização das partes da planta"; "torna a aula mais interessante"; "a aula se torna mais clara, mais didática e participativa".

As atividades práticas com uso de herbário didático funcionam muito bem como uma ferramenta facilitadora do ensino e se mostram capazes de despertar o interesse do aluno em aprender o conteúdo de Botânica. Segundo Nunes et al. (2015), essas estratégias ajudam a enriquecer o conhecimento, melhoram as relações entre o professor e o aluno, possibilitam a criatividade, aumentam a participação nas aulas e proporciona momentos de reflexão.

\section{CONCLUSÃO}

A pesquisa realizada possibilitou através da análise do pós-questionário, a compreensão dos efeitos e das contribuições da ferramenta herbário didático no processo de aprendizagem dos discentes.

Esta ferramenta mostrou-se como um excelente recurso facilitador do ensino de Botânica, viabilizando a construção do conhecimento científico de forma participativa, tornando as mais atraentes e dinâmicas.

Conclui-se que os discentes reconheceram a importância do herbário didático, mostrando-se mais interessados durante a aula prática.

A implementação do herbário didático no polo de São Gonçalo UENF/Cederj constitui uma ferramenta importante para o ensino-aprendizado, pois a mesma foi capaz de desenvolver habilidades, de estimular pensamentos críticos e criativos, de promover o conhecimento e de facilitar o entendimento de conteúdos complexos. 


\section{REFERÊNCIAS}

ALBUQUERQUE, J.V.; ZÁRATE, E.L.P. Materiais didáticos de Botânica Criptogâmica muito além dos livros: Entrelaçando os saberes na graduação. Experiências em Ensino de Ciências, v. 12, p. 239-249, 2017.

ALVES, L.C.; RODRIGUES, J.J.P.; MENDONZA, A.Y.G.; PINTO, M.N.; LIMA, R.A. Construção de coleções botânicas para melhoria do ensino aprendizagem de Biologia em escola pública de Benjamin Constant - AM. Anais do LXVIII Congresso Nacional de Botânica e XXXVI Jornada Fluminense de Botânica. Rio de Janeiro, p. 484, 2017.

ARAÚJO, M.S.; MIGUEL, J.R. Herbário Didático no ensino da Botânica. I Encontro de Pesquisa em Ensino de Ciências e Matemática: questões atuais, 2013.

BESSA, M.G. Montagem de Coleção Botânica para o auxílio do ensino de Biologia no Ensino Médio. (Trabalho de Conclusão de Curso) Licenciatura em Ciências Biológicas Centro Universitário de Brasília, Brasília, 2011.

BIELSCHOWSKY, C. Consórcio Cederj: A História da Construção do Projeto. EaD em Foco, v. 07, n. 02, p. 08-27, 2017.

BRASIL. Lei Municipal № 400, de 6 de Novembro de 2011. Dispõe sobre a Criação e Instituição do Polo de Apoio Presencial - UAB/CEDERJ - São Gonçalo, denominado de O Polo Universitário de São Gonçalo - UAB/CEDERJ São Gonçalo e dá outras providências. Disponível em: <https://leismuni cipais.com.br/a/rj/s/saogoncalo/leiordinaria/2011/40/400/leiordinaria-n-400-2011-disp oe-sobre-a-criacao-einstituicao-do-polo-de-apoio-presencial-uabcederj-sao-goncalo-denominado-de-o-polouniversitario-de-sao-goncalo-uab-cederj-sao-goncalo-e-da-ou tras-providencias >. Acesso em: 30/4/2019.

COSTA, J.M.; FONSECA, D.J.S. Atividades de ensino e extensão promovidas pelo Herbário do Instituto Federal do Pará - Campus Abaetetuba (HIFPA). UNISANTA Bioscience, v. 6, n. 5, p. 31-36, 2017.

COSTA, P.R.A.M.; SPINELLI, A.C.T.M. Conteúdos Botânicos na formação de professores de Ciências e Biologia da UFPB. IV Congresso Nacional de Educação CONEDU, 2017. Disponível em: <http://editorarealize.com.br/revistas/conedu/tra balhos/TRABALHO_EV073_MD1_SA1_ID3546_15092017165457.pdf>. Acesso em: $11 / 10 / 2019$

FONSECA, L.R.; RAMOS, P. Ensino de Botânica na Licenciatura em Ciências Biológicas de uma Universidade Pública do Rio de Janeiro: Contribuições dos Professores do Ensino Superior. Ens. Pesqui. Educ. Ciênc. v. 20, e11378, 2018.

GADELHA NETO, P.C.G.; LIMA, J.R.; BARBOSA, M.R.V.; BARBOSA, M.A.; MENEZES, M.; PÔRTO, K.C.; WARTCHOW, F.; GIBERTONI, T.B. Manual de procedimentos para herbários. $1^{a}$ ed., Editora Universitária da UFPE, 2013. 
GONÇALVES, H.F.; MORAES, M.G. Atlas de Anatomia Vegetal como recurso didático para dinamizar o ensino de Botânica. Enciclopédia Biosfera, v. 7, n. 13, p. 1608-1619, 2011.

KATON, G.F.; TOWATA, N.; SAITO, L.C. A cegueira Botânica e o uso estratégico para o ensino da Botânica. III Botânica no Inverno, 2013.

LOPES, M.C.L.; SALVAGO, B.M.; PISTORI, J.; DORSA, A.C.; ALMEIDA, D.T.R. Educação a distância no Ensino Superior: uma possibilidade concreta de inclusão social. Revista Diálogo Educacional, v. 10, n. 29, p. 191-204, 2010.

MARTINS, E.K.; NOGUEIRA, M.K.F.S.; FERREIRA, A.R.; MORALES, A.G.M. A utilização de material didático botânico no Ensino de Ciências. II SIMPÓSIO NACIONAL DE ENSINO DE CIÊNCIA E TECNOLOGIA, 2010.

MATOS, G.M.A.; MAKNAMARA, M.; MATOS, E.C.A.; PRATA, A.P. Recursos didáticos para o ensino de Botânica: Uma avaliação das produções de estudantes em universidade Sergipana. Holos, v. 5, n. 31, p. 213-230, 2015.

MENEZES, E.P. A Espacialidade e a Temporalidade da Educação a Distância: 0 caso do CEDERJ/CECIERJ. Rio de Janeiro, p. 01-10, 2007.

MENEZES, L.C.; SOUZA, V.C.; NICOMEDES, M.P.; SILVA, N.A.; QUIRINO, M.R.; OLIVEIRA, A.G.; ANDRADE, R.R.D.; SANTOS, B.A.C. Iniciativas para o aprendizado de Botânica no Ensino Médio. XI Encontro de iniciação à Docência, 2008.

MOORE, M.G.; KEARSLEY, G. Educação a distância: uma visão integrada [Tradução Roberto Galman]. Cengage Learning, São Paulo, p. 01-385, 2008.

MORAN, J.M. O que é Educação a Distância. Universidade de São Paulo, 2002. Disponível em: <http://www2.eca.usp.br/moran/wp-content/uploads/2013/12/dist.pdf> Acesso em: 30/12/2018.

NUNES, J.A.; ALVES, N.B. Herbário HUEMG como ferramenta para educação e conservação da biodiversidade. Revista Científica Semana Acadêmica, v. 1, p. 01-16, 2016.

NUNES, M.J.M; OLIVEIRA, T.F.; SOUZA, R.T.B; LEMOS, J.R. Herbário Didático como ferramenta diferenciada para a aprendizagem em uma escola de Ensino Médio em Parnaíba, Piauí. Momento, v. 24, n. 2, p. 41-55, 2015.

OLIVEIRA, M.A.N. Educação a distância como estratégia para a educação permanente em saúde: possibilidades e desafios. Revista Brasileira de Enfermagem, v. 60, n. 5, p. 585589, 2007.

PEREIRA, A.K.S.; CALLIARI, R.B.; LIMA, B.C.C.; OLIVEIRA, W.M.C. JÉFERSON, M.; FONSECA, D.J.S. Herbário do IFPA: uma Ferramenta no Ensino da Botânica para Alunos de Ensino Médio do Município de Abaetetuba, Pará, Brasil. LXVIII Congresso Nacional de Botânica e XXXVI Jornada Fluminense de Botânica, 2017. 
PIRES, C.S.; SANTOS, C.R.; JUNIOR, E.B.A. Herbário do Maranhão: Contribuições pra o Ensino de Botânica. IV Congresso Nacional de Educação, 2017.

ROTTA, E.; CARVALHO, L.C.; ZONTA, B.M. Manual de prática de coleta e herborização de material botânico. $1^{\text {a }}$ ed., Embrapa Florestas, 2008.

SANTOS, M.C.F. Coleções biológicas para o ensino de ciências: o Herbário Didático do Instituto de Aplicação da UERJ. Cadernos do Aplicação, v. 26, n. 1, p. 11-18, 2013.

SANTOS, M.L.; OLIVEIRA, R.R.S.; MIRANDA, S.C.; RAMOS, M.V.V. O Ensino de Botânica na Formação Inicial de Professores em Instituições de Ensino Superior Públicas no Estado de Goiás. X Encontro Nacional de Pesquisa em Educação em Ciências, 2015.

SILVA, J.N.; LOPES, N.P.G. Botânica no Ensino Fundamental: diagnósticos de dificuldades no ensino e da percepção e representação da biodiversidade vegetal por estudantes. Revista Electrónica de Enseñanza de las Ciencias, v. 13, n. 2, p. 115-136, 2014.

SILVA, J.J.L.; CAVALCANTE, F.L.P.; XAVIER, V.F.; GOUVEIA, L.F.P. Produção de exsicatas como auxílio para o ensino de Botânica na Escola. Conexões Ciência e Tecnologia, v. 13, n. 1, p. 30-37, 2019.

SIPAVICIUS, B.K.A.; CERATI, T.M. A percepção da morfologia vegetal por estudantes do ensino fundamental. XXIV Reunião Anual do Instituto de Botânica, p.12-15, 2017.

SPÍNDOLA, M.; MOUSINHO, S.H. CEDERJ: Um caminho na direção da educação inclusiva. EAD em foco - Revista Cientifica em Educação a Distância, v. 2, p. 36-118, 2012.

VIDAL, E.M.; MAIA, J.E.B. Introdução à educação a distância. 1ed., Editora RDS, 2010.

VINHOLI JÚNIOR, A.J. Contribuições da Teoria da Aprendizagem Significativa para a aprendizagem de conceitos em Botânica. Acta Scientiarum Education, v. 33, n. 02, p. 281 288, 2011. 


\title{
CAPÍTULO 12
}

\section{HERBÁRIOS VIRTUAIS E DIVULGAÇÃO CIENTÍFICA: DESAFIOS E AVANÇOS RECENTES DO HERBÁRIO SMDB}

\author{
Liliana Essi ${ }^{1}$, Maria Eduarda do Nascimento Kowalski ${ }^{2}$, Rute Vitória Malinski Pessoa ${ }^{2}$, \\ Deborah Sosmayer Saydelles ${ }^{3}$, Benardete de Fátima Panno ${ }^{4}$, Tania Maria Boucinha Viana ${ }^{4}$ \\ Tanea Maria Bisognin Garlet ${ }^{5}$
}

1. Universidade Federal de Santa Maria (UFSM), Departamento de Biologia, Programa de Pós-Graduação em Agrobiologia, Santa Maria, Rio Grande do Sul, Brasil;

2. Universidade Federal de Santa Maria (UFSM), Curso de Engenharia Florestal, Santa Maria, Rio Grande do Sul, Brasil;

3. Universidade Federal de Santa Maria (UFSM), Curso de Ciências Biológicas, Santa Maria, Rio Grande do Sul, Brasil;

4. Universidade Federal de Santa Maria (UFSM), Herbário do Jardim Botânico da UFSM, Rio Grande do Sul, Brasil;

5. Universidade Federal de Santa Maria (UFSM), Departamento de Zootecnia e Ciências Biológicas, Palmeira das Missões, Rio Grande do Sul, Brasil;

\section{RESUMO}

O herbário SMDB foi fundado em 1962 e atualmente está vinculado ao Jardim Botânico da Universidade Federal de Santa Maria. Possui um acervo de mais de 19 mil espécimes, a maioria exsicatas de angiospermas, e apresenta grande importância em termos de representatividade da flora do estado do Rio Grande do Sul. Com o objetivo de organizar o acervo, inventariar e viabilizar o manejo mais adequado dos exemplares tombados, bem como otimizar a consulta às informações do acervo pela equipe do herbário e pela comunidade em geral, está sendo desenvolvido um programa de informatização, compartilhamento de dados on-line (herbário virtual) e divulgação científica. Para tal, foi criado um banco de dados com o uso do software BRAHMS, e foi realizada a adesão ao INCT-Herbário Virtual, para compartilhamento das informações e imagens de espécimes via rede speciesLink. Também foi realizada a seleção e elaboração de conteúdos de divulgação sobre o herbário e sobre Botânica para compartilhamento nas redes sociais, bem como a participação da equipe do herbário em eventos de divulgação acadêmicos e não acadêmicos. Como resultado, informações de mais da metade das exsicatas do acervo estão disponíveis on-line, sendo mais de 300 registros com imagem. Foram registrados mais de 900 mil acessos a dados do herbário compartilhados no speciesLink, evidenciando o aumento da visibilidade do herbário e do uso das informações disponíveis no seu acervo. Como desafios, apresenta-se a continuidade do processo de informatização e melhoria da qualidade da informação compartilhada, e a necessidade de continuidade de atividades de divulgação científica.

palavras-chave: Exsicatas, SpeciesLink e Coleções biológicas 


\section{ABSTRACT}

The SMDB herbarium was founded in 1962 and currently belongs to the Botanical Garden of the Federal University of Santa Maria. It has a collection of more than 19 thousand specimens, most of which are exsiccate of angiosperms, and is of great importance in terms of the representativeness of the flora of the state of Rio Grande do Sul. With the goal of optimizing the consultation of the collection information by the herbarium team and the community in general, a program is being developed, including the activities of computerization, online data sharing (virtual herbarium) and scientific dissemination. A database was created using the BRAHMS software, and the INCT-Virtual Herbarium was joined, to share information and images of specimens via the speciesLink network. The selection and preparation of dissemination content about the herbarium and botany for sharing on social networks was also carried out, as well as the participation of the herbarium team in academic and non-academic dissemination events. As a result, information from more than half of the collection's exsiccates is available online, with more than 300 image records. More than 900 thousand accesses to herbarium data shared on speciesLink were recorded, showing the increased visibility of the herbarium and the use of information available in its collection. As challenges, there is the continuity of the computerization process and improvement of the quality of the shared information, and the need for continuity of scientific dissemination activities.

keywords: Exsiccates, SpeciesLink and Biological collections

\section{INTRODUÇÃO}

\subsection{OS HERBÁRIOS E SUA IMPORTÂNCIA}

Herbários são coleções biológicas ex situ, dedicadas à guarda e à conservação de exemplares de fungos, e, em especial, de plantas (grupos algálicos, inclusive), ou partes deles, devidamente preservados. A maior parte dos exemplares tombados nos herbários é de plantas secas e prensadas, dispostas em pastas chamadas exsicatas e organizadas de acordo com um sistema de classificação pré-definido. Por essa razão, muitas vezes os herbários são conceituados simplesmente como coleções de exsicatas de plantas. Os herbários, como instituições que fazem a guarda das coleções botânicas, também costumam ser associados a outras coleções, além daquelas de exsicatas, tais como carpotecas, xilotecas, coleções em meio líquido, laminários, bibliotecas especializadas em literatura botânica, contemplando uma estrutura técnico-científica que dá suporte ao estudo das plantas, dos fungos e de sua diversidade. Os herbários proveem material comparativo que é essencial para estudos em taxonomia, sistemática, ecologia, anatomia, morfologia, biologia da conservação, etnobotânica, além de serem utilizados para o ensino e para outros usos pelo público em geral (FUNK, 2002). 
Considerando a importância de se conhecer um herbário, a maior parte das pessoas sequer ouviu falar. Mesmo dentro do ambiente acadêmico, as funções do herbário são pouco compreendidas, e por isso muitas vezes os herbários são bastante negligenciados. Os herbários possuem inúmeras utilizações. Funk (2002) listou 32 usos para um herbário (Quadro 1) e, dois anos mais tarde, completou a lista para 72 diferentes usos (FUNK, 2004), que compreendem desde a identificação de espécies, passando pela descoberta ou confirmação de espécies novas, provimento de dados para florística, ecologia, para acompanhamento de mudanças ambientais, estudos evolutivos, conhecimento dos usos populares das plantas, repositório de vouchers (testemunhos) para pesquisas, até a promoção de intercâmbio técnico e científico entre instituições.

Quadro 1. Usos de um herbário, traduzido de Funk (2002).

\begin{tabular}{|l|l|}
\hline 1 & $\begin{array}{l}\text { Descobrir ou confirmar a identidade de uma planta ou determinar que ela é nova para } \\
\text { a ciência (taxonomia); }\end{array}$ \\
\hline 2 & $\begin{array}{l}\text { Documentar os conceitos dos especialistas que estudaram as amostras no passado } \\
\text { (taxonomia); }\end{array}$ \\
\hline 3 & $\begin{array}{l}\text { Fornecer dados da localidade para o planejamento de viagens de campo (taxonomia, } \\
\text { sistemática, ensino); }\end{array}$ \\
\hline 4 & Fornecer dados para estudos florísticos (taxonomia); \\
\hline 5 & Servir como repositório de novas coleções (taxonomia e sistemática); \\
\hline 6 & Fornecer dados para revisões e monografias (sistemática); \\
\hline 7 & Verificar nomes de plantas em latim (nomenclatura); \\
\hline 8 & Servir como repositório seguro para espécimes "tipo" (taxonomia); \\
\hline 9 & $\begin{array}{l}\text { Fornecer infraestrutura para a obtenção de empréstimos, etc., de material de pesquisa } \\
\text { (taxonomia, sistemática); }\end{array}$ \\
\hline 10 & Facilitar e promover o intercâmbio de novos materiais entre instituições (taxonomia); \\
\hline 11 & $\begin{array}{l}\text { Permitir a documentação dos tempos de floração e frutificação e formas juvenis de } \\
\text { plantas (taxonomia, sistemática, ecologia, fenologia); }\end{array}$ \\
\hline 12 & Fornecer base para ilustração de uma planta (taxonomia, publicação geral); \\
\hline
\end{tabular}




\begin{tabular}{|c|c|}
\hline 13 & $\begin{array}{l}\text { Fornecer pólen para estudos taxonômicos, sistemáticos e de polinização, bem como } \\
\text { estudos de alergia (taxonomia, sistemática, ecologia de polinização, ecologia de } \\
\text { insetos, estudos médicos); }\end{array}$ \\
\hline 14 & $\begin{array}{l}\text { Fornecer amostras para a identificação de plantas comidas por animais (ecologia } \\
\text { animal); }\end{array}$ \\
\hline 15 & $\begin{array}{l}\text { Documentar quais plantas aumentaram em frequência com o tempo (espécies } \\
\text { invasoras, mudanças climáticas, destruição de habitats); }\end{array}$ \\
\hline 16 & Documentar quais plantas cresceram com quais outras plantas (ecologia); \\
\hline 17 & $\begin{array}{l}\text { Documentar a morfologia e a anatomia de indivíduos de uma determinada espécie em } \\
\text { diferentes locais (variação ambiental); }\end{array}$ \\
\hline 18 & Fornecer material para observações microscópicas (anatomia, morfologia); \\
\hline 19 & $\begin{array}{l}\text { Servir como repositório de amostras de testemunhos (vouchers) (ecologia, estudos de } \\
\text { impacto ambiental); }\end{array}$ \\
\hline 20 & Fornecer material para análise de DNA (sistemática, evolução, genética); \\
\hline 21 & $\begin{array}{l}\text { Fornecer material para análise química (documentação sobre poluição; prospecção } \\
\text { biológica, para algas coralinas - determinação de temperaturas oceânicas passadas e } \\
\text { concentração química); }\end{array}$ \\
\hline 22 & $\begin{array}{l}\text { Fornecer material para o ensino (botânica, taxonomia, botânica de campo, } \\
\text { comunidades vegetais); }\end{array}$ \\
\hline 23 & $\begin{array}{l}\text { Fornecer informações para estudos de expedições e exploradores (história da } \\
\text { ciência); }\end{array}$ \\
\hline 24 & $\begin{array}{l}\text { Fornecer os dados de etiquetas necessários para a base precisa de informações das } \\
\text { amostras (biodiversidade e biologia da conservação, biogeografia); }\end{array}$ \\
\hline 25 & $\begin{array}{l}\text { Servir como biblioteca de referência para a identificação de partes de plantas } \\
\text { encontradas em escavações arqueológicas (paleoetnobotânica); }\end{array}$ \\
\hline 26 & $\begin{array}{l}\text { Fornecer espaço e contexto para acompanhar a biblioteca e outros recursos } \\
\text { bibliográficos (ciências da biblioteca, pesquisa geral, taxonomia); }\end{array}$ \\
\hline 27 & $\begin{array}{l}\text { Servir como arquivo de material relacionado (cadernos de campo, cartas, } \\
\text { reimpressões); }\end{array}$ \\
\hline
\end{tabular}




\begin{tabular}{|l|l|}
\hline 28 & $\begin{array}{l}\text { Fornecer informações sobre nomes comuns e usos locais de plantas (etnobotânica, } \\
\text { botânica econômica); }\end{array}$ \\
\hline 29 & $\begin{array}{l}\text { Fornecer amostras para a identificação de plantas que possam ser significativas para } \\
\text { investigações criminais (forenses); }\end{array}$ \\
\hline 30 & $\begin{array}{l}\text { Servir como meio de localizar espécies raras ou possivelmente extintas, por meio da } \\
\text { coleta de áreas listadas nos dados das etiquetas (biologia da conservação, } \\
\text { declarações de impacto ambiental, espécies ameaçadas de extinção); }\end{array}$ \\
\hline 31 & $\begin{array}{l}\text { Servir como ferramenta educacional para o público (clubes de jardinagem, grupos } \\
\text { escolares); }\end{array}$ \\
\hline 32 & $\begin{array}{l}\text { Fornecer um ponto focal para interações botânicas de todos os tipos (palestras, } \\
\text { reuniões de clube). }\end{array}$ \\
\hline
\end{tabular}

Na área de Taxonomia, os herbários são fundamentais, conforme enfatiza Barroso (2003): o taxonomista sem herbário é como um herbário sem taxonomista; um depende do outro, o crescimento de um está vinculado ao crescimento do outro. Além disso, para cumprir adequadamente suas variadas funções, os exemplares de herbário devem ter condições de permitir uma ideia mais ou menos perfeita do organismo do qual foi colhido; suas etiquetas devem registrar as observações a campo, de forma minuciosa, e os espécimes devem ser completos (BARROSO, 2003). Para plantas, recomenda-se coletar um ramo fértil, com mais de duas folhas, permitindo identificar sua filotaxia, e com o maior número possível de estruturas que auxiliem na identificação, como flores e frutos. Cada grupo de organismos possui recomendações específicas para coleta e herborização, e estes procedimentos estão, em geral, bem descritos na literatura, como em Fidalgo e Bononi (1989), Rotta, Beltrame e Zonta (2008) e Peixoto e Maia (2013).

Um herbário pode servir como fonte de dados sobre a biodiversidade, devido à riqueza de informações presentes nas exsicatas, que vão além da morfologia. As etiquetas apresentam dados úteis para determinar distribuição geográfica, período de floração/frutificação, ecossistemas onde as espécies ocorrem, localizar nomes de especialistas e pesquisadores de cada grupo, raridade, e muito mais. Na Figura 1, consta um exemplo de exsicata com modelo de etiqueta com informações básicas. Nas etiquetas, estão relacionados dados como local de coleta, data, coletor(es), determinador(es), 
informações sobre o ambiente e características do espécime que se perdem na herborização ou que não ficam representadas na amostra, tais como cor de flor, cheiro, hábito da espécie, dentre outras. Todas estas informações por muito tempo estavam reservadas às pessoas que podiam visitar pessoalmente os herbários. Entretanto, no Brasil, visitar todos os acervos importantes pode ser uma tarefa inviável, principalmente em termos financeiros. Uma característica interessante das coleções nacionais, é que elas são numerosas, pois existem 265 herbários cadastrados na Rede Brasileira de Herbários, todavia são pequenas em comparação com grandes coleções mundo afora. $\mathrm{O}$ maior herbário do Brasil, o herbário do Jardim Botânico do Rio de Janeiro (RB), possui cerca de 780.000 espécimes, um número ainda muito aquém das coleções de referência de outras partes do mundo, como o herbário do Museu de História Natural de Paris ( $P$, com 8 milhões de espécimes) e do Jardim Botânico Real de Londres, Kew (K, com 8 milhões e 125 mil exemplares) (números conforme o Index Herbariorum: THIERS, continuamente atualizado). A maioria dos herbários brasileiros possui representação predominantemente regional ou local, com acervos oriundos de programas de coletas intensivas, em áreas ou ecossistemas específicos (BARBOSA; PEIXOTO, 2003). Assim, seria necessário visitar muitos herbários diferentes, às vezes em locais bastante distantes, para poder recolher um volume significativo de informações sobre determinado tema.

Tradicionalmente, quando devidamente justificado, os herbários costumam emprestar materiais para outros herbários, enviando pelos Correios, o que facilita bastante o trabalho dos pesquisadores e usuários ao centralizar os materiais para análise em um só local. As desvantagens deste procedimento são o custo com despesas de remessa, que podem se tornar impraticáveis nas condições financeiras da maioria das coleções, além dos riscos que os exemplares correm durante o transporte (extravio, danos, contaminação com insetos). Por dificuldades operacionais como estas e também como uma maneira de aumentar o acesso às informações dos herbários, permitindo a consulta por um público mais amplo, surgiu a necessidade de iniciativas de informatização dos acervos e digitalização de imagens. As imagens das exsicatas não substituem plenamente a análise direta do exemplar, mas reduzem enormemente sua manipulação, danos no transporte, gastos e aumentam o número de usuários que, ao mesmo tempo, podem analisar os espécimes. 


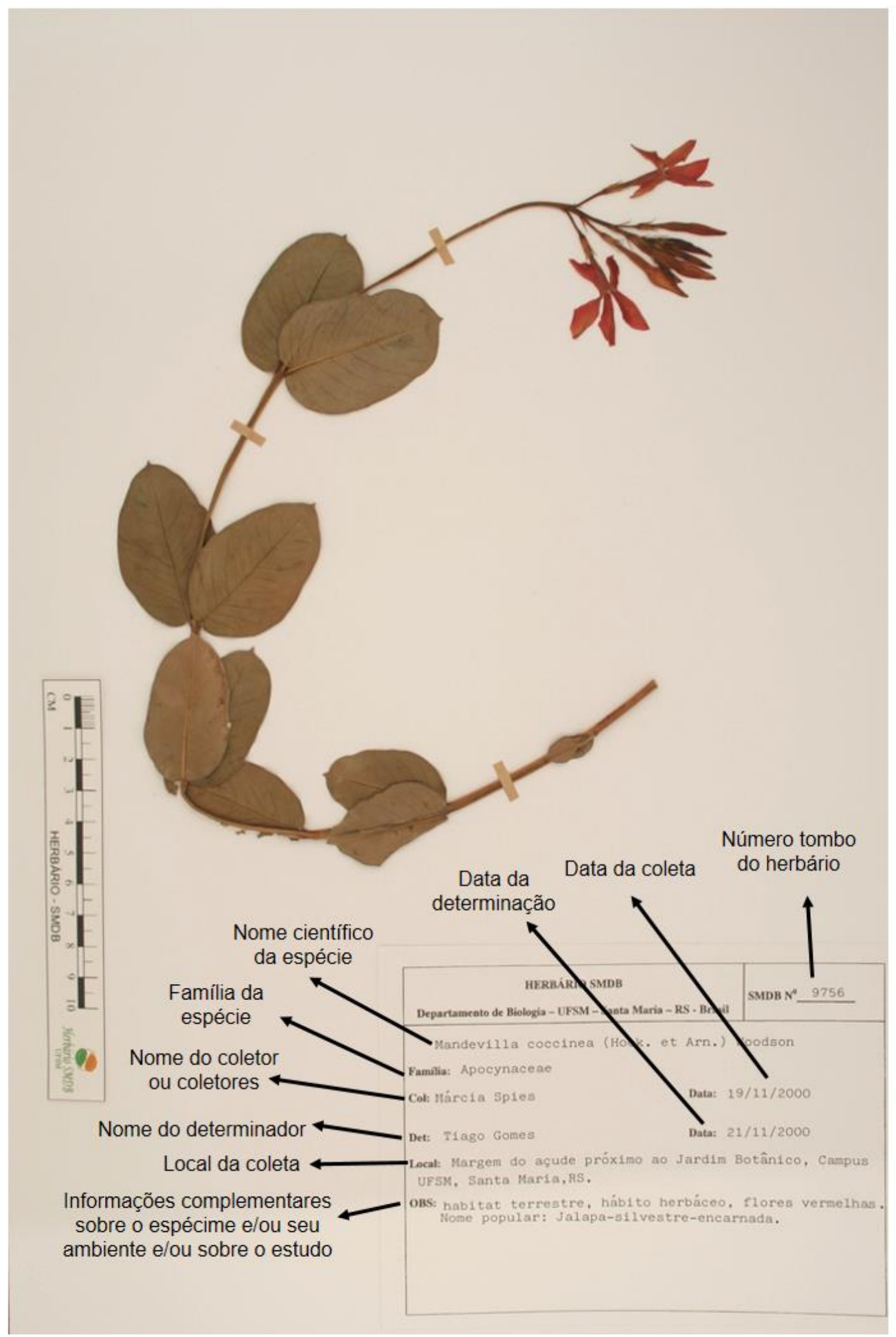

Figura 1. Exsicata do herbário SMDB detalhando a etiqueta com informações básicas: Espécie, Família, Coletor, Data da coleta, Determinador (quem identificou), Data da determinação, Local (completo, com informações gerais, como país, estado e município, e mais locais) e Observações. Algumas etiquetas podem separar outros campos, tais como para nome popular, coordenadas geográficas e altitude, ou estes detalhes podem ser informados nas observações. 
Assim, cedo foi se percebendo que a informatização dos acervos era uma necessidade, não apenas para gerenciamento da própria coleção, como também para o compartilhamento dos dados com a comunidade (WILSON, 2001). Os avanços na informatização dos herbários no Brasil começaram lentamente e de forma desordenada, muito em função da falta de incentivo institucionalizado e de padrões para integração de dados (BARBOSA; PEIXOTO, 2003). No ano de 2002, pouco mais da metade dos acervos era informatizada, e 11\% dos acervos sequer tinham iniciado a informatização (BARBOSA; PEIXOTO, 2003). A situação atualmente é bem melhor. A maioria dos herbários é informatizada, ou está em processo mais avançado de informatização, e um número crescente de acervos está aderindo a programas de digitalização de espécimes e compartilhamento em rede dos acervos. Esses repositórios on-line de imagens de espécimes com informações de tombamento, que correspondem àquelas das etiquetas, vêm sendo chamados de herbários virtuais.

\subsection{O HERBÁRIO SMDB: HISTÓRICO E ESTADO ATUAL}

O herbário de Santa Maria foi criado em 1938, pelo médico e professor de Botânica Romeu Beltrão, tendo como finalidade didática para uso na disciplina de Botânica Aplicada à Farmácia. A princípio, as coletas iniciaram frente a necessidade de manter uma coleção de plantas medicinais. Foi essencial a colaboração do Dr. Guilherme Rau (William Rau), que doou sua coleção particular de plantas ao herbário. Nessa época, o herbário de plantas medicinais pertencia à Faculdade de Farmácia de Santa Maria, que foi fundada em 30 de setembro de 1931. A exsicata número 1, um espécime de Eupatorium serratum Spreng. (atualmente, sob o nome Grazielia intermedia (DC.) R.M. King \& H. Rob.), foi coletada por Guilherme Rau, no dia 02 de novembro de 1931 em Santa Maria - RS. O livro tombo mais antigo do herbário, de 1938 (livro 1), possui 320 registros.

Mereceu destaque no herbário SMDB o Padre e Botânico Balduíno Rambo, pois foi imprescindível sua contribuição, devido à identificação da maioria das espécies de valor histórico do acervo. Tendo em vista seu valioso trabalho, o Dr. Romeu Beltrão, em maio de 1962, homenageou o Padre Balduíno Rambo, dando seu o nome à sala que compunha o Herbário.

Em 1962, foi fundado o Instituto de Ciências Naturais, da Universidade Federal de Santa Maria, sendo o Diretor o Dr. Romeu Beltrão, que permaneceu até sua aposentadoria, 
em 1969. Nessa mesma época, com a reforma da Universidade, os Institutos foram desmembrados, criando-se os departamentos. Com essas reformas, o Herbário da Faculdade de Farmácia passou para o Departamento de Biologia. Em agosto de 1978, o herbário foi registrado no Index herbariorum, com a sigla SMDB, que significa "Santa Maria Departamento de Biologia". Desde sua fundação até o presente momento, teve como Curadores os seguintes professores: Romeu Beltrão, Francisca Marlene da Silveira Vianna, Adelino Alvarez-Filho, Amélia Moema Veiga Lopes, Thaís Scotti do Canto Dorow, Juçara Teresinha Paranhos, Renato Aquino Záchia e Liliana Essi.

O Herbário SMDB pertence ao Jardim Botânico da UFSM desde 2014, com 0 propósito de crescimento na área de Educação Ambiental e Biodiversidade. Atualmente, ele possui 19.400 espécimes tombados, sendo 11.942 disponíveis no acervo on-line speciesLink (Figura 2). Este acervo on-line teve início em maio de 2014, coincidindo com a informatização do banco de dados do herbário com software BRAHMS (Botanical Research and Herbarium Management Systems).

Em termos de diversidade registrada, destacam-se as angiospermas. O herbário também conta com espécimes de samambaias, licófitas, briófitas, alguns grupos de algas e de fungos. Possui registros de diversas partes do Brasil, bem como coletas de outros países, mas se destacam as coletas realizadas no estado do Rio Grande do Sul em diferentes fitofisionomias e coletas de plantas de interesse medicinal.

\subsection{HERBÁRIOS VIRTUAIS}

Com o objetivo de aumentar o acesso aos espécimes dos herbários e aumentar a sua longevidade, reduzindo perdas e danos no transporte e pela manipulação excessiva, foram sendo criados diversos projetos de digitalização de acervos no mundo, para compor herbários virtuais. Nos Estados Unidos, o projeto de herbário virtual com espécimes de herbários de todo o país foi iniciado em 2008 (BARKWORTH; MURRELL, 2012). No mesmo ano, no Brasil, foi iniciado o INCT-Herbário Virtual, uma proposta inovadora que reuniu 25 herbários em rede, que se comprometeram a disponibilizar os dados contidos nas etiquetas dos espécimes de plantas e fungos, na plataforma speciesLink, acessível e aberta (MAIA et al., 2017). Nos últimos anos, o INCT-Herbário Virtual cresceu, e hoje conta com 130 herbários, sendo 21 do exterior. Ao todo, são mais de 5,5 milhões de registros on-line (MAIA et al., 2017). Outra iniciativa brasileira importante é o Herbário Virtual REFLORA, que surgiu como uma iniciativa de resgatar imagens dos espécimes da flora brasileira e das 
informações a eles associadas, que são depositados nos herbários estrangeiros. Surgiu, portanto, como uma espécie de repatriamento eletrônico. A partir de 2014, além do aumento no número de herbários estrangeiros participantes, o programa REFLORA passou a publicar imagens de herbários nacionais, expandindo seus objetivos e metas, e aumentando as possibilidades de acesso a informações sobre a flora brasileira on-line.

Os herbários virtuais também estão se tornando uma excelente ferramenta de divulgação e qualificação de coleções de médio e pequeno porte, como o herbário do Jardim Botânico da Universidade Federal de Santa Maria, o SMDB. Pequenas coleções em geral são pouco visitadas por especialistas, e a possibilidade de visualização de espécimes pela internet facilita a qualificação das identificações, com auxílio de especialistas pela internet, e aumenta o interesse pela visitação, na medida em que os especialistas podem avaliar melhor em quais coleções há materiais relevantes a estudar - materiais que muitas vezes estavam "escondidos" em pequenas instituições, que passam a ser mais conhecidas.

Dessa forma, pretende-se promover a divulgação científica do Herbário SMDB e possibilitar o conhecimento da Flora de Santa Maria com a disponibilização de um banco de dados informatizado. As atividades apresentadas a seguir são resultados de um processo contínuo, e fazem parte dos produtos do programa "Botânica Digital: Divulgação Científica através da digitalização do Acervo do Herbário SMDB Universidade Federal de Santa Maria". Este programa tem como objetivo organizar, inventariar, viabilizar o manejo dos exemplares, otimizar a consulta às informações e principalmente, elaborar um banco de dados detalhado e eficiente sobre a Flora de Santa Maria.

\section{MATERIAIS E MÉTODOS}

\subsection{DIGITALIZAÇÃO DO ACERVO}

O acervo on-line do Herbário SMDB Universidade Federal de Santa Maria teve início com a informatização do banco de dados com software BRAHMS, em maio de 2014. Foi iniciado o processo com a digitação das informações dos livros tombo, e posteriormente com a inclusão de novos materiais diretamente no software. Para o compartilhamento dos dados do acervo e organização de um herbário virtual, o SMDB aderiu ao Herbário Virtual da Flora e dos Fungos, uma iniciativa do INCT (Instituto de Ciência e Tecnologia), o qual 
disponibiliza dados das coleções através da rede speciesLink (http://inct.splink.org.br/). O trabalho de informatização segue algumas etapas, sendo uma delas e primeira a digitação das informações registradas nos livros tombo manuscritos ou das etiquetas de exsicatas em arquivos RDE do software BRAHMS. Também é realizada a digitalização de imagens de exsicatas, por meio de fotografias padronizadas, para posterior compartilhamento.

\subsection{COMPARTILHAMENTO DOS DADOS VIA SPECIESLINK}

Após a inclusão das informações das exsicatas por meio dos arquivos RDE, estes dados são enviados ao speciesLink, para compartilhamento. Os dados compartilhados voltam à revisão, se detectadas inconsistências com o auxílio da ferramenta de DataCleaning do próprio speciesLink. São conferidas informações sobre localização (em especial coordenadas geográficas), identificação, nomes de coletores e atualizações ou correções nomenclaturais. $O$ trabalho de conferência é contínuo, bem como a inclusão de novos registros. Durante esse processo de conferência, a atualização de nomes de famílias também é realizada, em especial para famílias de Angiospermas, seguindo-se a classificação proposta por APG IV (2016). Além do compartilhamento dos dados das exsicatas, são compartilhadas imagens. As imagens estão sendo produzidas em blocos, em sistema fotográfico emprestado pelo herbário HDCF, seguindo uma sequência por família botânica.

\subsection{FORMAS DE DIVULGAÇÃO CIENTÍFICA}

O trabalho de informatização e compartilhamento está sendo divulgado principalmente por intermédio das redes sociais, na página do Facebook do herbário. Nesta mesma página, são compartilhados conteúdos produzidos pela equipe sobre botânica, coleções científicas, e curiosidades sobre plantas, procurando-se incentivar a interatividade. Além deste tipo de divulgação, a equipe participa de eventos de divulgação de ciência para a população, participação em palestras, além da divulgação ao público acadêmico, com a participação em eventos (Jornadas, Congressos). 


\section{RESULTADOS E DISCUSSÃO}

\subsection{HERBÁRIOS VIRTUAIS E AVANÇOS NA DIGITALIZAÇÃO DO ACERVO DO HERBÁRIO SMDB}

Os herbários virtuais podem ser excelentes ferramentas para a democratização do conhecimento e para a divulgação científica, em especial para a divulgação da Botânica. Oliveira (2016) analisou diversos editais e chamadas públicas de fomento dos Institutos Nacionais de Ciência e Tecnologia (INCTs) e algumas ações e materiais produzidos, para compreender a integração entre o fomento à pesquisa e a divulgação científica ou popularização da ciência. Encontrou no INCT-Herbário Virtual diversos elementos que revelam indicadores de alfabetização científica, relacionados à divulgação científica, bem como uma preocupação preponderante de transferência do conhecimento à sociedade. Essa transferência de conhecimento é fundamental, mas não necessariamente o papel dos herbários virtuais restringe-se a isso. As interações possíveis por meio destas plataformas de informações são inúmeras e não totalmente exploradas. Até mesmo dentro do ambiente acadêmico as possibilidades apresentadas pelos herbários virtuais ainda são modestas, porém crescentes. A interface social fora do contexto acadêmico ainda é incipiente, e é muito mais potencializada por outras mídias, como redes sociais (Facebook, Twitter e YouTube). Apresentar os herbários virtuais e seus potenciais de uso nestas redes pode ser uma saída eficiente, para um primeiro passo.

Considerando essa maior facilidade de atingir um público mais diversificado, muitos herbários brasileiros têm criado perfis nestas redes sociais, a fim de atrair a atenção de usuários de perfil variado para temas relevantes em Botânica, inclusive sobre os herbários propriamente ditos. Atualmente, existe uma grande preocupação mundial em não apenas preservar os espécimes e suas informações nos acervos físicos, mas em compartilhar globalmente seus dados, pelos "herbários virtuais". A adesão do Herbário SMDB a essa tendência está apresentando resultados bastante satisfatórios.

Conforme já mencionado anteriormente, o acervo do SMDB conta com 19.400 espécimes tombados, destes 11.942 estão informatizados e estão disponíveis para consulta no speciesLink (Figura 2). De 2018 para cá, o número de exemplares on-line praticamente dobrou (Figura 2). No início de 2019 (março), parte dos dados foi removido da rede para adequações de formato e resolução de problemas técnicos, e prontamente 
reincluído. Há informações sobre 100 famílias de plantas e fungos do herbário disponíveis on-line. No ano de 2019, o herbário SMDB começou a aprimorar seu banco de dados com a inserção de coordenadas geográficas e imagens, que têm o intuito de possibilitar a localização e a identificação dos espécimes, colaborando com o levantamento taxonômico das regiões. São 315 fotos compartilhadas até o momento, muitos destes espécimes são de plantas ameaçadas de extinção. O compartilhamento destas imagens auxilia no conhecimento tanto da flora em geral quanto no reconhecimento de espécies que requerem proteção.

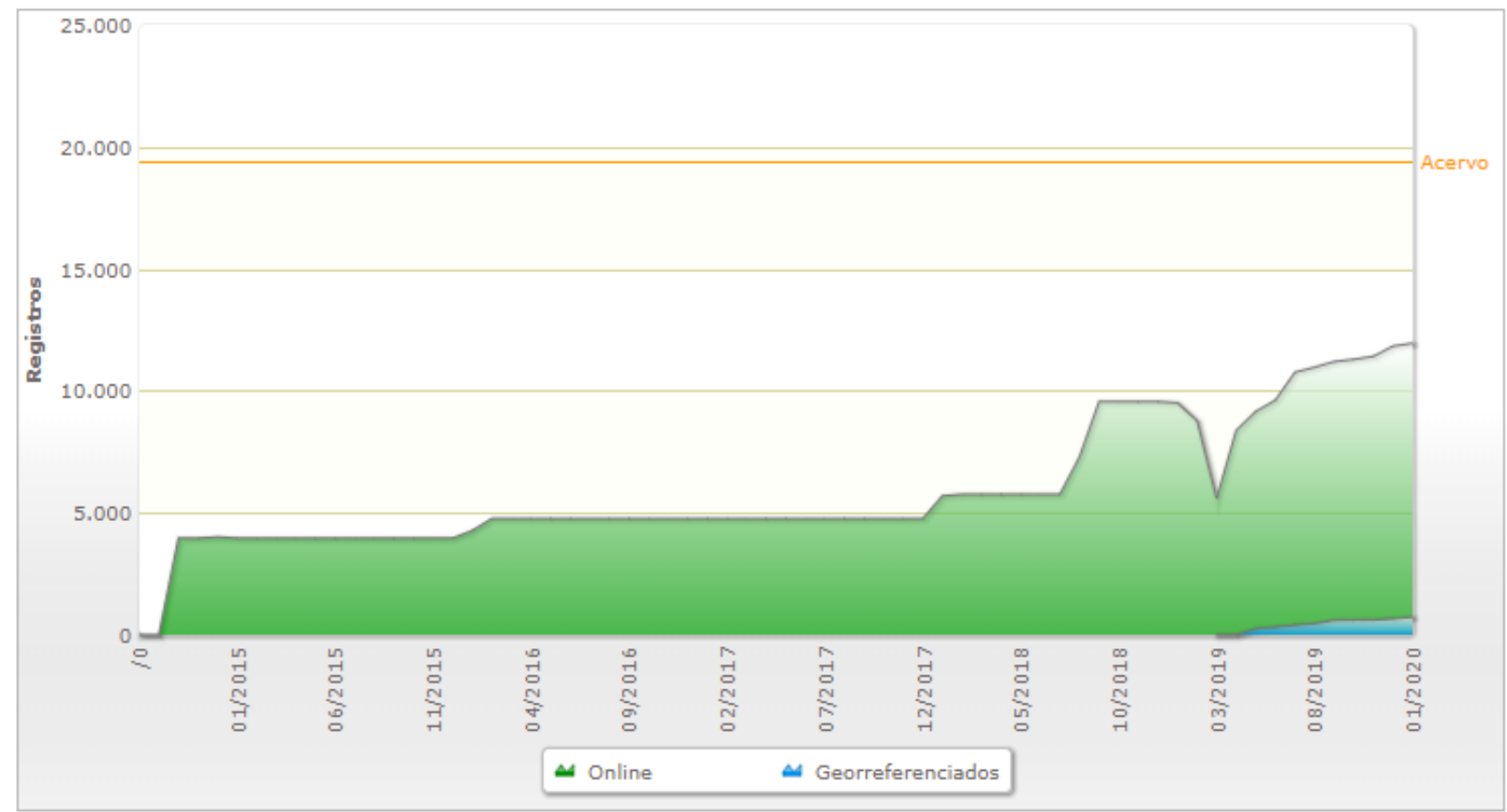

Figura 2. Histórico do fluxo de registros disponível na rede para o herbário SMDB. São apresentadas as médias mensais, tanto do número total de registros on-line, como também do número de registros georreferenciados. A linha laranja representa o número total do acervo da coleção. Gráfico gerado pela ferramenta Network Manager do speciesLink em 22/01/2020.

\subsection{COMPARTILHAMENTO DOS DADOS VIA SPECIESLINK E SEUS IMPACTOS}

Com a informatização do acervo, foi possível realizar diversos levantamentos, os quais eram inviáveis de serem feitos quando os dados do acervo estavam distribuídos apenas em livros tombo manuscritos, pois levariam muito tempo e eram passíveis à inexatidão. Houve também a catalogação das famílias presentes no SMDB, facilitando a gestão da coleção e definição de objetivos estratégicos (Figura 3). Deste modo, permitiu 
visualizar quais grupos são menos representados no acervo e requerem mais coletas ou permuta, e quais grupos se destacam e podem atrair estudos de especialistas. Para ilustrar, seguem as famílias com mais e menos registros no SMDB. As cinco famílias de Angiospermas com mais registros no acervo on-line foram: Fabaceae (1815 registros), Asteraceae (1344 registros), Poaceae (701 registros), Lamiaceae (503 registros) e Myrtaceae (396 registros). A representatividade das famílias está exposta na figura 3.

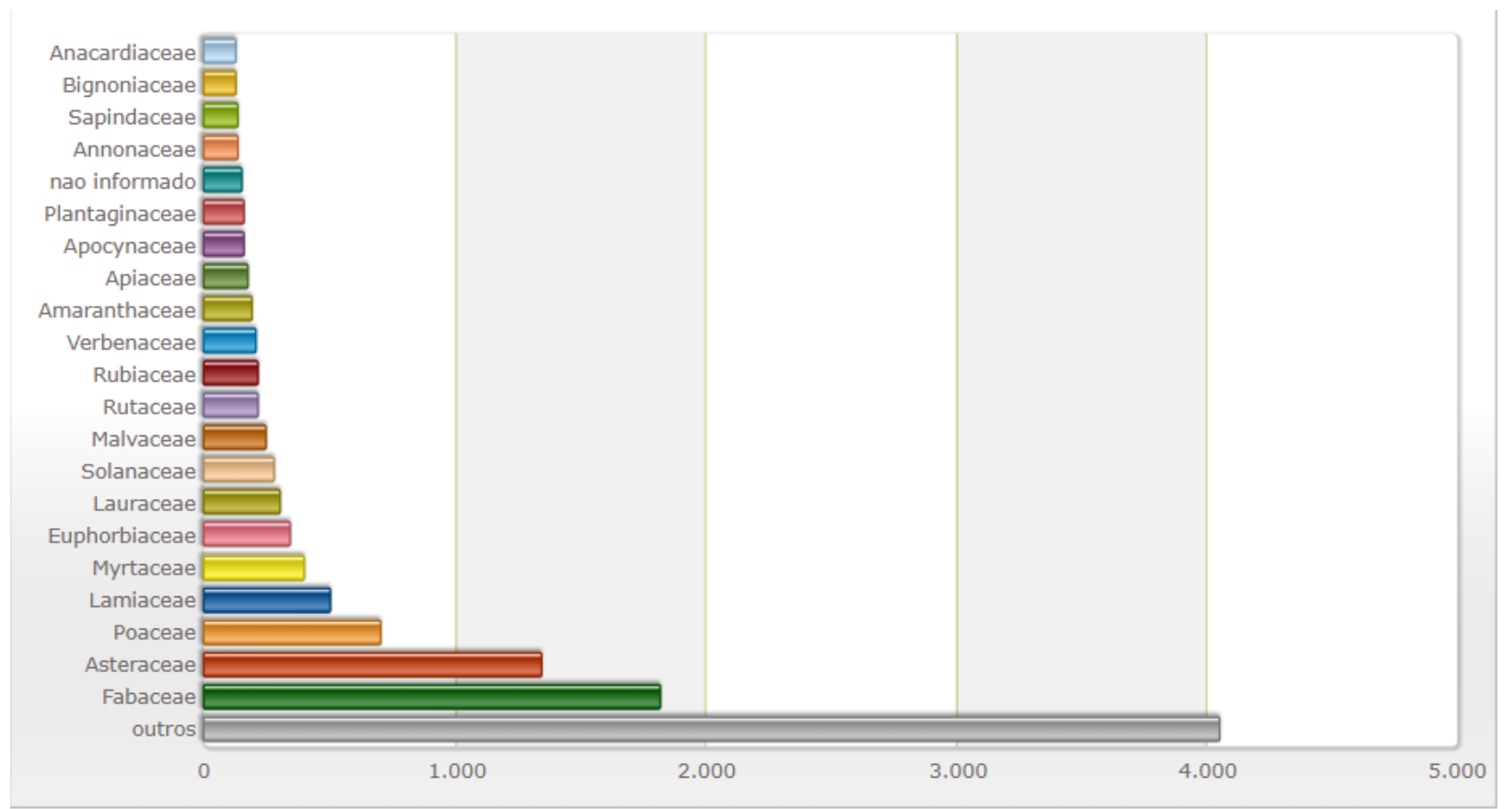

Figura 3. Famílias com maior número de registros on-line. Famílias com poucos exemplares on-line estão agrupadas em "outros".

Gráfico gerado pela ferramenta Network Manager do speciesLink em 22/01/2020.

A informatização e suas ferramentas proporcionaram avaliar as lacunas presentes no acervo, ao tornar possível sua rápida e clara visualização. Foi perceptível que um grande número de famílias estão subrepresentadas, mostrando quais famílias tinham a maior necessidade de ampliar as coletas e projetos de permuta para enriquecimento do herbário, visto que quanto maior a diversificação em famílias e espécies, mais importante é um herbário. Também se verificou um percentual significativo de espécimes sem identificação em nível de família, o que chama a atenção para a necessidade de mais investimento em determinações e visitas de especialistas.

Além do impacto apresentado na gestão e atividades internas do herbário, há impactos importantes no que diz respeito ao público atingido pelo herbário. Até outubro de 2019 foram registrados 925.432 acessos a informações do SMDB disponibilizadas on-line. 
Esse alto número demonstra o quanto os dados estão mais acessíveis e mais aproveitados pela população em geral após a adesão ao speciesLink. O número de visitas presenciais ainda é modesto, se comparado com estes milhares de acessos on-line. A informatização permite que pessoas de diversas partes do mundo, de variados perfis, façam uso gratuito da informação. O próprio interesse no conhecimento presencial do herbário tem aumentado. Sem dúvida, é um movimento importante de democratização de informação e de divulgação do trabalho do herbário.

\subsection{DIVULGAÇÃO CIENTÍFICA: UM DESAFIO DENTRO E FORA DA ACADEMIA}

A divulgação científica tem um papel importante para que a população em geral adquira conhecimento sobre ciência e conheça o quanto ela está presente em seu dia-adia. Também é fundamental às pessoas na identificação dos avanços científicos genuínos e distinção de propagandas falaciosas e notícias falsas, que são propagadas por desconhecimento ou má fé. As ciências conquistaram um enorme prestígio na sociedade, por seus evidentes benefícios, sejam eles de conhecimento básico sobre o mundo que nos cerca, ou por suas aplicações. Entretanto, para muitas pessoas, a ciência parece algo muito distante e inacessível, e a população acaba sendo privada de acesso a conhecimento de qualidade. Uma das maneiras de ampliar este conhecimento para a população e incentivar a curiosidade sobre as ciências em geral é realizar atividades para divulgar ciência. A divulgação científica tem se tornado uma preocupação em todas as áreas, inclusive na Botânica. Amplos espaços estão sendo ocupados na mídia com pseudociência, notícias falsas ou conteúdo de baixa qualidade, confundido a população e tornando o aproveitamento dos avanços da ciência difíceis ao público geral, e eventualmente até ao público acadêmico. Não são raros casos de falta de comunicação entre diferentes áreas das ciências. Assim, a divulgação científica deve ser uma ferramenta tanto para a comunicação com o público não acadêmico quanto para o público acadêmico.

As estratégias de divulgação científica são muito variadas, e o aproveitamento de canais de comunicação já existentes é um atalho bastante eficaz. Por isso, para a divulgação do herbário, sua importância, suas atividades, e de curiosidades sobre Botânica, optou-se por, primeiramente, aproveitar redes sociais consagradas, como o Facebook, como espaço de divulgação. Foram realizadas postagens periódicas sobre os temas no perfil do herbário, convidando pessoas de diferentes perfis para seguir a página. O número de seguidores ainda é modesto (774 em janeiro de 2020), mas as interações sinalizam que 
as postagens têm resultado em interesse sobre Botânica e sobre o herbário. Foram elaboradas postagens relacionadas a datas comemorativas (por exemplo, espécies de plantas que são símbolos natalinos), selecionados vídeos relacionados à Botânica (como o histórico da ilustradora botânica Margaret Mee), bem como relatos das atividades e avanços no herbário SMDB. Além do ativismo virtual, a equipe participou de atividades acadêmicas e não acadêmicas, divulgando os herbários e suas atividades, como a participação no evento "Dose de Ciência", "Bio na Rua" (no município de Santa Maria, RS), bem como em Jornadas e Congressos.

\section{CONCLUSÃO}

Conclui-se que a informatização do herbário SMDB e o compartilhamento do acervo na internet via speciesLink aumentou a visibilidade e uso do acervo nos últimos anos, bem como propiciou um melhor conhecimento e gestão do mesmo. Além disso, ajudou na promoção de atividades de divulgação científica. Ainda há muitos desafios a superar em termos de aumento de volume e qualidade de dados a compartilhar, bem como de estratégias de divulgação, mas se trata de um trabalho de crescimento e aperfeiçoamento permanente ao qual toda equipe está comprometida.

\section{AGRADECIMENTOS}

As autoras agradecem à Pró-Reitoria de Assuntos Estudantis e à Pró-Reitoria de Extensão pelas bolsas concedidas à segunda, terceira e quarta autoras para desenvolvimento dos projetos no herbário (PRAE e FIEX).

\section{REFERÊNCIAS}

APG IV (The Angiosperm Phylogeny Group). An update of the Angiosperm Phylogeny Group classification for the orders and families of flowering plants: APG IV. Botanical Journal of the Linnean Society, v. 181, n. 1, p. 1-20, 2016.

BARBOSA, M. R. V.; PEIXOTO, A.L. Coleções botânicas brasileiras: situação atual e perspectivas. p.113-125. In: PEIXOTO, A.L. (org.) Coleções Biológicas de Apoio ao 
Inventário, Uso Sustentável e Conservação da Biodiversidade. Instituto de Pesquisas do Jardim Botânico do Rio de Janeiro, 2003.

BARKWORTH, M.E.; MURRELL, Z.E. The US Virtual Herbarium: working with individual herbaria to build a national resource. Zookeys, v. 209, p. 55-73, 2012

BARROSO, G.M. O taxonomista e o herbário. p. 141-148. In: PEIXOTO, A.L. (org.) Coleções Biológicas de Apoio ao Inventário, Uso Sustentável e Conservação da Biodiversidade. Instituto de Pesquisas do Jardim Botânico do Rio de Janeiro, 2003.

FIDALGO, O.; BONONI, V.L.R. Técnicas de coleta, preservação e herborização de material botânico. São Paulo: Instituto de Botânica, 1989. 62p.

FUNK, V. A. The Importance of Herbaria. Plant Science Bulletin, v. 49, p. 94-95, 2002.

FUNK, V. A. 100 Uses for an Herbarium (Well at Least 72). p.1-4. 2004.

MAIA, L.C.; VIEIRA, A.O.S.; PEIXOTO, A.L.; CANHOS, D.A.L.; STEHMANN, J.R.; BARBOSA, M.R.V.; MENEZES, M. Construindo Redes para promover o conhecimento da biodiversidade brasileira: a experiência do INCT - Herbário Virtual. Editora Universitária da UFPE, 2017.

OLIVEIRA, D. Biodiversidade em Políticas Públicas de Ciência, Tecnologia e Informação: caracterização e perspectivas na integração do fomento à divulgação e educação em ciências. (Tese) Doutorado do Programa de Pós-Graduação em Ciências: Química da Vida e Saúde, da Universidade Federal do Rio Grande (FURG). Rio Grande, Brasil, 2016. 320 p.

PEIXOTO, A.L.; MAIA, L.C. (orgs.). Manual de Procedimentos para Herbário. Recife: Editora Universitária UFPE, 2013.

ROTTA, E.; BELTRAMI, L.C.C.; ZONTA, M. Manual de Prática de Coleta e Herborização de Material Botânico. Colombo: EMBRAPA Florestas, 2008.

THIERS, B. [continuamente atualizado] Index Herbariorum: a global directory of public herbaria and associated staff. New York Botanical Garden's Virtual Herbarium. Disponível em <http://sweetgum.nybg.org/science/ ih/>. Acessado em 28 de novembro de 2019.

WILSON, H.D. Informatics: new media and paths of data flow. Taxon, v. 50, p. 381-387, 2001. 


\title{
CAPÍTULO 13
}

\section{LEVANTAMENTO DE PLANTAS CONDIMENTARES NA FEIRA}

\author{
MUNICIPAL DE HUMAITÁ - AM
}

\author{
Luciana Diniz Ferreira1, Carolina Wagner', Adriana Pires de Lima1, Elizabeth da Silva \\ Lima1, Jakeline Coelho dos Santos ${ }^{1}$, Izabela Augusta Veiga de Souza1, Renato \\ Abreu Lima ${ }^{1}$
}

1. Curso de Licenciatura em Ciências: Biologia e Química, Instituto de Educação, Agricultura e Ambiente (IEAA), Universidade Federal do Amazonas (UFAM), Humaitá, Amazonas, Brasil.

\section{RESUMO}

O estudo da Etnobotânica ainda merece uma maior atenção, pois esta é uma questão importantíssima visto que envolve a relação do homem com os vegetais. Assim, optou-se por realizar um levantamento para identificar as espécies condimentares comercializadas no mercado municipal de Humaitá - AM, enfatizando a origem, produção, importância econômica, e a forma que é inserida na alimentação e na saúde. A coleta de dados se deu por meio de questionário semiestruturado no período de março a maio de 2019. Foram listadas 28 espécies hortícolas e condimentares, distribuídas em 15 famílias, as que se destacaram a Solanaceae com cinco espécies, Apiaceae e Alliaceae com três espécies cada, Amaranthaceae, Asteraceae, Brassicaceae, Curcubitaceae e Euphorbiaceae com duas espécies cada. As espécies mais encontradas foram à pimenta de cheiro (Capsicum spp.), a cebolinha (Allium schoenoprasum L.), coentro (Coriandrum sativum L.), couve-flor (Brassica oleracea L.), chicória (Eryngium foetidum L.), alface (Lactuca sativa L.), mandioca (Manihot esculenta Crantz), jambu (Acmella oleracea L.), urucum (Bixa orellana L.), cariru (Talinum triangulare (Jacq.). Willd.) e o colorau (Bixa orellana L.). Quanto à origem dessas espécies, $73 \%$ são exóticas e $27 \%$ são nativas do país e da região amazônica. Muitas são as formas de uso dessas plantas, sendo inseridas à mesa do consumidor como simples alimento ou até mesmo como fitoterápicos no alívio ou tratamento de infecções. Dessa forma, a comercialização desses produtos é importante para os produtores familiares, pois a venda destes serve como renda familiar, contribuindo economicamente para o município. Palavras-chave: Etnobotânica, Exóticas e Amazonas.

\footnotetext{
ABSTRACT

The study of Ethnobotany still deserves greater attention, as this is a very important issue since it involves the relationship between man and plants. Thus, it was decided to conduct a survey to identify the condiment species sold in the municipal market of Humaitá - AM, emphasizing the origin, production, economic importance, and the form that is inserted in food and health. Data collection took place through a semi-structured questionnaire from
} 
March to May 2019. 28 vegetable and condiment species were listed, distributed in 15 families, the ones that stood out Solanaceae with five species, Apiaceae and Alliaceae with three species each, Amaranthaceae, Asteraceae, Brassicaceae, Curcubitaceae and Euphorbiaceae with two species each. The most common species were pepper (Capsicum spp.), chives (Allium schoenoprasum L.), coriander (Coriandrum sativum L.), cauliflower (Brassica oleracea L.), chicory (Eryngium foetidum L.), lettuce (Lactuca sativa L.), manioc (Manihot esculenta Crantz), jambu (Acmella oleracea L.), annatto (Bixa orellana L.), cariru (Talinum triangulare (Jacq.). Willd.) and paprika (Bixa orellana L.). As for the origin of these species, $73 \%$ are exotic and $27 \%$ are native to the country and the Amazon region. There are many ways of using these plants, being inserted at the consumer's table as simple food or even as herbal medicines for the relief or treatment of infections. Thus, the commercialization of these products is important for family producers, since the sale of these products serves as family income, contributing economically to the municipality.

Keywords: Ethnobotany, Exotics and Amazonas.

\section{INTRODUÇÃO}

A floresta amazônica é uma região rica em sua diversidade de plantas, gerando um grande interesse científico. Embora haja esse grande interesse pela sua diversidade vegetal, percebe-se que ainda há poucos estudos voltados para a Etnobotânica das plantas frutíferas e condimentares no interior do estado do Amazonas.

O estudo etnobotânico dessas espécies ainda é muito incipiente em se tratando das áreas interioranas da região e segundo Ranieri (2018) esses estudos permitem obter informações que fortalecem o conhecimento de espécies vegetais por populações humanas. A comercialização de condimentos vem se difundindo a cada dia e sabe-se que cada vez mais as pessoas vêm introduzindo-as no mercado, inclusive as nativas.

O Amazonas, por ser um estado situado em plena Amazônia, constitui em seu território uma grande variabilidade de plantas, sejam estas frutíferas, condimentares ou medicinais, mas apesar de sua grande diversidade, percebe-se que existe também, uma grande variedade de plantas exóticas, trazidas de outras regiões do país.

A comercialização de plantas acontece desde há muito tempo, pois o uso de plantas para diversos fins é uma cultura milenar que foi trazida por antepassados, juntamente com os conhecimentos populares acerca de vegetais, tanto para uso medicinal como também para uso na culinária. E a maioria desses vegetais é cultivada em quintais e sítios e em sua maioria, servem como um meio de sobrevivência para muitas famílias. Conforme Marchese (2004) "dentre os produtos que podem ser cultivados de forma orgânica estão às plantas 
medicinais e condimentares, importante opção para a diversificação da pequena propriedade".

Guarim Neto (1996) apud Souza (2015) "considera que a prática de cultivo de espécies em quintais, hortos, chácaras e jardim botânico etc. devem ser incentivados uma vez que somente dessa forma haverá possibilidades de se perpetuá-las [...]", além do fato de ser uma importante cultura que vem sendo utilizada pela humanidade há anos e que traz inúmeros conhecimentos indispensáveis para estudos científicos dos vegetais e ainda por serem de suma importância para pequenos produtores que em sua maioria sobrevivem da comercialização desses produtos.

Desta forma, as feiras livres são uma forma de sobrevivência para muitas famílias, sendo importante para a economia da região, entre outros aspectos. Observa-se que no município de Humaitá-AM existe uma grande presença de plantas condimentares e hortaliças que são comercializadas e que são oriundas de outras regiões do país ou de outros países.

Assim, optou-se por realizar esta pesquisa por meio de um levantamento etnobotânico de plantas condimentares comercializadas em um mercado que funciona como uma feira livre no município para avaliar a porcentagem dessas plantas condimentares nativas e exóticas, de forma quantitativa e qualitativa, verificando sua origem, importância e a forma como é incorporada na alimentação e na saúde, além da sua contribuição socioeconômica para a comunidade local.

\section{MATERIAIS E MÉTODOS}

O levantamento foi realizado no Mercado Municipal de Humaitá - Amazonas, no período de março a maio de 2019, local que funciona como uma feira livre e são comercializados vários tipos de produtos, inclusive os advindos das comunidades ribeirinhas próximas.

Este mercado foi estruturado há alguns anos, sendo a única feira livre que há no município. Existem outros pontos de vendas de produtos hortícolas, mas atuam isoladamente. A inserção deste mercado no município deu aos pequenos produtores a oportunidade de comercializarem seus produtos, ajudando assim, na economia de muitas famílias que trabalham no local. 
A coleta de dados para a obtenção de informações se deu por meio de um questionário respeitando a resolução no 466 de 12 de dezembro de 2012, e de acordo com a autorização dos feirantes durante o mês de janeiro de 2019, onde se fez uma investigação junto aos proprietários dos pontos onde são comercializadas essas espécies de condimentares.

Foram analisados oito pontos de venda, no qual se realizou um questionamento oral para saber quais as espécies eram comercializadas, quanto à origem de cultivo dessas espécies e fins para consumo, a importância de cada produto para a comunidade local e qual sua contribuição socioeconômica para a região.

O levantamento das espécies condimentares comercializadas no local foi realizado de forma quantitativa e qualitativa, avaliando origem, produção, famílias botânicas e espécies encontradas no local. As espécies vegetais foram contabilizadas em campo. A identificação das plantas foi feita por comparação com material especializado em taxonomia vegetal, realizando-se um levantamento bibliográfico em acervos digitais.

\section{RESULTADOS E DISCUSSÃO}

No estudo realizado, foram contabilizadas 28 espécies vegetais diferentes de plantas agrupadas em hortícolas e condimentares, distribuídas em 15 famílias botânicas.

Dentre as famílias botânicas que mais se destacaram foram Solanaceae com cinco espécies diferentes, seguida da Apiaceae e Alliaceae com três espécies diferentes cada, Amaranthaceae, Asteraceae, Brassicaceae, Curcubitaceae e Euphorbiaceae com duas espécies diferentes cada, Bixaceae, Convolvulaceae, Fabaceae, Malvaceae, Piperaceae, Taliaceae e Umbellifereae com uma espécie cada.

Diante desses resultados, percebe-se a diversidade vegetal que existe na região, pois o número de famílias botânicas encontradas nesta feira para espécies condimentares e hortícolas foi satisfatório. Podemos comparar algumas famílias botânicas encontradas no trabalho de Lima (2011), no qual também cita a presença das famílias botânicas Amaranthaceae, Asteraceae, Curcubitaceae, Euphorbiaceae, Fabaceae e Malvaceae. Enquanto que em comparação com o trabalho de Gaia (2017) os resultados foram positivos para as famílias botânicas Fabaceae, Asteraceae, Brassicaceae, Curcubitaceae e Bixaceae. 
Ao comparar esses resultados, percebeu-se uma grande dificuldade em virtude de haver poucos trabalhos relacionados à temática, o que nos mostra que ainda há muitos estudos a serem realizados quando se trata de trabalhos voltados à Etnobotânica, sendo imprescindível que novos trabalhos e resultados sejam atingidos.

A espécie de maior incidência foi à pimenta de cheiro (Capsicum spp.), presente em seis pontos de venda, seguida da cebolinha (Allium schoenoprasum L.), coentro (Coriandrum sativum L.) e da couve (Brassica oleracea L.) encontradas em cinco pontos de venda, em seguida de chicória (Eryngium foetidum L.), alface (Lactuca sativa L.), colorau (Bixa orellana L.), tomate (Solanum lycopersicum L.), batata (Solanum tuberosum L.) e cenoura (Daucus carota subsp. sativus L.) encontradas em quatro pontos de venda (Tabela $1)$.

Tabela 1. Levantamento de espécies comercializadas no mercado municipal de Humaitá-AM.

\begin{tabular}{lll}
\hline Nome popular & Nome científico & Família botânica \\
\hline Abóbora & Cucurbita moschata Duch & Curcubitaceae \\
\hline Alface & Lactuca sativa L. & Asteraceae \\
\hline Alho & Allium sativum L. & Alliaceae \\
\hline Batata & Solanum tuberosum L. & Solanaceae \\
\hline Batata doce & Ipomoea batatas L. & Convolvulaceae \\
\hline Beterraba & Beta vulgaris L. & Amaranthaceae \\
\hline Cariru & Talinum triangulare (Jacq.) Willd.) & Talinaceae \\
\hline Cebola & Allium sepa L. & Alliaceae \\
\hline Cebolinha & Allium schoenoprasum L. & Alliaceae \\
\hline Cenoura & Daucus carota subsp. sativus L. & Apiaceae \\
\hline Chicória & Eryngium foetidum L. & Umbellifereae \\
\hline Coentro & Coriandrum sativum L. & Apiaceae \\
\hline Colorau & Bixa orellana L. & Bixaceae \\
\hline Couve & Brassica oleracea L. & Brasicaceae \\
\hline
\end{tabular}




\begin{tabular}{lll}
\hline Feijão caupi & Vigna unguiculata (L.) Walp. & Fabaceae \\
\hline Jambu & Acmella oleracea (L.) R. K.Jansen & Asteraceae \\
\hline Macaxeira & Manihot esculenta Crantz & Euphorbiaceae \\
\hline Mastruz & Chenopodium ambrosioides L. & Amaranthaceae \\
\hline Pepino & Cucumis sativus L. & Curcubitaceae \\
\hline Pimenta de & Capsicum spp. & Solanaceae \\
cheiro & & \\
\hline Pimenta do & Piper nigrum L. & Piperaceae \\
reino & & \\
\hline Pimenta morupi & Capsicum chinense Jacq. & Solanaceae \\
\hline Pimentão & Capsicum annuum L. & Solanaceae \\
\hline Quiabo & Abbemoschus esculentus (L.) & Malvaceae \\
& Moench & \\
\hline Repolho & Bressica oleracea L. & Brassicaceae \\
\hline Salsa & Petroselinum crisum (Mill.) Nym. & Apiaceae \\
\hline Tomate & Solanum lycopersicum L. & Solanaceae \\
\hline Tucupi & Manihot esculenta Crantz & Euphorbiaceae \\
\hline & & \\
\hline
\end{tabular}

Dentre as espécies contabilizadas, foram citadas como espécie de uso medicinal a salsa (Apiaceae), mastruz (Amaranthaceae), jambu (Asteraceae), alho (Alliaceae) e a chicória (Umbellifereae).

Essas espécies são bastante utilizadas pela população local não só como medicinal, mas também em forma de condimentos e temperos. Em comparação com o trabalho de Lima (2011), observa-se que o alho e o mastruz também foram citados por ele como plantas medicinais.

A salsa é também citada no trabalho de Garutti (2011) como uma espécie utilizada como medicinal. Isso nos mostra que os conhecimentos populares sobre o uso de plantas como fitoterápicos está espalhado por diversas regiões do país, e que estão sendo repassados de geração a geração, mas, no entanto, existem muitas perdas em relação aos saberes populares sobre o uso desses vegetais. 
Quanto à origem dessas espécies $71 \%$ são exóticas e $29 \%$ são nativas do país e região amazônica (Figura 1) nos quais se destacaram a chicória (Eryngium foetidum L.), macaxeira e o tucupi (oriundo da mandioca - Manihot esculenta (Crantz), jambu (Acmella oleracea (L.) R. K. Jansen), colorau (Bixa orellana L.) e o cariru (Talinum triangulare (Jacq.)

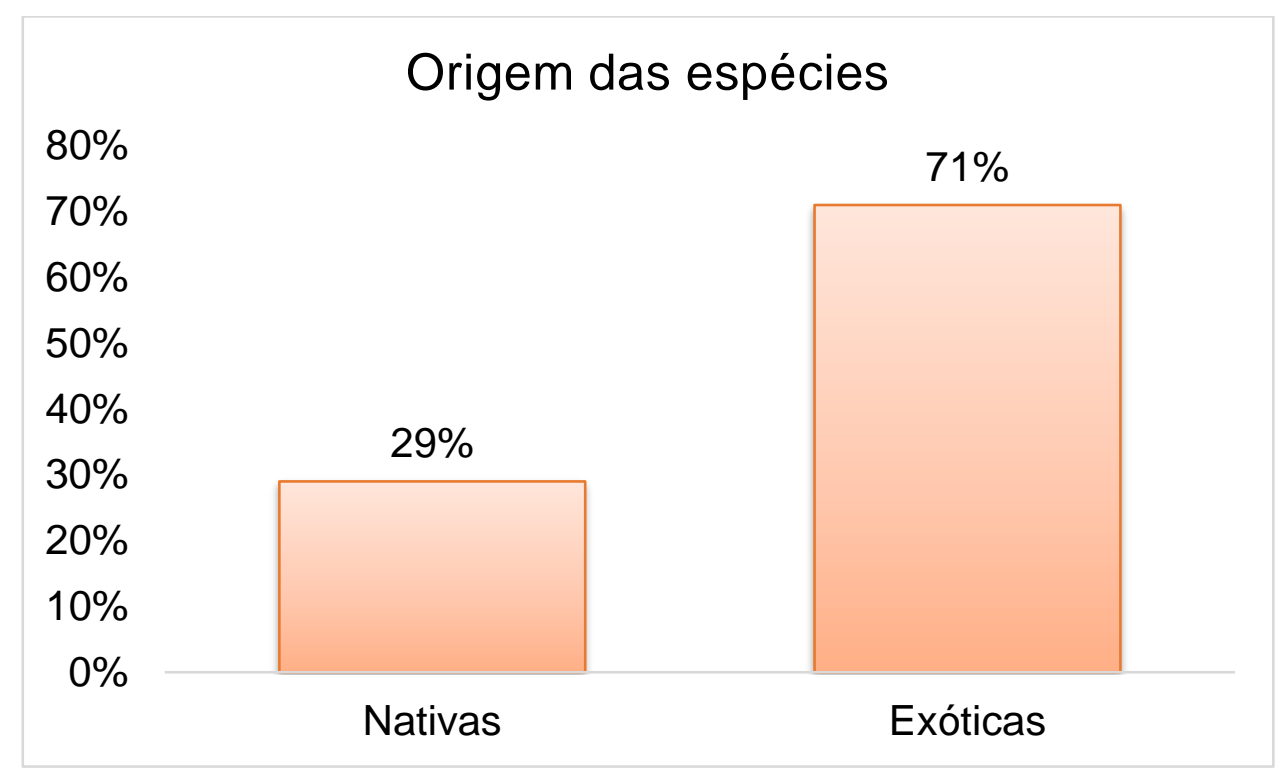

Figura 1. Origem das espécies comercializadas no mercado municipal de Humaitá-AM.

A comercialização desses produtos é de suma importância para os pequenos produtores, já que estes utilizam a venda desses produtos como forma de renda familiar. Desde há muito tempo a sociedade vem introduzindo a agricultura em seu dia a dia. Muitos são as formas de uso dessas plantas, sendo inseridas à mesa do consumidor como simples alimento ou até mesmo como fitoterápico, ou seja, muitos consumidores além de utilizarem na alimentação, fazem uso dessas espécies como forma de combater ou prevenir certas afecções e doenças.

Miura (2007) afirma que "a fitoterapia é uma opção no tratamento de diversas doenças, por ser financeiramente acessível e por se tratar de uma alternativa mais natural frente à medicina alopática". Como as espécies vegetais por serem economicamente mais acessíveis, as pessoas muitas vezes optam por espécies com efeitos fitoterápicos para diversos fins, que vão desde a cura de certas enfermidades até a eliminação de gorduras no organismo. 
Outro modo de utilizar essas espécies é no cotidiano como condimentos, que cada vez mais vem sendo estudado e introduzido na culinária. Desta forma, é imprescindível que se seja realizado estudos voltados para a Etnobotânica de condimentares na região, pois são poucos os estudos que possam contribuir para uma maior gama maior de informações que tratam dessa Ciência.

A comercialização de condimentares, aromáticas e plantas com efeito medicinal são importantíssimas para a sociedade local, pois esses feirantes representam uma importante fonte de informação sobre essas plantas, por serem uma ligação entre a produção, comercialização e o consumo destes produtos. Apesar disso, a maioria dos comerciantes trazem esses conhecimentos de forma informal, ou seja, repassados de geração a geração.

Não ter a confirmação científica não significa que não há benefícios ao homem, pois o conhecimento é passado de geração em geração e ampliados no decorrer do tempo (BEGOSSI et al. 2004 apud GAIA 2017). Sendo esses conhecimentos imprescindíveis para que se busquem estudos científicos e se comprovem tais benefícios que estas plantas apresentam.

Outro fator importante é o método de produção dessas espécies, que a grande maioria é feita em quintais e sítios, sendo cultivadas na maioria das vezes, em consórcio com outras espécies vegetais, muitas vezes utilizando áreas que estavam sendo degradadas e agora substituídas por um consórcio de plantas de diferentes famílias botânicas.

Souza (2015) coloca que os quintais são áreas muitas vezes imperceptíveis, mas que podem servir como fonte alternativa de nutrição para a família ou até mesmo fonte de renda, o que torna ainda mais interessante, estudos que envolvam essa cultura. Outro fator interessante seria o incentivo a essas pessoas para que esta cultura não se perca e junto a ela, os conhecimentos populares que as pessoas trazem de seus antepassados, pois, como já citado outrora, o saber popular é imprescindível para a construção e concretização de novos conhecimentos científicos.

O conhecimento e o estudo de ervas condimentares estão atrelados à própria humanidade, sua necessidade de sobreviver, reinventar os alimentos, recuperar a saúde, reverenciar o incompreensível por meio de rituais, conquistar terras, dominar povos e registrar seus feitos. As especiarias transformaram o alimento em refeição, em banquete, festa, prazer, oferenda, sacrifício e remédio, revolucionaram costumes e traduziram a eterna busca do homem pela felicidade (PEREIRA; SANTOS, 2013). 


\section{CONCLUSÃO}

Com base no que já foi mencionado ao longo deste trabalho, pode-se dizer que a Etnobotânica é uma área de estudo bastante interessante, pois esta pode nos revelar conhecimentos relevantes, visto que por meio de estudos como este se pode resgatar saberes que necessitaria de muitos estudos para tal.

Este trabalho mostra a grande cultura que existe quando se fala em uso de plantas, seja para fins medicinais ou de uso na culinária, além de ter um importante papel para novos estudos como, por exemplo, na área da medicina.

A aplicação de trabalhos como este é de grande valia, pois pode nos mostrar a importância da relação do homem com os vegetais, podendo observar como ocorre à interação homem-planta, além de também tornar conhecida a diversidade de vegetais que são consumidas e utilizadas para diversos fins pela sociedade.

Além disso, a comercialização desses produtos é importantíssima para os produtores familiares, pois a venda destes serve como renda familiar, contribuindo economicamente para o município, além dos feirantes representarem uma importante fonte de informação sobre essas plantas. Valendo salientar a importância de preservar essa cultura que tem sido tão importante para os avanços dos estudos científicos seja na área medicinal ou outra qualquer que envolva os estudos dos vegetais.

\section{AGRADECIMENTOS}

Aos feirantes que nos deram a oportunidade de realizar esse levantamento, passando os seus conhecimentos a respeito dessas plantas.

\section{REFERÊNCIAS}

BARROS, L.S. Levantamento etnobotânico em feiras livres da Paraíba e saberes da tradição dos raizeiros. 2015.

GAIA, S.D.C. Levantamento etnobotânico de frutas comercializadas no Município de Tefé-AM. 2017.

GARUTTI, S.; PINHEIRO, F. C. Horta escolar de plantas medicinais: Uma prática de vida saudável. Iniciação Científica Cesumar, v. 13, n. 1, p. 25-29, 2011. 
LIMA, R.A.; MAGALHÃES, S.A.; SANTOS, M.R.A. Levantamento etnobotânico de plantas medicinais utilizadas na cidade de Vilhena, Rondônia. Revista Pesquisa \& Criação, v. 10, n. 2, p.165-179, 2011.

MARCHESE, J.A.; BROETTO, F.; MING, L.C.; GOTO, R.; STEFANINI, M.B.; GALINA, A.; TEDESCO, A.C.; CONTE, C.; MINIUK, C.M.; SCHURT, D.A.; SANGALETTI, E.; SILVA, G.O.; GOMES, G.; BERTAGNOLLI, J.A.; FRANCHESCHI, L.; COSSA, M.L.; MORAES, M.R.D.; LIMA, P.M.; LIRA, R.; COSTA, S. Perfil dos consumidores de plantas medicinais e condimentares do município de Pato Branco (PR). Horticultura Brasileira, v.22, n.2, p.332335, 2004.

MIURA, A.K.; LOWE, T.; SCHINESTSCK, C.F. Comércio de plantas medicinais, condimentares e aromáticas por ervateiros da Área Central de Pelotas-RS: estudo etnobotânico preliminar. Revista Brasileira de Agroecologia, v. 2, n.1, 2007.

PEREIRA, R.C.A.; SANTOS, O.G. Plantas condimentares: cultivo e utilização. Fortaleza: Embrapa Agroindústria Tropical, 2013. 55f.

RANIERI, G.R. Levantamento etnobotânico das plantas alimentícias nos municípios de Areias e São José do Barreiro - SP: um patrimônio nos quintais urbanos. 2018. Dissertação (Mestrado em Ciência Ambiental). Instituto de Energia e Ambiente da Universidade de São Paulo. 2018. $169 f$.

SILVA, A.G.; LIMA, R.A.; SOUZA, A.C.R. Uso, conservação e diversidade de plantas aromáticas, condimentares e medicinais para fins medicinais na comunidade Vila Princesa, Porto Velho-RO. Revista Pesquisa \& Criação, v.10, n.2, p.21-35, 2011.

SOUZA, B.N.O.; VEIGA, J.; ORTIZ, K.L.L.; GALVÃO, T.A.; PASA, M.C. Diversidade e uso das plantas cultivada na comunidade cinturão colina verde, Cuiabá - MT, Brasil. Biodiversidade, v.14, n.3, p. 84-93, 2015. 


\title{
CAPÍTULO 14
}

\section{RESPOSTA DE GENÓTIPOS DE MILHO A INTERAÇÃO COM BACTÉRIAS ENDOFÍTICAS DE NÓDULOS DE LEGUMINOSAS}

\author{
Alaide Maria Silva Santos ${ }^{1}$, Joseliane Fernandes Miguel dos Santos ${ }^{1}$, José Wilisson \\ Ferreira dos Santos ${ }^{2}$, Roberta Samara Nunes de Lima², Flávia de Barros Prado \\ Moura $^{3}$, Jakson Leite ${ }^{2}$
}

1. Programa de Pós-Graduação em Agricultura e Ambiente, Universidade Federal de Alagoas, Campus Arapiraca, Alagoas, Brasil.

2. Universidade Federal de Alagoas, Campus Arapiraca, Arapiraca, Alagoas, Brasil.

3. Universidade Federal de Alagoas, Campus A. C. Simões, Arapiraca, Alagoas, Brasil.

\section{RESUMO}

Bactérias endofíticas de nódulos de leguminosas podem promover o crescimento de plantas, mas ainda são poucos os relatos que confirmam esse fenômeno. O objetivo desse estudo foi avaliar as respostas de dois genótipos de milho à interação com bactérias endofíticas de nódulos de leguminosas. Bactérias (14) de sete diferentes gêneros foram inoculadas, individualmente, em sementes de dois genótipos de milho (crioula e híbrido). Aos quatro e oitos dias após a inoculação foi a avaliado a germinação, brotações laterais e comprimento da radícula. A resposta positiva à inoculação no genótipo crioulo foi identificada já aos quatro dias após a inoculação com oito isolados promovendo o crescimento radicular (AD47, ShS3, ShP6, ShS2, AD3, AT20, ShP11 e SsP7). Aos oito dias após a germinação, 13 isolados mostraram interação positiva com o genótipo crioulo promovendo o crescimento da radícula. No genótipo híbrido, a resposta à inoculação ocorreu um pouco mais tarde, aos oito dias após a inoculação. Somente dois isolados (ShP6 e AD3) promoveram o crescimento radicular do genótipo híbrido. O isolado ShP6, pertencente ao gênero Bacillus, dobrou o crescimento radicular no genótipo híbrido, representando um recurso microbiano promissor para testes em campo com este genótipo. Bactérias endofíticas de nódulos promovem o crescimento radicular do milho e esta reposta é dependente do genótipo da planta e da bactéria.

Palavras-chave: Zea mays, Inoculação e Bactérias promotoras do crescimento de plantas.

\section{ABSTRACT}

Nodule endophytic bacteria can promote plant growth, but there are still few reports that confirm this phenomenon. The objective of this study was to evaluate the interaction between nodule endophytic bacteria and two maize genotypes. Bacteria (14) from seven different genera were inoculated, individually, in seeds of two genotypes of corn ('crioulo' and hybrid). Germination, lateral root shoots and root length were evaluated four and eight days after inoculation. The positive response to inoculation in the 'crioulo' genotype was identified four days after inoculation with eight isolates promoting root growth (AD47, ShS3, ShP6, ShS2, AD3, AT20, ShP11 and SsP7). Eight days after germination, 13 isolates 
showed a positive interaction with the 'crioulo' genotype promoting root growth. For the hybrid genotype, the response to inoculation occurred later, eight days after inoculation. Only two isolates (ShP6 and AD3) promoted the root growth of the hybrid genotype. The isolate ShP6, belonging to the genus Bacillus, doubled the root growth in the hybrid genotype, representing a promising microbial resource for field tests with this genotype. Endophytic nodule bacteria promote root growth of corn and this response is dependent on the plant and bacteria genotype.

Keywords: Zea mays, Inoculation and Plant growth-promoting bacteria.

\section{INTRODUÇÃO}

A domesticação do milho (Zea mays L.) no México, a partir de uma gramínea selvagem conhecida como teosinto do gênero Tripsacum, é um exemplo inquestionável de como grandes mudanças morfológicas podem acontecer em resposta à seleção (KELLOGG, 1997).

O padrão evolutivo desse processo de domesticação era desconhecido até a década de 30, quando pesquisadores produziram uma progênie fértil a partir do cruzamento do milho com o teosinto. Nesse cruzamento, Doebley, Stec e Hubbard (1993) descobriram que haviam cinco regiões ou loci, correspondendo a genes únicos, com grandes efeitos nas características que diferenciam milho e teosinto.

Atualmente, o milho (Zea mays L.) é uma gramínea botanicamente classificada como reino Plantae, divisão Anthophta, classe Monocotiledonea, ordem Poales, família Poaceae, gênero Zea, espécie Zea mays (GODOY, 2017). É uma planta C4 extremamente eficiente na conversão de dióxido de carbono $\left(\mathrm{CO}_{2}\right)$. Caracteriza-se como alógoma, monóica e apresenta uma inflorescência masculina (pendão) e uma feminina (espiga) em diferentes locais da planta (GALVÃO et al., 2015).

Por ser uma das espécies produtoras de grãos mais cultivadas no mundo e de grande importância para alimentação humana e animal, além de matéria-prima para diversas agroindústrias, o milho tem sido alvo de vários estudos, tanto utilizando suas variedades híbridas quanto crioulas. O germoplasma do milho é constituído por raças crioulas, populações adaptadas e materiais exóticos introduzidos, sendo caracterizado por uma ampla variabilidade genética (FONTINELE et al., 2018).

A hibridização do milho é um exemplo de como essa espécie é melhorada. A hibridação é um processo que permite o fluxo gênico entre plantas de uma espécie com características diferentes, nesse processo o objetivo é produzir uma variedade com as 
melhores características das plantas parentais que se adaptem as condições ambientais (FU et al., 2015). As sementes de milho resultantes desse cruzamento darão origem a plantas com genótipos mais tolerantes a seca, mais resistentes a estresses e desenvolvimento de uma melhor produtividade (WITT et al., 2012).

Diferentemente das sementes hibridas do milho, as sementes crioulas do milho são sementes que passaram pela polinização aberta e que não foram expostas a reprodução híbrida (DELAFOULHOUZE et al., 2016). Essas sementes têm o mesmo genótipo de seu parental. $O$ uso de variedades crioulas permite que as sementes sejam guardadas para plantios seguintes, o que diminui o custo de produção. Além de manter, variedades adaptadas localmente, mantém a diversidade genética da espécie, podendo servir de fonte para melhoramento genético.

Por se tratar de uma cultura importante, com consequente demanda de muitos insumos agrícolas, adotar técnicas que aumentem a produtividade e reduza o uso de fertilizantes pode baixar os custos de produção e proteger os ecossistemas. Recentemente tem-se observado o aumento no interesse pela manipulação de bactérias promotoras do crescimento de plantas como recurso biológico para promover a produção do milho (OLIVEIRA et al., 2012). No entanto, as respostas do milho a inoculação com bactérias são dependentes do genótipo da planta e da bactéria, o que leva a necessidade de estudos de interação para seleção dos pares simbióticos. O objetivo desse estudo foi avaliar as respostas de dois genótipos de milho (um híbrido, variedade Thander e outro crioulo, variedade Jaboatão) em relação à interação com bactérias promotoras do crescimento de plantas.

\section{MATERIAIS E MÉTODOS}

A resposta de dois genótipos de milho à interação com bactérias promotoras do crescimento de plantas foi avaliada com base no teste de germinação e crescimento radicular.

O experimento ocorreu no Laboratório de Fisiologia Vegetal da Universidade Federal de Alagoas, Campus Arapiraca. As sementes de milho utilizadas foram das variedades Thander (híbrido) e Jaboatão (crioulo). As sementes foram previamente testadas quanto ao potencial germinativo para averiguar a viabilidade. As bactérias utilizadas para a inoculação 
dos genótipos de milho foram isoladas de nódulos de leguminosas da Caatinga cultivadas em solos de Alagoas, sendo quatro do gênero Bacillus (AD47, ShS9, ShS3, ShP6), uma do gênero Brevundiomona (ShS2), uma do gênero Enterobacter (AD3), duas do gênero Leifsonia (AT20, AT8), uma do gênero Pseudomonas (ShP11), três do gênero Paenibacillus (SsS3, AP93, ShP12) e duas do gênero Roseomonas (SsP7, ShS9), totalizando 14 bactérias endofíticas de nódulos de leguminosas. As sementes foram desinfestadas por imersão em álcool 70\% por 1 minuto, depois em hipoclorito de sódio por 3 minutos e, posteriormente, lavadas seis vezes sucessivamente com água destilada estéril. A inoculação foi feita por imersão, em que 32 sementes ficaram submersas por 1 hora em 10 $\mathrm{mL}$ do crescimento bacteriano com concentração de $5,2 \times 10^{7}$ UFC $\mathrm{mL}^{-1}$ do respectivo tratamento. As sementes do controle foram submersas em meio YM por 1 hora. $\mathrm{O}$ inóculo bacteriano foi obtido após o crescimento de colônias puras de cada bactéria em meio de cultivo YM (VINCENT, 1970) por 24 a $150 \mathrm{rpm}$, quando atingiu a concentração de 5,2 × 107 UFC $\mathrm{mL}^{-1}$. Cada tratamento contou com quatro repetições, sendo cada repetição composta por oito sementes. As oitos sementes foram colocadas em cima de duas de papéis germitest umedecidas com água destilada e autoclavada ( $1 \mathrm{~atm}, 120 \stackrel{\circ}{\circ} \mathrm{C}, 30 \mathrm{~min}$ ) e então coberta com outra folha de papel, enroladas e colocadas em BOD na temperatura de $25 \stackrel{\circ}{\circ}$ para a germinação.

As coletas de dados foram feitas aos quatro e oito dias após a germinação das sementes de milho. As variáveis medidas foram: germinação (\%), comprimento da raiz principal $(\mathrm{cm})$ e o número de raízes laterais. Foi feita a média de cada repetição por tratamento e verificada a distribuição normal dos dados aplicando o teste de Shapiro-Wilk e posteriormente aplicada a análise de variância (ANOVA) através do teste $F$ com agrupamento das médias utilizando o teste de Scott-Knott com significância de 5\%. 0 programa Sisvar v 5.0 (FERREIRA, 2011) foi utilizado para a produção das análises estatísticas.

\section{RESULTADOS E DISCUSSÃO}

A resposta da interação entre bactérias endofíticas de nódulos de leguminosas e dois genótipos de milho foi avaliada, aos quatro e oito dias após inoculação, quanto à promoção do crescimento radicular, germinação e número de raízes laterais. Aos quatro 
dias aos a inoculação, o genótipo de milho crioulo respondeu a interação com as bactérias, sendo que das 14 bactérias avaliadas 8 promoveram o crescimento radicular em relação ao controle. As bactérias que promoveram o crescimento pertencem aos gêneros Bacillus sp. (AD47, ShS3 e ShP6), Brevundimonas sp. (ShS2), Enterobacter sp. (AD3), Leifsonia sp. (AT20), Pseudomonas sp. (ShP11) e Roseomonas sp. (SsP7) (Figura 1A). O genótipo de milho híbrido também respondeu a inoculação com as bactérias já aos quatro dias após a inoculação. No entanto, o efeito foi contrário, em que das 14 bactérias testadas 10 reduziram o crescimento radicular em relação ao controle e nenhuma promoveu 0 crescimento.
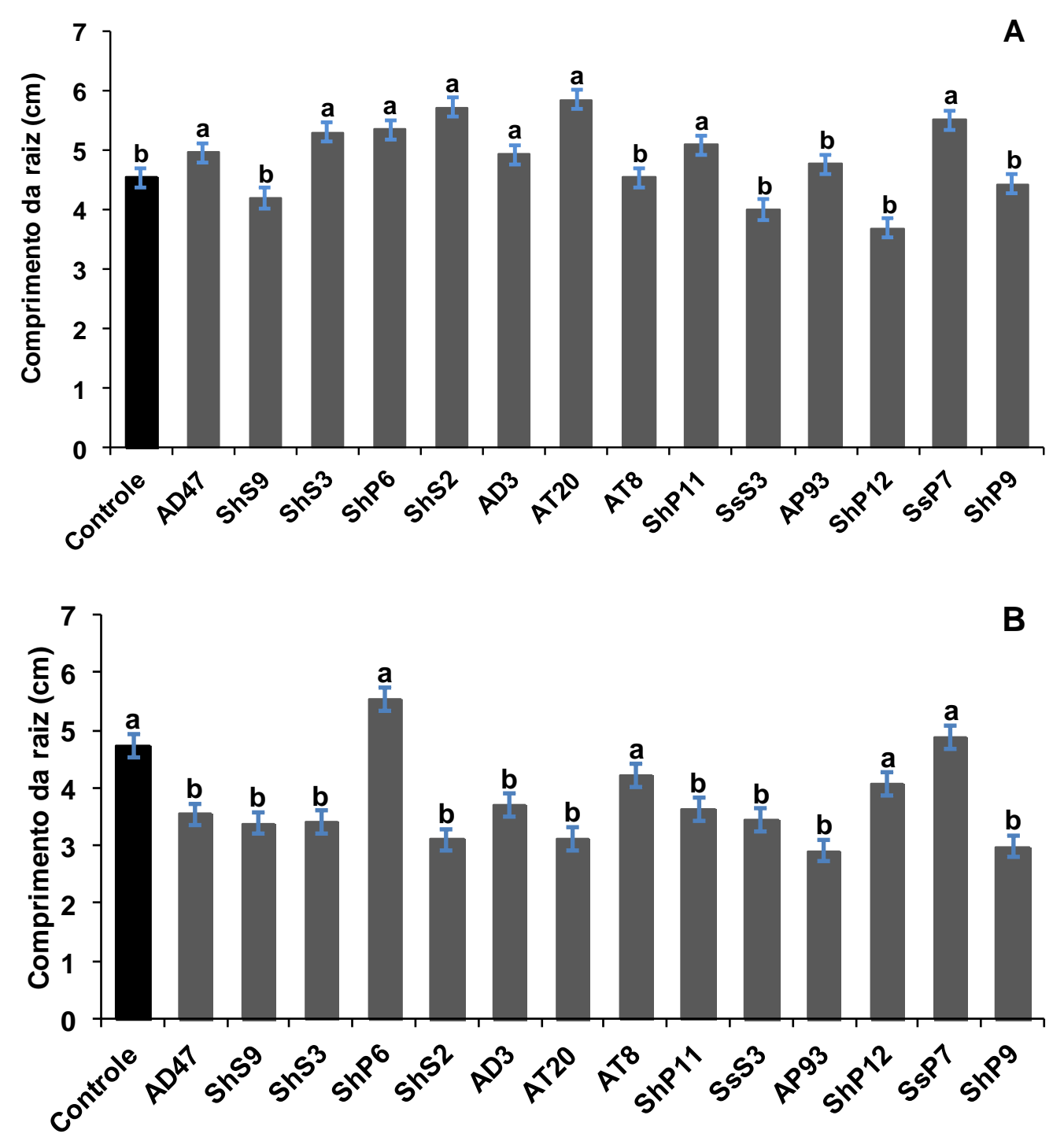

Figura 1. Comprimento da raiz de genótipo de milho crioulo $(A)$ e híbrido $(B)$ após quatro dias de inoculação com bactérias. Médias seguidas da mesma letra não diferem significativamente entre si a $5 \%$ de probabilidade pelo teste de Scott-Knott. 
Aos oito dias após á inoculação, o genótipo crioulo respondeu positivamente à inoculação com 13 bactérias das 14 avaliadas, sendo que as 13 bactérias que promoveram o crescimento radicular do genótipo de milho crioulo pertencem a setes diferentes gêneros, a saber: Bacillus (AD47, ShS9, ShS3, ShP6), Brevundiomonas (ShS2), Enterobacter (AD3), Leifsonia (AT20, AT8), Pseudomonas (ShP11), Paenibacillus (AP93, ShP12) e Roseomonas (SsP7, ShS9) (Figura 2A).
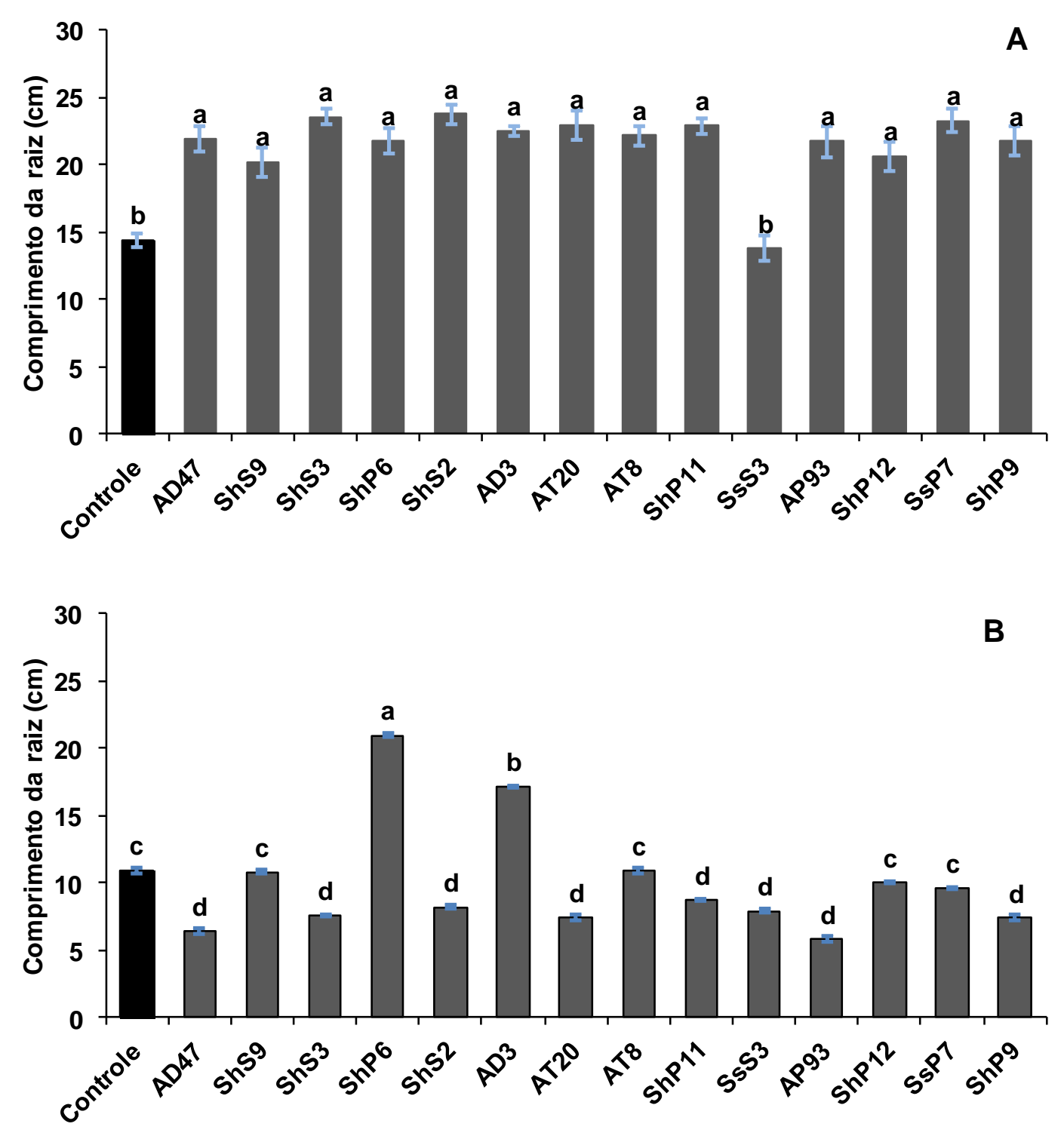

Figura 2. Comprimento da raiz de genótipo de milho crioulo $(A)$ e híbrido (B) após oito dias de inoculação com bactérias. Médias seguidas da mesma letra não diferem significativamente entre si a $5 \%$ de probabilidade pelo teste de Scott-Knott. 
Na segunda avaliação do crescimento radicular, aos oito dias após a inoculação, o genótipo de milho híbrido mostrou interação positiva com duas bactérias (Bacillus sp. ShP6 e Enterobacter sp. AD3), interação negativa com oito bactérias (Bacillus sp. AD47, Bacillus sp. ShS3, Brevundiomona sp. ShS2, Leifsonia sp. AT20, Pseudomonas sp. ShP11, Paenibacillus sp. SsS3, Paenibacillus sp. AP93 e Roseomonas sp. ShS9) e neutra com quatro isolados (Bacillus sp. ShS9, Leifsonia sp. AT8, Paenibacillus sp. ShP12 e Roseomonas sp. SsP7) (Figura 2B).

A promoção do crescimento radicular nos dois genótipos de milho pelas bactérias pode ter ocorrido devido à capacidade que algumas bactérias possuem de produzir hormônios, como a auxina, que atuam na fisiologia do processo germinativo promovendo mudanças na arquitetura do sistema radicular, tanto no crescimento com na ramificação (NUMAN et al., 2018).

Nesse estudo, foi possível ver que houve interação entre os genótipos de milho e dos isolados bacterianos (Figura 1 e 2). Das 14 bactérias avaliadas 13 promoveram 0 crescimento radicular do genótipo de milho crioulo (Figura 2A), enquanto somente 2 promoveram o crescimento radicular do genótipo híbrido (Figura 2B). Roesch e colaboradores (2005) discorreram que o fato do milho ter uma variabilidade genética muito alta, faz com que este apresente uma população muito alta de bactérias associadas que promovem o crescimento vegetativo da planta, o que pode explicar o fato do milho crioulo ter tido uma interação tão forte com 13 estirpes bacterianas de 7 gêneros diferentes.

A resposta positiva à inoculação no genótipo crioulo foi identificada já aos quatro dias após a inoculação (Figura 1A), em que oito isolados promoveram o crescimento radicular (AD47, ShS3, ShP6, ShS2, AD3, AT20, ShP11 e SsP7). No genótipo híbrido, a resposta à inoculação ocorreu um pouco mais tarde, aos oito dias após a inoculação (Figura B). Somente dois isolados (ShP6 e AD3) promoveram o crescimento radicular do genótipo híbrido. O isolado ShP6, pertencente ao gênero Bacillus, dobrou o crescimento radicular no genótipo híbrido, representando um recurso microbiano promissor para testes em campo com este genótipo.

Os resultados da figura 2B mostram que a interação do milho híbrido com bactérias dos gênero Bacillus sp. é algo frequentemente positivo, visto que, nesse gênero, há muitas espécies de rizobactérias, que além de promoverem o crescimento radicular, também são fixadores de nitrogênio, melhorando assim as condições vegetativas e fisiológicas do milho (ARAÚJO; GUERREIRO, 2009). 
Silva e colaboradores (2016) relatam que plantas de milho podem estabelecer associações benéficas com bactérias promotoras de crescimento de plantas. Esses autores ainda mostram que a maioria das bactérias isoladas de milho são dos gêneros Pseudomonas, Acinetobacter; Enterobacter e Bacillus, gêneros esses comuns aos mais representativos na interação com o milho híbrido.

Não houve diferença significativa entre a resposta do milho (híbrido e crioulo) em relação as estirpes bacterianas para as variáveis número de raízes laterais e germinação. Isso pode ter ocorrido pelo fato do milho ser uma espécie que vem sofrendo muitos processos seleção.

\section{CONCLUSÃO}

O milho apresenta uma grande diversidade de bactérias endofíticas com capacidade de promover o crescimento vegetal associadas a ele. Os dois genótipos de milho interagiram de forma diferente com as bactérias. Enquanto o crioulo obteve uma interação de promoção radicular com 13 estirpes, o híbrido obteve interação positiva de crescimento radicular apenas com duas estirpes. A inoculação melhorou o crescimento radicular do milho.

\section{REFERÊNCIAS}

ARAÚJO, F. F; GUERREIRO, R. T. Bioprospection of Bacillus isolates promoters of corn growth in natural and sterile soil. Ciências agrotecnicas, v. 34, n. 4, p. 837-844, 2010.

COIMBRA, R. A; TOMAZ, C. A; MARTINS, C. C; NAKAGAWA, J. Teste de germinação com acondicionamento dos rolos de papel em sacos plásticos. Revista Brasileira de Sementes, v. 29, n. 1, p.92-97, 2007.

DELAFOULHOUZE, M. H. F.; WEIRICH NETO P. H.; SOUZA, N. M. DE; ROCHA, C. H. Sementes Crioulas: conquistando a soberania. In: Rocha, C. H.; Weirich Neto, P. H.; Souza, N. M. de (org.). Sustentabilidade: a transformação vem da agricultura familiar. Ponta Grossa: Estúdio Texto, 2016.

DOEBLEY, J; STEC, A. Inheritance of the morphological diferences between maize and teosinte: comparison of results for two F2 populations. Genetics, v.134, n.2, p.559-570. 1993. 
FERREIRA, D. F. Sisvar: um sistema computacional de análise estatística. Ciências. Agrotecnicas, v.35, n.6, p.1039-1042, 2011.

FONTINELLE, Y. R; BORGES, V. S; LIMA, M. S; NASCIMENTO, M. M; HAVERROTH, M; SILVA, S. A. A. Variabilidade entre variedades de milho crioulo. Revista RG News. v. 4, p. $1,2018$.

FU, J; YANG, X; CHENG, M; LÜ, G; WANG, P; WU, Y; ZHENG, M; ZHOU, S; RONG, T; TANG, Q. Perennial aneuploidy as a potential material for gene introgression between maize and Zea perennis. Journal of Integrative Agriculture, v.14, p. 839-846, 2015.

GALVÃO, J. C. C., MIRANDA, G. V., TROGELLO, E. E FRITSCHE-NETO, R. Sete décadas de evolução do sistema produtivo da cultura do milho. Revista Ceres, v.61, p.819-828. 2015.

KELLOG, E. A. Plant evolution: The dominance of maize. Current Biology, v.7, n.7, p. 1-3, 1997.

LIMA, T. M; PASCOAL, P. R. P; CARVALHO, F. J; LANA, R. M. Q. Adubação de milho crioulo com resíduos orgânicos em associação com Azospirillum brasilense. Revista Brasileira de Agropecuária Sustentável (RBAS), v.9, n.2, p.9-16, 2019.

NUMAN, M.; BASHIR, S.; KHAN, Y.; MUMTAZ, R.; SHINWARI, Z. K.; KHAN, A. L.; KHAN, A.; AL-HARRASI, A. Plant growth promoting bacteria as an alternative strategy for salt tolerance in plants: A review. Microbiological Research, v.209, p. 21-32, 2018.

OLIVEIRA, M. A; ZUCARELI, C; SPOLAOR, L. T; DOMINGUES, A. R; FERREIRA, A. S. Desempenho agronômico do milho sob adubação mineral e inoculação das sementes com rizobactérias. Revista Brasileira de Engenharia Agrícola e Ambiental, v.16, n.10, p.1040-1046, 2012.

ROESCH, L. F; CAMARGO, F; SELBACH, P; SACCOL DE SÁ, E; PASSAGLIA, L. Identificação de cultivares de milho eficientes na absorção de nitrogênio e na associação com bactérias diazotróficas. Ciência Rural, v. 35, n.4, p.924-927, 2005.

SILVA, K; PERIN, L; GOMES, M. L; BARAÚNA, A. C; PEREIRA, G. M. D; MOSQUEIRA, C. A; COSTA, I. B; O'HARA, G; ZILLI, J. E. Diversity and capacity to promote maize growth of bacteria isolated from the Amazon region. Acta amazônica, v.46, n.2, p. 111-118, 2016.

WITT, S; GALICIA, L; LISEC, J; CAIRNS, J; TIESSEN, A; ARAUS, J. L; PALACIOS-ROJAS, $\mathrm{N}$; FERNIE, A. R. Metabolic and phenotypic responses of greenhouse-grown maize hybrids to experimentally controlled drought stress. Molecular Plant, v.5, n.2, p.401-417, 2012. 


\title{
CAPÍTULO 15
}

\section{VISITANTES FLORAIS DE TRÊS ESPÉCIES DE PLANTAS}

\author{
RUDERAIS: Alternanthera tenella, Mimosa debilis E TridaX
}

\author{
PROCUMBENS
}

\section{Cristina Filomena Justo ${ }^{1}$, Camila Abreu Rocha ${ }^{2}$}

1. Curso de Ciências Biológicas, Instituto de Ciências Biológicas e da Saúde/Campus Universitário do Araguaia/Universidade Federal de Mato Grosso, Pontal do Araguaia, MT, Brasil;

2. Curso de Agronomia, Instituto de Ciências Exatas e da Terra/ Campus Universitário do Araguaia/Universidade Federal de Mato Grosso, Barra do Garças, MT, Brasil.

\section{RESUMO}

Três espécies de plantas herbáceas nativas classificadas como daninhas de pastagens e cultivos foram analisadas com os objetivos de: i) registrar os horários de abertura e fechamento das inflorescências, suas cores e tamanhos, ii) anotar a quantidade de visitantes florais, iii) comparar os visitantes florais em função do horário, da espécie de planta e local. Contabilizou-se os visitantes durante dez minutos a cada hora das 7:00 às 18:00 horas durante cinco dias para as três espécies no local (1). Registrou-se os visitantes em $T$. procumbens em dois locais adicionais: (2) entre construções, (3) arborizado, com a mesma metodologia. Observou-se senescência das inflorescências de $M$. debilis a partir de 11:00; as de A. tenella e T. procumbens permaneceram abertas até 18:00 horas. Anotouse 3578 visitantes no total; os mais frequentes foram Apis mellifera (49,2\%), Lepidoptera $(25,2 \%)$ e Trigona spinipes $(22,4 \%)$. Mais visitas ocorreram das 7:00 às 8:00 horas para $M$. debilis e entre 11:00 e 15:00 horas para A. tenella e T. procumbens. A. mellifera raramente visitou $A$. tenella e visitou $M$. debilis apenas até 9:00 horas. Lepidoptera foram mais frequentes em $T$. procumbens e $T$. spinipes em $A$. tenella. $T$. procumbens recebeu mais visitas no local (1), seguido do (3). Ocorreu diferença entre horários para $A$. mellifera e Lepidoptera em T. procumbens. Conclui-se que as plantas analisadas são relevantes fontes alimentares para os visitantes florais, os quais tem preferências distintas para a espécie de planta e horário de visitação.

Palavras chave: Apaga-fogo, sensitiva-de-leite e erva-de-touro.

\section{ABSTRACT}

Three species of native herbaceous plants classified as weeds in context of pastures and cultivation were analyzed with the aim of: i) to register the opening and closing time of the inflorescences, their colors and sizes, ii) to annotate the amount of floral visitors, iii) to compare floral visitors by time, plant species, and place. The following observations were made: (A) Accounting of the visitors for ten minutes per hour from 7 a.m. to 6 p.m. during five days for the three species in location (1). (B) Visitors were registered at $T$. procumbens in two aditional locations: (2) between buildings, (3) location with trees, with the same 
methodology. Senescence of the inflorescences of $M$. debilis happened after 11 a.m; the ones of $A$. tenella and $T$. procumbens kept open up to 6 p.m. 3500 visitors were registered; the most frequent ones were Apis mellifera $(49,2 \%)$, Lepidoptera $(25,2 \%)$ and Trigona spinipes (22,4\%). More visits occurred from 7 a.m. to 8 a.m. for M. debilis, from 11 a.m. to 3 p.m. for $A$. tenella and $T$. procumbens. A. mellifera rarely visited $A$. tenella, visited $M$. debilis until 9 a.m. Lepidoptera were more frequent in $T$. procumbens, $T$. spinipes in $A$. tenella. T. procumbens received more visits in location (1), followed by (3). Significant difference occurred in visiting time for $A$. mellifera and Lepidoptera in T. procumbens. It was concluded that the analyzed plants are relevant feeding sources for the floral visitors, which have different preferences for plant species and visiting time.

Keywords: Sanguinaria, Mimosa spp and coat-buttons.

\section{INTRODUÇÃO}

A palavra ruderal provém de 'ruderes', que tem como significado ruínas, entulho (RIZZINI, 1979). O termo é utilizado para nomear as plantas que durante o processo evolutivo adaptaram-se a ambientes antropizados, comportando-se como invasoras de culturas e pastagens. São comumente denominadas de ervas daninhas (LORENZI, 2008). O termo "daninha" se limita a espécies que afetam os interesses humanos, enquanto que ruderal tem uma nuance ecológica, tratando das espécies resistentes aos impactos antrópicos e que ocorrem em áreas degradadas (MORO et al., 2012). A maioria das plantas ruderais são ervas anuais ou bienais que tem como característica ciclo curto, ampla distribuição geográfica, rápidas taxas de crescimento e alta produção de sementes (MATESANZ; VALLADARES, 2009).

Há poucos estudos da polinização de plantas ruderais (SILVA et al., 2011), mas globalmente, quase $90 \%$ das plantas silvestres com flores dependem da transferência de pólen por animais (IPBES, 2016), variando de 78\% nas comunidades vegetais da zona temperada para 94\% nas comunidades tropicais (OLLERTON; WINFREE; TARRANT, 2011). Estima-se que $86 \%$ das espécies tenha polinização zoófila a partir de levantamentos em diversas áreas do Cerrado entre plantas lenhosas e herbáceas (SILBERBAUERGOTTSBERGER; GOTTSBERGER; 1988), enquanto 100\% das espécies lenhosas de um cerrado em Brasília (DF) tinha polinização zoófila, com destaque para pequenos insetos (44\%) e abelhas grandes, com 32\% (OLIVEIRA; GIBBS, 2000) e observou-se entre 91 e $100 \%$ das espécies de plantas herbáceas eram polinizadas por abelhas em áreas de cerrado localizadas em MG (SILVA; ARAÚJO; OLIVEIRA, 2012). 
A espécie Apis mellifera geralmente é considerada como polinizador mais eficiente, mas um estudo comparativo em 41 sistemas agrícolas distribuídos no mundo todo mostrou que outros insetos podem ser mais relevantes na polinização efetiva (GARIBALDI et al., 2013); a maioria dos quais são de espécies não domesticadas (IPBES, 2016), incluindo outras abelhas, borboletas, mariposas, vespas, moscas e besouros, e vertebrados como morcegos, esquilos, pássaros e alguns primatas (CENTRO DE GESTÃO E ESTUDOS ESTRATÉGICOS, 2017).

Embora algumas abelhas possam persistir ou até prosperar em paisagens moderadamente perturbadas pelo ser humano (WINFREE et al., 2009), Aguiar (2003) afirma que pouco se sabe sobre os recursos florais necessários à manutenção das comunidades de abelhas em habitats naturais brasileiros. Vieira et al. (2008) realizaram um levantamento da flora apícola em área de Cerrado no Mato Grosso do Sul e constataram que os diferentes períodos de florescimento das espécies vegetais existentes no cerrado garantem oferta de recurso alimentar durante todo o ano. Pinheiro et al. (2008) avaliaram uma comunidade herbácea no Sul do Brasil, com alta diversidade de fontes alimentares e verificaram que a família Asteraceae foi a principal fonte de recursos florais utilizada durante o ano, com grande importância para a manutenção das populações de muitas espécies de visitantes.

Agostini e Sazima (2003) ressaltam que o conhecimento dos recursos florais de plantas pode ser útil para a elaboração de planos de manejo em ambientes urbanos visando à utilização de plantas ornamentais adequadas para atender maior diversidade de abelhas, pois as flores apresentam diferentes recursos que podem ser utilizados pelos visitantes florais.

Os recursos florais mais comuns são pólen, néctar, óleo e água. O grão de pólen integra a dieta de vários grupos de insetos, contendo quantidades variáveis de proteínas, lipídeos, amido, açúcares, além de fósforo, vitaminas, água e outros componentes. O néctar geralmente é produzido para ser oferecido como recurso para os polinizadores (AGOSTINI; LOPES; MACHADO, 2014). Provavelmente os nectários tiveram várias origens evolutivas e se desenvolveram em várias posições e tecidos das flores (ENDRESS, 1994). Os principais componentes do néctar são: água, carboidratos na forma de mono- e dissacarídeos, aminoácidos e proteínas, íons, lipídeos em quantidades mínimas e metabólitos secundários diversos (AGOSTINI; LOPES; MACHADO, 2014). A concentração de açúcares varia de 6 a 85\%, com mediana em torno de 40\% (PAMMINGER et al., 2019). 
As espécies Alternanthera tenella Colla, Mimosa debilis Humb. \& Bonpl. ex Willd. e Tridax procumbens $L$. ocorrem de forma espontânea em área antropizadas, sendo citadas em diferentes estudos da flora ruderal (PEDROTTI; GUARIM NETO 1998; VICHIATO; VICHIATO, 2016), ou como invasoras de cultivos e pastagens (LORENZI, 2008; REIS et al., 2011). Brandão et al. (1984) ressaltam a importância de plantas daninhas como fonte de néctar e/ou pólen e sugerem o cultivo delas para o fornecimento de néctar e pólen em períodos de escassez. Kiill, Haji e Lima (2000) reforçam a ideia ao analisar os visitantes florais de plantas invasoras em cultivos irrigados de plantas frutíferas.

A. tenella, M. debilis e $T$. procumbens foram citadas em estudos de polinização (KINOSHITA et al., 2006; SILVA; ARAÚJO; OLIVEIRA, 2012; SANTOS; LIMA; LEITE, 2016, respectivamente), mas em nenhum dos trabalhos as plantas foram estudadas em conjunto ou de modo comparativo. O objetivo deste trabalho foi estudar a biologia floral das três espécies, de modo a avaliar suas características florais (horário de abertura e fechamento das flores, suas cores e tamanhos) e os visitantes florais na região do Médio Araguaia, com o propósito de compará-los e identificá-los; avaliar a frequência de visita em função do horário, da espécie de planta e do local de ocorrência da planta.

\section{MATERIAIS E MÉTODOS}

As plantas A. tenella (Apaga fogo), M. debilis (Dormideira ou Sensitiva-de-leite), $T$. procumbens (Erva de touro) estão amplamente distribuídas no Brasil e são consideradas plantas daninhas (LORENZI, 2008). Todas têm porte herbáceo e pertencem respectivamente às famílias Amaranthaceae (MOREIRA; BRAGANÇA, 2011), Fabaceae (SILVA et al., 2010) e Asteraceae (MOREIRA; BRAGANÇA, 2011).

A. tenella recebe diversas designações vernaculares: alecrim, apaga-fogo, carrapichinho, carrapicho, corrente, mangericão, mangerico, manjericão, periquito, perpétua-do-campo e ocorre em plantios hortícolas e de frutíferas, sendo relatada como espécie apícola em Piracicaba- SP (MARCHINI et al., 2001).

M. debilis forma densas reboleiras, infestando áreas de pastagens, beiras de estradas e terrenos baldios (LORENZI, 2008). É conhecida por causar lesões de pele e mucosas em equinos devido à ação de seus espinhos (REIS et al., 2011). De acordo com Barneby (1991), a espécie tem cinco variedades; com a ocorrência na região do estudo de 
Mimosa debilis Humboldt \& Bonpland ex Willdenow var. debilis e Mimosa debilis Humboldt \& Bonpland ex Willdenow var. amnis-mortium, Barneby, var. nov.

Pedrotti e Guarim Neto (1998) citam T. procumbens para a flora ruderal de Cuiabá com o nome vulgar de beiço de boi; também mencionam Alternanthera ficoidea (L.) R. Br., que é sinonímia homotípica para A. tenella (SENNA, 2015).

Assim como muitas outras plantas ruderais, as espécies em estudo são nativas do Brasil e a sua ocorrência em área urbana pode estar relacionada com a proximidade com áreas naturais e semi-naturais que servem como fonte de diásporos (VICHIATO; VICHIATO, 2016).

O local de estudo foi Campus Universitário do Araguaia, Unidade Barra do Garças-

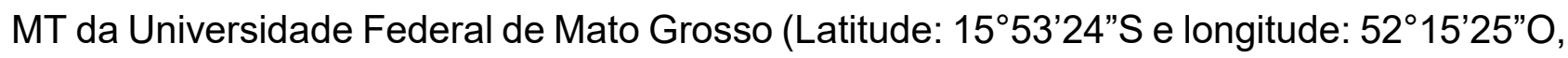
altitude $337 \mathrm{~m}$ ), no qual realizou-se observações de visitantes florais nas espécies de plantas citadas. $\mathrm{O}$ ambiente geral do campus é pobre em árvores, com extensas áreas de solo nu ou exposição de subsolo em fase de colonização por plantas ruderais. Ao redor dele há setores urbanizados e áreas rurais com predomínio de pastagens e vegetação de cerrado e o Parque Estadual da Serra Azul a cerca de $5 \mathrm{~km}$ de distância.

O clima da região da região é tropical semiúmido (tipo Aw, segundo Köppen-Geiger) e caracteriza-se por duas estações bem definidas: uma chuvosa (outubro a abril) e outra seca (maio a setembro). A precipitação média anual é de $1500 \mathrm{~mm}$ e a temperatura média 25,5ㄷ (PIRANI; SANCHEZ; PEDRONI, 2009). O estudo foi realizado durante a estação seca do ano de 2017.

Selecionou-se três locais no Campus, o local 1) próximo da pista de atletismo, a 50 $m$ de vegetação nativa, o local 2) em área sem árvores entre construções e o local 3) entre construções e a $20 \mathrm{~m}$ de distância de árvores plantadas. As três espécies de plantas ocorriam espontaneamente no local 1 em moitas monoespecíficas localizadas a 20 metros de distância uma da outra. Apenas T. procumbens ocorria nos locais 2 e 3 . Os três locais estavam entre 600 e 700 m de distância da mata ciliar do córrego Fundo, afluente da margem esquerda do Rio Garças.

A realização dos experimentos foi precedida de uma análise exploratória em 15 de maio de 2017, no local 1 com ocorrência das três espécies. Observou-se os horários de abertura e fechamento das flores, iniciando a observação às 7:00 horas da manhã até às 18:00. As moitas das três espécies estavam a uma distância que podia ser percorrida à pé entre as observações ao longo do dia. Realizou-se ainda registros fotográficos com a câmera de aparelho celular (Marca LG, modelo L Prime Dual TV D337). 
As observações do primeiro experimento ocorreram entre 17 de Maio e 14 de Junho de 2017, para quantificar e identificar os visitantes florais nas três espécies de planta no local 1. Registrou-se os visitantes a cada hora por 10 minutos nas flores de cada espécie, desde às 7:00 da manhã até às 18:00 horas, durante cinco dias não consecutivos, num total de 180 observações em 55 horas de campo. Para isso delimitou-se uma área de $50 \times 50 \mathrm{~cm}$ nas moitas de cada planta, anotando-se o número de insetos e a espécie que visitava cada planta no intervalo cronometrado.

As observações do segundo experimento foram realizadas entre 05 e 19 de julho de 2017, avaliando-se os visitantes florais para T. procumbens nos locais 2 e 3 , de modo a comparar com visitantes para a mesma planta no local 1 . Anotou-se o número de indivíduos de cada visitante floral com a mesma metodologia, gerando 144 observações em 55 horas de campo adicionais. A distância entre os locais 2 e 3 podia ser percorrida à pé no intervalo entre as observações (100 m).

A identificação das plantas foi feita pelo prof. Dr. Sidnei Roberto de Marchi (ICET/CUA/UFMT). A identificação dos visitantes florais foi realizada por observação visual na área de estudos e coleta de insetos para a confirmação da espécie através de chave de identificação entomológica com auxílio da profa. Dra. Geane Brizzola dos Santos (ICBS/CUA/UFMT).

O número de visitantes florais nas diferentes espécies de ervas foi tabulado em planilha eletrônica. Para as análises estatísticas do experimento 1, os dias de observação foram considerados repetições (5), enquanto os horários de visita (12) e as espécies (3) como fontes de variação. Usou-se o delineamento inteiramente casualisado, em esquema fatorial $12 \times 3$. Para o experimento 2 , as fontes de variação foram os horários de visita (12) e os locais (3) também em esquema fatorial $12 \times 3$.

Os dados foram submetidos à análise de variância e as comparações entre médias foram realizadas pelo teste Scott-Knott a $5 \%$ de probabilidade no programa estatístico Sisvar Versão 5.6 (FERREIRA, 2011). Os dados não foram transformados para as análises estatísticas.

\section{RESULTADOS E DISCUSSÃO}

A partir da análise exploratória verificou-se que a inflorescência de $A$. tenella é do tipo glomérulo, formada por flores com tépalas brancas, secas e livres entre si (Figura 1), 
estando de acordo com a característica de Amaranthaceae (MOREIRA; BRAGANÇA, 2011). Os glomérulos são eretos e acessíveis aos visitantes (Figura $1 A$ ), medindo aproximadamente $1,0 \mathrm{~cm}$ (Figura 1B). A abertura das flores ocorreu a partir das 9:00 horas da manhã e perdurou até o final das observações às 18:00. As flores são bissexuadas, campanuladas, monoclamídeas, amarelas, sem odor (RCPOL, 2020a).

Os botões florais que compõem a inflorescência de $M$. debilis em pré-antese são esverdeados (Figura $1 \mathrm{C}$, à direita). No estágio de antese, a inflorescência tem forma globosa e chega a medir $2,5 \mathrm{~cm}$ de diâmetro, o fenômeno ocorre no início da manhã, com total abertura das flores de coloração rósea devido aos conjuntos dos filetes dos estames (Figura 1C, ao centro); perdendo a cor a partir das 10:00 horas, a medida que a inflorescência começava a murchar (Figura 1C, à esquerda).

De acordo com Dutra (2009), as flores de M. debilis são homomórficas e o pólen foi estudado por Lima, Silva e Santos (2008), sendo observados em tétrades tetraédricas e decussadas esféricas. Não foram encontradas outras informações a respeito da biologia floral de M. debilis, mas em Mimosa bimucronata (DC.) Kuntze as flores recém-abertas exalam aroma frutado produzido por osmóforos que se localizam nas bordas das pétalas (SILVA et al., 2011).

$\mathrm{Na}$ inflorescência de $T$. procumbens, o primeiro estágio é o de botões florais, com todas as flores fechadas (Figura 1D, à esquerda), quando o capítulo se encontra em antese, as flores abrem-se progressivamente (Figura 1D, à direita). As flores periféricas possuem lígula de coloração branca. As flores centrais do capítulo são amarelas (Figura 1E). Com a maturação, as brácteas do capítulo se rompem dando lugar aos frutos, do tipo aquênios, coroados por tufos de pelos sedosos (Figura 1F). As inflorescências de T. procumbens, medem aproximadamente $1,5 \mathrm{~cm}$ (Figura 1G).

Tal descrição concorda com Santos, Lima e Leite (2016), que afirmam ainda que a inflorescência contém aproximadamente 50 flores, na qual as flores periféricas têm $4,9 \mathrm{~mm}$ de diâmetro e 4,2 mm de comprimento e as flores centrais com diâmetro de 1,0 mm e 6,3 $\mathrm{mm}$ de comprimento. $\mathrm{O}$ capítulo é do tipo isolado heteromórfico, sendo as flores periféricas masculinas e as centrais hermafroditas (MOREIRA; BRAGANÇA, 2011) e as flores apresentam odor (RCPOL, 2020b).

De acordo com Kevan (1983), as flores amarelas e brancas, como as de A. tenella e T. procumbens, são muito reflexivas e são visitadas por uma grande variedade de insetos. Esse autor destaca ainda que a percepção das cores pelos insetos é distinta daquela do ser humano. Martins e Batalha (2006) tentam relacionar a cor da flor com o tipo de visitante 
floral, enquanto Silberbauer-Gottsberger e Gottsberger, 1988 ligam o visitante à forma e recompensa oferecida pela flor. Em ambas as espécies, o néctar e o pólen são recursos florais (RCPOL, 2020a, 2020b).

No primeiro experimento registrou-se 3.578 indivíduos em 5 dias de observações. Himenoptera foi a ordem de insetos mais representativa (72,44\%), seguido de Lepidoptera $(25,18 \%)$ - (Figura 2 A-F). Dentre os Himenoptera, Apis mellifera scutellata Lepeletier, 1836 (abelha africanizada) foi a espécie com maior número de visitantes (Figura 2G e 2H), representando $49,16 \%$ do total de insetos registrados, a seguir Trigona spinipes (Fabricius, 1793) com $22,44 \%$.

Ocorreram os seguintes visitantes ocasionais: Diptera (Musca sp. com 2,21\% e um Syrphidae- mosca das flores, com 0,03\%); outros Himenoptera (Vespidae, com 0,62\% e Halictidae- Augochloropsis sp. com 0,22\%- Figura 21); o Hemiptera Euschistus heros Fabricius, 1798 (0,11\%) e o Coleoptera Diabrotica speciosa Germar, 1824, com 0,03\%.

A. mellifera e $T$. spinipes são insetos sociais que podem comunicar aos seus pares o encontro de uma fonte representativa de alimento. Esta última é uma espécie nativa do Brasil, pertence à tribo Meliponini, sendo conhecida como Arapuá ou Irapuá, entre outros nomes (CAMARGO; PEDRO, 2013), enquanto A. mellifera foi introduzida no Brasil há pouco menos de dois séculos (ROCHA, 2008; BARROS et al., 2016).

Foram observadas cinco morfótipos de Lepidoptera, pertencentes à família Hesperiidae (Figura 2 A, 2D, 2E e 2F) e Nymphalidae (Figura 2B e 2C); foram identificados até níveis taxonômicos inferiores os Pyrginae (Figura 2 A, 2D e 2F), sendo Pyrgus orcus (Stoll, 1780) (Figura 2F) e Danainae: Danaus sp. (Figura 2B). Os Lepidoptera compuseram $25 \%$ do total das observações deste estudo, sendo bastante representativos em comparação a Giannini et al. (2015) que relatam 2\% de Lepidoptera nos registros de polinizadores e visitantes florais em plantas cultivadas, enquanto Silberbauer-Gottsberger e Gottsberger (1988) estimaram em 16\% a proporção de lepidópteros diurnos visitantes florais num cerrado em Botucatu, SP.

Na planta $A$. tenella, a abelha $T$. spinipes foi o visitante mais frequente em todos os horários (Figura $3 \mathrm{~A}$ ), enquanto a abelha africanizada ( $A$. mellifera) foi mais frequente em $M$. debilis e $T$. procumbens (Figura $3 \mathrm{~B}$ e $3 \mathrm{C}$ ). Os Lepidoptera foram mais frequentes nos capítulos de T. procumbens (Figura $3 \mathrm{C}$ ), com poucas visitas para $A$. tenella (Figura $3 \mathrm{~A}$ ) e praticamente ausentes das flores de M. debilis (Figura 3B). 

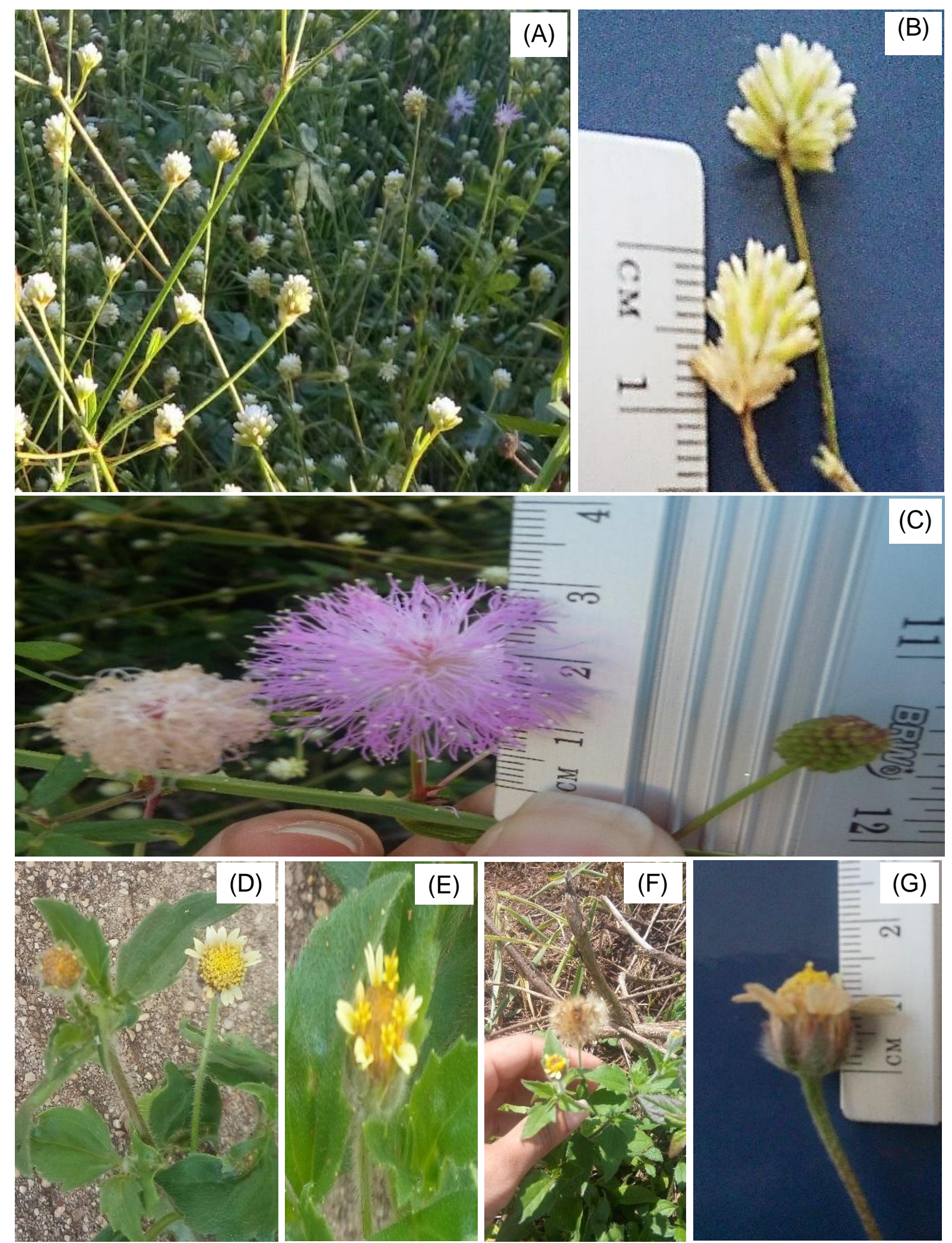

Figura 1. Inflorescências no local de observação. (A) glomérulos de Alternanthera tenella;

(B) tamanho da inflorescência de A. tenella. (C) Inflorescência de Mimosa debilis, em botão floral (à direita), antese (ao centro) e senescência (à esquerda). (D-G) Inflorescência de Tridax procumbens. (D) inflorescência imatura (à esquerda) e antese (à direita), (E) Flores masculinas e as hermafroditas em antese, $(F)$ senescência e abertura dos tufos de pelos que circundam os aquênios e $(G)$ tamanho da inflorescência em antese. Barra do Garças-MT, 2017. 

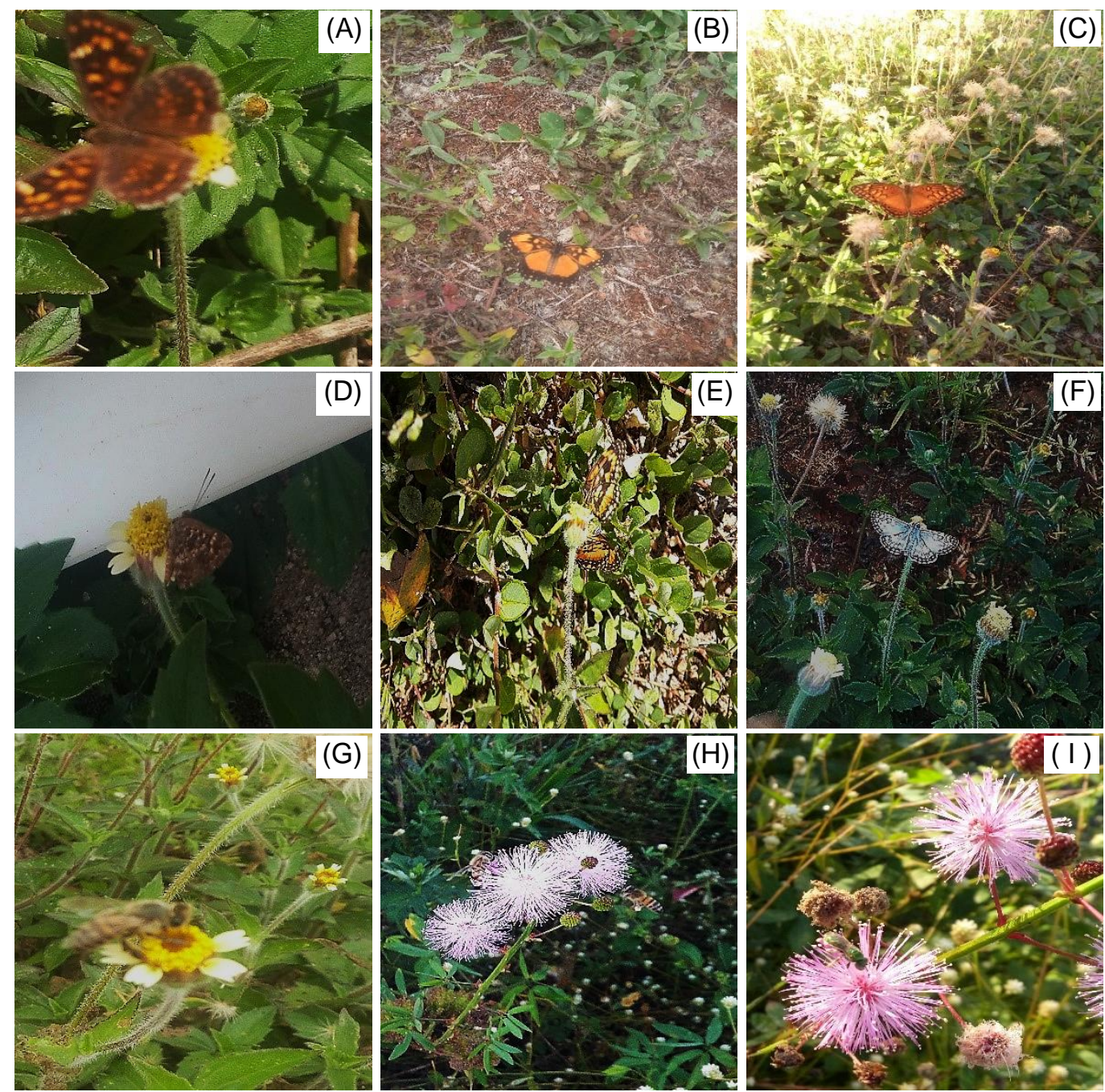

Figura 2. Visitantes florais de Alternanthera tenella, Mimosa debilis e Tridax procumbens registrados no Campus Universitário do Araguaia, (A-F) Lepidoptera diversos, $(\mathrm{G} \mathrm{e} \mathrm{H})$ Apis mellifera e (I) Augochloropsis sp. Barra do Garças, MT, 2017.

Entre 7:00 e 8:00 horas da manhã, $M$. debilis recebeu mais visitantes do que as outras duas espécies, mas o maior número de visitantes foi observado na planta $T$. procumbens em quase todos os horários. Em A. tenella e T. procumbens, houve maior frequência de visitantes entre 11:00 e 15:00 (Figura 3).

Com relação ao horário de visitas, há relatos de atividade de $A$. mellifera antes de 6:00 da manhã em M. bimucronata (SILVA et al., 2011) o que não foi observado neste estudo. Lepidoptera estiveram mais ativos entre 10:00 e 16:00, mas ocorreram desde às 7:00 até às 18:00 horas (Figura 3). Segundo Antonini et al. (2005), Lepidoptera forrageia na planta Stachytarpheta glabra Cham. (Verbenaceae) preferencialmente em luminosidade entre 600 e 1300 lux e temperatura entre 27 e 33ํㅡ, já abelhas sociais (Apidae) mostraram alta tolerância a variações na temperatura e luminosidade, corroborando com os dados 
observados neste trabalho, pois forragearam desde o início do dia até o final da tarde (Figura 3). Houve interação significativa entre os fatores espécie de planta (E) e horário de observação $(H)$ para os três visitantes florais principais (Tabela 1).
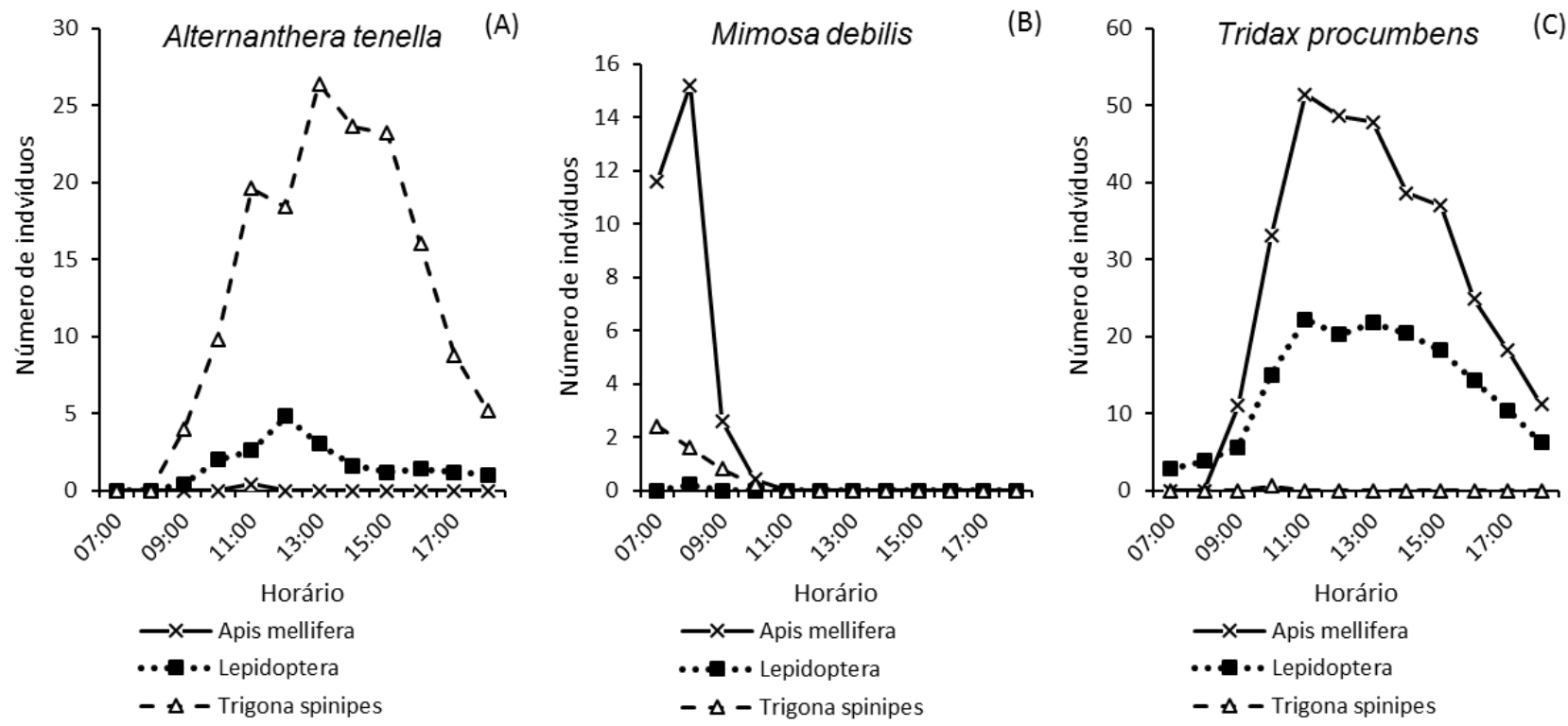

Figura 3. Número de visitantes florais para três espécies de plantas ruderais em função do horário de visita em área antropizada (local 1) no campus Universitário do Araguaia, Barra do Garças-MT, 2017. Cada ponto representa a média de cinco observações em dias não consecutivos.

Tabela 1. Quadrados médios resultantes da análise de variância para o número de visitantes florais observados em três espécies de plantas em diferentes horários do dia no campus Universitário (local 1), Barra do Garças-MT, 2017. N=180.

\begin{tabular}{|c|c|c|c|c|}
\hline $\begin{array}{l}\text { Fonte de } \\
\text { variação }\end{array}$ & $\begin{array}{l}\text { Graus de } \\
\text { liberdade }\end{array}$ & Apis mellifera & Lepidoptera & Trigona spinipes \\
\hline $\begin{array}{l}\text { Espécie de } \\
\text { planta }(E) \\
\text { Horários de }\end{array}$ & 2 & $13137,572^{\star \star \star \star}$ & $3208,606^{\star \star \star \star}$ & $3219,356^{\star \star \star \star}$ \\
\hline observação (H) & 11 & $395,945^{\star \star \star \star}$ & $119,399^{\star \star \star \star}$ & $131,775^{\star \star \star \star}$ \\
\hline$E * H$ & 22 & $735,942^{\star \star \star \star}$ & $80,381^{\star \star \star \star}$ & $159,695^{\star \star \star \star}$ \\
\hline Resíduo & 144 & 99,197 & 16,417 & 26,481 \\
\hline CV $(\%)$ & & 101,92 & 80,95 & 115,35 \\
\hline
\end{tabular}


O nascer do sol ocorreu às 5:45 em 17 de Maio, sendo 10 minutos mais tardio em 14 de Junho, enquanto o pôr do sol ocorreu por volta das 17 horas em ambas as datas, com fotoperíodo de cerca de 11 horas (WWW.SUNRISE-AND-SUNSET.COM). Aparentemente essa diferença não interferiu na atividade dos insetos.

Como não havia dados meteorológicos disponíveis para as datas dos experimentos, comparou-se com os dados do ano de 2014 da estação meteorológica do Campus de Barra do Garças (Tabela 1S, material suplementar). A temperatura nas primeiras horas da manhã geralmente é inferior a $20^{\circ} \mathrm{C}$, podendo atingir valores superiores a $30^{\circ} \mathrm{C}$ nas horas mais quentes do dia. A radiação solar não é muito elevada ao meio dia (máximo de $715 \mathrm{~W} \cdot \mathrm{m}^{-2}$ ) por ser tratar do período de inverno. A umidade relativa do ar pode variar de 96,6\% nas primeiras horas da manhã até menos de 35\% no final da tarde. Essa época do ano tem vento variável com máximo de $1,2 \mathrm{~m} . \mathrm{s}^{-1}\left(4,32 \mathrm{~km} \cdot \mathrm{h}^{-1}\right)$ e a precipitação geralmente é nula ou muito reduzida (Tabela 1S, material suplementar). A baixa umidade do ar pode ser limitante para os insetos, influenciando negativamente em sua visita às flores após às 15 horas (Figura 3 e 4).

No segundo experimento houve interação significativa entre local de observação (L) e horário de observação $(\mathrm{H})$ para $A$. mellifera, enquanto para Lepidoptera os fatores $\mathrm{L}$ e $\mathrm{H}$ foram significativos isoladamente. Para T. spinipes nenhum dos fatores foi significativo, devido ao número reduzido de visitas dessa abelha a $T$. procumbens nos três locais (Tabela 2).

Tabela 2. Quadrados médios resultantes da análise de variância para o número de visitantes florais observados diferentes horários do dia em Tridax procumbens em três locais diferentes no campus Universitário, Barra do Garças-MT, 2017. N=180.

\begin{tabular}{lcccc}
\hline \multicolumn{1}{c}{$\begin{array}{c}\text { Fonte de } \\
\text { variação }\end{array}$} & $\begin{array}{c}\text { Graus de } \\
\text { liberdade }\end{array}$ & Apis melífera & Lepidoptera & $\begin{array}{c}\text { Trigona } \\
\text { spinipes }\end{array}$ \\
\hline $\begin{array}{l}\text { Local de } \\
\text { observação }(\mathrm{L})\end{array}$ & 2 & $8851,206^{* * * *}$ & $1426,872^{* * * *}$ & $0,03889^{\text {ns }}$ \\
Horários de & & & & \\
observação $(\mathrm{H})$ & 11 & $1754,018^{* * * *}$ & $502,822^{* * * *}$ & $0,16313^{\text {ns }}$ \\
$\mathrm{L}^{*} \mathrm{H}$ & 22 & $338,963^{* * * *}$ & $28,133^{\text {ns }}$ & $0,09950^{\text {ns }}$ \\
Resíduo & 144 & 98,294 & 17,594 & 0,11111 \\
$\mathrm{CV}(\%)$ & 74,51 & 51,64 & 461,54 \\
\hline $\mathrm{CV}=$ coeficiente de variação, $\mathrm{N}=$ número de parcelas. ${ }^{* * *}$ Significativo a mais de $0,01 \%$ de \\
probabilidade ou mais $(\mathrm{p}<0,0001)$.
\end{tabular}


O local 2 recebeu o menor número de visitantes que os outros dois. Como anteriormente descrito, ele era desprovido de árvores e Zanette, Martins e Ribeiro (2005) afirmam que a abundância de abelhas eussociais foi diretamente afetada pela perda de cobertura vegetal e pelo aumento de edifícios associados à urbanização.

O maior número de visitas de $A$. mellifera a T.procumbens ocorreu às 11:00 horas nos locais 1 e 2, enquanto no local 3 , o horário de pico foi às 14:00 horas (Figura 4A). Lepidoptera fez mais visitas às 11:00 horas no local 1; para o local 2 não houve diferença significativa entre número de visitas dos horários das 11:00 às 15:00, com valores médios oscilando entre 6,8 e 9,0 indivíduos. O mesmo ocorreu para o local 3, com número de visitas entre 12,4 e 16,2 nesses horários (Figura 4B).
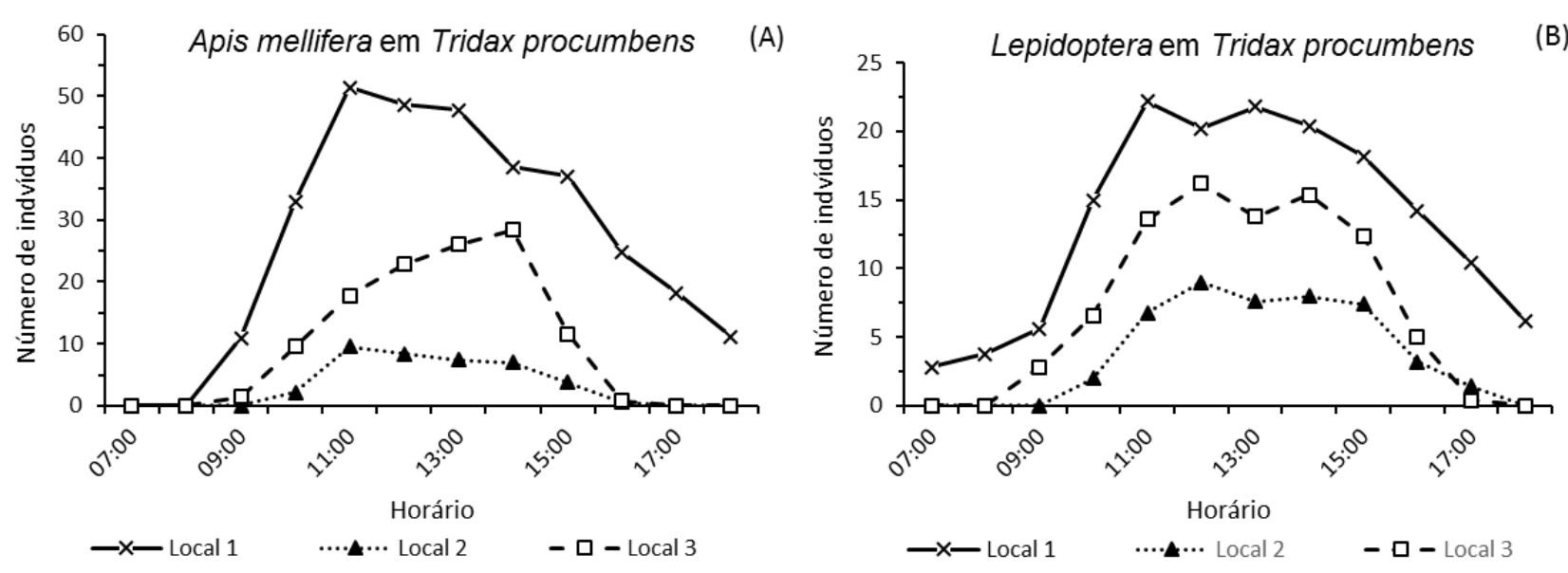

Figura 4. Variação do número de visitantes florais em Tridax procumbens em função do horário e do local em áreas antropizadas no campus Universitário do Araguaia. Barra do Garças-MT, 2017. Cada ponto representa a média de cinco observações em dias não consecutivos.

As visitas às flores seguiram o mesmo padrão de variação em função do horário nos três locais, sendo baixa nas primeiras horas da manhã, aumentando ao longo do dia e declinando no final da tarde (Figura 4A e 4B).

No período de realização das observações (entre 5 e 19 de julho de 2017), o nascer do sol ocorreu às 5:58, enquanto o pôr do sol ocorreu às 17:09 na primeira data e às 17:13 na segunda. $O$ fotoperíodo foi 11 horas e 11 minutos em 5 de julho e sete minutos mais longo na segunda data (WWW.SUNRISE-AND-SUNSET.COM). As visitas iniciaram-se 
com radiação solar de baixa intensidade, entre 20 e $82 \mathrm{~W} \cdot \mathrm{m}^{-2}$, cerca de uma hora após o nascer do sol (Figura 4 e Tabela 1S, material suplementar).

Como as condições meteorológicas do ano de 2017 foram similares às do ano de 2014, pode-se inferir que no início da manhã, provavelmente o fator limitante às visitas seja a temperatura mais baixa, de 12,9 a $15,2^{\circ} \mathrm{C}$ (Tabela $1 \mathrm{~S}$, material suplementar), enquanto no final da tarde talvez a baixa umidade relativa do ar (31 a 46\%) teve maior impacto sobre a atividade dos insetos.

\subsection{MATERIAL SUPLEMENTAR}

TABELA 1S. Variáveis meteorológicas em diferentes horários do dia no campus Universitário, Barra do Garças-MT, 2014.

\begin{tabular}{|c|c|c|c|c|c|c|}
\hline $\begin{array}{c}\text { Data } \\
\text { (dia/mês) }\end{array}$ & Horário & $\begin{array}{c}\text { Temperatura } \\
\left({ }^{\circ} \mathrm{C}\right)\end{array}$ & $\begin{array}{l}\text { Radiação } \\
\text { solar } \\
\left(\mathrm{W} \cdot \mathrm{m}^{-2}\right)\end{array}$ & $\begin{array}{l}\text { UR } \\
(\%)\end{array}$ & $\begin{array}{l}\text { Vento } \\
\left(\mathrm{m} \cdot \mathrm{s}^{-1}\right)\end{array}$ & $\begin{array}{l}\text { Precipitação } \\
(\mathrm{mm})\end{array}$ \\
\hline \multirow{4}{*}{ 17/maio } & 7:00 & 18,1 & 81,9 & 96,6 & 0,0 & 0,0 \\
\hline & $12: 00$ & 32,4 & 685,0 & 49,2 & 0,4 & 0,0 \\
\hline & $17: 00$ & 31,0 & 25,6 & 46,0 & 0,0 & 0,0 \\
\hline & 7:00 & 16,0 & 48,1 & 95,6 & 0,0 & 0,0 \\
\hline \multirow{3}{*}{ 14/junho } & $12: 00$ & 30,3 & 660,6 & 49,8 & 0,6 & 0,0 \\
\hline & $17: 00$ & 30,9 & 43,1 & 46,4 & 0,0 & 0,0 \\
\hline & 7:00 & 12,9 & 20,6 & 90,7 & 0,1 & 0,0 \\
\hline \multirow[t]{3}{*}{ 05/julho } & $12: 00$ & 32,0 & 664,4 & 33,5 & 1,0 & 0,0 \\
\hline & $17: 00$ & 30,9 & 80,6 & 31,0 & 0,0 & 0,0 \\
\hline & 7:00 & 15,1 & 43,1 & 91,5 & 0,2 & 0,0 \\
\hline \multirow{2}{*}{ 19/julho } & $12: 00$ & 29,6 & 715,6 & 46,6 & 1,2 & 0,0 \\
\hline & $17: 00$ & 31,0 & 76,9 & 36,9 & 0,0 & 0,0 \\
\hline
\end{tabular}

Fonte: Adaptado de Estação meteorológica Campus Barra do Garças, Lat.: 1552'28"S, Long.: 52¹8'48'W, Alt.: 370m. Disponível em: <http://araguaia.ufmt.br/estacao-meterologica/>. Acesso em: 24 Jan. 2020.

\section{CONSIDERAÇÕES FINAIS}

O número de visitantes observados foi bastante elevado, considerando que o estudo foi realizado durante a estação seca na região, além disso a maior parte dos visitantes foi observada nos horários de umidade relativa do ar mais baixa (Tabela 1S, material suplementar). 
Pode-se dizer que $T$. procumbens é uma planta polifílica por ter recebido visitas de abelhas e borboletas, enquanto $A$. tenella e M. debilis são oligofílicas, de acordo com o conceito de Silberbauer-Gottsberger e Gottsberger (1988).

Kinoshita et al. (2006) afirmam que A. tenella tem síndrome de polinização anemófila, discordando dos resultados obtidos, pois a espécie foi visitada de forma representativa por insetos na área de estudo, o que reforça a descoberta a respeito de sistemas de polinização anteriormente considerados abióticos que na verdade constituem-se em sistema mistos (CRESSWELL et al., 2004).

M. debilis tem como agente polinizador principal as abelhas, em fisionomias do Cerrado no Triangulo Mineiro (SILVA; ARAÚJO; OLIVEIRA, 2012), o que corrobora com este trabalho. A ausência de Lepidoptera em M. debilis, provavelmente se deve ao aparelho bucal do inseto ser adaptado a alimentos fluídos (OLIVEIRA et al., 2014), uma vez que o recurso provável seja pólen, por similaridade com M. bimucronata (SILVA et al., 2011). Quando o pólen é o recurso exclusivo, há conflito entre a função reprodutiva da planta e a de recurso alimentar para o visitante; geralmente tais flores produzem grande quantidade de pólen para garantir as duas funções (AGOSTINI; LOPES; MACHADO, 2014).

Santos, Lima e Leite (2016) observaram que T. procumbens tem um sistema de polinização generalista, devido à ocorrência de ao menos 10 espécies forrageando em suas flores, o que corrobora com os dados aqui obtidos, no entanto relatam que $T$. spinipes é polinizador ocasional para $T$. procumbens, com horários de visita entre 7:00 e 14:00 na Estação Ecológica de Caetés (PE), o que discorda deste trabalho, pois $T$. spinipes praticamente não realizou visitas a essa planta (Figura 3C).

Pode-se supor competição entre T. spinipes e A. mellifera, embora Aguiar (2003) afirme que há apenas $23 \%$ de sobreposição de nicho entre as duas abelhas em ambiente de Caatinga. Wilms et al. (1996) também encontraram sobreposição moderada do nicho trófico dessas duas abelhas (33\%) na Mata Atlântica, porém esses autores observaram que a pressão competitiva da abelha africanizada foi geralmente alta sobre quase todas as espécies de meliponíneos, levando em conta também a abundância relativa e o peso corporal.

É importante destacar que nem todo visitante floral é um polinizador. Os visitantes podem roubar recursos florais sem tocar as partes reprodutivas e nesse processo ainda danificar as flores de diferentes maneiras (ALVES-DOS-SANTOS et al., 2016). Giannini et al. (2015) estimaram que $12 \%$ das visitas a flores de plantas agrícolas resultam em roubo e/ou danos. T. spinipes é conhecida como pilhadora de flores em várias espécies 
(POLATTO; ALVES JR., 2008; ESPÍRITO SANTO et al., 2009; ALVES-DOS-SANTOS et al., 2016), no entanto para as plantas aqui analisadas realizou visitas legítimas nas flores em antese, tocando as estruturas reprodutivas. Lepidoptera também podem ser pilhadoras, como observado por Kiill, Haji e Lima (2000) para seis espécies de plantas invasoras de cultivos irrigados.

Conclui-se que as três espécies de plantas analisadas compõem recursos florais alternativos para abelhas e Lepidoptera na área de estudo, como preconizado por Brandão et al. (1984), Kiill, Haji e Lima (2000) e Pamminger et al. (2019).

\section{REFERÊNCIAS}

AGOSTINI, K.; LOPES, A.V.; MACHADO, I.C. Recursos florais. In: RECH, A. R.; AGOSTINI, K.; OLIVEIRA, P.E.; MACHADO, I.C. Biologia da Polinização. Rio de Janeiro: Projeto Cultural, 2014. p. 129-150.

AGOSTINI, K.; SAZIMA, M. Plantas ornamentais e seus recursos para abelhas no Campus da Universidade Estadual de Campinas, estado de São Paulo, Brasil. Bragantia, v.62, n.3, p.335-343, 2003.

ALVES-DOS-SANTOS, I.; SILVA, C.I. da; PINHEIRO, M.; KLEINERT, A. de P. Quando um visitante floral é um polinizador? Rodriguésia, v. 67, n. 2, p. 295-307, 2016.

ANTONINI, Y.; SOUZA, H. G.; JACOBI, C.M.; MURY, F.B. Diversidade e comportamento dos insetos visitantes florais de Stachytarpheta glabra Cham. (Verbenaceae), em uma área de campo ferruginoso, Ouro Preto, MG. Neotropical Entomology, v. 34, n. 4, p. 555-564, 2005.

BARNEBY, R.C. Sensitivae censitae: a description of the genus Mimosa Linnaeus (Mimosaceae) in the New World. New Yourk, Memoirs of the Ne w Yor k Botanical Garden, v $65,1991.835 \mathrm{p}$.

BARROS, D.C. de; KADRI, S.M.; ZALUSKI, R.; ORSI, R.O. Histórico das abelhas Apis mellifera $\mathrm{L}$. no Brasil e a influência do Promotor $\mathrm{L} \circledast$ (suplemento aminoácido vitamínico) em áreas de cria e reserva de alimento. 5. Jornada Científica e Tecnológica da FATEC de Botucatu, Botucatu-São Paulo, Brasil, 2016.

BRANDÃO, M.; GAVILANES, M.L.; CUNHA, L.H.S.; LACA-BUENDIA, J.P.; CARDOSÓ, C. Plantas consideradas daninhas para culturas como fonte de néctar e pólen. Planta Daninha, Campinas, v. 7, n. 2, p. 1-22, 1984.

CAMARGO, J.M.F.; PEDRO, S.R.M. Meliponini Lepeletier, 1836. In: MOURE, J. S., URBAN, D.; MELO, G. A. R. (Orgs). Catalogue of Bees (Hymenoptera, Apoidea) in the Neotropical Region - online version. 2013. Disponível em: <http://www.moure.cria.org.br/catalogue>. Acesso em: 19 Jan. 2020. 
CENTRO DE GESTÃO E ESTUDOS ESTRATÉGICOS (CGEE). Importância dos polinizadores na produção de alimentos e na segurança alimentar global. Brasília, DF: 2017. $124 \mathrm{p}$.

CRESSWELL, J.E.; DAVIES, T.W.; PATRICK, M.A.; RUSSELL, F.; PENNEL, C.; VICOT, M.; LAHOUBI, M. Aerodynamics of wind pollination in a zoophilous flower Brassica napus. Functional Ecology, v. 18, p. 861-866, 2004.

DUTRA, V.F. Diversidade de Mimosa L. (Leguminosae) nos campos rupestres de Minas Gerais: Taxonomia, distribuição geográfica e filogeografia. 2009. 294 f. Tese (Pós-Graduação) - Universidade Federal de Viçosa, Viçosa, 2009.

ENDRESS, P.K. Diversity and evolutionary biology of tropical flowers. Oxford, Pergamon Press. Furness, 1994. 511 pp.

ESPÍRITO-SANTO, F. da S. do; PEQUENO, I.D.; SEIDO, C.L.; FAZOLLO, R.; SIQUEIRAFILHO, J. de A. Táticas de pilhagem por Trigona spinipes (Apidae) na Caatinga. 60. Congresso Nacional de Botânica, 2009.

FERREIRA, D.F. Sisvar: a computer statistical analysis system. Ciência e Agrotecnologia (UFLA), v. 35, n. 6, p. 1039-1042, 2011.

GARIBALDI, L.A. et al. Wild Pollinators Enhance Fruit Set of Crops Regardless of Honey Bee Abundance. Science, v. 229, n. 6127, p. 1608-1611, 2013.

GIANNINI, T. C.; BOFF, S.; CORDEIRO, G. D.; CARTOLANO Jr., E. A.; VEIGA, A. K.; IMPERATRIZ-FONSECA, V. L.; SARAIVA, A. M. Crop pollinators in Brazil: a review of reported interactions. Apidologie, v. 46, p. 209-223, 2015.

IPBES - INTERGOVERNMENTAL SCIENCE-POLICY PLATFORM ON BIODIVERSITY AND ECOSYSTEM SERVICES -. Summary for policymakers of the assessment report of the Intergovernmental Science-Policy Platform on Biodiversity and Ecosystem Services on pollinators, pollination and food production. POTTS, S.G. et al. (eds.). Bonn, Germany, United Nations, 2016. 30 p.

LORENZI, H. Plantas Daninhas do Brasil: terrestres, aquáticas, parasitas e tóxicas. 4. ed. Nova Odessa: Instituto Plantarum, 2008. 640 p.

KEVAN, P. Floral colors through the insect eye: what they are and what they mean. In: JONES, C.E.; LITTLE, J.R. (eds.). The Handbook of Experimental Pollination Biology. Michigan, Scientific and Academic Editions. 1983. p. 3-30.

KIILL, L.H.P.; HAJI, F.N.P.; LIMA, P.C.F. Visitantes florais de plantas invasoras de áreas com fruteiras irrigadas. Scientia Agricola, v.57, n.3, p.575-580, 2000.

KINOSHITA, L.S.; TORRES, R.B.; FORNI-MARTINS, E.R.; SPINELLI, T.; AHN, Y.J.; CONSTÂNCIO, S.S. Composição florística e síndromes de polinização e de dispersão da mata do Sítio São Francisco, Campinas, SP, Brasil. Acta Botanica Brasilica, v. 20, n. 2, p. 313-327, 2006. 
LIMA, L.C.L e; SILVA, F.H.M e; SANTOS F.S.R. dos. Palinologia de espécies de Mimosa L. (Leguminosae - Mimosoideae) do Semi-Árido brasileiro. Acta Botanica Brasilica, v. 22, n.3, p. 794-805, 2008.

MATESANZ, S.; VALLADARES, F. Plantas ruderales. Una relación milenária de amor y ódio que genera conocimiento, problemas y desafios. Investigacion y ciência, v. 390, p. 10-11, 2009.

MARCHINI, L.C.; MORETI, A.C.C.C.; TEIXEIRA, E.W.; SILVA, E.C.A.; RODRIGUES, R.R.; SOUZA, V.C. Plantas visitadas por abelhas africanizadas em duas localidades do estado de São Paulo. Scientia Agricola, v. 58, n. 2, p.413-420, 2001.

MARTINS, F.Q.; BATALHA, M. A. Pollination systems and floral traits in Cerrado woody species of the upper Taquari region (Central Brazil). Brazilian Journal of Biology, v. 66, n. $2 A$, p. 543-552, 2006.

MOREIRA, H.J. da C.; BRAGANÇA, H.B.N. Manual de Identificação de Plantas Infestantes: Hortifrúti. São Paulo: FMC Agricultural Products, 2011.

MORO, M.F.; SOUZA, V.C.; OLIVIERA-FILHO, A.T. de; QUEIROZ, L.P. de; FRAGA, C.N. de; RODAL, M.J.N.; ARAÚJO, F.S. de; MARTINS, F.R. Alienígenas na sala: o que fazer com espécies exóticas em trabalhos de taxonomia, florística e fitossociologia? Acta Botanica Brasilica, v. 26, n. 4, p. 991-999, 2012.

OLLERTON, J.; WINFREE, R.; TARRANT, S. How many flowering plants are pollinated by animals? Oikos, v. 120, p. 321-326, 2011.

OLIVEIRA, P.E.; GIBBS, P.E. Reprodutive biology of woody plants in a cerrado community of Central Brazil. Flora, v. 195, p. 311-329, 2000.

OLIVEIRA, R.; DUARTE JUNIOR, J.A.; RECH, A.R.; AVILA JR, R.S. de. Polinização por lepidópteros. In: RECH, A.R.; AGOSTINI, K.; OLIVEIRA, P.E.; MACHADO, I.C. Biologia da Polinização. Rio de Janeiro: Projeto Cultural, 2014. p. 235-257.

PAMMINGER, T.; BECKER, R.; SOPHIE HIMMELREICH, S.; SCHNEIDER, C.W.; BERGTOLD, M. The nectar report: quantitative review of nectar sugar concentrations offered by bee visited flowers in agricultural and nonagricultural landscapes. Peer Journal, Ecology, v. 7, e6329, 2019.

PEDROTTI, D.; GUARIM-NETO, G. Flora ruderal da cidade de Cuiabá, Mato Grosso, Brasil. Acta Botanica Brasilica, v. 12, n. 2, p. 135-143, 1998.

PINHEIRO, M.; ABRÃO, B.S. de; HARTER-MARQUES, B.; MIOTTO, S.T.S. Floral resources used by insects in a grassland community in Southern Brazil. Revista Brasileira de Botânica, v.31, n.3, p.469-489, 2008.

PIRANI, F. R.; SANCHEZ, M.; PEDRONI, F. Fenologia de uma comunidade arbórea em cerrado sentido restrito, Barra do Garças, MT, Brasil. Acta Botanica Brasilica, v. 23, n. 4, p. 1096-1110, 2009. 
POLATTO, L.P.; ALVES JR., V.V. Utilização dos recursos florais pelos visitantes em Sparattosperma leucanthum (Vell.) K. Schum. (Bignoniaceae). Neotropical Entomology, v. 37, n. 4, p. 389-398, 2008.

RCPOL. Rede de catálogos polínicos on line: Alternanthera tenella Colla. 2020a. Disponível em: <http://chaves.rcpol.org.br/profile/species/eco/eco:ptBR:Alternanthera\%20tenella>. Acesso em: 07 Jan. 2020.

RCPOL. Rede de catálogos polínicos on line: Tridax procumbens L. 2020b. Disponível em: $\quad$ http://chaves.rcpol.org.br/profile/species/eco/eco:pt-BR:Tridax\%20procumbens>. Acesso em: 07 Jan. 2020.

REIS, A.S.B.; DUARTE, M.D.; SOUSA, M.G.S. de; FREITAS, N.F. de Q.R.; YAMASAKI, E.M.; SILVA, A.G.M. e; CARLOS MAGNO C. OLIVEIRA, C.M.C.; BARBOSA, J.D. Lesões traumáticas de pele causadas pelos espinhos de Mimosa pudica e Mimosa debilis em equídeos. Pesquisa Veterinária Brasileira, v. 31, n. 9, p. 768-772, 2011.

RIZZINI, C.T. Tratado de fitogeografia do Brasil. v.2. Aspectos sociológicos e florísticos. Hucitec / Edusp, São Paulo, 1979.

ROCHA, J.S. Apicultura. Niterói, Programa Rio Rural, 2008. 27 f. (Programa Rio Rural. Manual Técnico, 05)

SANTOS, B.Y.M.; LIMA, G. de. O.; LEITE, A.V. Tridax procumbens L. (Asteraceae): importância do sistema de polinização generalista em uma área perturbada. In: Congresso Nacional de Pesquisa e Ensino em Ciências, CONAPESC. Campina Grande, Paraíba, 2016.

SENNA, L. Alternanthera. In: Lista de Espécies da Flora do Brasil. Jardim Botânico do Rio de Janeiro. 2015.2 Disponível em: <http://floradobrasil.jbrj.gov.br/jabot/floradobrasil/FB79983>. Acesso em 07 Jan. 2020.

SILBERBAUER-GOTTSBERGER, I.; GOTTSBERGER, G. A polinização de plantas do Cerrado. Revista Brasileira de Biologia, v. 48, n. 4, p. 651-663, 1988.

SILVA, C.I. da; ARAÚJO, G.; OLIVEIRA, P.E.A.M. de. Distribuição vertical dos sistemas de polinização bióticos em áreas de cerrado sentido restrito no Triângulo Mineiro, MG, Brasil. Acta Botanica Brasilica, v. 26, n. 4, p. 748-760, 2012.

SILVA, L.A.; GUIMARÃES, E.; ROSSI, M.N.; MAIMONI-RODELLA, R.C.S. Biologia da reprodução de Mimosa bimucronata - uma espécie ruderal. Planta Daninha, v. 29, p. 10111021, 2011.

SILVA, R. R.; PRADO, A. L. do; FORTUNA-PEREZ, A. P.; SEGALLA, R. Espécies herbáceas e lenhosas de Leguminosae numa área de Cerrado no Mato Grosso, Brasil. Revista Brasileira de Biociências, v. 8, n. 4, p. 373-376, 2010.

VICHIATO, M.R. de M.; VICHIATO, M. Flora ruderal da cidade de Belo Horizonte, Minas Gerais. Tecnologia e Ciência Agropecuária, v. 10, n. 5, p. 7-15, 2016.

VIEIRA, G.H. da C; MARCHINI, L.C.; SOUZA, B. de A.; MORETI, A.C. de C.C. Fontes florais usadas por abelhas (Hymenoptera, Apoidea) em área de cerrado no município de 
Cassilândia, Mato Grosso do Sul, Brasil. Ciência e Agrotecnologia, v. 32, n. 5, p. 14541460, 2008.

WILMS, W.; IMPERATRIZ-FONSECA, V.L.; ENGELS, W. Resource partitioning between highly eusocial bees and possible impact of the introduced Africanized honey bee on native stingless bees in the Brazilian Atlantic rainforest. Studies on Neotropical Fauna and Environment, v. 31, p. 137-151, 1996.

WINFREE, R.; AGUILAR, R.; VAZQUEZ, D. P.; LEBUHN, G.; AIZEN, M.A. A meta-analysis of bees' responses to anthropogenic disturbance. Ecology, v. 90, n. 8, pp. 2068-2076, 2009.

WWW.SUNRISE-AND-SUNSET.COM. Horário do nascer e pôr do sol: Pesquisa. Disponível em: <https://www.sunrise-and-sunset.com/pt>. Acesso em: 15 dez. 2017.

ZANETTE, L.R.S.; MARTINS, R.P.; RIBEIRO, S.P. Effects of urbanization on Neotropical wasp and bee assemblages in a Brazilian metropolis. Landscape and Urban Planning, v.71, 105-121, 2005. 


\section{ORGANIZADOR}

\section{Renato Abreu Lima}

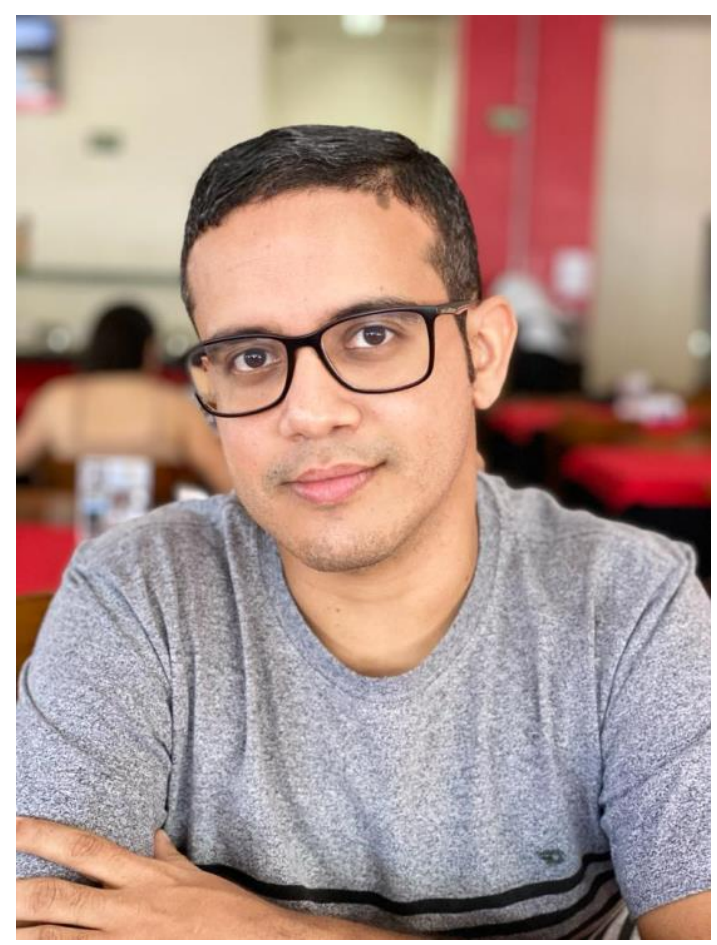

Possui graduação em Ciências Biológicas (Licenciatura e Bacharelado) pelo Centro Universitário São Lucas (2009); Especialista em Gestão Ambiental pela mesma instituição (2010); Mestre em Desenvolvimento Regional e Meio Ambiente pela Universidade Federal de Rondônia - UNIR (2011) e Doutor em Biodiversidade e Biotecnologia, REDE BIONORTE, pela Universidade Federal do Amazonas - UFAM (2016). Professor do Magistério Superior na graduação (Ciências: Biologia e Química) e na pós-graduação (Ciências Ambientais e Ensino de Ciências e Humanidades) no Instituto de Educação, Agricultura e Ambiente (IEAA/UFAM) em Humaitá-AM, atuando nas áreas de Botânica, Plantas Medicinais e Biotecnologia. É Membro da Sociedade Botânica do Brasil (SBB). CRBio-6 sob nº 073096/AM-D. 


\section{ÍNDICE REMISSIVO}

A

Amazônia Ocidental: 139.

Ambientes antropizados: 91, 92, 131 e 203.

Antimicrobiano: 71 e 77.

Aquecimento global: 109, 110, 112, 117 e 119

Área urbana: 59 e 206.

B

Bactérias promotoras do crescimento de plantas: 193 e 195.

C

Capsicum spp: 71, 72, 183, 184, 187 e 188.

Cloreto de Cálcio: 40, 42 e 43.

Coleção botânica: 151, 154 e 158.

E

Ensino-aprendizagem: 151, 152 e 155.

Equilíbrio: 12, 16, 18 e 20.

Erva-de-touro: 96 e 202.

Ervas: 22, 103, 104, 126, 140, 190, 203 e 207.

Espécie arbórea: 59.

Espécies alóctones: 126 e 133.

Espécies autóctones: 22.

Espécies frutíferas: 139, 141, 143 e 146.

Espécies vegetais: 12, 15, 17, 25, 72, 93, 184, 186, 189, 190 e 204.

Exsicatas: 95, 151, 157, 158, 161, 166, 167, 170, 171 e 176.

$\mathbf{F}$

Fisiologia vegetal: 4, 109, 154 e 195. 
G

Gases estufa: 109 e 110.

I

Inoculação: 193, 195, 196, 197, 198, 199 e 200.

Invasão biológica: 126 e 127.

Inventário florístico: 59, 61 e 63.

L

Lantana camara: 79, 80, 81, 83, 84 e 85.

M

Morfoanatomia: 79 , 81 e 82.

Myrtaceae: 12, 13, 16, 17, 43, 65, 66, 139, 140, 144, 158 e 179.

0

Óleos essenciais: 71, 72, 73, 75 e 83.

$\mathbf{P}$

Parque Nacional Serra de Itabaiana: 22, 23, 25, 26, 30, 31 e 32.

Plantas daninhas: 91 e 205.

$\mathbf{R}$

Recurso didático: 151.

S

Sensitiva-de-leite: 202 e 205.

Silvicultura Urbana: 19 e 139.

SpeciesLink: 166, 167, 174, 176, 177, 178, 179, 180 e 181.

T

Tecido: 79 e 204. 
V

Vigor de sementes: 40 .

Z

Zea mays: 113, 193 e 194.

Zona urbana: 91, 95, 102 e 142. 


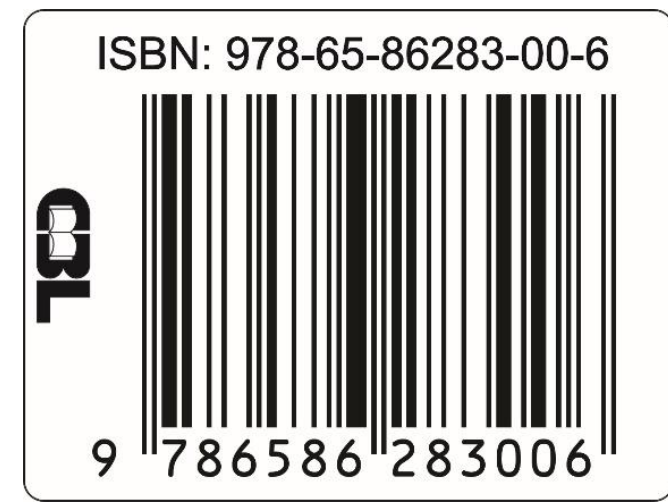

DOI: $10.35170 /$ ss.ed. 9786586283006 